The Rise of Mental Health Nursing 



\section{The Rise of Mental Health Nursing}

A History of Psychiatric Care
in Dutch Asylums, 1890-1920

Geertje Boschma 
For my parents, Yke Boschma and Jetske Jorritsma

This publication was made possible by a grant from the Netherlands Organisation for Scientific Research (NWO).

Cover illustration

Patients on bed rest in the observation ward with two nurses. Female department at the Franeker Asylum, ca. I900. Historical Photograph Collection, Psychiatric Hospital Franeker.

Cover design: Crasborn Grafisch Ontwerpers bno, Valkenburg aan de Geul Lay-out: Het Steen Typografie, Maarssen

ISBN 9053565019

NUR $895 / 897$

(C) Amsterdam University Press, Amsterdam, 2003

All rights reserved. Without limiting the rights under copyright reserved above, no part of this book may be reproduced, stored in or introduced into a retrieval system, or transmitted, in any form or by any means (electronic, mechanical, photocopying, recording, or otherwise), without the written permission of both the copyright owner and the author of this book. 


\section{Contents}

\section{Acknowledgments II}

\section{Introduction I5}

Care of the Mentally Ill I8

Asylum Attendants and Mental Nurses I9

The Historiography of Mental Health Nursing 20

Four Asylums as Case Studies 26

The Chapters in Brief 28

\section{Chapter I - Asylum Reform Ideals: Personnel Matters 3I}

The Appeal of Institutional Care and Moral Treatment 3I

A Legal Basis for Asylum Reform 33

Increased Medical Influence 35

Liberal Views, Reform Rhetoric, and the Problem of Personnel 36

Lower-Class Institutions $4 \mathrm{I}$

The Position of Attendants and Patients in the Asylum Hierarchy 42

Different Responses and Different Solutions: Roman Catholic Initiatives 45

Reform Ideals Frustrated: Asylum Growth and a New Law 50

A Second Law on the Insane 52

Awakening of Protestant Duty 54

Conclusion 57 
Chapter II - The Ideal of a Mental Hospital 59

New Medical Opinions: Scientific Psychiatry 60

Medical Views in Veldwijk: A Christian Psychiatry $\sigma_{3}$

Bed Rest 65

Architectural Changes and the Increased Application of Bed Rest 67

Hydrotherapy and Bath Treatment 70

Work Remained 73

The Inspiring Example of the General Hospital: A New Demand for Skilled Nursing 75

Conclusion 78

\section{Chapter III - Female Compassion: Mental Nurse Training} Gendered Female 8I

Religious Roots 8I

Female Compassion, Domestic Ideology and the Women's

Movement 87

Growing Demand 90

A New Educational Structure for Nursesv 92

A Respectable Salaried Occupation 95

Female Influence 97

Hospital Hierarchyv 98

Raising the Status of Psychiatry: The Introduction of Mental

Nurse Training Io०

Gendered Ideals: Raising the Morality of Asylum Personnel Io6

Het Wilhelminahuis (The Wilhelmina Home) Io8

Conclusions IIO 
Chapter IV • The Burdensome Task of Nurses II3

The Invisible Role of Nurses II5

The Nurse as Object and Agent of a Disciplined Asylum Routine II8

Threat, Repression, and Abuse: The Division of Wards as a

Control Mechanism II9

An Analysis of Patient Records I23

Responding to Dependency I25

Growing Old and Demented I27

Sick since Youth I29

Suffering from Mania, Acutely or Periodically I3I

The Care of Paralyzed and Handicapped Syphilis Patients $\quad$ I32

They Wished to Be Dead: The Risk of Suicide I33

Overcome by Delusions: The Risk of Refusing Food, Self-Mutilation, Violence, and Escape 136

Nervous Afflictions and Brain Trauma: Rare Cases in the

Turn-of-the-Century Asylum $\quad$ 13 8

Conclusion I40

\section{Chapter V • Negotiating Class and Culture I4I}

A Gendered Structure I4I

A New Discipline and Morale 147

Culture Shock 150

The Orthodox Protestant Perception of Mental Nurse Training:

A Family Ideology 153

Gendered Nursing Leadership in Veldwijk I54

Implementing an Educational Structure 157

Mental Nurse Training at Veldwijk I6o

Debate over The Boschhoek $\mathrm{I}_{2} 2$

The Boschhoek Revisited $\mathrm{I}_{4}$

Roman Catholic "Resistance” ${ }^{2} 6_{7}$

Conclusion I73 
Chapter VI • The Marginalization of Male Nurses I75

Nursing, a Respected Occupation - but not for Men $\quad$ I75

Squeezed out I76

Nurse Artisans 179

The Home of a Married Nurse: A Place of Family Care? I83

Growing Class Consciousness I86

Male Nurse Activism and the Career of P.N. Bras $\quad 186$

Gendered Politics versus Expertise I92

Conclusion $\quad$ I96

\section{Chapter VII - Controversy and Conflict over the Social Position} of Nurses 197

An Ambiguous Social Position I97

Growing Social Awareness among Asylum Nursing Personnel I99

Activism among the VCV Nurses 204

Seeking Legal Protection from the State 206

Controversy over Training 209

Ambivalence over Morality and Class Background 2IO

The Threat of Private Duty 2I5

Tension over the NVP Exam Criteria 216

Controversy over the Somatic Approach and Biomedical Footing of

Psychiatric Care 2I9

Conclusion 223

\section{Conclusion - The Politics of Mental Health Nursing 225}

The Disappointment of Somatic Explanations in Turn-of-the-Century

Psychiatry 225

A Gendered Notion of Civilized Care 227

The Educational versus the Social Value of Mental Nurse

Training 229

Economic Problems, Growing Costs 232

Ideals and Limitations 233 
Appendix 235

Notes 24I

List of Illustrations 289

List of Abbreviations 29I

List of Archives 293

Bibliography 297

Index $3 \mathrm{I} 3$ 



\section{Acknowledgments}

During the time I was working on this book I benefited from the scholarly support and advice of a large number of people. I am grateful for the generous comments and thoughtful critique on various papers, presentations and earlier drafts of this research. The study grew from an exploratory inquiry into the history of mental health nursing in the Netherlands in 1993 into a dissertation on the nursing care of the mentally ill in Dutch asylums under the dedicated and inspiring guidance of Joan Lynaugh at the Center for the Study of the History of Nursing, School of Nursing, at the University of Pennsylvania in I997. I am especially grateful to the University of Calgary for a Killam Resident Fellowship and Research Award in 2000 , which provided me with additional research time to further develop this study into a book. Additional financial research support came from Sigma Theta Tau Chi Chapter, the Catherine van Tussenbroek Foundation, Sigma Theta Tau International, the American Nurses Foundation and the University of Pennsylvania School of Nursing. I would like to thank my colleagues at the Faculty of Nursing of the University of Calgary for their support and interest in the completion of this study. I would also like to thank women's historians Sarah Carter and Elizabeth Jameson at the Department of History at the University of Calgary for their encouragement in the final stages of this work. Joyce Hildebrand and Nadine Kozak provided excellent editorial and research assistance.

I am indebted to the faculty and fellow students at the University of Pennsylvania, Philadelphia, both in the graduate program and the Center for the Study of the History of Nursing of the School of Nursing, and in the Department of the History and Sociology of Science. Working with this outstanding community of scholars has profoundly influenced my thinking and shaped the direction of my research. From the School of Nursing I am especially grateful to Joan Lynaugh, Ellen Baer, Karen Wilkerson, and Margaret Cotroneo for their superb guidance, insightful comments and attentive reading of my work. I also thank Patricia D'Antonio, Julie Fairman, Barbara Brush, Betsy Weiss, Linda Cook, Eileen Sullivan and Terry Richmond for their comments and support. From the Department of the History and Sociology of Science, I am particularly indebted to Henrika Kuklick and Charles Rosenberg for their generous advice, and I thank Hans Pols for his support. 
Whilst completing the research for this study in the Netherlands, I was very fortunate to be able to work with a fine group of historians of psychiatry at the Dutch Institute for Mental Health in Utrecht, now called the Trimbos Institute. In particular, the expertise and support of Joost Vijselaar has been invaluable. Without his help I could not have completed this study. I also thank Leonie de Goei, Annemarie Kerkhoven, Gemma Blok, and Giel Hutschemaeker. They provided me with the scholarly support so vital whilst far away from Philadelphia. The same is true for Eddy Houwaart, medical historian at the University of Maastricht, who generously invested time and interest. I wish to thank all of them for their insightful comments on parts of this work. I also thank Cecile aan de Stegge for bringing me into contact with the faculty of the Departments of Nursing and History at the University of Maastricht. During the preparatory work for this research, the Department of Nursing in Maastricht, directed by Huda Huijer Abu-Saad, provided me with hospitality, as did the Trimbos Institute.

Many librarians and archivists have given valuable assistance throughout this research. In particular, I am indebted to Ingrid Verhoeven, librarian at the historical library of the Trimbos Institute. Many people assisted my investigation of the institutional archives of the psychiatric hospitals Franeker, Veldwijk, and Reinier van Arkel, as well as of the archival collection of the psychiatric hospital in Amsterdam. I am grateful to Mr. de Vries, Martje Haitsma, Tom Kappelhof, Joke Leenders, Mr. van Faassen, Mr. L. Boerman, Piet van Twuyer, and the staff of the "Rijksarchief Noord-Holland" (State Archives of North Holland). I also thank those individuals who gave helpful scholarly advice at various points, of whom I would like to mention Cora van der Kooij, Nanny Wiegman, Mart van Lieburg, Hans Binneveld, and Jaap van Belzen.

Last, but not least, I would like to thank my husband Hotze for his incredible support and love. I also thank my family and family-in-law for their unfailing support, in particular my mother Jetske, my sisters Ytje and Eppy, my mother-in-law Frouwien, and my in-laws Ton, Cora, Anna, Tineke, and Jan for their hospitality and generous help. My children Henk, Nico and Jenny contributed in their own special way to this book.

Parts of chapters V and VI in this book have previously been published in journal articles: "High Ideal versus Harsh Reality: A Historical Analysis of Mental Health Nursing in Dutch Asylums, I890-I920", Nursing History Review 7(I999): I27-I5I, and "The Gender Specific Role of Male Nurses in Dutch Asylums, I890-I9I0”, International History of Nursing Journal 4, no. 3 (I999): I3-I9. I would like to acknowledge the permission from Springer Publishing Company and RCN Publishing Company respectively to include this material. Two Dutch papers, based on the same material, have been pub- 
lished in Maandblad Geestelijke Volksgezondheid 52, no. Io (I997): 959-976 ("Psychiatrische Verpleegkunde: Een Historisch Perspectief"), and in Gesticht in de Duinen: De geschiedenis van de provinciale psychiatrische ziekenhuizen van Noord-Holland, 1848-1994, Joost Vijselaar (Ed.), Hilversum: Verloren, I997 (Chapter 4, "Naar een professionele psychiatrie (I884-I9I8)", pp.9II2I). I thank the Trimbos Institute and Verloren Publishing respectively for their permission to use this material. 



\section{Introduction}

Mental health nursing emerged as a new occupational field in the late nineteenth century in the context of the rise of scientific psychiatry. Based on new understandings of mental illness and new forms of psychiatric treatment, asylum physicians legitimized and initiated the introduction of mental nursing in asylums, which restructured a field of work that had hitherto been the domain of lay attendants. In light of the new significance that skilled nursing care had acquired in the context of general hospital reform, psychiatrists, themselves a rising professional group, argued that more refined and better trained personnel would greatly improve psychiatric care. Shifting social and gender relationships, particularly the changing social position of middleclass women, constructed and shaped mental nursing. The emergence of mental nursing mirrored larger social changes for lower middle- and working-class men and women and their work illustrates the social complexity of the care of the mentally ill.

In both nursing and psychiatric historiography, little attention has been paid to the gendered nature of the asylums' mental health nursing politics. The introduction of mental nurse training was based on the projected image of the well-educated, middle-class female nurse who would bring competence and female compassion to the care of the mentally ill. The aim of establishing a nursing staff skilled in somatic care in the asylums created new opportunities for women, while at the same time restricting the role of men in nursing. This study explicitly discusses the gendered restructuring of asylum care that the new training scheme for mental nurses implied. Reform profoundly changed the work relationships of the new male and female mental nurses. The explicit attention paid to male and female nurses' gendered experiences illustrates how concepts of femininity and masculinity were formed in relation to each other. Moreover, it paints a more nuanced picture of nursing as a gendered field of both men's and women's work. ${ }^{1}$

In addition to gender, class is another important category for analysis. This study argues that the introduction of mental nurse training was an attempt to uplift the morality and class of asylum personnel. In their effort to place asylum care on the same footing as the work of their counterparts in general medicine, middle-class psychiatrists sought the assistance of middle-class 
women skilled in somatic care. They considered a humanitarian, refined attitude to be a characteristic not only of gender, but also of class. The process by which the hierarchical mental nurse training structure facilitated the instilling of class-based values such as discipline, punctuality, and obedience in a mental nurse workforce of largely lower middle- and working-class background paralleled attempts to create a disciplined, respectable workforce in industry.

A third category that plays an important role in this analysis is religion. Among many social groups in the nineteenth century, religious inspiration was an important motivation for taking up philanthropic reform work, including the reform of the care of the mentally ill. As women's historian Annemieke van Drenth and Francisca de Haan have pointed out, much like evangelicalism in North America, an influential Protestant religious revival movement of the Inner Mission in continental Europe, also called "Reveil", had generated reform initiatives, such as the Deaconess Movement. ${ }^{2}$ Moreover, Roman Catholic religious revival had a strong impact in the Netherlands at that time as well. ${ }^{3}$ Numerous socially respected religious and secular organizations of nursing were established in this context. Building on these religious and secular images of respectful care, skilled nursing could acquire social prestige as a new field of paid work for women in the late nineteenth century. At that time the demand for skilled nurses increased and the preparation for nursing as a paid professional occupation took the form of hospitalbased nurse training programs and - modeled after this example - asylumbased mental nurse training programs. But the legitimization of these new occupational roles - that it was the female compassion of middle-class women and their refined attitude that would make this new form of nursing a success - was in many ways a secularized version of older religious notions of disciplined devotion that had a long tradition in nursing.

Furthermore, religious and political pluriformity shaped the social and political constellation of Dutch society from the late nineteenth century until about the mid-twentieth century in a particular way. A specific, hard-to-translate term has been coined in Dutch historical, political, and social scientific writings to refer to this phenomenon: verzuiling, often literally translated as "pillarization" (and more correctly as "compartmentalization") and in an attempt to be more explanatory, also referred to as the emergence of "segmental cleavages". ${ }^{4}$ In the nineteenth century, Dutch democracy took the form of a plural society, which was divided along political and religious lines. Liberalizing and democratic politics of the nineteenth century prompted revisions of the constitution at several points in time, which by 1848 had resulted in the adoption of a liberal constitution that guaranteed freedom of religion, educa- 
tion, press, and association. Politically this had an emancipatory impact, particularly on religious groups such as the Roman Catholics, who had been banned from public life since the Reformation. It enabled them to re-establish themselves and participate in a parliamentary structure and coalition government with liberal groups. The same was true for revivalist Protestant groups, who formed their own organizations, and in the latter part of the nineteenth century socialists also formed their own segment. As a result Dutch political culture was divided up into vertical groupings of Catholic, Calvinist-Protestant, socialist and liberal zuilen or pillars. ${ }^{5}$ Such a political form is not unique to the Netherlands. Segmental differentiation can occur along religious, ideological, linguistic, regional, cultural, racial, or ethnic lines. ${ }^{6}$ Political scientist Arend Lijphart refers to Switzerland, Belgium, Austria, and Luxembourg as examples of other plural, stable democracies that are characterized by deep segmental cleavages in their societies.

Since none of the sectors of Dutch society had a political majority, cooperation among the "pillars" had to take place at the top in the form of a coalition government. Yet in day-to-day life, people operated within their own sector with hardly any interaction with other sectors. Pillarization, therefore, was a particular way in which "Dutch society [was] organized along denominational lines.... In due course the main Pillars [denominational groups] established their own network of organizations, ranging from political parties, trade unions and educational systems (including a Catholic and a Calvinist university) to broadcasting corporations, welfare agencies, sport associations and even social research institutes." 7 This process allowed leaders within the various political and religious groups to maintain their influence over their own communities, while rationalization and transformation of traditional structures and institutions could still take place. Each sector, in its own way, responded to social changes and modernizing trends, resulting in different, yet parallel developments.

This particular way in which Dutch society modernized also impacted on the organization of health care. In the second half of the nineteenth century, in response to drastic socioeconomic changes, a rising political debate on the social position of workers, and the emergence of labor and feminist movements, the laissez-faire politics of previous predominantly liberal-conservative parliamentary cabinets was replaced by the interventionism of progressive liberal and Christian politicians. ${ }^{8}$ An increased level of organization of various new professional and occupational groups emerged from the late nineteenth century, and subsequent social legislation materialized. As this study will reveal, institutional care of the mentally ill, which dramatically expanded in the context of nineteenth-century reform and the fight against 
pauperism, was influenced by this process of pillarization. It also took a segmented form, which necessarily influenced the way mental health nursing developed.

\section{Care of the Mentally Ill}

In the Netherlands, care of the indigent mentally ill was part of the nineteenth-century poor relief system. For most of the nineteenth century the Netherlands experienced economic hardship, which stemmed from economic malaise in the late eighteenth century and a period of French occupation at the beginning of the nineteenth century. This hardship resulted in a growing number of poor people. The Dutch population grew from about three million in 1850 to five million by the end of the century. The social structure of the Netherlands was characterized by a relatively large urban population in an extensive network of relatively small towns and cities. However, particularly in the rural areas, the Netherlands retained the characteristics of an agrarian society for most of the nineteenth century, during which time the Dutch economy was based on trade and on wealth gained from the colonies.

It was not until the I870 that the impact of industrialization began to be felt. In part driven by the economic recession in agriculture during the I870s, the mechanization of farming began with the introduction of new machines and techniques. An increasing number of former farm workers moved to cities where new industries such as ship and machine building emerged. Increased international trade, new means of transportation, improvement of the infrastructure, and an emerging service industry characterized the appearance of an industrial society. By the late nineteenth century, the economy had begun to flourish, leading to an increase in the average income as of I890. ${ }^{9}$

Under the influence of the Enlightenment, a cultural uplift began at the beginning of the nineteenth century. The rising middle class sought to combat pauperism, which they perceived as predominantly a problem of poor morality and improper habits. In particular, the threat of several epidemics of contagious diseases during the earlier part of the nineteenth century, which hit hardest among the poor, prompted social reform initiatives. With various philanthropic, often religiously inspired reform efforts, progressive middleclass citizens sought to educate and transform the lower class into industrious, productive, and loyal citizens. The national government, established after the end of French occupation in I8I5, gradually attempted to reorganize poor relief and to bring it under national regulations. Public education became available to the lower social classes and special projects to provide work for the poor emerged. ${ }^{\text {I }}$ 
Within the context of the general cultural uplift and the reorganization of poor relief, reform-minded citizens and physicians began advocating for asylum reform at the beginning of the nineteenth century. The hope for a cure for the mentally ill also prompted reform. As early as I84I, when legal regulations on insanity care passed in parliament, the management of the indigent mentally ill began to change. The reformed asylum initially resembled a large, disciplined middle-class household, albeit with gradual expansion of medical responsibility and influence on the care of the insane.

\section{Asylum Attendants and Mental Nurses}

Nineteenth-century asylum management was characterized by paternalism and hierarchical subordination. Until around I890 asylum boards and officers, including the asylum doctors, referred to the day-to-day caretakers most commonly as "servants" (bedienden) or "keepers or attendants" (oppassers) responsible for overseeing patients. ${ }^{\text {II }}$ Day-to-day caretakers in the asylums left little evidence behind about themselves or their experience. They were largely anonymous. Attendants were just one level up from the lowest group in the asylum hierarchy, the patients. Asylum boards and physicians considered good attendants those who had a respectable and humane attitude and knew their place in society. ${ }^{\mathrm{I2}}$ The expectation was that attendants would keep order and discipline among patients by maintaining moral, pedagogical predominance over them. Such ideals reflected the aspirations and class values of the rising middle class. But from the outset of asylum reform physicians regularly complained about the supposed poor quality of the asylums' attending personnel. They felt that the behavior and work morality of attendants were ill-fitted for the medical ideas of kind and humane treatment that emerged in the first half of the nineteenth century.

However, as the late nineteenth-century progressed, medical ideas on treatment for the mentally ill again changed as a result of social and medical transformations. During the I870s and I880s psychiatrists began to orient themselves towards the values and findings of the natural sciences and emphasized organic origins of mental illness. They conceptualized mental illness as a brain disease. In principle, they argued, mental patients should receive the same care and treatment as physically ill patients in the general hospital. Hospital medicine gained momentum during the late nineteenth century, and psychiatrists attempted to model the traditional asylum after the example of the general hospital. In this context they initiated new treatments, the most important being bed rest.

As a result, the rhetoric about asylum personnel took on a new dimension. 
The reorganization and restructuring of the class base of hospital personnel was of central importance in hospital reform. Traditionally caretakers of patients in public hospitals came from the lowest social classes. This changed profoundly as middle-class women skilled in patient care took up supervisory roles in hospitals in the context of social reform activities and a broader changing social role for middle-class women. Similarly, asylum doctors argued that they needed more refined, better trained personnel who would have the same qualities as trained hospital nurses. Psychiatrists and, following in their wake, nurses established themselves in new professional groups. Psychiatrists not only felt that a higher standard of skill and morality among personnel was necessary, they also designed a training scheme that brought the socialization of asylum personnel under medical control. Instead of attendants, they argued, they needed nurses who were properly trained in the care of the sick. The emergence of mental nursing work and training, and an analysis of its meaning, is the focus of this study. To refer to the new type of trained asylum nurses this study uses the term "mental nurse" as a translation of krankzinnigenverplegende, the common term used in Dutch psychiatry at the time. ${ }^{\mathrm{I}}$

\section{The Historiography of Mental Health Nursing}

Historical analysis of the work of mental nurses has received little scholarly attention. The few studies on the history of mental nursing that are available in the Anglo-American historical literature developed largely in two contexts. Firstly, in the history of psychiatry the role of attendants or asylum nurses has been studied as part of the analysis of the broader social and medical meaning of the asylum. Secondly, in the context of the history of nursing, psychiatric nursing history has been examined as part of the analysis of the rise of nursing as a new occupational field. Both threads of historical analysis contributed to the understanding of psychiatric nursing's past in different ways. Yet in neither of the two contexts has gender taken center stage. In women's history the notion of a domestic ideology of women in the nineteenth century became central to the explanation of women's changing role. Furthermore, in the analysis of gender differences the notion that gender is socially constructed has become increasingly more accepted. ${ }^{\mathrm{I}}$ Yet neither of these perspectives has figured importantly in the historiography of mental nurses. The emphasis on gender in this study was largely prompted by the evidence found in historical records. On studying both archival records and contemporary published literature, it became clear that gendered arguments were of central importance in the debates on the establishment of mental nurse training. 
Philanthropic reform initiatives, the changing status of medical science, and the changing role of women were intertwined contexts for understanding the emergence of mental nurse training. Moreover, strong connections existed between the introduction of nurse training in hospitals and asylums. Another finding that prompted a closer look at gender differentiation was the resistance of male nurses to their exclusion from the caring domain, which was particularly evident in the records of a male nurse organization founded at the time. To the best of my knowledge, current nursing historiography has paid almost no attention to the phenomenon of men resisting exclusion from caring roles. The emphasis on women's roles in women's history has unintentionally rendered the gendered behavior of men invisible. ${ }^{15}$ From that perspective, nursing history may make an important addition to gender history. In current women's and nursing history, which depicts caring work as women's work, the historical persistence of men seeking access to nursing work remains invisible and is therefore left unexplained. ${ }^{.6}$

The role of asylum attendants in North American and British asylums has been scrutinized by several authors, including Patricia D'Antonio, Anne Digby, Ellen Dwyer, and Nancy Tomes. They have analyzed the inner workings of the asylum as both a medical and a social institution in the era of mid-nineteenth-century moral treatment. ${ }^{17}$ These studies emerged in a broader historical debate on the meaning of the rise of the nineteenth-century asylum that began as a result of the I960s and I970s "anti-psychiatry" and "decarceration" movements. ${ }^{18}$ In this debate a new generation of revisionist social scientists and historians challenged traditionalist interpretations of psychiatric history, such as those of Albert Deutch (I937) and Richard Hunter and Ida McAlpine (1963) in the United States and Britain, or Pieter van der Esch (I975) in the Netherlands. The traditionalists interpreted asylum reform and the introduction of medical treatment as clear evidence of enlightened benevolence and scientific progress, a shift from ancient darkness towards enlightened rationality characterized by the effective, humane, and scientific treatment of the insane. ${ }^{19}$

Revisionist social scientists such as Erving Goffman (I96I) and Thomas Szasz (1974), the philosopher Michel Foucault (1965) or historian David Rothman (I97I) portray mental institutes as repressive institutions and challenge the assumptions of humanitarian reform. ${ }^{20}$ They present psychiatric care as either a process of normalization and disciplining or as institutionalization of social control and class domination. Initially these social scientists argued that the nineteenth-century "liberation" of the insane from their imprisonment and the introduction of moral treatment were just alternative means for the state to effectively separate and exclude those who did not meet 
the requirements of self-control and self-responsibility in a capitalist society. Consequently, the insane were subjected to "a gigantic moral imprisonment". ${ }^{21}$ Andrew Scull, within this same context, adds to the argument of social control the postulate of moral entrepreneurship of doctors. In part to establish themselves as a scientific profession, he argues, psychiatrists successfully claimed an ever-increasing domain of eccentric behavior as their domain of expertise. As a result, the disproportionately expanding number of patients admitted to the asylums led to overcrowded institutions, which defeated the original purpose of asylum reform. ${ }^{22}$

In his analysis of nineteenth-century mental health reform in the United States, social historian Gerald Grob challenges the one-sided assumptions of the social control theorists and counteracts their almost hostile view of psychiatry with a more detailed historical analysis of public policy of the care of the mentally ill. ${ }^{23}$ Grob argues that the changes in psychiatric care resulted from complex social processes rather than from deliberate control strategies. These social processes produced dilemmas that "gave rise to results that diametrically contradicted starting intentions and objectives". ${ }^{24}$ The pressures of continuous underfunding, the accumulation of chronic and incurable patients, and issues of class, ethnicity, and race compromised the care of the mentally ill. Grob concludes that by the end of the nineteenth century, the ever-growing size of mental institutions constrained the initially liberating attempts of reform and moral treatment, reshaping institutional care into custodial care. Similar social processes affecting the care of the mentally ill have been observed in Western European countries, although the political context varies from country to country. ${ }^{25}$

Notwithstanding the one-sidedness of many of the revisionist criticisms, these broad analyses of large-scale social responses to the problems arising out of mental illness inspired a new group of historians in the 1980 s to produce more narrowly focused and more detailed studies of the asylum, particularly in Britain and the United State ${ }^{26}$ As nurse historian D'Antonio argues, this refocusing may have been related to the fact that during the I980s researchers had seen the devastating effects of the "deinstitutionalization" process, itself a response to the severe criticism of mental institution practices. Facing a new reality of homeless insane, the role of the mental hospital was reassessed, resulting in more nuanced portraits of psychiatric institutes and practices. ${ }^{27}$

Detailed asylum studies have produced both a reconstruction of patient experiences and an analysis of daily operations and dynamics among patients, staff, and families. ${ }^{28}$ D'Antonio's study demonstrates how the early nineteenth-century metaphor of moral treatment - that is, the institution as a 
family - produced its own dilemmas. The idea of an institutional family was incompatible with the day-to-day institutional reality of chaos and confusion presented by the behavior of the insane. Repressing the inevitable chaos belied the promise of compassionate family-like care. As a result the lay staff began to seek involvement of physicians and thus contributed to the medicalization of care. ${ }^{29}$ The studies of Digby, Dwyer, and Tomes all devote part of their work to the role of attendants in their broader analyses of the inner workings of the asylum and the implications of a new, humane moral treatment regimen..$^{30}$ They emphasize the ambiguity of the attendants' role. Although the attendants' impact on patient treatment was crucial, they formed the lowest ranks and were the least valued in the asylum hierarchy. This resulted in an inherent contradiction: for the day-to-day application of moral treatment the physician staff were dependent on the lay attendants, who were unprepared for the work.

The historiography of Dutch psychiatry and mental health care has been limited. ${ }^{3 \mathrm{I}}$ During the I970s, when the anti-psychiatric movement impacted the Netherlands, a renewed interest in psychiatric history resulted in various revisionist publications, including a historical analysis of the rise of Dutch asylums by Hans Binneveld and various publications by Joost Vijselaar on the application of moral treatment and the inner workings of the asylum..$^{32}$ In this literature the role of the asylum attendant and nursing personnel remained underexamined. ${ }^{33}$ The introduction of mental nurse training is usually addressed as a measure for improving the level of personnel in the broader context of asylum reform. ${ }^{34}$ Recently, more detailed asylum studies have appeared, one of which focuses in particular on the patient experience of asylum care. ${ }^{35}$

A new approach towards historical analysis within the historiography of nursing evolved in the I980s. Beginning with works such as Celia Davies' Rewriting Nursing History and Ellen Condliffe Lagemann's Nursing History: New Perspectives, New Possibilities, a new generation of historians, most often nurse historians, broke away from a traditionalist, celebratory style of writing nursing history. ${ }^{36}$ Traditionalist history merely highlighted nursing's past as undeniable progression from dark times to enlightened professional discipline and scientifically based authority, usually marking the role of Florence Nightingale as a definite turning point. The new generation of (nurse) historians seeks to develop social historical analyses of nursing's past that puts it in the broader context of social, women's, and labor history. In other words, this new scholarship contextualizes nursing in the complex social and political dynamics of work and gender relationships. In this way it seeks to be critical and more realistic in understanding nurses' individual and collective experi- 
ences in the context of broader social trends and cultural transformations. ${ }^{37}$

However, most nursing history studies, written from a revisionist view on nursing history, focus on general rather than psychiatric nursing. ${ }^{38}$ Only a few mental nurse historians, interested in the history of their own discipline, have analyzed the development of mental nursing within the broader context of nursing and social history. At the same time they have attempted to provide psychiatric nurses with an empowering historical identity. The best wellknown studies in this area are those of Olga Church on the emergence of mental health nursing in the United States and of Peter Nolan on the history of psychiatric nursing in Britain. 39

Church's work can probably best be characterized as a transitional style of writing nursing history. She outlines how the establishment of the first training program in the asylums was established as part of a medical reform effort by doctor Edward Cowles - and headed by nurse Linda Richards - at the McLean Asylum near Boston in I882. She views mental nursing in particular in its struggle for professional autonomy. Church's study contrasts the efforts of professional nursing organizations and their nursing leadership, who claimed psychiatric nursing as a separate but shared sector of the professional nursing community, with the initiatives of organized psychiatrists to control the work of asylum nursing through apprenticeship training. Church interprets psychiatric nursing history as a process of professionalization in which asylum nursing eventually escaped from medical domination and grew "out of a state of apprenticeship toward an autonomous and self-reliant discipline," 40 particularly in the shift towards community mental health in the mid-twentieth century. The study's emphasis on professionalizing strategies prevents an analysis of the construction of nursing's work or nursepatient dynamics.

Peter Nolan highlights the nurses' point of view in psychiatric nursing work and training from the late nineteenth century to the present. He builds on recent revisionist historiography in psychiatry, which, he argues, often overlooked the role of nursing in mental health care but at the same time empowered nurses to question such marginalization. Using a social historical perspective, Nolan strives to elucidate the identity of mental nursing and to give it a rightful place in psychiatric history. He gives a vivid description of the mental nurse experience, particularly after I920, using oral history. He places the traditional scheme of mental nurse training, established in the I89os and largely maintained until the I980s, in its historical context. Despite the discrepancy between medical aspirations and the lived experience of nursing, he argues, and despite medical domination, mental nurses developed their own identity and sought their own organizations in response 
to their social circumstances and work conditions. He emphasizes the gap between the work culture of the asylum workforce and the general nursing leadership's understanding of nursing work, a gap that underlay a separation between the two groups and led to the separate organization of asylum nurses. Nolan perceives the recent shift from institutional to community care as an opportunity for nurses to acquire a more central place in mental health care.

Furthermore, several articles provide the beginnings of the documentation and analysis of the work conditions and class background of attendants or asylum nurses and their role in asylum discipline in the nineteenth and early twentieth centuries..$^{4}$ These articles speak explicitly of the day-to-day experience of nineteenth-century institutional caretaking of the mentally ill and the often harsh working conditions in the ever growing mental institutions. The articles emphasize how attendants were usually young and were recruited from the local working class. Both pay and appreciation of caretaking were low, and asylum life very much restricted the attendants' social life. ${ }^{42}$ Strict discipline and bureaucratic control regulated the attendants' work. ${ }^{43}$

Some of these articles pay explicit attention to the significance of the introduction of training. ${ }^{44}$ Focusing on the introduction of nurse training in the British asylum system, the British historians Mick Carpenter, Peter Nolan, Robert Dingwall, Anne Marie Rafferty, and Charles Webster note that training was introduced predominantly in order to improve recruitment. 45 The failure to realize the increased expectations of career opportunities among trained attendants led to unionization on the one hand, while, on the other hand, the majority of nurses remained poorly educated and predominantly attached to working-class values. In his discussion of asylum nursing in Alabama, American historian John Hughes is probably one of the first to begin to use gender as a category to identify differences that emerged between male and female nurses when training was introduced. Not only did the number of female nurses in the asylum increase compared to men, but more women also became trained nurses, whereas most males remained untrained attendants. ${ }^{4}$

Somewhat similarly to the emergence of a critical social historical nursing literature in the Anglo-American context, several Dutch books and articles were published that analyzed nursing from a revisionist perspective. Although modest in extent, this literature marks the beginning of a new social historical scholarship in Dutch nursing. ${ }^{47}$ Most of this work pertains to the history of general nursing. The most prominent proponent of this new nursing history is Cora van der Kooij..$^{8}$ She has made a ground-breaking, indepth analysis of the way class and gender relationships structured patterns 
of nurse organization. In attempting to understand the often fragmented and contradictory political positions in nurse organization patterns, Van der Kooij examines the reciprocal relationship between a gendered social position and the social consciousness of nurses. She demonstrates how nurses, themselves divided by class and gender, formed different groups either in juxtaposition to or alliance with the medical profession, and in an ambivalent relationship with the broader labor and women's movements. Truus Spijker and Victor van Gemert provide a thoughtful discussion of the ambivalent appraisal of nursing as a highly valued moral calling and as low-valued work, which characterized the emergence of nursing as a profession. ${ }^{49}$ Both high and low values were combined in one and the same person, the nurse as "mistressservant". Such ambivalence continued in the politics surrounding the establishment of nurse training and nursing organizations, and in the development of nursing as medical assistance. Post-World War II professionalizing strategies among nurses further expressed the ambivalent values. Nursing became stratified in routine bedside care provided by less qualified nurses and "professional" tasks for more highly qualified nurses. Van der Kooij and Spijker and Van Gemert point to the tension that grew between female and male nurses in an increasingly feminized domain of work, which resulted in a separate male nurse organization in the early twentieth century. In that context mental health nursing receives some attention from them, since most of the male nurses worked in asylums. Nanny Wiegman has recently furthered the history of general nursing, also from a social historical perspective. $5^{\circ}$

The present study clearly builds on this work. The analysis of the creation of nursing care in Dutch asylums and of the introduction of mental nurse training in the I 890 s can be placed on the crossroads of the two ways of writing psychiatric nursing history - that is, a social historical analysis of nursing history on the one hand and a detailed examination of psychiatric history and the inner workings of the asylum on the other. In addition, this study draws on women's history in order to analyze how gender affected the restructuring of caring work within the asylums. Examining the development of mental nurse training against the backdrop of the creation of the mental hospital explains psychiatric nursing's past in its clinical and social contexts.

\section{Four Asylums as Case Studies}

This study follows the approach of writing "history from below", which addresses the life experience of the common man and woman rather than the politics of the elite in order to elucidate broader social changes..$^{51}$ However, this approach is at the same time limited by the fact that nurses, who 
remained largely anonymous, left behind little evidence of their work experience and their aspirations. In juxtaposing the aspirations nurses developed in facing their new circumstances and conditions of training with the ambitions of doctors, the study also addresses the perspective of this more powerful group. For the most part, the study draws on records written not by nurses themselves, but by doctors or administrators. However, despite the medical domination, an attempt is made to read their records from the perspective of nurses. Nursing journals, where available, have been used to explore the nurses' point of view as closely as possible.

The core material for the study are the records of four Dutch asylums from I890 to I920, including the provincial asylum Meerenberg near Amsterdam, the municipal asylum Franeker in Franeker, the Protestant asylum Veldwijk in Ermelo, and the Voorburg asylum near Den Bosch, governed by the College of Regents of the so-called Godshouses, which were strongly rooted in the Roman Catholic tradition. Meerenberg was the largest and most prestigious institution in the country, serving the fast-growing population of Amsterdam and the surrounding province of North Holland. Franeker, one of the smaller, and for a long time the poorest institution in the country served the indigent insane from the province of Friesland in the rural north. The Veldwijk asylum in Ermelo was another prestigious and ambitious endeavor, founded by a group of orthodox Protestants. Motivated by missionary zeal, this group saw their undertaking as a Christian duty in the broader context of religious revival. The fourth asylum, Voorburg, near 's-Hertogenbosch (Den Bosch) represented typical Roman Catholic culture in the southern part of the country. It predominantly served the province of North Brabant.

These four institutions were selected because they formed a balanced reflection of the most important trends and changes in psychiatric care in the late nineteenth century. Moreover, they represented the process of verzuiling or "pillarization" typical of Dutch society at the time as discussed above. Institutions influenced by a Protestant religious revival developed in a different manner to institutions in Roman Catholic areas, which, under the influence of Roman Catholic revival during the nineteenth century, attracted religious orders to manage care in their institutions. Municipal or provincial institutions such as Franeker and Meerenberg did not formally adhere to a particular denomination, although of course their staff and inmates reflected the values and (religious) beliefs of the population at large. However, as the study will show, the various asylums were not so different to each other that they cannot be compared. They all adhered to a somatically oriented medical treatment model by the early twentieth century, which illustrates how they all adapted to similar larger social and medical developments. 
The asylums' annual reports, other reports, documents, minutes, and selected patient records form the most important archival sources used. They were located either in provincial or municipal archives, or, in part, within the archives of the institutions themselves, most of which are still functioning as psychiatric hospitals. Since the archives of the Meerenberg and Veldwijk asylums held the most elaborate documentation, and these were the most prestigious institutions at the time, they receive relatively more attention in this study compared to the other asylums. Relatively few records from the Voorburg asylum have survived from the period under scrutiny in this study.

Furthermore, a rich source of primary books, brochures and journals, and other published material was available in the historical library of the Trimbos Institute, formerly the Nederlands Centrum Geestelijke Volksgezondheid (Dutch Center of Mental Health). The archives of the Staatstoezicht op de Geestelijke Volksgezondheid (State Inspectorate of Mental Health) in Rijswijk held important documents regarding the state registration of mental nursing, and the Verslagen van het Staatstoezicht (Reports of the State Inspectors), published intermittently throughout the period of this study, provided a rich source of documentation and statistical material on asylums. The collections of the Internationaal Instituut voor Sociale Geschiedenis (International Institute for Social History) on nursing organizations and one civil servant union have been used to study the impact of nurse organization on mental health nursing. Finally, relevant libraries and collections of other archives, such as the Internationaal Informatie Centrum en Archief voor de Vrouwenbeweging (International Information Center and Archive for the Women's Movement) and the municipal archives of Amsterdam and Haarlem have been included in the study.

\section{The Chapters in Brief}

This study puts the gendered politics of mental nursing in perspective. It highlights the ambition of doctors to create a mental hospital and to establish a skilled nursing staff in the context of broader social, gender, and religious transformations. The implementation of mental health nursing mirrors the broader process of feminization of caring work from which men were increasingly excluded. By means of an analysis of the nurses' gender and class background, their occupational aspirations and relationships, and their sources of knowledge - that is, the training nurses received and the textbooks and journals they read and learned from - the study unravels the factors that shaped the social and cultural identity of nurses. The nurses' work conditions and the new circumstances of training are also scrutinized. Using patient 
records, an effort has been made to describe in detail the patient behaviors with which nurses had to deal. The reality of nursing work often formed a harsh contrast with the more or less idealistic notions of female compassion employed in the construction of a nurse training ideology. In examining what kind of historical actors nurses were, their own responses to their circumstances were analyzed as much as possible given the limitations of the available evidence..$^{52}$

Chapter I maps out the major changes in psychiatric care during the nineteenth century. It outlines the legal regulations that passed through parliament, the social background of asylum development, and the moral treatment regimen the asylums initially adhered to. This chapter includes a portrayal of the position of the traditional, lay attendants within the asylums before the introduction of mental nurse training. Chapter II discusses the emergence of scientific psychiatry, the application of new somatic treatments, and the creation of a new nursing domain predominantly from the perspective of doctors. It outlines how the ideal of a mental hospital replaced previous aspirations of moral treatment.

Chapters III through VII analyze the gendered nature and social complexity of the position of mental nurses. Chapter III puts the emergence of mental nursing in the broader context of the feminization of caring work. It addresses the religious roots of a socially respected image of nursing that provided the basis for the eventual development of nursing as paid work for middleclass women in the late nineteenth century. It highlights how women's social position changed based on the belief that women were able to offer a specific moral capacity for benevolent work. Images of women's potential social contribution figured highly in the emergence of a women's movement and formed the context for the attraction of women to nursing work. Growing demand for skilled nursing prompted the implementation of institutionalized nurse training. Chapter IV gives a more detailed description of the reality and contradictions of nursing work within the asylum, primarily based on material from patient records. Chapter $V$ provides a detailed discussion of the introduction of mental nurse training. It describes the gendered work and living arrangements of nurses in asylums that emerged under the influence of the new training discipline. The new training system emphasized character training and the instilling of a gendered, disciplined work ethos. It had a profoundly different meaning for female nurses as compared to male nurses, which reflected the development of caring work as a woman's job in an industrializing society. Chapter VI examines the mental nursing experience from the perspective of male nurses. The gender differences in nursing work that emerged with the introduction of training had a profound impact on the pro- 
fessional identity of male nurses. They organized themselves in response to their exclusion from the caring domain. Yet the space they were able to carve out for themselves reflected the constraints imposed on caring as a man's job. The final chapter addresses the conflicts and controversies that arose as nurse training developed, and it examines nurses' organized responses towards their new circumstances and training. The gendered notion of refined, female care had to bridge conflicting demands imposed on nurses. The reliance on organic explanations of mental diseases provided a weak footing for the day-to-day reality of asylum care, and as a result the system of mental nurse training, built on these premises, incorporated many inherent contradictions. 


\section{CHAPTER I}

\section{Asylum Reform Ideals: Personnel Matters}

\section{The Appeal of Institutional Care and Moral Treatment}

Until the nineteenth century, institutional care for the mentally ill had only existed on a small scale in the Netherlands. Most of the mentally afflicted either remained with their families or were boarded out by their legal guardians with relatives or other families for a fee. For profoundly disturbed lunatics who threatened themselves, their relatives, or their fellow citizens, most towns maintained a facility in which to lock them. Usually this was a prison or a separate wing of the local charitable guest- or poor-house. Only a few towns had an asylum or madhouse for this purpose, and these often inadequate facilities were part of the extensive network of poor relief services in existence since the Reformation. ${ }^{\mathrm{I}}$

The organizational management of insane asylums was similar to that of other guest- or poor-houses. Boards of regents administered the asylums, which were financed by owned stock or property such as land or farms, or through the support of the local government. ${ }^{2}$ Usually a married couple served as the steward and matron, assisted by a few servants. ${ }^{3}$ They managed the asylum as they would any large household. Medical care was rarely available, and if so only for physical pain and sickness. The mentally ill shared their residence with the old, sick, and orphaned, or with convicts or other socially marginalized indigent people. Poor relief was both a charitable service and a measure to protect the municipal community against social upheaval. ${ }^{4}$

However, under the influence of the Enlightenment, medical and social opinions on insanity changed during the late eighteenth and early nineteenth centuries, both in Europe and North America. Enlightened reformers rejected the notion of insanity as a spiritual malady beyond human control. Despite their afflictions, reformers argued, the insane were rational beings with a human nature and should be treated as such. ${ }^{5}$ This view replaced previous notions of insanity as a loss of reason that supposedly kept the afflicted in a bestial stage and legitimized their enchainment. Reformers believed that a pedagogical moral - that is social-psychological - approach and kind supervision combined with proper medical treatment within the confines of a carefully designed asylum could indeed cure the insane. This belief was based on 
the idea that the insane had an innate capacity for self-control, reason, and a moral, ordered way of living that could be brought out if they were treated as rational human beings. ${ }^{6}$

Locking the insane in chains or keeping them in cages, as had hitherto been common practice, was antithetical to such beliefs and provided strong motivation to seek change. Existing facilities for the insane began to be considered inadequate and inhumane. The efforts of Philippe Pinel to develop the "traitement moral" in the Bicetre Hospital in Paris (founded in I794) and of William Tuke, who humanized care at the Quaker Retreat in York, England (founded in I796), served as powerful examples for reform initiatives.?

The psychiatric reform that subsequently developed resulted in a new medical regimen, framed as "moral treatment", ${ }^{8}$ which had its roots in the evangelical, utilitarian, and hygienist movements. ${ }^{9}$ It aimed to reawaken the insane's supposedly innate capacity for self-control and consisted of gentle, pedagogical discipline and supervision combined with a daily regimen of proper occupations, leisure activities, and relaxing walks in the soothing, healthy setting of a purpose-built medical institution, preferably in the country. ${ }^{\text {IO }}$ Confinement and separate quarters for different groups of patients formed an essential part of the treatment as a means to isolate the afflicted from existing psychological causes and societal influences and bring them

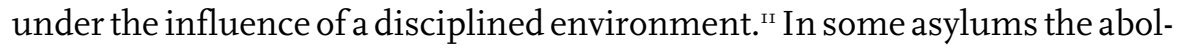
ishment of mechanical restraints became part of the broader approach of moral treatment. ${ }^{12}$ However, the adherence to non-restraint varied widely and depended largely on the asylum physicians' initiative. ${ }^{\mathrm{I} 3}$ Reformers believed that the asylum's proper management could be best placed in the hands of a single medical authority. ${ }^{\mathrm{I}}$

Moral treatment was congruent with a medical perception of insanity as a diseased state, that is, an imbalance in the strong reciprocal connection between mind and body. "Any shock to or disturbance of the body's functions could derange the mind, and vice versa," notes historian Nancy Tomes. ${ }^{15}$ Although the mind existed independently from the body, it could be affected through sensory or emotional impressions. ${ }^{16}$ Basically, it was believed that all life experiences, such as prolonged periods of stress, physical illness, emotional trauma, or debilitating vices, such as overindulgent drinking or masturbation, could cause an imbalanced state of mind and body. ${ }^{17}$ Based on these medical assumptions, confinement itself supposedly had a healing influence because, by means of changing the environment and daily regimen, it allegedly imposed regularity and order on a disordered state of existence. ${ }^{18}$ 
Socially the moral approach represented a contemporary middle-class conception of a "civil" way of living that the emerging middle class sought to impose on the lower social classes. ${ }^{19}$ Moral treatment emerged within a broader movement of poor reform that differentiated hitherto unspecified groups of the socially marginalized into distinct categories. The indigent insane was one of these groups. As capitalism arose, the emerging middle classes grew increasingly concerned with the growing number of paupers, whose existence was believed to put pressure on the economy and create social instability. Middle-class fears of the dangers of dirt, poverty, and contagious diseases fueled this concern. Motivated by humanitarian and scientific values, the middle class rationalized existing forms of poor relief. The promise of rational control, moral order, and scientific efficiency inherent in new institutional responses to pauperism (such as the improvement of education, but also the creation of workhouses and the reorganization of prisons and asylums) appealed to reform-minded middle-class citizens. They perceived such changes as measures of social betterment and as effective ways of fighting pauperism and increasing well-being and productivity among the poor. ${ }^{2 \circ}$

New criteria for the categorization of indigent people arose and new norms produced new distinctions and hierarchies, such as the difference between the able- and non-able-bodied poor on the one hand, and social and antisocial or deviant behavior on the other. The social theorists Michel Foucault and Andrew Scull have pointed out the intrinsic class contradiction of this process. They argue that middle-class efforts to humanize and "civilize" the poor at the same time generated increased social and bureaucratic control; an all-pervasive concern with cleanliness, order, and discipline; and a decreased tolerance of deviant behavior. ${ }^{2 \mathrm{I}}$

\section{A Legal Basis for Asylum Reform}

In the Netherlands asylum reform was a response to growing pauperism in the late eighteenth and early nineteenth centuries resulting from economic depression, foreign occupation, and continued economic stagnation. When the country came under French rule in 1796 , groups loyal to the occupiers sought to spread the principles of the Revolution. Liberal ideals of freedom and legal equality impacted politics. However, the country experienced a deep economic malaise. By I8Io Napoleon had annexed the country to France. After Napoleon's defeat, the Netherlands re-established itself as a sovereign monarchy in I8I5. New state policies reflected the attempt to rationalize poor relief and bring it under centralized regulations. In spite of this, a central government was a new concept in the Netherlands, which, until then had been 
characterized by decentralized government. The central government was relatively weak and local authorities kept much of their power, including power over traditional poor relief, which had been in the hands of local parish and civil poor boards ever since the Reformation in the sixteenth century.

New liberal, humanitarian insights appealed to King William I and his state officers. For example, the prison system was rationalized based on the opinion that, if placed in a proper environment, prisoners could be re-educated and once again be productive citizens. In $18 \mathrm{I} 8$, the King issued the first Royal Decree regarding the insane, noting that asylums should aim to cure the insane and ineffective asylums should be either closed or reformed. Determined civil servants undertook surveys of the situation of the indigent insane and even designed an ambitious plan for the development of a state asylum system. However, due to the relatively weak position of the government, these measures were never carried out. ${ }^{22}$ Moreover, national financial resources were largely depleted, particularly after the secession of Belgium from the Dutch Kingdom in I830. ${ }^{23}$

Philanthropic initiatives eventually furthered asylum reform. The noted medical professor and member of the board of regents of the lunatic asylum in Utrecht, Jacob Schroeder van der Kolk, was instrumental in denouncing the ineptness of existing facilities. He attracted national attention for reorganizing the old inner-city asylum in Utrecht, and adapting it to meet the requirements of moral treatment by 1830 . Separate male and female quarters; distinct rooms for groups of quiet, disturbed, and dirty patients of various social classes; large gardens where patients could walk; and some facilities for work and proper leisure activities changed the traditional madhouse into a suitable medical institution. ${ }^{24}$ With modest financial means Schroeder van der Kolk successfully concretized the reform ideal into a model that fitted the existing local social and political circumstances. Prompted by this success, state officer C. J. Feith of the Home Office department for poor relief, who was responsible for state policy on the care of the insane, invited Schroeder van der Kolk to take part in drafting a new state law on the care of the indigent insane. The law was passed in parliament in I84I, providing legal grounds for psychiatric reform..$^{25}$ The law subjected the operation of an asylum to governmental supervision and established specific hygienic and medical standards that had to be met. In I85I, ten years after the law had come into effect, the country had twelve approved medical asylums with a total of I, 637 patients. ${ }^{26}$ In 1870 this system had grown to thirteen asylums for about 3,750 patients, with one of the institutions holding I,300 patients. The total population at that time was about three and a half million. ${ }^{27}$ 
The law established a State Inspectorate of the Insane, of which Feith and Schroeder van der Kolk became the first officers. Admission procedures were made consistent for all asylums. Judicial authorization of medical certification was a requirement for admission. ${ }^{28}$ Provincial councils were given the obligatory responsibility of providing placement for the indigent insane. However, only one province decided to build a new institution, the Meerenberg asylum near Amsterdam. Most provinces opted to follow Schroeder van der Kolk's attractive example of renovating existing facilities rather than constructing new buildings.

Because of the prevailing decentralized politics, a system of state asylums never developed in Holland, and individual asylums never grew to the size of some of their counterparts in Britain or North America. Until the I920s, Meerenberg was the only asylum that had developed into an institution for over I, 300 patients. Other institutions remained considerably smaller, usually accommodating four to five hundred patients. ${ }^{29}$ The poor law of I854 reflected a similar decentralized political balance. As a result, local poor boards kept much of their decision-making power. ${ }^{30}$ The poor law made municipalities legally responsible for financing the confinement of the indigent insane; the municipality from which a patient originated paid the fixed patient fee. ${ }^{3 \mathrm{I}}$ To encourage municipalities to send their insane to the contracted asylum, the provincial council subsidized part of the fee. The national government, which had had a supervisory responsibility since the law of I84I, encouraged provinces to provide placement by paying a fixed proportion of the fee. ${ }^{32}$

Overall medical influence on the care of the insane increased. The state inspectors represented state authority and visited asylums regularly. A public prosecution officer and a general medical inspector visited each asylum every three months. ${ }^{33}$ To facilitate state inspection, asylum boards had to keep legally prescribed patient records and registers. They submitted an annual report to the government, including detailed information regarding the maintenance and hygienic state of the building, personnel changes, and patient information such as admissions; discharges; the number of patients cured and deceased; the length of stay; diseases, both physical and mental; suicide and escape attempts; and patient activities. After I884, the use of restraint was also included in the reports. These reporting measures clearly presumed medical involvement. 


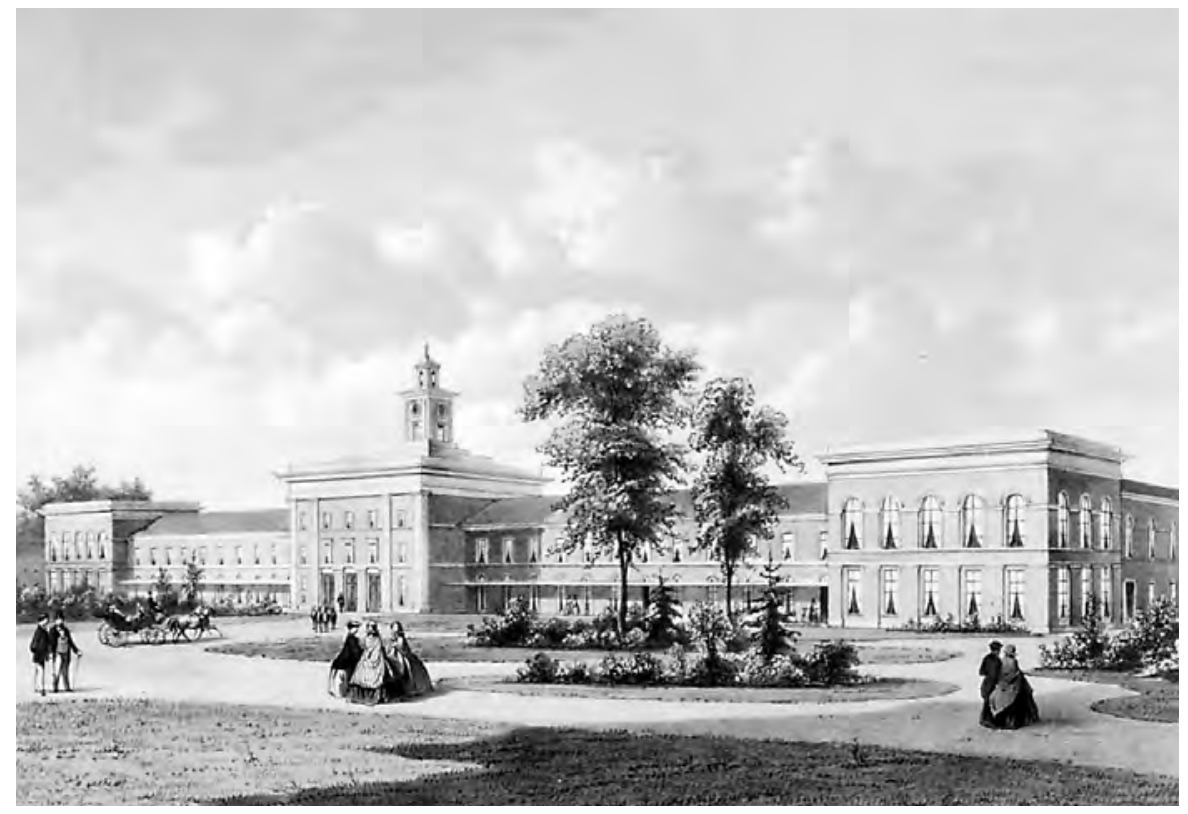

I. Meerenberg Asylum, I86I.

Liberal Views, Reform Rhetoric, and the Problem of Personnel

The case studies of the four asylums that form the basis for this study illustrate the tensions, contradictions, and conflicting responses that arose in the transformation of asylum care. Reformers found that one of the most profound problems in all of the asylums, was attracting personnel who were considered capable of providing humane patient care. Reform-minded physicians became irritated and frustrated with attending personnel and the difficulty of meeting recruitment demands. The process mirrored broad social changes in work and gender relationships. Enlightened humanitarianism and scientific ideals created tension between old and new ways, traditional and modern outlooks, and provoked strong cultural, religious and class responses. Class differences characterized the expectations of the middleclass asylum administrators and the lower-class attendants' understanding of their work. Class and gender relationships in the institutions reflected the traditional patriarchal and hierarchical structures of a large middle-class household. Middle-class men managed the asylum while their wives or daughters played typical nineteenth-century middle-class women's roles, usually taking no direct part in asylum management. Instead, they often formed a female volunteer society, complementing the work of the asylum 
board with minor tasks considered those of a woman: choosing the fabric for drapes or patients' clothes, for example, or bringing some distraction to patients by means of fruit or flowers, probably while keeping an eye on domestic affairs. ${ }^{34}$ Male and female servants, strictly divided by gender, served the male and female patients in opposite wings of the institution.

The Meerenberg asylum prototypically represented the intentions and ideals of liberal medical reformers and the state inspectors alike. Founded in I849 in the province of North Holland, about twenty miles from Amsterdam, Meerenberg became a model institution, both nationally and internationally. ${ }^{35}$ Its founding was initiated in response to the Insanity Law of I84I by a group of influential, liberal-minded citizens and doctors from the Provincial Committee of Medical Inspection and the provincial council of the province of North Holland. ${ }^{6}$ Rather than renovating the old inner-city asylums in Amsterdam and Haarlem, the founders decided to establish a purpose-built medical institution for the moral treatment of about 250 insane patients in the rustic, coastal area close to Amsterdam. ${ }^{37}$ Spacious grounds with long, winding lanes and gardens surrounded the building. Patients were involved in work on the land and in workshops as part of their treatment. The building was designed as a large landed estate, quite typical for new, early nineteenthcentury asylums in western Europe and the United States, with a corridor system of wards and other rooms opening off long hallways connected in wings and right angles (Appendix, Figure A.I). $3^{8}$

A board of regents, appointed by the provincial council, oversaw the management. Quite different to regents in other asylums, they purposely limited their managerial task to financial supervision and an advisory role to the medical director. They endorsed the new idea that a physician should direct the institution in order to make its curative, moral influence effective. From the outset a medical director headed the asylum, assisted by a second physician. ${ }^{39}$ The physicians, however, had no direct control over personnel. A steward and a matron managed the household and oversaw both servants and patients, assisted by servant supervisors. The south wing comprised the female department and the north wing the male department. By the late nineteenth century the building had expanded into seven sub-departments for over I,200 patients, and accordingly the physician staff of Meerenberg had grown to seven members. $4^{\circ}$

The first medical director, Bernardus Everts (I8IO-I883), introduced moral treatment, with which he had gained experience in his previous position as the physician of the Deventer asylum. Patients were subjected to order and regularity, and appropriate rewards and punishment as a pedagogical measure. Ideally, the physician guided their thoughts through gentle admonition 
and discussion. In addition to physical treatments such as medication, the application of baths, purging, and bleeding, patients were involved in regular work and leisure activities, religious service, and education. The physician, steward, and matron also paid careful attention to the quality of clothing, feeding, bedding, and hygiene..$^{4 \mathrm{~T}}$ Everts was the first asylum medical director on the European continent to apply the system of non-restraint, to which he had been introduced during a visit to various British asylums in 1848 , prior to the opening of Meerenberg. ${ }^{42} \mathrm{He}$ saw the abolition of mechanical restraints as the most advanced application of humane treatment. Restraints, he argued, provoked disturbed behavior rather than calming patients down and made attendants less attentive to their supervising task. Instead, agitated and disturbed patients should be treated in single rooms or specially designed isolation cells where they could obtain appropriate care and rest. When building expansion became necessary in I855, Everts used his influence to design the new space according to his non-restraint philosophy. Two large wings with many cells and single rooms were added particularly for disturbed patients, which enabled Everts to abolish restraints completely. ${ }^{43}$

In spite of this, from the outset of asylum reform, both boards and state inspectors noticed that hiring good servants capable of applying the more humane approaches was not easy. ${ }^{44}$ In fact, asylums that removed mechanical restraints in order to increase the reliance on kindness rather than coercion in the context of moral treatment placed higher expectations and a more burdensome responsibility on the attendants. They had to rely more heavily on personal, moral preponderance, and personal authority to maintain discipline. ${ }^{45}$ Such behavioral expectations, however, were class based. The moral treatment philosophy, defining care in moral terms, reflected middle-class values of calmness, self-control, decency, regularity, discipline and order. Accordingly, the medical directors' belief that an appropriate, humane attitude would make a servant a good keeper was grounded in middle-class morality. They felt attendants should be models of decency and subservience towards their superiors. According to the rhetoric, attendants should model appropriate (class) behavior so that patients would learn how to behave and participate in a productive social structure. Instructions for attendants of the Franeker asylum, written in 1850 , gave a detailed account of their duties and exemplary role to the patients in subordination and discipline. For example, attendants should take off their hat if a board member or physician passed by so patients could learn this appropriate behavior from them. ${ }^{46}$

But attendants, like the patients, came from the lower social classes. Strictly separated by gender in opposite wings of the building, attendants and patients shared common spaces of sleeping, living, and eating, and a joint 
work routine. Getting up, taking meals, cleaning wards, and keeping the place in order were the joint responsibility of attendants and patients alike. Attendants closely experienced the often trying behaviors of the mentally ill and had to deal with them directly and intimately. It may not have been a particular humanitarian motivation that called them to the job, but rather an interest in earning a living. Most often they saw it as a temporary living and left as soon as they could find something better, if they had not yet been fired because of supposedly improper behavior. Many workers resisted the job and soon left, perhaps because the work itself was unattractive or because the work expectations were conflicting. Annually more than half, sometimes up to 90 percent, of the workforce left, which created continuous instability. ${ }^{47}$

From the beginning of mid-nineteenth-century reform, medical directors and asylum physicians complained about the inappropriate behavior and "unrefined attitude" of attendants. Meerenberg's director, Bernardus Everts, referred to the servants' drinking and dancing in public places and their frivolous and improper clothing..$^{8}$ Cursing, ridiculing patients, patient abuse, neglect of duties, and indecent behavior were other frequently mentioned shortcomings. ${ }^{49-}$ Medical staff felt that the poor quality of attendants strongly limited the success of moral treatment. The noted medical professor Jacob Schroeder van der Kolk had addressed the issue in his famous lecture on the requirements of "a good asylum for the cure of the insane" in I $838.5^{\circ}$ In order to make the moral treatment work, he noted, all institutional arrangements needed to contribute to the creation of a therapeutic environment. Servants should be "carefully selected".$^{51} \mathrm{He}$ based his moral approach on the values of a respectable nineteenth-century middle-class household. Asylum management was rooted in liberal "refined" middle class ethics. ${ }^{52}$ Medical men, who sought to apply hygienic principles and moral treatment, emphasized instilling personnel with values of punctuality, decency, cleanliness, industriousness, and self-control.

In his first annual report in I851, R. Lammers van Bueren, medical director of the Franeker asylum, noted that finding proper personnel was indeed difficult; it was particularly difficult to find people "who are filled with philanthropy in such a way that they seek their fulfillment and satisfaction only through benevolence towards the suffering and the poor" ${ }^{53} \mathrm{He}$ found that attendants lacked compassion and the ability to interpret patients' aggression, harassment, or offenses as expressions of their illness. Like the patients, servants were from the pauper class and reformers considered their low morale to be a consequence of their low social standing. Medical directors objected to the fact that so many applicants for attendant positions were out of work or unable to find any other position. Former workhouse inmates, discharged 
veterans, and inexperienced young girls were among the applicants. Quite commonly seasonal workers filled vacant positions and left as soon as alternate opportunities for work increased. ${ }^{54}$ If attendants did not leave of their own accord, they were often dismissed because of misbehavior, drunkenness, disobedience, and, not infrequently, patient abuse..$^{55}$ Everts' successor, Cornelis Johannes van Persijn, faced similar problems in I888 when he had to find new personnel for the New Meerenberg complex annexed to the original building. He considered the most important aspect of the expansion finding good personnel, because good care was completely dependent on that. Yet in the same year that the expansion opened, all the attendants, who had been hired with great difficulty, had to be replaced, either because they resigned or seemed unfit for the job..$^{6}$

Complaints about servants were not unique to asylum reformers. The difficulty of finding good servants was a common complaint among the middle class in general.57 "Poor servants" mirrored a deep cultural and social gap between middle-class values and the morality of the lower social classes. Tension between these groups grew during the nineteenth century, when the middle class attempted to reform the poor into a disciplined workforce..$^{8} \mathrm{In}$ the context of American hospital reform, historian Charles Rosenberg notes how reformers were confronted with lower-class values and behaviors that were antithetical to their conception of moral order. 59 The frustration of asylum reformers about their dependency on pauper personnel reflected this class contradiction.

Beginning in the I86os, physicians attempted to give some instructions to attendants. Some of them wrote textbooks for this purpose, explaining the main phenomena of insanity and providing advice for attendants. The booklet "Raadgevingen aan oppassers en bedienden in Krankzinnigen-gestichten" (Advice to keepers and attendants of insane asylums), published in 1865 by physician N. B. Donkersloot of the Dordrecht asylum, illustrates the aspirations of asylum doctors. ${ }^{60}$ It reflects their frustration about their perceptions that the inadequate attitude of attendants undermined their medical therapies.

The shift from simply locking up "madmen" to a humane treatment of the insane, Donkersloot noted, required a new attitude on the part of the staff. Frenzied and unruly mad people had to be approached gently, with a calm and firm manner. Delusions and hallucinations of patients should never be denied or refuted. Crying, irritable, or agitated depressed patients should be treated with a serious, cheerful, but not lighthearted, mood and a supportive attitude. The patients' unruly behaviors were just symptoms of their illness, Donkersloot explained. Vulnerable and dependent idiots and epileptics, often incontinent and unable to feed themselves, should receive tender, reli- 
able care. Attendants had to follow the doctor's prescription to care for patients with compassion and never blame patients for their behavior nor show any aggression themselves. Attendants should never lie to patients, nor gossip about them, but should skillfully distract them. ${ }^{6 r}$

However, the opportunites for attendants to study such instructions were limited. Their work environment did not encourage the development of an intellectual interest in medical and psychological matters. Even if attendants had sufficient reading and writing skills, studying was scarcely possible. ${ }^{62}$ The instability and potential disruptiveness of the patients further compromised the creation of a steady, predictable work routine for servants. ${ }^{63}$ Personnel had to be available for patients, if not for domestic work, all day and usually also at night. They were often worn out by demanding patients and constrained by the social situation and mentality of the lower social class themselves. Under these conditions, a book might have been ineffective in developing a more philanthropic attitude. ${ }^{64}$

\section{Lower-Class Institutions}

Medical director Everts, in an I854 report on asylum personnel, stressed that the board should take the material and moral interests of attendants seriously. Not only the standard of personnel within the asylum but also the reputation of the personnel outside the asylum should be improved, he argued, for only then would "respectable middle class citizens encourage their sons and daughters to take service at Meerenberg" ${ }^{65}$ Everts recommended compulsory savings as part of the salaries, the regulation of leisure time, uniform clothing, elementary education, rewards for extended service, clerical attention for personnel, the freedom to marry, the improvement of food and living conditions, and regular personal contact between higher officers and servants. Some measures were indeed implemented in Meerenberg, such as the establishment of a hierarchy with supervising servants, uniformity in clothing, regular days off, and some improvement of salaries, particularly a distinction between a (higher) male and a (lower) female salary, ${ }^{66}$ but on the other hand the board remained hesitant to make drastic changes in its attempt to keep costs low.

Everts' recommendations for improving personnel quality appeared repeatedly in the reports of the state inspectors over the next decades.$^{67}$ They recommended an increase in salary, rewards, annuity, more leisure time, and, particularly for male attendants, permission to marry as measures to improve the attendants' work conditions. Nevertheless, limited finances, conservative strategies, and unwillingness or inability to acknowledge the 
need for better work conditions prevented asylum boards from taking innovative measures, and as a result not much changed. ${ }^{68}$

While a prestigious institution such as Meerenberg experienced difficulty in staffing its wards, poorer institutions, which struggled to maintain themselves financially, had an even harder time finding appropriate personnel. For example, the Franeker asylum in the rural north of the country, founded in I85I as a liberal reform inititiative in response to the I84I law, saw ideals constantly restricted by a very tight budget. Designed for about ioo patients, the Franeker asylum was established in an age-old monasterial building in the town of Franeker, which had housed a university for a long time. ${ }^{69}$ In the late eighteenth century, when the town lost its cultural influence, the university fell into decay. By 1843 it was an empty complex in the center of the town..$^{\circ}$ Its subsequent use as an asylum began when the provincial council of the province of Friesland was forced by the law of I84I to provide separate accommodation for the indigent insane. ${ }^{7 \mathrm{I}}$ In 1848 , the provincial council agreed with the Franeker town council to establish an asylum in the empty building complex in Franeker for the indigent insane from Friesland. ${ }^{22}$ The old, manifoldly used building necessarily meant a compromise, if not a burden for the asylum. ${ }^{73}$

The Meerenberg asylum was an inspiring example to Franeker's first medical director, R. Lammers van Bueren. He adapted the asylum to the requirements of moral treatment and, like Meerenberg, adhered to the non-restraint system. His first annual report revealed the expectation that humane, moral treatment would indeed cure the insane. A married couple, as steward and matron, assisted him in supervising both patients and servants. ${ }^{74}$ But as a result of financial restrictions, much less support from the local authorities, and a more remote rural setting than the Meerenberg asylum, the Franeker asylum did not develop into an institution of similar reputation as Meerenberg. Franeker had one of the lowest patient fees compared to other asylums in the country.75 Moreover, the town's council usually insisted on the transfer of any surplus on the balance back to the municipal account..$^{76}$ Financial constraints often delayed any proposal for innovations of care. The tension over the administration of the asylum reflected its status as a lower-class institution for indigent patients. ${ }^{77}$

\section{The Position of Attendants and Patients in the Asylum Hierarchy}

Until the late nineteenth century servants or attendants (bedienden) oversaw patients in the asylums, under the supervision of a steward and matron, or house father and mother, who managed the large household. An equal num- 
ber of male and female attendants did the work, assigned by gender to the male and female departments. Only one level up from the patients, attendants formed the lowest rank of the institutional hierarchy. They received no particular preparation for their work. As with the indigent patients, they came from the lowest social classes. They were lay people, whose skills learned in previous jobs as servants and workmen would suffice. Ideally male attendants were artisans or skilled workmen, because they could then involve and oversee the patients in work activities; a good record in servant jobs was sufficient for female attendants. Like servants in any large middle-class household or farm, attendants learned their presumably ordinary tasks by word of mouth and example from their fellow keepers. The rhythm of the day followed that of traditional farm and artisan work, albeit in a more regulated form.

As asylums grew in size and complexity, the hierarchy expanded with some degree of specialization. During the I86os "overseers" (opzichters en opzichteressen) in charge of particular wards assisted the house father and mother in supervising the attendants or "keepers" (oppassers en oppasseressen), whom they charged both with domestic service and the task of overseeing the patients. In addition, some domestic servants who had no responsibility for patients were hired.

The status and prestige of attendants' work was in many ways dependent on the status of the patients. Working with the most afflicted or disruptive patients was the least attractive, most burdensome, and dirty, and as a consequence represented a lower prestige in the institutional hierarchy. These patients' marginal status was reflected in the design of the building. The most unsettled patients were quartered in the outer wings of the building where they would be least intrusive to others.

The architecture of the newly built Meerenberg asylum illustrated how patients were classified within the institution according to three criteria: gender, social standing, and behavior (Appendix, Figure A.I). ${ }^{8}$ Despite the increased medical authority, medical diagnoses were only of minor influence in the assignment of patients to wards. ${ }^{79}$ The class differentiation reflected the division of social standing within society at large. A broad middle class was formed when industrialization had its impact in the second half of the century. Roughly three main classes could be distinguished: the upper class or elite, the middle class, and the lower class. The second two layers were divided into upper and lower strata, yet divisions varied greatly dependent on the geographic area and the level of urbanization. The indigent lower or pauper class split during the nineteenth century along the lines of their capacity to work; the "able-bodied" poor formed the labor class, the "non-able-bodied" poor remained dependent on poor relief. ${ }^{8 \circ}$ 
Based on their gender, patients were assigned to the male or female department. Female servants were put to work in the female department under the authority of a matron, traditionally the steward's wife, and male servants worked in the male department supervised by the steward. Supervisors and head servants, divided over the various divisions and wards, assisted the steward and matron in overseeing personnel. The gender-based division of labor was extended within the various workshops. The laundry facilities and large seamstress workshop were located in the female wings, whereas, for instance, the shoemaking and mattress-making workshops were stationed in the male department.

Meerenberg had an extensive differentiation according to class and corresponding levels of payment. Social standing was expressed in a front-to-back hierarchy of patient quarters and wards, with the higher-class patients closer to the front of the building. Each social class had its particular privileges expressed in the design of living arrangements, the level of service and the menu, and paid accordingly. The first three levels of patient fees, which formed classes one to three, were intended for patients from the upper and middle classes. A particular investment was made to give the upper-class wards a home-like ambience according to the patients' middle-class style of living, with fine furniture, china, artwork, and proper amusements such as a piano and a billiard table. There was a special ward that separated disturbed patients from these classes. A fourth level of payment, the fourth class, was intended for working-class families who could still afford to pay for their insane family members. It was only a small group. Apparently very disturbed fourth-class patients went to the fifth-class ward.

By far the largest group of patients comprised the fifth class of indigent patients, whose fees were paid by public funds. They formed about 90 percent of the patient population..$^{{ }_{\mathrm{I}}}$ The living and sleeping quarters of the indigent patients were much simpler than those of the higher classes. Beds were placed in a strict order at a prescribed distance on large wards, and the fifthclass menu was dominated by easy-to-cook one-pot meals without much variety. ${ }^{82}$

The living arrangements of Meerenberg's personnel followed the same hierarchy of social standing. Administrative and managing officers had their rooms on the second level of the front of the building. Servant personnel of each particular class of patients had their sleeping quarters upstairs from the day quarters, right next to or on the sleeping wards of the patients. The artisan personnel had a separate sleeping room above the workshops. Meals for personnel were arranged in congruity with social standing. Servants always had a fourth-class menu not very different to that of the indigent patients. 
Finally, in addition to gender and social standing, a third classification of patients was based on their behavior. Five types were distinguished: quiet, sick and old, disturbed, semi-disturbed, and incontinent patients. The classification of behavior also depended on social standing. Disturbed patients of the first, second and third classes had a separate quarter, but still at the front side of the building; the self paying patients of the fourth class were very few and mostly grouped together in rooms next to the disturbed patients of the upper three classes. The indigent patients were all placed on large wards at the middle and rear of the building, according to their behavior. The quiet fifth-class patient rooms were in the middle of building and the quarters for the semi-disturbed were in the rear of the building. For the most disturbed patients there was a separate wing with cells and single rooms, and a ward for incontinent, predominantly demented, and epileptic patients had been established in a separate building block outside the main building. ${ }^{83}$

Special architectural measures for the prevention of violence, suicide, and escape characterized the sections for disturbed patients. In I889, Meerenberg's director, Van Persijn, noted how the doors of the euphemistically named "single rooms" had been fortified with solid wooden panels, because patients "smashed them constantly". In that same year various semi-disturbed and disturbed patients had successfully escaped from the new building by breaking the windows in the hallway, which turned out to be too large and framed with wood that was too fragile. They were replaced by thick ironframed plate glass windows but, for financial reasons, this was done only on the male wards.$^{8}$ Although in theory cells and single rooms had replaced the use of straitjackets and other mechanical restraints, to encourage personnel to closely watch patients rather than tying them down, attendants were still confronted with high levels of unrest and violence on these wards.

\section{Different Responses and Different Solutions: Roman Catholic Initiatives}

Religious revival among Roman Catholics provoked a rather different response to the problems created by growing pauperism and were in fact antithetical to, if not a reaction against, rationalistic, liberal views. During the first half of the nineteenth century Dutch Roman Catholics began to overcome a period of more than two centuries of subordination. Since the Reformation in the sixteenth century, Roman Catholic organizations had been banned from public life. In 1796, when the Netherlands came under French rule, Roman Catholics and other religious groups attained freedom of religion. The new Parliament, established by the French, felt that a privileged, state-supported (Protestant Reformed) Church was not in line with the revolutionary ideas 
and approved of legal equality for everyone, irrespective of religious orientation. This measure paved the way for hitherto suppressed religious groups to re-establish themselves publicly. When the French left after the defeat of Napoleon in 18 I3, the Constitution of the new Kingdom of the Netherlands maintained the equality rule, although the absolutist-minded King William I, strongly influenced by Protestants, sought to restrict the "Roman" influence. Further legal freedom for the Roman Catholics came in 1848 , when, primarily in response to the revolutionary atmosphere in Europe at large, King William II approved a revision of the Constitution. A new liberal government was the result and the liberal Constitution guaranteed freedom of education, press, and association. This led to a boom in newly founded Roman Catholic organizations and institutions, including charitable orders, ${ }^{85}$ particularly after the reinstitution of the Roman Catholic Episcopal hierarchy in $\mathrm{I} 853 .{ }^{86}$

These developments both produced and enforced a strong ultramontanist movement among Roman Catholics, particularly in the conservative south of the Netherlands. Ultramontane Roman Catholics sought to assert an independent Roman Catholic identity and reinforce a religious Roman Catholic life. Catholic religious revival and a clerical attempt to strengthen religious practices that enforced the universal authority of the Roman Catholic Church among Roman Catholic citizens became one and the same effort within the ultramontane movement. The foundation of many new congregations fit with this broader religious revival, which created social space for religiously inspired charitable work. ${ }^{87}$ Roman Catholic leaders and their Protestant counterparts, each within their own sector, responded to liberal modernization and increased state involvement with missionary attempts to revitalize Christian faith and benevolence, thus maintaining their influence over their respective communities. ${ }^{88}$ Religious revival among Roman Catholics profoundly influenced reform in the Voorburg asylum, which was located in the predominantly Roman Catholic province of Noord-Brabant. The College of Regents that oversaw asylum care in the town of Den Bosch in the age-old Reinier van Arkel asylum and its I885 extension, the Voorburg asylum, responded to reform pressures with measures that fitted the Roman Catholicist emancipation.

The Reinier van Arkel asylum, named after a noted citizen of the town of Den Bosch, was founded as a small madhouse for five insane as an act of benevolence in I442. Neither the church nor doctors were involved in this civilian, charitable enterprise. ${ }^{89}$ Small-scale asylums emerged in several European countries at that time, housing initially about six to ten people. Bedlam in London, England (I37I), and the Willem Arntsz asylum in Utrecht, also in the Netherlands (I46I), are other examples. For centuries, these 
homes never exceeded fifty inmates, $9^{\circ}$ but during eighteenth- and nineteenth-century social changes these homes grew into larger institutions. Historian Ton Kappelhof argues that in this same period private corporate madhouses and workhouses began to emerge, suggesting that the shift was related to changing economic and social relationships, such as pauperization (particularly in rural areas), depleted family resources, and increased dependency on public support. Moreover, tolerance among the rising middle class for "unproductive" and deviant behavior decreased. By I803 the Reinier van Arkel asylum held sixty patients..$^{\text {I }}$

During the French occupation, the influence of which was most strongly felt in the southern provinces, the Reinier van Arkel asylum became part of the centralized administration, put in place by French decree, of all charitable institutions for poor relief in Den Bosch. After the French left, this centralized system remained in place, and from I8I5 on the asylum was managed by a College of Regents, which replaced the French committee..$^{92}$ These notable local authorities were not eager to follow new national regulations. In response to the I84I law, they designed new house rules that reflected the new moral view of treatment, and restricted the use of restraints. But these measures did not correspond with the state inspectors' view of reform. In their opinion, neither the building nor the condition of the patients was appropriate: the buildings required renovation and the patients more medical supervision. A long process of negotiations between the Regents, the provincial council of Noord-Brabant, which sought to negotiate a contract for the indigent insane from the province, and the state inspectors eventually resulted in the expansion of the old inner-city complex to a total of 270 patients. The Regents agreed on a contract with the provincial council in I844 and appointed one of the city's poor doctors as asylum physician; four years later their institution was approved by the state. ${ }^{93}$

The asylum, however, did not become the prototype medical institution the inspectors had in mind. Any potential for increased medical authority was restricted when, to the surprise of the inspectors, the College of Regents switched to a profoundly Roman Catholic management of the institution and contacted the local vicar of the diocese of Den Bosch for the appointment of a priest. Moreover, not only in Reinier van Arkel, but in all charitable institutions of Den Bosch that fell under the administration of the College of Regents, the Regents shifted to a contract with Roman Catholic nursing orders to take over the internal management and care of patients. ${ }^{94}$

This measure of the College of Regents must be seen within the context of Catholic religious revival. The Reinier van Arkel, and the later extension, Voorburg, were not church-owned institutions, nor were they managed by 
the Roman Catholic Church. The College of Regents was a civil board, appointed by the municipal council to oversee the charitable institutions of the town. However, because the majority of these Regents were notable and devoted Roman Catholic citizens, the influence of religion strongly affected their policy. Strongly influenced by ultramontanist views, the College of Regents of the charitable institutions in Den Bosch supported the re-establishment of Roman Catholic orders, which had been banned since the Reformation, within their institutions. Because nursing orders considered their work to be a charitable service, their fees were very low, and the Regents had a keen sense of the financial profit this would bring. In I852, the Regents contracted with the "Congregatie van Goede Werken" (Congregation of Mercy) from the Belgium town of Ronse. Eight brothers of their male nursing order "Broeders van Onze Lieve Vrouwe van Lourdes" (Brothers of Our Lady of Lourdes) and ten sisters of their female nursing order "Zusters van Goede Werken" (Sisters of Mercy), both founded in I830, took over the daily care and patient management in the Reinier van Arkel; the lay personnel were all dismissed. 95

This shift in management laid the groundwork for much tension and conflict between the diverging interests of the Regents and the leaders of the order on the one hand and the asylum's physicians on the other hand. When over the next few decades medical status and influence increased, the asylum physicians at Voorburg sought to increase their influence on patient management, but within the dual hierarchy of the Regents and the nursing order, the physicians did not attain the position of authority to which they aspired. The physicians had little control over the male and female nurses, who reported directly to the Brother or Sister Prior. These groups were deeply divided as to how the humane treatment of patients should be viewed and applied. Although both groups adhered to humanitarian ideals, the nursing orders saw their work as that of Christian benevolence, grounded in faith and as a contribution to the spiritual salvation of the sufferer. These norms shaped their actions. Physicians, on the other hand, strongly supported by the state inspectors, were inspired by enlightened, scientific values. They felt that treatment should be built on the scientific norms of hygiene, building architecture, and utilitarian principles, which were in many ways antithetical to the way nursing orders planned their religiously based management. ${ }^{96}$

The rapidly increasing number of patients compounded existing tensions. By I870, when the Reinier van Arkel building was in urgent need of expansion, the two asylum physicians, dissatisfied with the Regents' lack of initiative, took the opportunity to found their own private, profit-based asylum, Coudewater. Strategically, they made an offer to the provincial council to take 
indigent patients for a lower fee than the Reinier van Arkel and in response, the provincial council contracted with them for the care of indigent patients. Suddenly the Reinier van Arkel lost almost all of its indigent patients to Coudewater. However, due to the high demand for the placement of indigent patients in the country at large, the asylum was once again soon filled to capacity. By I885, on the renewal of the provincial contract, the College of Regents negotiated anew offering a lower fee. When the provincial council subsequently renewed the contract with the Regents, it did so on condition that the Regents expand the asylum with a new building outside of the city; as a result the new asylum Voorburg opened that same year. However, in all three institutions - Reinier van Arkel, Coudewater and Voorburg - the Brothers of Our Lady of Lourdes and the Sisters of Mercy remained in charge of the internal management and patient care. ${ }^{97}$

From the outset the Voorburg asylum represented a compromise with the new trend of asylum building proposed by the state inspectors. The inspectors had pushed hard for adapting to the cottage system, a design in which relatively small groups of patients were cared for in separate pavilions preferably in a quiet, wooded rural area. However, the College of Regents opted for the outdated corridor system. The interest in possible profit seemed a forceful motive for a building design in which large numbers of patients could easily be overseen. The building was designed for about 600 patients, but by 1890 the number of patients had increased to almost 900. Although the Regents appointed the required number of physicians, the inspectors felt that the building barely met the legal medical and hygienic requirements with regard to sanitary facilities and ventilation..$^{8}$

Voorburg's building construction clearly reflected the differing views on patient care held by the Regents as opposed to those of the physicians and the state inspectors. A large Catholic chapel dominated the facade of the building, symbolizing the Regents' pride in their Catholic heritage. Somewhat cynically, a visiting physician noted that, in his opinion, the asylum was overshadowed by an overly grandiose church while the medical and administrative offices were not immediately visible. Moreover, the non-restraint system was not widely adopted. ${ }^{99}$ Likewise, the state inspectors complained about the lack of proper medical observation quarters, the lack of personnel for patient supervision, the widespread use of restraints, and the problem that measures of restraint could still be applied without consulting the asylum physician. ${ }^{100}$ Their medical view differed profoundly from the managerial vision of the College of Regents and the nursing orders, who grounded their care in religious views and practices. Moreover, whilst the introduction of nursing orders may have meant an improvement in care compared to the 
earlier situation, physicians clearly resented the lack of control over personnel.

\section{Reform Ideals Frustrated: Asylum Growth and a New Law}

The rapidly increasing number of patients soon compromised the humane ideals underlying legal and medical reform in all of the asylums. In I859 the country had $\sigma_{3}$ asylum patients for every I00,000 inhabitants, but by 1889 this number had increased to 135 per I00,000. ${ }^{\text {IoI }}$ Between 1850 and I 884 the number of asylum patients tripled, from about I, 600 to 4,800 , whereas the total population increased by only 30 percent. ${ }^{\mathrm{IO2}}$ Due to overcrowding, the conditions for patients worsened and this created a tense and unattractive work environment, which made hiring sufficient personnel more difficult. The level of patient care grew even worse as a result of personnel shortages. This downward spiral seemed to generate a hopeless situation.

The therapeutic optimism that the mentally ill could indeed be cured through moral treatment was soon deflated. The afflictions of the majority of asylum patients turned out to be of a chronic nature. Psychiatrists began to distinguish these cases from acute ones, whom they considered curable. The acute mentally ill, patients with afflictions such as mania, melancholia, amentia, insania hysterica, and insania neurotica, usually left the asylum within one or two years at the most. These patients recovered after a relatively short, intense period of illness.. But they comprised only a small proportion of the total asylum population. In Meerenberg, for example, patients with these acute ailments made up only sixteen percent of the population by the late nineteenth century. ${ }^{\mathrm{IO}}$

In contrast, the chance of recovery for chronic epileptic, idiot, imbecile, paranoid, and demented patients was nil. Their conditions slowly but inevitably deteriorated. Once they were admitted, they usually stayed in the asylum. ${ }^{104}$ The accumulating number of chronic cases began to form the majority of the asylum population. By I884, 73 percent of the patients confined were hospitalized for more than three years, many of them for much longer. ${ }^{105}$ By the late nineteenth century Meerenberg's patient population of over I, 300 patients consisted of 74 percent chronically mentally ill, among whom about I5 percent were idiot, 6 percent imbecile, II percent epileptic, 36 percent paranoid, and 6 percent demented patients. ${ }^{106}$

As a result, during the second half of the nineteenth century asylums changed into overcrowded institutions with large numbers of physically weak patients. Not much more than custodial care was applied. Too many patients packed into too little space led to unacceptable levels of unrest and violence, 
further compromising the position of the personnel. In the eyes of physicians these conditions were an affront to any ideal of proper medical care and antithetical to the original ideals of moral reform. In I882, Franeker's medical director, S. Doedes Breuning, cynically noted that due to overcrowding the asylum was little more than "a warehouse" rather than an institution that met the scientific requirements for curing the insane. ${ }^{107}$ Meerenberg's medical director, Cornelis Johannes van Persijn, reported with similar frustration that the overpopulation led to unmanageable situations. ${ }^{108}$ Their criticism, however, was predominantly directed against the asylum boards and local authorities, which refused to invest in the renovation and expansion that the physicians found most necessary.

At the time, asylum physicians perceived the growth of the asylum population as an indication of increased public faith in asylum treatment and of much-needed expansion. ${ }^{109}$ Current historical explanations of asylum growth emphasize the broader economic and demographic changes that provoked the increase in confinement, leading to a process of medicalization, in which an increased number of social problems began to be framed as medical problems. As Kappelhof noted, Marxist-oriented arguments emphasize that changes in demographics and the pauperization of the masses during industrialization increased familial tension, alcoholism, begging, and so on, which in turn led to increased confinement of those engaging in intolerable behavior. Social historians highlight the idea that due to middle-class "civilizing strategies", tolerance of deviant behavior decreased and state involvement with public order and guardianship expanded, both leading to increased confinement. In addition, according to Kappelhof, economic factors such as the increase of the average standard of living, making confinement affordable for families, must not be overlooked.

The Dutch psychiatric historian Hans Binneveld considers social control theorist Andrew Scull's opinion - that an expanding asylum system created its own demand while decreasing family tolerance - to be applicable to the Dutch situation. Particularly among the indigent, Binneveld argues, families could not afford care and were therefore relieved when publicly funded institutional care became available. Moreover, families' living situations and their ability to care for relatives changed as a result of industrialization and urbanization. However, Scull's point that asylum expansion also resulted from an increasing medical interest in labeling more and more deviant behavior as mad - the idea of medical men as moral entrepreneurs - Binneveld considered too limited an explanation for the Dutch situation. Particularly on the European continent, Binneveld notes, state bureaucracy also facilitated an expanding notion of insanity - for instance, in the area of crime and sub- 
stance abuse prevention. An increasing number of behaviors were considered mad rather than criminal. Similarly, Gerald Grob argues for the United States that doctors did not have that much control over the influx of asylum patients. Following Giel Hutschemaeker, who argues that mental illness must be seen as socially constructed, this analysis emphasizes that increased confinement was a complex process of social interaction in which various groups, including doctors, patients, government and families negotiated and constructed the meaning of mental illness. As the medicalization theory assumes, the domain of medical problems in this process expanded. ${ }^{\text {IIO }}$

\section{A Second Law on the Insane}

In an attempt to deal with the problems of expansion, a second law on the insane was passed by parliament in I884. The State Inspectorate expanded to include patients outside asylums, and the obligatory guardianship was abolished. ${ }^{\text {III }}$ In addition, the law set out hygienic and medical requirements intended to improve the asylum's hygienic conditions. Asylums had to be established in a spacious, healthy spot, and they should contain sufficient rooms to differentiate patients according to gender, nature, and number. A prescribed minimum number of physicians, one for every two hundred patients, was thought to guarantee a sufficient level of medical care. ${ }^{\mathrm{II}}$

The second law's most important impact was the limitations it put on the unbridled increase of numbers of patients per asylum through a prescribed maximum of patients per asylum based on space requirements. To determine the maximum number of patients, the state inspectors set new norms of a specific number of cubic meters of fresh air and a minimum distance between beds. ${ }^{113}$ These norms strengthened the influence of medicine on policy for the insane and reinforced the position of the psychiatrist. Asylum boards could no longer increase admission capacity by merely crowding more patients into the existing space. But the law did not stop the growth of confinement itself, nor did it resolve the problems resulting from the predominantly chronically ill patient population. The law clearly reflected an increased medical confidence in the necessity of asylums. The state inspectors strongly recommended the establishment of new asylums, preferably in the countryside, and the number of asylums doubled from I4 in 1884 to 29 in I9I5. ${ }^{\text {II } 4}$

Adaptation to the new i 884 law was slow. The Franeker asylum, for example, initially designed for 100 patients, held 225 patients by i 887 . Forced by the law, the asylum board appointed a second physician but responded hesitantly to the pressure for new building. The medical director proposed plans 
for renovation at various points from the early i880s. ${ }^{\mathrm{II}}$ Although the board was not unwilling to support the plans, they lacked the control to finance any innovations, and renovation plans were usually rejected by the provincial and and town councils. When the province eventually raised the patient fee in I882, the board and medical director proposed the use of the increased income for the long-debated renovation, but much to their chagrin the municipal council rejected such plans and required the transfer of any surplus on the next yearly balance back to the municipal account. ${ }^{\mathrm{Ir} 6}$ The state inspectors, who supported the director's view, pressured the board to take stronger measures, and in I886 the municipal council finally agreed to buy some land outside the town for possible expansion; a second building complex was not built until I930.

However, additional space did not necessarily imply a solution to the inherent problems of asylum growth. In response to the insanity law of $\mathrm{i} 884$, the provincial council of North Holland enlarged the facilities of Meerenberg by building a second asylum complex for about four hundred patients close to the old one, on a purposely bought adjacent estate. The new building was ready in 1887 , and the first patients were admitted a year later. ${ }^{117}$ The year the new building opened, the frustrated medical director, Van Persijn, pointed out to the board that within a year it, too, would be almost filled to capacity with chronic patients. About three hundred patients temporarily placed in facilities outside of the province had to return to New Meerenberg; in addition the Buitengast Hospital in Amsterdam sent about two hundred a year, and then there were the regular admissions from the remainder of the province. ${ }^{118}$ The number of discharged patients by no means kept in step with this increase. As a result, Meerenberg held about I,200 patients by the end of I890, almost the legal maximum, which in I888 the state inspectors had determined to be I,2I7. ${ }^{\text {II }}$ Two hundred of these were epileptic patients, and about a fifth (79) of the extremely high number of admissions in 1889 (388) were idiot or imbecile patients. Demented elderly also comprised a large number of admissions; in 1890 over 20 percent $(56)$ of the new admissions were diagnosed with dementia. ${ }^{120}$ The irreversible nature of these patients' illnesses meant that once admitted they would never leave the asylum.

In response to the I884 law, many asylum boards eventually opened a second building complex outside of town. These innovations of care were usually proposed by medical directors and asylum physicians, who were most eager to adapt the institution to national medical trends. During their yearly visits the state inspectors supported their views and pressed boards to act on them. Moreover, in the context of religious revival among Protestants, various new asylums were also founded. 
The founding of Veldwijk was the first of a wave of new asylum building undertaken by private, religiously motivated groups during the late nineteenth and early twentieth century. An independent group of orthodox Protestant church leaders, ministers, doctors, and professors of the Christian Reformed theology school for ministers in Kampen founded the Veldwijk asylum in I886 as a Protestant, missionary initiative. They were part of a broader Protestant religious revival movement during the second half of the nineteenth century, which - like that of their Roman Catholic counterparts intended to revive the Christian obligation to alleviate social distress among the poor and sick, a task that they felt the formal Protestant church had neglected. ${ }^{\text {I2I }}$ This endeavor was comparable to similar objectives within the broader Anglo-American Evangelical movement and the continental European Inner Mission movement (Reveilbeweging).

Protestant revival was in part a reaction to the increasingly liberal stand of the dominant Dutch Protestant church, the Hervormde Kerk (Reformed Church), since the Reformation. During the nineteenth century, various groups felt that this church neglected its Christian duty of an active evangelical life and relief of social distress, resulting in a Protestant revival movement (Inner Mission) producing various offshoots of the formal Hervormde Kerk. The first separation movement began in I834 (Afscheidingsbeweging). In I869 these various separated churches merged to form the Christian Reformed Church. A second wave of separation occurred beginning in I886 (Doleantiebeweging). The first wave of separatist Reformed Christians criticized the formal Reformed Church for its adherence to presumably too rationalistic, enlightened views and for its denial of God as the only source of truth. Followers of the separation movement put themselves at considerable risk. Because the Reformed Church at that time was legally regulated and protected by the state government, leaders of the first wave were imprisoned and experienced other forms of discrimination. In response to such threats and humiliations the Afgescheidenen turned inward, emphasizing their separate pious Christian identity, and searching to create independent institutions for their own group. The second wave of separating Reformed Christians (Doleantie) were more inspired by a neo-Calvinist mentality and missionary motive to re-Christianize society; they sought to revitalize Christian beliefs within culture, politics, and science and thus had a broader missionary intent compared to the first group. Both groups eventually unified in 1892 into the Gereformeerde Kerken (Dutch Reformed Churches). Not all separatist groups, however, agreed with the amalgamation and remained independent from the 
Dutch Reformed Churches; these groups bonded together and formed the Christian Reformed Churches at that time..$^{122}$

In the liberal climate of nineteenth-century politics, especially after the new Constitution of I848, the emancipatory movement of Roman Catholic and Protestant groups (and later on of socialist groups) contributed to the development of the segmented social and political democratic structure typical of Dutch society at the time. ${ }^{123}$ Increased liberalization and democratization facilitated the emancipatory movements of hitherto banned or repressed groups, which were only in part class related. Intertwined with class contradictions was the strong desire for religious and cultural freedom. Where Roman Catholics re-established religious orders to manage hospitals, asylums, and other charitable institutions, Protestant groups also established their own hospitals and asylums and molded them according to their own traditions and beliefs.

The founders of Veldwijk belonged to the Christian Reformed Church of I869 and participated in the Dutch Reformed Churches after I892. Inspired by religious motives, this orthodox Protestant group wished to establish an institution for insane patients. Their leader, Lucas Lindeboom (I845-I933), at that time a professor at the theology school, felt that the Protestant church had neglected its Christian philanthropic obligation to provide adequate care for the suffering and poor. Traditional poor relief, he argued, was not enough to meet contemporary social needs. In particular, the formal church had neglected to provide institutional care for such groups such as the sick, the deaf, the blind, and the insane. He believed that founding charitable institutions was a task of Christian philanthropy and should not be left to the state government. His ideas fitted with the broader Protestant revival movement (Inner Mission) that spread over Europe during the nineteenth century. ${ }^{124}$

In fact, in his missionary endeavor Lindeboom unified the ambitions and mentality of both the first wave of Reformed separation of I834 (Afscheidingsbeweging) and the second wave of I886 (Doleantie). Lindeboom came out of the first group. His initial intent was to found an asylum for Reformed Christians of his group, in line with the motives of the Afgescheidenen. But within the process of founding such an asylum, in which second wave separatists were also involved, he grew sympathetic to the second wave separatist mentality. For instance, he became a strong supporter of the idea of developing a Christian psychiatry as part of the attempt to revitalize Christian beliefs. ${ }^{125}$

Lindeboom had seen examples of the deaconess movement's institutional care in Germany at an early point in his career, which had inspired him to take a similar initiative in Holland. In his work as a minister, the needs of the insane had impressed him deeply, motivating him to take up a leadership role 
in gathering a group of like-minded orthodox Protestants who founded the Vereniging voor Christelijke Verzorging van Krankzinnigen en Zenuwlijders in Nederland (Dutch Association for the Christian Care of Insane and Nervous Patients [VCV]) in I884. This initiative was unique at that time. The group had initially sought the support of the Church Assembly, but as church boards turned out to be hesitant in founding asylums themselves, the group decided to operate as a private association.

Interwoven with the differing Christian views as to the role of the church in relief of nineteenth-century social distress was political disagreement over the role of the state government in social tasks such as public education and relief of the poor, the sick, and also of the insane. Although the groups that separated themselves from the formal Reformed Church had done so because they felt that this church neglected its Christian duty, they also felt that the state should not take over charitable activities. As the influence of government increased during the nineteenth century, these Protestant groups, like their Roman Catholic counterparts, pleaded for independence in founding their own educational and charitable institutions. For example, traditionally the state subsidized the training of ministers for the Reformed Church in the State Universities. In response, the new Christian Reformed Church groups founded their own independent school of theology and later on, in I880, their own university as well (Free University). The emergence of such denominational institutions were part of the aforementioned "pillarization" process. ${ }^{\mathrm{I} 2}$

The VCV clearly saw itself as a missionary movement with a broader mandate than just managing institutions. The goal of the VCV was to advance Christian care of insane and nervous patients based on the word of God by the foundation of asylums and to promote Christian benevolence among Reformed families for the cause of Christian psychiatry. ${ }^{127}$ They considered insanity to be the result of sin and not living in faith. The instilling of benevolence and a faithful Reformed family life was as important as the provision of proper care in relieving society from this misery. Through propaganda meetings and local representatives the VCV spread their ideas and elicited membership and financial support for their association within their community. They were an energetic group: in a forty-year period they founded four asylums, a psychiatric clinic, and a university department for psychiatry at the Protestant Free University in Amsterdam. ${ }^{128}$

Because their effort was partly the result of criticism of existing facilities that supposedly lacked a Christian identity, they sought to provide care that would compete with the best institutions and possibly even be better. ${ }^{129}$ From the outset, the VCV perceived the asylums they founded as medical institu- 
tions. A medical director headed the institution but fulfilled the management role in close cooperation with a minister and an administrator. These three people formed the Asylum Council. Veldwijk began as a small-scale endeavor with the admission of almost seventy patients in its opening year of I886. The number of pavilions gradually increased and by 1900 it housed $45^{\mathrm{I}}$ patients. ${ }^{130}$

On its foundation the VCV board consulted with the state inspectors as to how their ideas could best be applied within the frame of existing medical and legal requirements. ${ }^{13 \mathrm{I}}$ The inspectors favored the VCV's initiatives, not necessarily because they supported an evangelical regimen but because the VCV initiative partly solved the lack of places to confine patients. The VCV followed the inspectors' advice and applied the cottage system. The idea of separate pavilions fitted well with the Reformed ideology of faithful family care. Purposely, the board followed a lay model for the day-to-day management of patients that resembled the faithful family. Within each pavilion a married couple were appointed as house father and mother to manage both nurses and patients. ${ }^{132}$ They shared their day-to-day life and work rooted in the ideology of faith-based Reformed Protestant family life.

The strong belief in the healing function of the family and faithfulness to lay-based care were in a sense antithetical to rationalistic medical ideas and to the demand for more expert-based patient management that would soon gain relevance in the day-to-day operation of the institution. Tensions soon arose over personnel, which - as the next chapters will show - reflected how the VCV, just like their counterparts in other institutions, struggled to bridge and restructure existing contradictions between lay and expert knowledge, charitable and scientific opinion, and ideology and practice. In creating a more rationalistic, expert-based organization for the care of the mentally ill, each institution - Protestant, Roman Catholic, or liberal non-denominational responded according to its own culture, mirroring larger social and cultural processes. As medical views changed after around 1870 , the rhetoric on the poor quality of asylum personnel took on a new dimension. Social and medical changes altered both the medical regimen and the position of personnel in asylums in the latter part of the nineteenth century.

\section{Conclusion}

Psychiatric reform profoundly changed the care of the insane in Dutch asylums as of the mid-nineteenth century. Religious inspiration figured highly in reform initiatives. Moral treatment ideals, legal regulations, and increased governmental involvement laid the groundwork for a new system of medical 
treatment. Medical authority increased, although not all asylums were headed by a medical director, and the adherence to moral treatment and nonrestraint varied considerably between institutions. Asylum reformers soon faced a rapidly increasing patient population, whose afflictions were predominantly of a chronic nature. As a result the ideals of cure based on a humane moral approach dwindled. Although the I 884 insanity law increased medical influence and restricted unbridled growth of single asylums, the asylum system at large continued to expand. Typically for late nineteenth century Dutch society, the private initiatives of denominational groups dominated the expansion of asylums.

Class and gender relationships structured the management of the asylums, which were run as large middle-class households. Divided by gender, patients were cared for in strictly separated male and female departments. If at all possible, indigent patients worked along with the attendants on the wards and in the workshops. Arrangements for patients from higher social classes mirrored their social standing. Male and female attendants formed the lowest ranks within asylum hierarchy. Throughout the nineteenth century medical directors complained of the low level and quality of personnel. The attendants' lives were closely tied to those of their patients by shared sleeping, eating, and living facilities. They did not necessarily have the philanthropic motivation for the burdensome work of patient care that their middle-class administrators and doctors expected of them. They often left if better work opportunities opened up. Asylum physicians considered the attendants' lack of motivation as a consequence of their low social standing. Complaints about the low standing and lack of a philanthropic attitude among personnel reflected a cultural and social gap between lower-class attendants and middleclass reformers. The various segmented groups that emerged in the late nineteenth century shaped asylum reform according to their own cultural and religious contexts. 


\section{CHAPTER I I}

\section{The Ideal of a Mental Hospital}

The rhetoric about the poor quality of asylum personnel took on a new dimension in the late nineteenth century. The traditional complaints about the low social standing of personnel did not disappear but acquired new import. As of the late I88os asylum doctors argued that asylum personnel should be better trained in medical matters. The class-based complaint that attendants lacked a philanthropic attitude became intertwined with the class- and gender-based argument that they lacked the skill and expertise of nurses experienced in taking care of the sick. The shift in thinking and the new demand for nursing expertise emerged in the context of the rise of scientific psychiatry and new medical explanations of insanity after 1870 . Psychiatrists aspired to a dual goal of uplifting their own status as practitioners of a scientific, medical discipline and of changing the traditional asylum into a mental hospital.

The early nineteenth-century optimism that the mentally ill could be cured by a humane, moral therapeutic regimen dwindled. Strongly affected by the cultural impact of the scientific ideals of the time, psychiatrists began to orient themselves to the values and findings of the natural sciences. They began to study specific organic causes of mental disease, giving up older holistic notions of insanity as an imbalanced state of mind and body. The forceful example of the general hospital's rising success became a strong impetus for change in psychiatry. The metaphor of fighting contagion and illness within an orderly, clean hospital in which symptoms of disease could be controlled gained enormous prestige and momentum in the late nineteenth century and raised the status of hospital medicine. With the introduction of anesthesia, antiseptics and aseptic procedures, surgical treatments could successfully be performed. Doctors became strong advocates of hygienist hospital reform in order to make them safe and acceptable places of treatment for the middle class. In response to the rising status of hospital medicine, psychiatry began to model the asylum after the example of the general hospital. ${ }^{1}$

Psychiatrists argued that the mentally ill needed to be treated in ways similar to hospital patients. This idea first gained ground in Germany, but it soon spread to the Netherlands. ${ }^{2}$ Relying on the new organic explanations of mental and physical exhaustion to explain insanity, they subjected asylum patients to a regimen of bed rest, good food and somatic treatments. They 
believed that a new scientifically based medical order, with psychiatrists in control of treatment and care, would be an enormous improvement over the previous middle-class household model of asylum care. In many ways, the asylum as an extension of the family controlled by laity gave way to the promise of a professionally based institution, a mental hospital controlled by experts. ${ }^{3}$ On the one hand, the psychiatrists' argument should be seen in the context of the changing asylum patient population. Among the ever-growing numbers of chronically mentally ill were many demented, physically weak, incontinent or paralyzed patients. They regularly suffered from physical ailments and fever or caught pneumonia or tuberculosis. In that context an organic explanation and somatic treatments seemed plausible. On the other hand, the promise of a mental hospital fitted the psychiatrists' attempt to uplift their scientific status and their own professional prestige.

Significantly, near the end of this period of transformation, the board of Meerenberg decided to change the asylum's name "Gesticht Meerenberg" (Meerenberg Asylum) to "Provinciaal Ziekenhuis nabij Santpoort" (Provincial Hospital near Santpoort) in I9I8. The name change reflected the aspiration to be considered a respectable medical institution, comparable to a general hospital, and to establish such a reputation with the general public. Also, the local railway stop at "Santpoort-Meerenberg" was renamed "Santpoort", and the four roads leading to the asylum were renamed after famous psychiatrists, including J. L. C. Schroeder van der Kolk and John Conolly. The board made every effort to remove the stigma attached to its legacy as a "lunatic asylum". ${ }^{4}$

\section{New Medical Opinions: Scientific Psychiatry}

Among psychiatrists the idea gained ground that care of the insane, like medical care, was indeed a science and should be grounded in the notion that disease could be located in specific organs and attributed to a specific cause. The older, moral explanation of insanity as the loss of self-control lost its meaning. ${ }^{5}$ Psychiatrists began to view mental disease in similar ways as somatic disorders. Based on organic and physiological explanations, psychiatrists interpreted insanity as a brain disease or a disorder of the nervous system. German psychiatry was the inspiring example on which Dutch psychiatrists shaped their scientific aspirations. ${ }^{6}$ In Germany physiological and pathological medical research in laboratories and university clinics boomed. The renowned German psychiatrist Wilhelm Griesinger (I8I7-I869) contributed significantly to the expansion of organic, somatic explanations of insanity. ${ }^{7}$

The view that disease was an entity related to a specific cause that could be 
explained organically and required specific treatment or therapy gained momentum and became the accepted view of illness. This notion of disease grew within the context of the fight of contagious diseases and resulted in the eventual acceptance of the germ theory. ${ }^{8}$ In their attempt to raise their status as scientists, psychiatrists based their actions and scientific research on similar bacteriological notions of disease. To the notable German psychiatrist Emil Kraepelin (1855-1926) infectious disease provided the model for looking at mental illness in his research at the psychiatric clinic in Heidelberg and later in Munich. His primary focus was to find the organic cause of mental illness. In theory, if the cause was identified, the proper therapy would logically follow. ${ }^{9}$ With an individualized approach to patients, who had to be observed precisely, psychiatrists attempted to uncover the causes and sequences of mental illness through objective, scientific research and systematic observation and measurement of the body. ${ }^{\text {io }}$

Dutch psychiatrists sought to uplift the scientific status of their field through organization, the improvement of psychiatric medical education

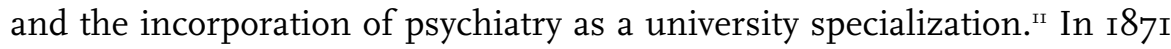
prominent psychiatrists such as Johannes Nicolaas Ramaer, Bernardus Everts and R. Lammers van Bueren, among others, founded the Nederlandse Vereniging voor Psychiatrie (Dutch Association of Psychiatry [NVP]) which during the I88os became an active body that promoted university training of psychiatrists. ${ }^{\mathrm{I2}}$ In $\mathrm{I} 885$ the Universities of Amsterdam and Utrecht appointed lecturers in psychiatric medicine. Around ten years later, long-sought-after opportunities for clinical research became reality. Between I893 and I903 all four state universities created professorships in psychiatry and neurology and opened university psychiatric clinics. ${ }^{13}$ The new discipline focused its scientific attention on brain pathology and physiological research and introduced more somatic treatments. ${ }^{14}$

The classification of mental diseases gained in importance. To enhance medical statistics, psychiatrists worked on a consistent, scientifically based taxonomy. Simple classifications of insanity based on symptoms of mania, monomania, melancholia, dementia, and idiocy, which still sufficed in Pinel's days, attained an increasingly complex and differentiated form. ${ }^{15}$ Rather than identifying symptoms of general bodily imbalance, based on humoral notions of illness, psychiatrists described mental illnesses as entities by studying the entire disease process. By the end of the nineteenth century, the nosology of Emil Kraepelin served as an influential model. ${ }^{16}$ Nervous disease, or neurasthenia, which became a fashionable disease among the middle class during the last quarter of the nineteenth century, was also explained as a malfunction of the nervous system. It was thought that the 
nervous system was excited by many influences of modernity, often considered disastrous, resulting in all kinds of nervous complaints. ${ }^{17}$

Hereditarian notions merged into the concept of insanity as an organic disease. Influenced by biological, evolutionist thought, the French doctor Bénédict A. Morel (I809-73) postulated the thesis of degeneration. He perceived insanity as a hereditary disease, an abnormal deviation of normal human development that could be transmitted by heredity. Alcoholism, perverse sexuality and poor social circumstances in particular could lead, in successive generations, to a more severe form of mental illness, beginning with nervousness and deteriorating into neurosis, psychosis, and eventually idiocy. With time the thesis of degeneration also acquired a social dimension. Like crime and venereal disease, insanity became an expression of the degeneration of society at large. ${ }^{18}$

Fundamentally all psychological and physiological influences could affect the nervous system and cause mental illness. Heredity, marriage between relatives, the neglectful upbringing of children, the neglect of bodily needs by overeating or drinking, the abuse of the body's integrity by sexual perversion or excessive alcohol use, and overexcitement of the brain resulting from the urges of modern civilization, such as gathering wealth, too much learning, or pursuit of pleasure, were accepted causes of insanity. It was also believed that acute or chronic illnesses such as infectious diseases and cancer, the consequences of pregnancy and maternity, or grief, sorrow, or anger could cause mental affliction. Moreover, psychiatrists considered overwork, poverty, fear of losing a job, family problems, and feelings of guilt about masturbation, using a pessary, and abortion to be "dejecting influences" that could cause psychosis. Alcohol abuse was an influential factor in many admissions. Physicians usually identified genetics or a nervous constitution as a related cause. ${ }^{19}$

In contrast to the older moral notions, which had provoked medical optimism about the curability of insanity, the somatic explanations of insanity generated skepticism as to the curability of mental symptoms. Since insanity was viewed as a brain disease, reinforced by hereditary and psychological factors, the individual seemed to be a victim of his or her biological constitution. ${ }^{2 \circ}$ Moreover, the predominantly chronically ill asylum population appeared to reflect the hereditary, incurable nature of mental disease. ${ }^{21}$ An increased social concern about the rapidly spreading nervous afflictions and disproportionate expansion of insanity generated the belief that an increased level of civilization and growing social complexity caused mental illness and in turn threatened the quality of the general population..$^{22}$ Despite increasing pessimism about finding a cure for mental disease, the metaphor of fighting 
"contagious" mental illness had a strong symbolic meaning. Restlessness and disturbing, antisocial, deviant behaviors of patients began to be interpreted as symptoms of an (organic) mental illness. The new organic view of mental illness called for new somatic treatments. Molded after the example of the fight against germs and contagion, psychiatrists attempted to seek control over mental, "antisocial" symptoms through somatic measures and disciplined nursing care.

The most distinguishing feature of late nineteenth century psychiatric treatment, historian Roger Qvarsell notes, is that "the ideal of activity, work, and idleness had been replaced by quietness, tranquility, and confinement in bed". ${ }^{23}$ Bed rest, hydrotherapy and bath therapy, usually applied with the concurrent use of sedative medication, were the most important new medical measures used to calm agitated psychiatric patients. Rather than aiming for a cure, the new treatments sought to adjust patient behavior and decrease antisocial symptoms. This was a fundamental shift away from the previous medical optimism of moral treatment. ${ }^{24}$ Within the somatic approach of mental illness, the control of symptoms almost became a goal in itself, since the relationship between cause of illness and therapy remained unclear. Significantly, medical director Jacob van Deventer of the Meerenberg asylum noted in I9O that admission to the asylum would relieve patients' suffering and diminish their socially unacceptable behaviors. ${ }^{25} \mathrm{He}$ did not emphasize the possibility of cure. In his opinion, "unacceptable behaviors" included all sorts of behaviors regularly demonstrated by patients: screaming, tearing up clothes or bed linen, destroying furniture, undressing, masturbating, incontinence or smearing feces, refusal of food intake, self-mutilation and suicide or escape attempts. ${ }^{26}$ Creating a hospital-like environment and subjecting patients to a regimen of somatic treatments, he believed, would convince mental patients that they truly had a disease.

\section{Medical Views in Veldwijk: A Christian Psychiatry}

In response to the materialistic medical notion of insanity, Orthodox Protestant founders of the Vereniging voor de Christelijke Verzorging van Krankzinnigen en Zenuwlijders in Nederland (Dutch Association for the Christian Care of Insane and Nervous Patients [VCV]) sought alternative explanations of mental illness. As a group composed primarily of theologians and some physicians, they vehemently rejected the reliance on "worldly" science and developed a different medical view. Motivated by their religious, missionary zeal the VCV leadership constructed a different Christian medical ideology. In an effort to re-Christianize society, and convinced that the 
increase in insanity was related to moral decay, they found biblical knowledge and faith to be a far better alternative to materialistic, organic notions, and a better measure of prevention. The VCV felt that knowledge grounded in biblical spirituality could provide a regimen for counteracting moral decay in the modern world, exemplified by prostitution or alcoholism. As a result, the medical doctrine they adhered to developed along different lines..$^{27}$

The desire to develop a medical philosophy based on Christian principles motivated the VCV in I887 to consider the establishment a Faculty of Medicine at the Orthodox Protestant Free University in Amsterdam that could develop a Christian-based psychiatric method and at the same time train psychiatrists from their Dutch Reformed community. ${ }^{28}$ The ideological gap between biblical and scientific foundations of medical knowledge, however, rendered the effort marginal. Even after a psychiatric clinic and a professorship in psychiatry and neurology were eventually founded in 1907, the integration of religion and psychopathology never really developed. The new medical faculty's predominant interest lay in the study of brain pathology and neurology. This gradual move towards contemporary psychiatric medicine may indicate that the VCV physicians' professional focus aligned them more closely with the broader community of psychiatrists than the formal VCV medical ideology suggested. ${ }^{29}$ The gap between the ideal and the reality of Christian psychiatry in many ways reflected the tension felt within this conservative group over modern scientific, secularized views and represented their ambivalent response to a rapidly modernizing world.

Tension arose within the VCV leadership as modern medical views gradually seemed to overrule their earnest investment in creating and maintaining a communal, family-based system of care within asylums. This tension grew because, despite their ideals, the VCV leadership had very little experience with care of the insane and no experience with running an asylum when they began their missionary endeavor in I884. In reality, they were highly dependent on the medical advice they received from the liberal, medically oriented state inspectors. The board members followed the state inspectors' advice and looked into existing examples of treatment of the insane, which they molded in accordance with their vision. Their ambivalence to new scientific thought is reflected in their agreement with the expertise of medical doctors on treating the insane, ${ }^{30}$ despite the fact that they considered the organic explanation of insanity to be too limited and too materialistic. ${ }^{3 \mathrm{I}}$ In particular they used the existing psychiatric medical literature as a counterpoint to establish their own Christian view of insanity. However, they did not challenge the view that insanity was a disease.

In essence the board considered health a balanced state of physical and 
spiritual well-being. ${ }^{22}$ They assumed that the human spirit or soul was divine and immortal, only temporarily linked with the body. Because it was bound to matter, it could be affected by sin. Satan reached the mind through his effect on the senses, nerves, and brain. Hereditarian notions that the sin of the fathers afflicted the children fit perfectly with these views. Fallen in sin, humankind was continuously exposed to suffering and temptation, and insanity was but one expression of it. Patients were considered to be victims of the sin of humankind and not personally responsible for their affliction. As a consequence, they were entitled to merciful treatment in order to recuperate to health and faith. ${ }^{33}$

Despite this doctrine, in practice VCV doctors did not use treatments that differed substantially from psychiatric care in other institutions. ${ }^{34}$ Instead, the physicians who came to work in the asylums strongly pushed for changes in a medical direction. Confronted with actual patient behaviors, they took the medical therapies of their fellow asylum physicians in other institutions as their example. And more importantly, they were extremely sensitive to the opinion of their medical colleagues from other institutions, with whom they regularly met as members of the Nederlandse Vereniging voor Psychiatrie (Dutch Association of Psychiatry [NVP]).

When the NVP was about to have its summer meeting at Veldwijk in I89o, medical director Cornelis Vermeulen noted that he would have enlarged the garden of the observation pavilion prior to the meeting in order to "avert critical remarks to that regard". ${ }^{35}$ In I89I, when Vermeulen's successor Johan H. A. van Dale likewise confronted the suicide of one of his patients, and on their investigation the state inspectors suggested that Veldwijk should establish observation quarters, Van Dale immediately asked the board for the establishment of such a quarter. ${ }^{36} \mathrm{VCV}$ physicians eventually also undertook post-mortem examinations for research purposes. In I907 Van Dale proudly announced that the third physician, A. J. de Blinde, had undertaken a reasonable amount of microscopic brain research in the new laboratory of Veldwijk, which had recently been established in I905. ${ }^{37}$ Nevertheless, the VCV did not give up its adherence to a biblical, family-based methodology but incorporated modern medical views into a regimen that maintained many of the older, familial notions of care.

\section{Bed Rest}

The most salient new psychiatric therapy was increased use of bed rest. Both physiological and psychological explanations underlay the application of such treatment. It was thought that afflicted brains and nerves needed rest in 
order to recuperate; bed rest helped to keep the patient warm, which in turn would calm the patient, and it stimulated circulation of the blood, which improved the working of the brain..$^{8}$ But bed rest also had psychological implications. It would convince patients that they were really sick, in need of rest, and obliged them to to adjust as patients. ${ }^{39}$ The new generation of psychiatrists considered bed rest therapeutic for both physical and mental exhaustion and applied it widely to all categories of psychotic patients, including those suffering from mania, melancholia, and paralysis..$^{\circ}$

Most likely, the introduction of bed treatment as a new medical regimen was more prominent in the asylums in continental European countries than in North America. The Anglo-American historiography of psychiatry hardly makes reference to bed treatment as a phenomenon that restructured the medical regimen in asylums in the late nineteenth century, both socially and architecturally. In his study of Swedish psychiatry, Roger Qvarsell identified a turn-of-the-century shift towards bed treatment as part of the medicalization of asylum care quite similar to the way bed treatment has been described in Dutch psychiatric literature. ${ }^{4 \mathrm{~T}}$ This may indicate that the new regimen initially developed on the European mainland.

The work of the German psychiatrist Clemens Neisser provides insight into contemporary psychiatric opinion on the application of bed rest. ${ }^{42}$ Neisser considered bed rest to be applicable to almost all forms of psychopathology: amentia, depressed neurasthenia, intermittent psychosis, paralysis, epilepsy, melancholia, and mania. ${ }^{43}$ He identified several advantages of bed rest that reflected how psychiatrists modeled the treatment after that of hospital medicine. He not only argued that it calmed the mental and physical functions of agitated patients, he also emphasized that bed treatment would give the asylum the outlook of a general hospital, which in turn would improve its public reputation and ameliorate the status of psychiatry as a field of medical science. Moreover, bed rest was found to enhance medical measurements and observations. Physical functions such as pulse rate, breathing, sleep, and the elimination of urine and feces could be observed more closely. More importantly, when patients were treated on a ward for bed rest under close supervision, they could be better oriented to reality and human habits. ${ }^{44}$ One other psychiatrist also noted that mutilation or even fighting among patients would diminish because of improved supervision of patients in bed.45

Psychiatrists were eager to claim success. It was thought that a better digestion and calmer blood circulation enhanced the working of the nervous system. According to psychiatrists, effective and competent care, calmness, bed rest, good food, and if necessary a diet with extra milk and eggs were the ingredients of an effective medical therapy. ${ }^{46}$ Not without pretension Neisser 
postulated that the change bed rest had induced in psychiatry could be compared to the reformation of surgery by antiseptic techniques. ${ }^{47}$ Just as surgeons had discovered that wound infection was a result of ineffective care rather than an inherent symptom of the disease process, Neisser reasoned that physical and mental exhaustion and manic overexcitement were the result of inappropriate care rather than an intrinsic characteristic of mental affliction. He believed that like wound infection - which had almost disappeared through hygienic measures, healthy food, and effective, antiseptic nursing care - psychotic symptoms and manic behavior would vanish with appropriate treatment.

Nevertheless, it is important to note that the organic and physiological research into psychiatry had not yet achieved success similar to surgical medicine, nor did the battle to control antisocial behavior equal the successful battle against contagious diseases. Within the organic view of mental illness, there was no clear relationship between (organic) cause and therapy. Although neurology and brain pathology enhanced knowledge of the structure and function of the brain and the nervous system, the relationship between lesions of the brain and deviant behavior or emotional distress remained unclear. In psychiatry, medical therapy usually addressed a state of behavior or antisocial symptoms rather than a particular organic cause..$^{8}$ The successful application of bed rest was dependent on strict regulation and discipline aimed at maintaining order, rest, and abstinence from antisocial inclinations. Despite its psychiatric and medical explanation, in practice bed rest meant the regulation of misbehavior and control of antisocial symptoms. The supposed efficacy of bed rest seemed more related to its ideological function of making the asylum appear to be a general hospital rather than to its efficiency in controlling patient behavior.

\section{Architectural Changes and the Increased Application of Bed Rest}

Taking the general hospital as their example, psychiatrists began to change the architectural design of the asylum in the I89os, creating wards for bed rest and close observation. The wards looked like general hospital wards, with beds put in regular order and emphasis placed on cleanliness and uniformity. The wards for sick patients were transformed into "observation rooms", reflecting the new emphasis on empirical observation and diagnosis. New admissions were put to bed for observation on these wards, and night shifts were established to facilitate the close observation of patients at night.

At Meerenberg, medical director Jacob van Deventer, appointed in I892, was the first to systematically introduce bed rest. Gradually he equipped more 


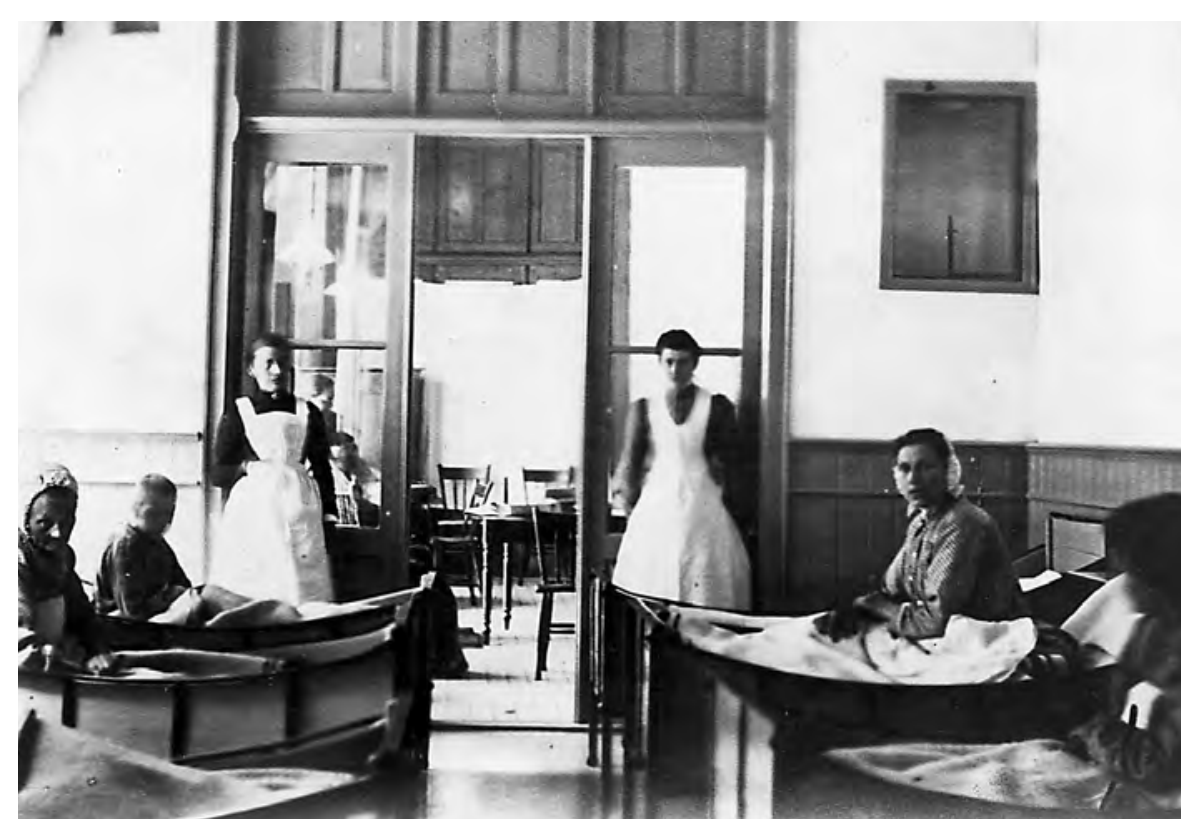

2. Patients on bed rest in the observation ward with two nurses. Female department at the Franeker Asylum, ca. I९००.

rooms as sick wards for bed rest. Likewise, bed rest was initiated in the wards on which disturbed patients were managed. In theory all patients could be treated with bed rest - including melancholic, manic, and disturbed patients as well as patients suffering from delirium or with epilepsy, paralysis, or imbecility - and thus remain on the ward rather than being put into isolation. According to Van Deventer, the antisocial behaviors diminished, and he also noted how traditional forms of coercion such as isolation in cells and the use of straitjackets and gloves were hardly used anymore. Single rooms were only used for very disturbed patients, preferably with an open door and only rarely in a final resort, did physicians order isolation in cells. 49

Van Deventer felt that the application of bed rest was a more humane treatment than previous methods of isolating agitated patients in cells. In practice, however, restless patients did not easily remain in bed. To prevent them getting out of bed, patients were sometimes treated in deep cribs, or bed rest was sustained with sedating hyoscine injections or lukewarm baths. ${ }^{5 \circ}$ Other regularly used sedative medication included opium, morphine, chloral hydrate, paraldehyde, sulfonyl, and broom for epileptics..$^{5 \mathrm{I}}$ Furthermore, the wards were probably not always the paragon of quiet and order the theory suggests. 
Sick, weak, and exhausted patients were on the same wards as suicidal and manic patients or those at risk of self-mutilation. The crying or screaming of restless patients, or the dancing or jumping in bed of the disturbed, could not always be prevented..$^{52}$ Therefore, excessively agitated patients were still separated in single rooms or cells in order to control their behavior. Despite the medical claims, in many ways the new bed-based treatment simply replaced previous forms of restraint rather than preventing restless, manic behavior.

Bed rest gradually increased between I890 and I9I0. In I896 and I897 Meerenberg reported, on randomly selected days, only i4 percent of the patients being put on bed rest..$^{53}$ In 1903 patients on bed rest in single rooms and cells were included in the reported number of patients on bed rest. ${ }^{54}$ In that year, during random observation, 26 percent of the patients were on bed rest, with about a third of those patients being in single rooms and cells..$^{55}$ Only five percent of the patients on the quiet wards, 35 percent of the patients on the disturbed wards, and 53 percent of the patients on the sick wards were on complete bed rest. ${ }^{56}$ Slightly more women than men were on bed rest. Of the total number of 358 patients on bed rest in I903, 40 percent were male and 60 percent were female. However, half of these 358 patients were cared for on the wards for disturbed patients, 4I percent on the sick wards, and nine percent on the quiet wards. These numbers demonstrate that bed rest was not applied just to observe and calm newly admitted or sick patients, but it also had an important role in handling unrest among disturbed patients. On the disturbed wards about half of the patients on bed rest stayed in single rooms and cells.

Other asylums also adapted their buildings, with more wards being equipped as observation rooms and wards for bed treatment. In I899 a corridor with four cells in one of the pavilions for disturbed patients in Veldwijk was rebuilt into a ward for bed rest for eight disturbed patients. A similar renovation was carried out within two other pavilions in I90I. ${ }^{57}$ Veldwijk reported in 1906 that 120 patients, about 25 percent of the patient population, were on bed rest. ${ }^{8}$ Franeker had twenty-five male and forty female patients on bed rest in I9IO ( 20 percent of all patients), which increased to 25 percent by I918.59 Voorburg converted to bed rest later than the other asylums, which probably reflected the relatively inferior position of Voorburg's medical staff, on the one hand, and the Roman Catholic religious orders' different view as to what constituted appropriate care, on the other. Around I9Io Voorburg began to establish special wards for bed rest, initially only in the male department. ${ }^{60}$ The reported application of bed-based treatment gradually increased from five percent of the patients in I9I5 to I9 percent in I9I $8 .^{61}$

At the beginning of the twentieth century, various asylums introduced a variation on the application of bed rest. Analogous to the care of tuberculosis 
patients, psychiatrists began to treat mental and physical exhaustion with "open air treatment", just like in sanatoria. Beds were put on large verandas or patients lay in armchairs in the open air, particularly in asylums in the countryside or along the coast. Veldwijk was one of the asylums that created lighallen, large verandas for outside bed-based treatment. ${ }^{62}$ This type of treatment most likely simultaneously met two goals: it underscored the similarity between treatment in mental hospitals and facilities for the physically ill, and accommodated the high number of mentally ill patients suffering from tuberculosis within the mental hospitals. ${ }^{63}$

Bed rest was not without risk. The greatest risk, especially for weak and incontinent patients, was decubitus, the breaking and infection of the skin. Some patients also developed an urge for bed rest, becoming attached to their bed and refusing to leave it. To prevent "bed urge", psychiatrists believed bed rest should not be applied for longer than necessary. As soon as patients gained weight or the most troublesome symptoms vanished, they needed to be readjusted to a day-and-night rhythm and regular work activity. ${ }^{64}$

\section{Hydrotherapy and Bath Treatment}

The therapeutic use of water has a long history in medical and psychiatric treatment. Warm or cold baths, sponge baths, and showers had been applied

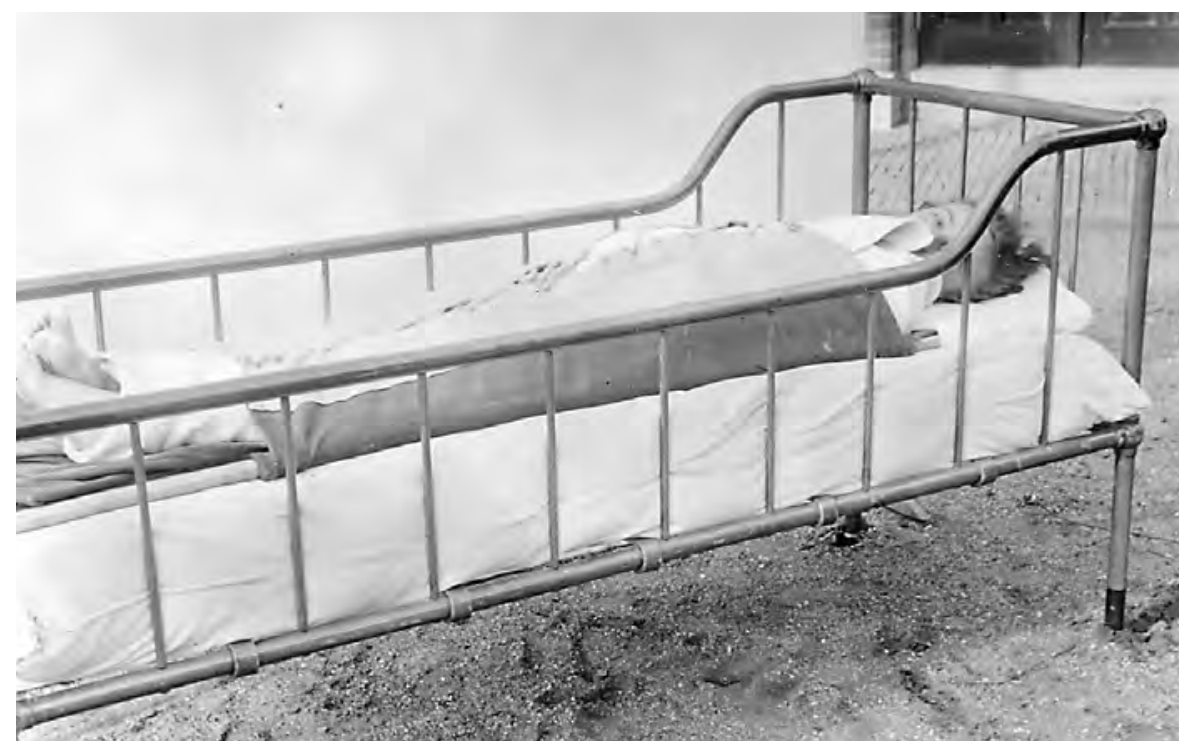

3. Patient in a hydrotherapeutic wet pack, Meerenberg Asylum, ca. I900. 


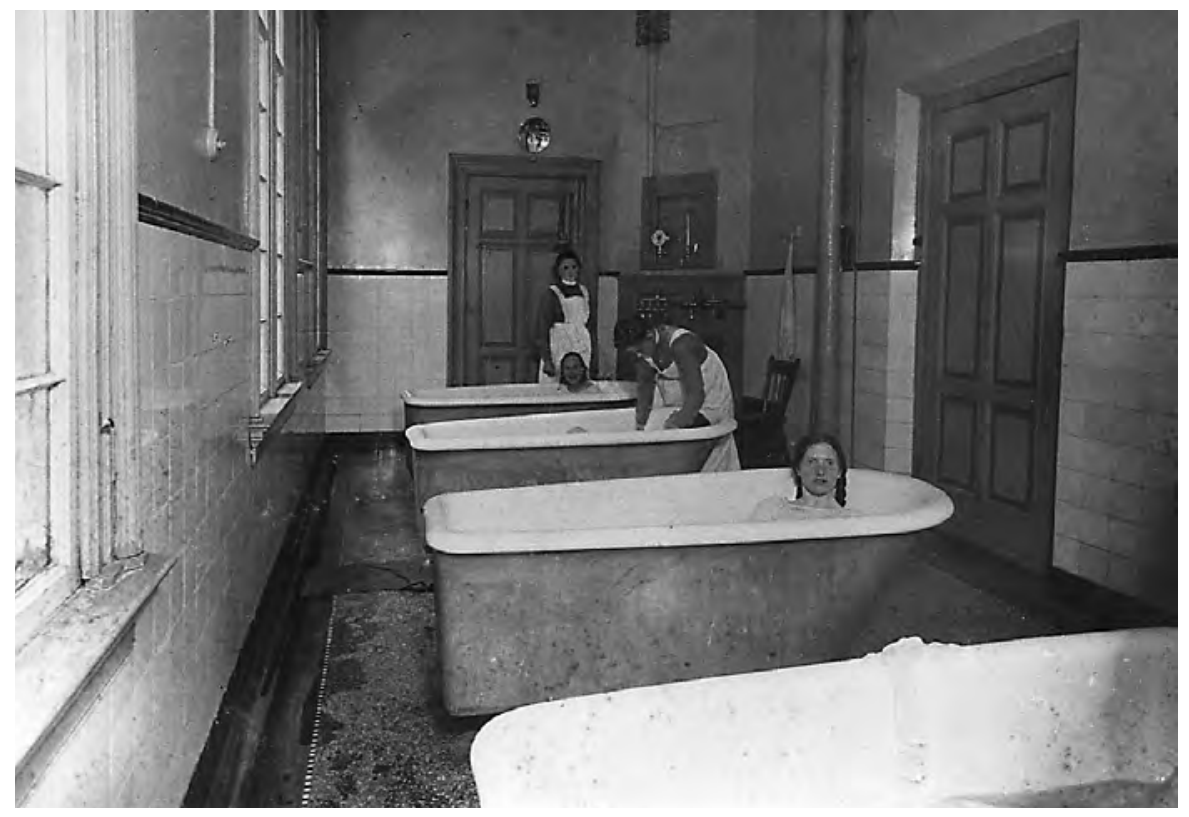

4. Patients and nurses in the department for prolonged bath treatment, Endegeest Asylum, I907.

to calm and sedate a patient or to provoke a frightening, mental shock that would change a patient's train of thought. In the I 890 s a new variation of hydrotherapy emerged: doctors began to prescribe hydrotherapeutic wrappings or wet packs. In this therapy, patients were wrapped in dry or wet sheets from top to toe, like a mummy, and then rolled in a blanket, either for short or extended periods of time. Wrapping a patient for fifteen minutes to two hours was often sufficient to calm them. However, if the goal of treatment was to control agitated behavior, the sheet could be applied for an entire night or longer - sometimes for days, with periodic changing of the sheets. ${ }^{65}$ This therapy was widely used to sustain bed rest. Decubitus was a great risk, particularly because wrapped patients had to release their urine and feces, which caused the skin to break down. Moreover, patients wrapped in sheets were at risk of congestion because of a disturbance of the body's temperature regulation. ${ }^{66}$

Some psychiatrists soon found these hydrotherapeutic wrappings to be just another form of restraint; the state inspectors in particular discouraged this form of treatment. ${ }^{67}$ Nevertheless, the application of wrapping grew within the context of bed rest, most likely because manic behaviors that theoreti- 
cally should have diminished in reality continued to exist. Moreover, hydrotherapeutic sheet wrappings were not included in the obligatory registration of restraints, while many other forms of restraint were.

The medical treatment of restless, agitated patients attained a new dimension with the application of "prolonged" or "permanent" baths. In I904 the Endegeest asylum at Leiden became the first in the Netherlands to design a special bath facility for this purpose. Agitated patients were put in lukewarm baths for twenty-four hours, or sometimes for weeks or months. The model was provided by the noted psychiatrist Kraepelin, who applied this therapy in his Heidelberg clinic beginning in $1890 .{ }^{68}$

The goal of bath treatment was similar to that of bed treatment. Psychiatrists believed that the calming influence of the water would reduce antisocial behaviors, such as motor restlessness, agitation, confusion, sleeplessness, refusal of food, destructive behavior, screaming, and tearing of clothes. They thought that the treatment was particularly effective for manic, agitated patients. The baths were sometimes covered with a canvas sheet or a wooden lid, with only the head left free, but doctors argued that this was not necessary in most cases. ${ }^{69}$ With "effective bath shirts" even dangerous patients could be treated with bath treatment. ${ }^{\circ}$ Overall, psychiatrists praised the results, although one of the Meerenberg physicians emphasized that the prognosis of mental illness did not change as a result of the treatment. The benefit, he argued, was the increased calmness, decreased exhaustion, and better appetite of the patient. ${ }^{7}$

In I9I3 Meerenberg built a new facility for prolonged bath treatment. For that purpose, the old wings with cells in the Old Meerenberg building were transformed, the male department into a facility with six baths, two isolation rooms, and four single rooms, and the female department into a facility with eight baths, one isolation room, and two single rooms. Medical director G. C. Van Walsum observed that he hardly noticed that he was in the middle of disturbed patients, which was the only remark he made about the new facility in his annual report. Van Walsum's remark illustrated that fighting symptoms and maintaining rest and order were the main goals of treatment. ${ }^{72}$

Prolonged bath treatment also had disadvantages and risks. Patients remained in the bath for days, sometimes weeks. Doctors recognized the labor-intensive nature and costliness as a disadvantage of bath treatment. Its successful application required competent personnel, who would not avoid a "strenuous and difficult regimen of care", as one psychiatrist argued. ${ }^{73}$ The board of Meerenberg approved an extra night shift at the prolonged bath facility. ${ }^{74}$ Moreover, the hygienic care of patients was complicated and labor intensive. Patients ate and slept while in bath, and they urinated and defecated in 
the water, which had to be regularly refreshed and kept at a steady temperature. A patient's skin had to be rubbed with vaseline to protect it. One of the Meerenberg physicians noted that bath treatment put patients at risk of bath eczema and swelling of the horny skin of the hands and feet, which could be rather painful..$^{5}$ Another physician reported the risk of furunculosis or boil disease, considered to be an indication to stop treatment. ${ }^{76}$

However, the risk of bath treatment took even more disastrous forms. In I9I9 a patient drowned in Meerenberg's bath facility. It was suicide. Because the physician in charge had noted the risk of suicide, the patient had been removed from an isolation room to the bath unit because the patient could then be permanently observed. According to the report to the board by the medical director, Van Walsum, the bath had been covered with boards, which the patient could remove. Two nurses supervised the ten patients in the unit in their baths. Van Walsum considered this number of personnel to be sufficient. At the time of the incident one nurse was refreshing a bath and the other was washing a patient's hair. Van Walsum thought that the nurses could have watched more carefully and advised the board to file charges. The prosecutor doubted the guilt of the nurses, considering two nurses to be insufficient for such an intensive task. ${ }^{77}$ Van Walsum's reaction revealed that the prolonged baths were not only applied because of their calming effect, but also because of the opportunity for continuous observation. He believed that this continuous evaluation could have prevented suicide if the nurses had not been negligent. From this perspective, the permanent bath was just another form of restraint, an attempt to prevent unpredictable behavior.

\section{Work Remained}

The new mental hospital did not lose the characteristics of the asylum entirely. The traditional therapies of work, distracting leisure activities, and regular religious service did not disappear. For the large, quiet group of chronically ill patients a regular work routine remained to structure daily life. Usually about two weeks after admission, if patients were calm and able to work, psychiatrists no longer prescribed bed-based treatment but had patients participate in work. Quiet, chronic patients, in particular, worked on the wards, in the kitchen, in the workshops, or in the asylum grounds and gardens.

Patient work was economically crucial to the asylum. In Meerenberg, for example, the majority of patients did housekeeping activities on the wards or assisted in the kitchen by peeling potatoes or cleaning vegetables. Male patients undertook physical labor, working in the gardens, or in the male workshops at tasks such as carpentry, tailoring, making carpets and mattress- 
es, shoemaking, painting, and forging. Women did the laundry, ironed, folded linen, sewed, knitted, and repaired clothes. These patients got up at 7:००, worked from 8:30 to noon and from I:30 p.m. until about 7:०० with a coffee and a tea break.

The financial profit from patient work was considerable, in part because patients were not paid for their work, although working patients received extra food and treats, such as cigars for the men and sweets for the women. In I903 medical director Van Deventer calculated that the economic value of the work of the Meerenberg patients, in terms of the potential salary of fit workmen, was about 22,464 guilders. It was quite a saving, considering that the total in salary paid to personnel at that time was II2,084 guilders. According to Van Deventer, two hundred patients working in housekeeping covered the work of thirty servants, and $\mathrm{I} 2 \mathrm{O}$ patients in clothing repair covered the work of twenty seamstresses and five tailors. ${ }^{78}$ In the summert, the vegetables produced were enough to supply the whole asylum. During the I9Ios about 50 percent to 60 percent of Meerenberg's patients worked. In I9I8 the percentage went down due to an epidemic of the Spanish influenza, which caused a heavy loss of life, but generally hundreds of working patients made a steady contribution to the asylum workforce. 79

The belief that patients needed to be isolated from the psychological causes of the disease did not disappear with the shift to more somatically oriented explanations. For that reason, leisure activities continued to be framed in a therapeutic context. In theory they brought some variety to the monotonous work routine and provided a distraction from the dullness of asylum life, but they did not imply personal freedom for patients. In particular, indigent patients had to request permission to have visitors, and they could not send letters without the approval of the physician, who first inspected the letters. Leisure was part of the therapeutic regimen, and was carefully supervised, as were all other activities in the asylum. The asylums' annual reports always included a note of such activities. Patients in Meerenberg went out on regular walks, and there was a concert or play in the theater about once a month. Most of the performances were given by personnel.

Although the motive of establishing regular services as part of moral treatment had disappeared, religious services remained a constant element in mental hospital culture, for both patients and personnel. On Sundays many patients attended a religious service. Funerals, baptisms of the personnel's babies, weddings, catechism training, and Sunday services were all held in the grounds of the hospital. The asylum church was not part of the local parish, a segregation that underscored the isolation of the mental hospital. ${ }^{80}$ The centrality of work, leisure, and religious therapies in maintaining asylum 
life illustrates that the majority of the asylum population were quiet, chronic patients who could work. The somatic treatment regimen only applied to about a quarter to a third of the patient population.

\section{The Inspiring Example of the General Hospital: A New Demand for Skilled} Nursing

The most crucial component in making the notion of a mental hospital work was the availability of knowledgeable personnel, who were capable of taking care of sick patients. Ambitious psychiatrists envisioned the same transformation for asylums that trained nursing had brought about in the general hospital. Competent nursing, which developed during the nineteenth century as a respectable, socially accepted field of work for middle-class women, deeply affected hospital reform because of the order, discipline, and cleanliness their work brought to the hospital wards. It was probably "the most important single element in reshaping the day-to-day texture of hospital life," historian Charles Rosenberg notes. ${ }^{{ }^{8} \mathrm{I}}$ In part it facilitated the success of hospital medicine ${ }^{82}$ By analogy with general hospital reform, some psychiatrists began to argue that the new regimen of bed-based treatment could best be applied if the care of the insane were placed in the hands of competent nurses who were experienced in the care of the sick.

Neisser, the German psychiatrist, explicitly stated in his analogy between the advances in surgery and psychiatry that just as competent care had successfully diminished the danger of wound infection, appropriate care would reduce the antisocial symptoms related to mental diseases. ${ }^{{ }_{3}}$ Appropriate care clearly included the role of disciplined, trained nurses who would assist the physician in the observation and application of treatments. In the opinion of progressive psychiatrists, the logical consequence of treating mental patients as equal to physically ill patients was the belief that these patients had to be taken care of in similar ways by competent nurses.

More importantly, nursing staff and their training would fall under the control of physicians, thus replacing the lay organization of a steward and matron supervising servant personnel. Traditionally, doctors had no direct control over lay servants, but nurses would fall in the medical domain. The gendered role of the new nurses, as much as their class background, facilitated the hierarchical structure that could consequently be created. The most influential advocate of the introduction of mental nurse training in asylums was Jacob van Deventer (I848-1916), until I892 the medical director of the Buitengast Hospital in Amsterdam. Significantly, in I883, he introduced the first Dutch hospital training program for nurses in this hospital. His interest 
in psychiatry had developed at the Buitengast Hospital, where he was appointed in I 878 after a brief assistantship in pathology and psychiatry at the University of Amsterdam Medical School. ${ }^{84}$ In I885 he became a private lecturer in psychiatry. ${ }^{85}$ The Buitengast Hospital admitted a considerable number of mentally ill patients in addition to contagious and chronically ill patients.$^{86}$ After the establishment of the Meerenberg asylum in 1849 , the intended closure of the Buitengast Hospital's overcrowded mental health wards never took place. In part, it remained an institution for the insane, albeit on a smaller scale. ${ }^{87}$ Quite suddenly, however, in the middle of the process of rebuilding the Buitengast Hospital to form a new university hospital, Van Deventer left to become the medical director of the Meerenberg asylum in 1892.88

Van Deventer strongly promoted the introduction of nurse training for asylum personnel among his colleagues in the Dutch Association of Psychiatry (NVP) and was the first person to push for such training. ${ }^{89}$ In addition to a physical environment similar to the hospital ward, Van Deventer noted, the competent action of women from the beschaafde stand (refined middle class), experienced in nursing the sick, could also persuade patients that they were indeed sick and in the need of rest. $9^{\circ}$ Middle-class women, he believed, would naturally fit the new tasks in the asylum and would have a calming influence. ${ }^{91} \mathrm{He}$ envisioned that the same type of nurse training that he had developed in the general hospital and that had raised its prestige enormously would also work for the asylum. Van Deventer strongly encouraged the NVP to take the lead in facilitating such training.

The new gendered idea of asylum nurse training was clearly the initiative of liberal, somatically oriented psychiatrists and drew together various aspirations of late nineteenth-century scientific psychiatry. These psychiatrists believed that transforming the traditional attendant staff into a disciplined corps of trained nurses would produce a hospital-like, orderly asylum environment, and attract a different type of caretaker who would raise the standard of existing personnel. The most ambitious psychiatrists felt that, in addition to the training of existing staff, middle-class women, who had brought about so much change in the general hospital, should be attracted to the asylums. Nurse training would fulfill the need for more skilled personnel of a higher intellectual level, and would also increase the psychiatrists' control over personnel. Nursing personnel would come under their direct supervision and would have to follow their orders rather than those of the traditional steward and matron. Moreover, the introduction of nurses on duty at night would enhance the continuous observation of patients and end the practice of personnel sleeping on the same wards as the patients, which most psychia- 
trists now perceived as outdated. Such aspirations and the intended transformation of patient care, structured by new professional values and new work methods, altered the asylum personnel's day-to-day working relationships and their interaction with patients.

The new medical expectations that personnel should be capable of close, continuous observation of the patients' bodily functions and behavioral symptoms, accompanied by daily reports, required an increased level of nursing competence and implied an entire set of new tasks..$^{92}$ Bed treatment presupposed another set of new tasks and techniques, including decubitus prevention, shifting patients from one bed to another, and helping patients on bed pans. Competent nurses were also expected to maintain order and calmly but firmly keep patients in bed. The application of new somatic treatments such as baths, hydrotherapeutic wrappings, enemas, medications, and new feeding regimens required skills that the attendants did not have. Attendants also lacked the competency and knowledge of medical concepts necessary to make the observations required by psychiatrists. ${ }^{93}$ The more ambitious psychiatrists felt that they had to train attendants to assist them with physical measurements, new neurological testing, or the application of new treatments, such as electric massage.

A case in point was that of psychiatrist F. M. Cowan of the Dordrecht asylum. In 1890 he began to teach attendants sick nursing and nursing of the insane in weekly one-hour evening sessions. For this he used the booklets on the nursing of the sick by the famous physician Theodor Billroth of Vienna, and by Florence Nightingale, as well as the handbook on the instruction of the attendants of the insane prepared by the British Medico-Psychological Association. Perhaps in the future, he noted, he could teach one of the attendants some simple massage techniques, which could be applied for the stomachmassage of constipated patients or even for the application of S. Weir Mitchell's therapy, a treatment that included isolation, bed rest, strengthening food, massage, and electrical therapy. This treatment was designed for nervous patients, but was applied to the insane as well. ${ }^{44}$ Similarly, the physician B. H. Stephan of the Burgerziekenhuis (CivicHospital) in Amsterdam emphasized how the treatment of nervous patients with a fattening cure of six to eight weeks of bed rest, isolation, massage, electrical therapy, and a fattening diet could be applied successfully only with the help of well-bred women who had been trained well as nurses. ${ }^{95}$ Despite the fact that nervous patients were usually of the higher social classes and rarely went to asylums for care, this was apparently the group of patients the most ambitious psychiatrists had in mind when they advocated for better nurses.

Psychiatrists, like their colleagues in general medicine, considered compe- 
tence to be a matter of class and, in the late nineteenth century, also of gender. Psychiatrists had argued for a long time that in order to increase the competence of asylum personnel, a higher grade of personnel had to be attracted to the asylums. The introduction of nurse training for asylum staff provided a forceful structure for reorganizing the class base of asylum staff and an attempt to uplift the morality of personnel while simultaneously increasing medical authority in asylum care. The asylum physicians used examples of nurse training with which they were familiar and that had gained momentum in hospital reform. The example of nursing reform in the municipal Buitengast Hospital in Amsterdam was the most influential. But the legacy of nursing care for the sick was much older than the foundation of hospitalbased nurse training itself. The roots of respectable nursing lay not in the hospitals but in a much older tradition of nursing orders and, molded after that tradition's example, lay associations of nursing. It was this tradition of order nursing and lay nursing associations that gave nurse training its socially respected image. These organizations provided a framework for the development of a secularized and gender-specific model of care during the nineteenth century while providing middle-class women an avenue for meaningful work.

While opting for nurse training, asylum physicians incorporated the legacy of these nursing orders and lay nursing associations. A more detailed analysis of this process reveals that such an effort was loaded with inherent class and gender contradictions. Psychiatrists believed that a disciplined corps of trained nurses would have the right morality and skills to provide the effective care that patients needed, similar to in general hospitals. Moreover, it would raise the status of the asylum and turn it into a respectable mental hospital of good reputation. But there was a problem as such nurses were not available in the asylums. More importantly, the high ideals of compassionate, refined, female care were not an obvious and easy match with the largely indigent, chronically ill patient population in asylums.

\section{Conclusion}

During the late nineteenth century psychiatrists tried to transform asylums into mental hospitals. This effort represented a shift in psychiatry to a scientific, organic orientation. In this context psychiatrists sought to increase the status and professional prestige of their field. Moreover, somatic treatment seemed plausible for an increasingly chronic, physically weak patient population. During this time all four asylums examined in this study modeled asylum care on the example of the general hospital. The conservatively oriented, 
religious groups molded the new medical ideas into their own ideology of care and in many ways remained ambivalent about the new scientific, organically oriented form of psychiatry. Nevertheless, more patients were put on bed rest and architectural changes were made to increase the opportunity for continuous, close observation as well as and bed and bath treatment. The transition to using these new treatments as forms of restraint was fluid and easily made. In psychiatry, the relationship between organic cause and somatic therapy was less clear.

The new somatic treatments called for more skilled personnel and a new sense of order and regularity. Psychiatrists argued that attendants were not sufficiently trained in medical matters and should receive theoretical and practical training in nursing. They derived these aspirations from the example of hospital reform. In the hospitals middle-class women, trained as nurses, changed the inner structure into a hygienic, ordered medical environment. Supposedly their gender-specific role had transformed the hospital into a respectable professional institution, which inspired psychiatrists to seek similar changes in asylums. 



\section{Female Compassion: Mental Nurse Training Gendered} Female

The innovative idea to attract nurses, preferably middle-class women experienced in the care of the sick, to the asylums built on a new gendered image of nursing that had evolved during the nineteenth century. From the beginning of that century nursing gradually became acceptable work for middle-class women. However, psychiatrists chose to institute the new training concept within the asylum structure as a system of hospital-based mental nurse training similar to the nurse training system within general hospitals. This differed drastically to the way nursing had originally evolved as a field of charitable work early in the nineteenth century. At that time, nursing had not yet been linked to the modern hospital as a system of training, nor with the concept of an independent paid professional occupation for middle-class women. The modern hospital did not yet exist at that time and only emerged during the late nineteenth century. Furthermore, a paid career for middleclass women was hardly conceivable or acceptable at the beginning of the nineteenth century; this only became possible during the latter part of the century. Asylum work was not yet considered to be women's work, since male and female patients were cared for by attendants of their own sex. When, psychiatrists incorporated the "nursing idea" into their professional aspirations during the 1890 s as a means to create the mental hospital, nursing had already undergone a profound change.

\section{Religious Roots}

The socially respected image of nursing - a seemingly natural blending of a refined morality, female compassion, and professional skill - that was so attractive to nineteenth-century doctors was carefully constructed within the context of religious communities of men and women actively involved in charitable work since the seventeenth century. Roman Catholic orders that undertook charitable work re-emerged in seventeenth-century France during the Counter Reformation. Prime examples were the influential male order of the Congregation of Lazarists and the female congregation of the Sisters of Mercy (or Daughters of Charity), founded by Vincent de Paul in I625 and I633, respectively, and which spread throughout Europe far into the nine- 
teenth century. Because public life for women was far more restricted, and at that time orders of nuns had to be formally cloistered, creating congregations for women that were actively involved in charitable work was far more difficult than creating such orders for men. Adopting a communal, motherhouse structure and the patriarchal support of a priest or other religious authority were crucial components in making the women's independent role acceptable. $^{\mathrm{I}}$

By the I830s, Roman Catholic and Orthodox Protestant Christian revival in the Netherlands - which, as a social phenomenon, parallels the rise of Evangelicalism in the Anglo-American world ${ }^{2}$ - provided a context for religiously inspired middle-class women to seek organized charitable initiatives; this was legitimized by the paternalistic protection of priests and pastors. Historian José Eijt argues that religiously inspired charitable work provided an avenue for women towards an independent existence and an alternative to traditional female roles as wives and mothers. Women who chose this path had a crucial role in founding new female charitable orders. ${ }^{3}$ Religious inspiration legitimized their charitable work. They could make themselves useful by relieving the destitution among the poor while at the same time bringing Christianity into practice. ${ }^{4}$ This blending of religious commitment and philanthropic activities made middle-class women's work acceptable, particularly in areas such as nursing and teaching, which were thought to be natural extensions of women's domestic roles.

Recently, in their analysis of the rise of caring power in the Dutch context, women's historians Annemieke van Drenth and Francisca de Haan have furthered this argument by providing a coherent framework for the understanding of nineteenth century women's activities. ${ }^{5}$ Based on a Foucaultian notion of power and social change, they argue that the rise of caring power - that is, the increased humanitarian sensitivity to being responsible for the wellbeing of marginalized groups that arose in Western society after I800 - provided a context for the reform activities of men and women. Religiously inspired reform work formed the foundation for new activism by women and consequently, the creation of new identities for women, for example in the anti-slavery movement, prison reform and reform activities directed at the salvation of "fallen women". The care of the sick, although not the primary focus of Van Drenth and De Haan's work, certainly includes this listing, for example as demonstrated in the influential Protestant Deaconess movement in Europe. ${ }^{6}$ They challenge the notion that religion was necessarily conservative or limiting to women. Rather, it fostered a new sense of womanhood and constituted women as a new social category. The radical implications of a shared humanity, they emphasize, hit home to some women, and they 
"became actors or agents on the social and political stage, and that in turn, would lead to their demanding formal citizenship."

However, such a view does not imply a direct leap from religious inspiration to feminism, Van Drenth and De Haan observe. They criticize existing analyses of women's activism for often using an unspecific notion of feminism and applying such a term without much consideration to all sorts of women's activities. As a result such analyses fail to understand the important role of the humanitarian impulse - whether religious or secular - in the transformation of the social role of women. They argue that the lack of a coherent framework has resulted in the inconsistent use in women's history of the term "feminist" for extremely diverse social activities by women. Van Drenth and De Haan state that scholars should distinguish between such activities and "clarify the dynamics of a social movement which led from women's new religiously inspired social responsibility for the welfare of 'others', and a feeling of responsibility for and solidarity with, in particular, 'those of their own sex', to an explicit fight for women's equality or changes in the gender hierarchy on behalf of women." They suggest distinguishing between women's activism, the women's movement, and feminism. At each stage women became organized as women, however, with different goals: to make the world a better place, to help other women, and to fight against male domination. ${ }^{8}$ According to their definitions, women's activism includes "women's social and social-political activities undertaken on behalf of others, such as the poor, or slaves, or to create a better world in general." The women's movement refers to "organized activities of women on behalf of other women, based on an identification with 'those of their own sex', sometimes expressed by the notion of sisterhood." Feminism or the feminist movement is concerned with "the fight for equal rights and/or activities aimed at ending male domination and privilege, a struggle for which arguments of women's and men's 'equality' as human beings, or of women's 'difference' could be used." 9 Van Drenth and De Haan demonstrate the usefulness of this framework in their analysis of the influence of the work of reformers Elizabeth Fry and Josephine Butler in Britain and the Netherlands.

The transformation of nursing and mental care, which is the focus of this study, underscores the value of Van Drenth and De Haan's framework, and also adds an important dimension. I argue that in the first part of the nineteenth century, in the context of religiously inspired reform work - which parallels Van Drenth and De Haan's notion of women's activism - nursing emerged as a new area of relatively independent work for women, building on a longstanding tradition of nursing work in religious orders. In the latter part of the nineteenth century, nursing work developed into a new, independent, 
salaried career for women. Although the women's movement in Van Drenth and De Haan's understanding of the term provided a context for this change, there was no strong feminist connection in nursing. I argue that this is related to the incorporation of nursing in a male dominated medical and hospital hierarchy by the late nineteenth century on the one hand and its shifting class base on the other. However, the image of female compassion and (middleclass) women's "difference" figured highly in all of the arguments and strategies to create a new area of respected mental nursing work. The assumption of women's different gendered identity, which, as has been widely discussed in women's history, ${ }^{10}$ may have formed a basis for separate male and female spheres, also reflected a process of gendering of (caring) work that impacted both women's and men's identities.

During the first part of the nineteenth century the idea dominated among the middle class that the primary role of women lay within the family. Paid work outside the home was though to be inappropriate, particularly among affluent upper middle-class families, who did not need to work for an income. Most middle-class daughters traditionally remained within their families until marriage or, if unmarried, made themselves useful within their family context. Women were presumed to naturally have a higher moral consciousness than men, and part of women's domestic roles as wives and mothers was to safeguard their offspring against immorality and sin and raise their children as moral, civilized beings. This gender-based view had a distinct class connotation. This argument had less relevance for women from the lower social classes, since they traditionally worked for an income in servant and other paid roles. Paid work was seen as incongruent with higher moral feelings. About I4 percent of Dutch women remained unmarried during the first part of the nineteenth century. However, the post-Napoleonic economic depression increased economic hardship among the middle classes and economic need forced many middle class women to seek ways to sustain themselves outside the protected boundaries of the family. ${ }^{\text {II }}$

Eijt challenges the traditional argument that women became attracted to charitable orders as a second choice because they had not been able to marry and were thus "redundant". Evidence from her analysis of the first female Roman Catholic congregations founded in the nineteenth century reveals that religiously inspired women sought an alternative, independent life of their own free will by founding an order themselves. The first nineteenthcentury religious female congregation "Dochters van Maria en Joseph" (Daughters of Mary and Joseph), also called the "Zusters van de Choorstraat" (Sisters of the Choor Street) in Den Bosch was founded in I820 by Anna Catherina van Hees, inspired by her religious revelations. Her supposed con- 
tact with Jesus Christ convinced priest Jacobus Heeren that she was the right woman to lead the congregation, and he approved of the small community of five women. It was her religious authority, Eijt argues, that provided Van Hees the opportunity to seek independence beyond the accepted boundaries of her class and gender. ${ }^{12}$ Similarly, in 1838 , the devoted and relatively affluent rentmaster's daughter Elisabeth Gruyters founded the nursing order of the "Zusters Onder de Bogen" (Sisters under the Arches) in Maastricht.

During the second half of the nineteenth century, after the re-establishment of the Roman Catholic episcopal hierarchy in I853, when Roman Catholic revival took its much stronger conservative ultramonist form, new Roman Catholic congregations flourished. In the second half of the nineteenth century, Roman Catholics founded over two hundred religious orders that provided nursing, education, and poor relief. The organization of religious communities of women was inspired by existing examples of Roman Catholic orders in France, Belgium, and Germany, such as the Sisters of Mercy. In I839, for example, several prosperous Roman Catholic families in Amsterdam established a house for a few Sisters of Mercy. Converts, called "sisters", learned their charitable work of caring for the sick and the poor within a protected social structure of the order's motherhouse or sister house. Sisters attained a living within their sister- or motherhouse without being paid individually. The house contracted with charitable boards to provide the management of their institutions, or, in the case of home care, fees were paid to the house. In this way the sisters' work was legitimized and socially accepted as work of religious commitment and Christian self-sacrifice. ${ }^{13}$

The Orthodox Protestant revival movement of the Inner Mission, the Reveil-beweging (Reveil-Movement), which began in Germany in the early nineteenth century but soon spread to Orthodox Protestant groups in Switzerland, France, Belgium, Holland, Denmark and Scandinavia, reflected awakening of piety and religious conscience. It expressed itself in religious commitment and philanthropy, in a way protesting the emphasis on dogma in the dominant Protestant church. ${ }^{14}$ It produced active communities concerned with philanthropy and poor relief, including communities of nurses. They were modeled after earlier Roman Catholic examples, often on the initiative of ministers and doctors. Protestant groups revived the role of the deacon or deaconess in the early Christian church. The most famous and influential community was the Kaiserswerth Deaconess Institute for Protestant deaconesses, founded by Theodor Fliedner in 1836 . Deaconesses did not limit their work to nursing. By 1850 , Fliedner had expanded his social reform initiative with a hospital nursing school; a motherhouse (for nurses and teachers); an orphanage; a teachers' seminary for infant, elementary, and 
industrial schoolteachers; an infant school; and an asylum for the female mentally ill..$^{\text {Is }}$ In the motherhouse, deaconesses from modest, respectable social backgrounds made a living while they learned their skill through apprenticeship. Fliedner himself provided biblical instruction, while a physician gave some lessons on medical matters. The first deaconess hospitals in the Netherlands were established in Utrecht and The Hague in I844 and I865, respectively. ${ }^{16}$

The motherhouse model spread among progressive, liberal-minded groups as well, often on the initiative of liberal Protestant doctors, who sought to improve the care of the sick and the poor. They founded secular, philanthropic nursing associations to improve the care of the sick and the poor in the context of a philanthropic reform movement. ${ }^{17} \mathrm{~A}$ prime example is the initiative of the liberal Protestant physician Jan Pieter Heije. In I843, he founded the Association of Sick Nursing in Amsterdam, aiming to provide an alternative to almshouse care for the sick and poor. Although inspired by the respected example of the Deaconess Institute, he opted for a secular form, which was more in line with his progressive political stand. The purpose of the new association was to have respectable women, experienced in nursing, provide care to the poor at home. Influenced by utilitarian views, Heije explicitly referred to the problem of redundancy among (unmarried) middle-class women, which he believed could be resolved if they became involved in respectable, philanthropic work. He and his friend, psychiatrist Gustaaf Eduard Voorhelm Schneevoogt, both on the board of the association, were members of the progressive-liberal Provincial Committee of Medical Inspection of North Holland, which had a crucial role in founding Meerenberg (I845-I849) as well. Moreover, the board of the new association included two ministers purposely appointed to support the reputation of being an institute of Christian philanthropy. ${ }^{\mathrm{I}}$

The board of the Amsterdam Association of Sick Nursing arranged the work according to the habits of their own middle-class families. In its voluntary task, the all-male board was assisted by a woman from its own circles, Miss Uhlenbroek-van den Brink, who voluntarily retained a supervisory position for the board, without being a board member, once the house was established. The Association bought a house and employed a small group of respectable women who lived in the house and went out during the day to nurse the sick in their own homes. The supervision of the nurses' work was arranged according to the model of a matron supervising servants. In fact, the model of sister supervision within religious orders was structured according to the same class relationships. ${ }^{19} \mathrm{~A}$ respected widow, Miss Coelman-Scheffer, was appointed as "sister-director" of the house. She supervised the nurses, 
managed the household and, most importantly, took the requests for care, visited the families to assess the need for care, and then assigned the nurses to the cases. ${ }^{20}$ Schneevoogt and his medical colleague and fellow board member C. B. Tilanus instructed the nurses in medical matters at a weekly meeting, while the ministers provided religious teaching. Nurses had no personal income; patient fees were paid to the house rather than to the nurses, which legitimized the nurses' work as a Christian duty. Unlike Roman Catholic orders, nurses of this association did not take vows. They were, however, confirmed in their duty in a religious service. ${ }^{2 \mathrm{I}}$

As of 1857 the association also took in patients (the institution was called the Prinsengracht Hospital), although a modern hospital did not grow out of this organization until the turn of nineteenth century. ${ }^{22}$ Based on this model, various secular, philanthropic associations of nursing spread during the second half of the nineteenth century. ${ }^{23}$ In their philanthropic social work women gained knowledge of and experience in leadership, managing an organization, and carrying out responsible tasks within the limits allowed by male authority. ${ }^{24}$ Consequently women found meaningful work, voluntary and paid, directly or indirectly, albeit within the limits of paternalistic control. Apprenticeship and biblical instruction, enriched with some medical teaching, socialized new recruits into their work. Disciplined skill became an extension of disciplined religious commitment.

The associations of nursing reflected the emergence of women's activism, as described by Van Drenth and De Haan. ${ }^{25}$ With the rise of the women's movement a growing number of liberal, (upper) middle-class women grew more conscious and articulate about their own role as women. Increasing awareness of their social responsibility and ethical influence also made women more sensitive to political and legal constraints on the public role of women, leading to the emergence of an organized women's or - as Van Drenth and De Haan identified - feminist movement in the Netherlands by the late nineteenth century.

\section{Female Compassion, Domestic Ideology and the Women's Movement}

The proper sphere of work and education for middle-class women became a matter of public debate with the emergence of an industrialized society, which took place in the Netherlands in the second half of the nineteenth century. The new liberal-democratic constitution adopted in the Netherlands in I848 reflected the changing political climate and occurred in the midst of an internationally revolutionary atmosphere in Europe. ${ }^{26}$ Philanthropic efforts to create a respectable working class and to fight pauperism provided women 
not only with an avenue towards a more meaningful life, but also with a context in which they began to articulate and legitimize the social meaning of women's work as a moral, ethical influence, complementary to that of men but of equal value. ${ }^{27}$

In the I86os, improvements in the education of girls and work opportunities for women were at the heart of the first public debates about the "women's question". The goals of social progress and the improvement of women's work opportunities became entwined. Better education would not only enhance the work opportunities for middle-class women, reformers argued, but would also make working-class girls better wives and mothers, and generate better servants. ${ }^{28} \mathrm{~A}$ middle-class domestic ideology of women's inclination for motherhood and domesticity, or women's work directly emanating from these responsibilities, underpinned the interest in and development of education for girls. ${ }^{29}$ Assumptions about the role of women in preserving morality in the family and bringing up children carried over to their role in society at large, thus legitimizing women's work in skilled occupations..$^{\circ}$ According to the rhetoric, education and training would develop women's moral talent into productive skills. ${ }^{3 \mathrm{I}}$

The emergence of a women's movement in the second half of the nineteenth century provided a context for transforming the traditional religious legitimization of women's work into a secular, ethical one. One of the leading Dutch women to articulate women's social responsibility and moral capacity was Hélène Mercier (I839-I9I0), who played an influential role in developing social work as a skilled occupation for women. She was instrumental in establishing the first Dutch settlement house in Amsterdam, modeled after the British Toynbee house, and she helped to found the first Dutch School of Social Work in $1898 .{ }^{32}$ She belonged to a group of progressive liberals who actively debated the "social question" of the time - the legal and social position of the working class.

Mercier believed women in particular would play a crucial role in establishing social progress, which, historian Waaldijk notes, she conceptualized as the evolution of benevolence and social justice for all members of society. Only this, in her eyes, characterized a civilized society. ${ }^{33}$ Mercier believed that men were stronger and more intelligent, but women had a greater moral capacity and could therefore carry out a complementary role. It was the duty and social responsibility of women to apply their ethical impact to social progress. ${ }^{34}$ The ethical influence of women, once formulated in terms of religious commitment, was reconceptualized as female compassion. ${ }^{35}$ The ideas Mercier articulated had a powerful influence on many men and women engaged in nursing reform and her view of women's contribution to social 
progress resonated in their arguments. When Van Deventer advocated the importance of women's role in asylum nursing reform, he explicitly referred to the work of Mercier. ${ }^{36}$

Nursing was but one avenue for women to enter a much broader domain of social and philanthropic work. Women allegedly had a special moral capacity for benevolence and safeguarding morality and virtue, which was expressed in characteristics such as sensitivity, devotion, patience, and sacrifice. Because of their level of civilization, middle-class women in particular were presumed to possess these "higher feelings", which made them excellent candidates for carrying out social reform and the improvement of standards of hygiene and living among the poor ${ }^{37}$ Based on their ethical influence, they claimed a social responsibility and duty to participate in social improvement and the protection of society against moral decadence. Women thus assumed an active role in a broad variety of social tasks such as the battle against alcoholism (the temperance movement) and prostitution, as well as the improvement of education for the poor, either as paid professional or voluntary philanthropic work. The claim of a public, ethical role for middle-class women underpinned a broader argument for women's right to work, education, and suffrage, which grew within the women's movement. ${ }^{38}$ In addition to concern for the well-being of others, women grew conscious of their own work opportunities. Middle-class women became involved in creating respectable work opportunities for women from their own circles as well as the broader middle class whose economic situation forced them to sustain themselves independently. For example, the women's associations Arbeid Adelt and Tesselschade, founded in $187 \mathrm{I}$ and 1872 , respectively, sought to create respectable work for middle-class women by contracting out needlework. 39

The Dutch women's movement obtained a more organized or feminist form by $1890.4^{\circ}$ Women increasingly felt that the patriarchal protection that had served to legitimize religiously inspired active roles for women was restricting them. Feminist-minded men and women challenged the subjected social position of women. ${ }^{4}$ With the foundation of the Vrije Vrouwen Vereniging (Free Association of Women) in 1889 and the Vereniging voor Vrouwenkiesrecht (Association for Women's Suffrage [VvV]) in I894, feminist women began to advocate explicitly for legal equality in the area of labor, family law and women's right to vote. ${ }^{42}$ The feminist battle for voting rights was not necessarily a unified movement. Political loyalties varied among women and their opinions as to the right strategies to fight their cause differed. ${ }^{43}$ Nevertheless, the organization of Nationale Tentoonstelling Vrouwenarbeid (National Exhibition of Women's Labor) in I898 sparked new unity within the movement. The exhibition attracted international attention and the 
membership of the $\mathrm{VvV}$ grew considerably. During the exhibition, collaborating women's organizations initiated the foundation of the Nationale Vrouwenraad (National Women's Council), after the international example, and established a Nationaal Bureau voor Vrouwenarbeid (National Bureau for Women's Work). 44

The National Exhibition of Women's Labor was organized in honor of Queen Wilhelmina's ascension to the throne in I898. This was of special significance for the Dutch women's movement. For generations the Dutch Kingdom had been ruled by a king. Because a queen had ascended the throne for the first time, women used the acceptance of a woman to fill the royal leadership of the country to underscore the argument that women could be trusted with organizational leadership, political participation and, ultimately, the right to vote. 45

The organizers of the exhibit had been sensitive to socialist criticism that in the initial plans for the event interests of working class women had been overlooked. The work conditions of women in industry obtained a prominent part in the exhibit. ${ }^{6}$ However, this may have contributed to the refusal of others to support the event. Middle-class feminist Lady de Bosch Kemper, for example, whose strong impact on the emergence of nursing as a paid career will be discussed later in the chapter, declined to take leadership in the event. A strong belief in women's special ethical role in social progress was reflected in the topics included in conference presentations: orphanage reform work, social hygiene, housing reform and hygiene, and district nursing. ${ }^{47}$

\section{Growing Demand}

Under the influence of an expanding economy, opportunities for women's work and education developed and paid careers, including nursing, for middle-class women increased..$^{8}$ This was a profound shift away from the structure within which middle-class nursing work had initially become accepted that is, within the protected boundaries of a religious, male-authorized female hierarchy of a motherhouse system. The articulation of middle-class women's different yet complementary social responsibility served as an important source of legitimization for nursing as a morally compassionate, yet socially respectable, independent, paid occupation. Due to the liberalizing climate, more women opted for nursing in order to earn a living, and the attraction to nursing was facilitated by the respectable reputation it had gained within the religious tradition. But probably the most salient factor impacting the increase in opportunity for middle-class women in nursing was a growing demand for nurses as a consequence of an expanding econo- 
my. ${ }^{49}$ The model of order-like associations for nursing grew too limited to meet the growing demand for experienced nurses during the late nineteenth century.

The increased demand for middle-class women trained in sick nursing but independent from benevolent associations or deaconess institutes came from various sources. ${ }^{\circ}$ Firstly, as the economy expanded after about I890, the growing middle class could afford to pay for private nursing that was not necessarily related to philanthropy or the care of the poor. ${ }^{5 \mathrm{I}}$ Affluent middleclass families began to hire private nurses, creating a market for private duty nursing. Many associations for sick nursing designed a sliding scale of fees for service intended for the middle class. ${ }^{52}$ The cases that private duty nurses covered were not limited to physically sick patients; the growing number of nervous patients among the middle class also formed a considerable part of their clientele. ${ }^{33}$ Beginning in 1895 , nursing bureaus emerged for the mediation of placements and the coordination of service in private duty. These were professionally run organizations, founded by nurses themselves, by various newly established professional organizations for nurses, or by lay boards of associations of nursing. ${ }^{54}$ In many ways, the bureaus were a source of protection for nurses, for whom independent work was not without the social risks of exploitation or disrespect, and they guaranteed a certain quality of work for families in need of nurses. As a result, they both attracted nurses and increased demand.

Secondly, hospital care developed as an acceptable option for the middle class during this time. Antisepsis and aseptic treatment made medical treatment more successful and hospital medicine increased in status. As a result, many new, small, middle-class hospitals emerged. Specialty clinics, such as small hospitals for children and eye clinics, emerged in the larger cities during the 1860 s and I870s.55 The Burgerziekenhuis (Bourgeois Hospital), founded in 1879 by theologian and physician A. W. C. Berns, who had practiced surgery in Amsterdam since 1876 , was but one example of a new middle-class hospital. As he required a good hospital for his practice, Berns founded one himself. Together with his wife he managed the modest hospital to which he attracted some middle-class nurses experienced in sick nursing. In I88I, when Berns joined the municipal council, he strongly advocated reform of the municipal hospitals. ${ }^{56}$ Around I 890 , hospital care in small clinics and small voluntary hospitals became available on a wider scale, increasing the need for nurses. Many boards of the Association of Sick Nursing established facilities to take in a few patients. In the period between I892 and I900, the hospital system in Amsterdam grew by 30 percent, while the general population growth was only i9 percent. ${ }^{57}$ 
Finally, probably the greatest impact on increased demand for experienced nurses was public hospital reform. Traditionally, public hospitals were stigmatized as last resorts for the poor. The problems of finding capable personnel resonated with similar complaints within the asylums. Servants who attended the patients in public hospitals came from the lower social classes. They never stayed long and turnover rates were usually high. During the second half of the nineteenth century when industrialization was affecting the Netherlands, the fast-growing city of Amsterdam sought to reform its public hospital system. Medical professors had an interest in public hospital reform for the sake of their research and teaching, and they sought to increase their control over personnel, who were traditionally overseen by a steward and matron. Physicians had a particular interest in having skilled nurses serve as their assistants. The civilizing role and respected reputation of respectable women within religious orders, deaconess associations, and secular associations of nursing, and the women's concomitant skill in the hygienic, disciplined care of the sick became an inspiration to liberal, reform-minded doctors for attracting similar respectable middle-class women for hospital reform..$^{8}$ Within the new and reformed hospitals, however, physicians preferred to employ and train these nurses themselves instead of relying on the authority of orders or associations of nursing.

\section{A New Educational Structure for Nurses}

Debates on the social role of women not only provided a context in which a traditionally religious motivation for nursing could be reworked into a secular, moral legitimization for an independent role for women, thereby providing an ideological basis for nursing work independent from motherhouse structures. The supposedly female ethical influence also validated a claim for the improvement of education for women, forming the basis for a new educational structure of nurse training outside the protected boundaries of a motherhouse system.

Within expanding economic demand for nurses, arguments of female compassion were employed to forge a new link between medical reform and middle-class women's interest in nursing. Nurse training was molded after the ideal of the education of girls. ${ }^{59}$ The emphasis on strengthening female skills and character in new nurse training programs that emerged in hospitals beginning in 1883 can be traced to domestic ideology and ideals of female compassion. ${ }^{60}$ This ideology supported the efforts of nurse reformers to develop nurse training as a female-oriented scheme that would enhance the respectability of nursing as middle-class women's work. In I879, the progres- 
sive liberal White Cross Association of Nursing in Amsterdam established the country's first diploma-based nurse training course. Founded in I878, this association was an offshoot of the liberal White Cross Organization, which had originated four years earlier in the province of North Holland to control infectious diseases and was part of a broader hygienic movement that gained momentum after 1840 . The threat of cholera epidemics in 1830,1832 , and I 848 had generated social and hygienic reform initiatives among progressive politicians and doctors. The upper and upper-middle class initiators of this reform considered their efforts to be a contribution to the elevation of cultural and social life. Liberal physicians were prominent participants in the movement. ${ }^{6 r}$

On the board of the Amsterdam branch of the White Cross Association were several physicians interested in resolving the precarious situation of the Amsterdam public hospital system. ${ }^{62}$ University medical professors and public hospital physicians continuously negotiated with the Amsterdam Municipal Council over the improvement of the public hospitals. They shared an interest in public hospital reform and welcomed the idea of skilled nursing in order to enhance the opportunity for medical practice and teaching. ${ }^{63}$ The board members of the Amsterdam branch decided to establish a new training course in nursing in order to attract better skilled nurses to reform work. ${ }^{64}$ The initiators molded the new nurse training after familiar and socially respected examples of nursing work in nursing associations. The nursing course was not initially affiliated to a hospital.

Hospital reform and medical interests linked up with feminists' attempts to improve career opportunities for women. The feminist interest in creating nurse training was embodied in the influential contribution of Lady Jeltje de Bosch Kemper, a daughter of the Amsterdam elite and a progressive feminist who had built a reputation for her initiatives for the cause of women's work. ${ }^{65}$ De Bosch Kemper was on the board of the Dutch women's association Tesselschade, which contracted out needlework to improve work opportunities for middle-class women. ${ }^{66}$ From I 885 to I 9 II she served as its chairperson. De Bosch Kemper also actively participated in the development of theoretical and practical training for girls in home economics. She was a co-founder of the Amsterdamse Huishoudschool (Amsterdam School of Home Economics) in I891. ${ }^{67}$ The school's dual aim was to prepare girls for their later responsibilities in the family context and enhance work opportunities for women in occupations such as housekeeper or nanny. The school reflected the belief within the women's movement, grounded in middle-class domestic ideology, that it would enhance a woman's independence and work opportunities if she received schooling and training in the areas of work for which she had a natu- 
ral talent. The school provided both formal training for women as housekeeper or teacher in home economics as well as education for girls in home economics and cooking. It was deliberately designed as a boarding school so that teachers and students would learn and live as a large family. In this way students learned the domestic skills, both in theory and practice, within a model that represented the family. ${ }^{68}$

In carrying out their mission of creating a nurse training course for middle-class women, the White Cross committee asked Lady de Bosch Kemper to give her support to their attempts to reform public hospital care. ${ }^{69}$ De Bosch Kemper immediately sensed the impact nurse training could have in creating careers for middle-class women. She attended the founding meeting of the White Cross Association of Sick Nursing and became a board member. The new White Cross Association of Sick Nursing developed as an ammalgamation of traditional associations of sick nursing in the context of philanthropy, and a more independent form of nursing education..$^{70}$ In the White Cross nurse training program, women had the option to remain with the association, quite similar to the traditional motherhouse model, or to establish themselves independently in private duty after graduation..$^{71}$

The nurse training course began in I 878 ; it took one year initially and later two. Similarly to the situation in associations of nursing, physicians lectured on rudimentary anatomy, physiology, and hygiene and delivered basic instruction on nursing the sick, but the teaching role for a minister had disappeared. The idea was that the trainees would obtain practical nursing experience in the public hospitals. Such a revolutionary concept generated much controversy, however, and initially made the course a limited success. Attaining access to the public hospitals to provide the new trainees with practical training turned out to be a major problem. Conservative public hospital boards were unwilling to accept the concept that the work of these middleclass women would be predominantly restricted to direct patient care rather than including domestic work as well. As the organizers of the course tried to provide practical training for pupils in the Buitengast Hospital, the municipal hospital of Amsterdam, the hospital board, including conservative medical director Thyssen, soon refused to give free board and lodging to the nurses in training. ${ }^{72}$ As a result, the course remained theoretical, aimed at private duty nurses who either became members of the association or continued to work independently. Only about four to six nurses graduated annually.73

However, the course did provide nurses with a valuable qualification as the association established an exam that nurses took on completion of the course. Although practical training initially was not available in an organized way, upper middle-class women did find ways to gain skills - for instance, in the 
new small private middle-class hospitals. Local physicians who supported the role of women in hospital reform comprised the White Cross exam committee. On completing the course and passing the exam, nurses received a diploma and a badge. The White Cross Association of Nursing successfully blended the traditional type of nurse organization with the new need for trained women in hospital work and facilitated increased medical control over nursing.

\section{A Respectable Salaried Occupation}

Jeltje de Bosch Kemper became an ardent spokeswoman for the cause of nursing and over the next decades she played an influential role in the organization of nursing into a respectable occupation. ${ }^{74}$ Initially, the White Cross training course successfully attracted upper middle-class women. One of the early graduates was an affluent patrician's daughter, Anna Reynvaan, who first worked in the previously mentioned new Burger Hospital founded by physician Bern. She later became deputy director of the first hospital-based nurse training program in the Buitengast Hospital. Reynvaan became close friends with Jeltje de Bosch Kemper. Strongly supported by physicians, they took the initiative to establish a public forum to discuss and propagate the cause of nursing by founding the Maandblad voor Ziekenverpleging, (Journal of Sick Nursing) in I890. The early upper-class graduates of the White Cross program soon began to fill supervisory positions when the training course was changed to a hospital-based system.

In 1883 , five years after its establishment, the training course evolved into a hierarchical hospital training system. In that year, Jacob van Deventer succeeded Thyssen as medical director of the Buitengast Hospital, and he immediately used his authority to fulfill the reform ideals of progressively minded municipal council members and physicians, reorganizing the Buitengast Hospital according to the new medical and hygienic standards. To facilitate proper medical treatment and observation, he made wards more orderly and hygienic; the reorganization of ward personnel was a key part of this change. In order to incorporate skilled nursing, he reorganized personnel in the Buitengast Hospital into a new hierarchy of apprenticing nurses. The training strongly emphasized employing the refined and respectable nature of the women or instilling such values in the student nurses if these were lacking; this was clearly based on ideas of girls' education. Van Deventer appointed upper middle-class women who, just like Reynvaan, had gained experience in sick nursing and had probably taken the White Cross course as head nurses, and he recruited respectable middle-class girls for nurse training. 
The civilizing influence and refined character that these head nurses brought with them as a natural extension of their class background made them important agents of reform as they inculcated middle-class values and behaviors into a student nurse workforce that came from the lower-middle and working classes. ${ }^{75}$ The supervisor-pupil relationship in many ways resembled the traditional mistress-servant relationship. The pupils most likely received free board and lodging and were probably paid a small salary, just like the servant staff. Van Deventer selected Reynvaan as deputy director to assist him in supervising the pupil nurses and preparing them for the White Cross exam while they worked as apprentices in the hospital. It is highly likely that this was a voluntary position. ${ }^{76}$ It can be assumed that the role of Van Deventer's wife, Antonia Wilhelmina Stelling, was a similar crucial ingredient in changing the inner structure of the hospital wards. She informally served as the matron of the Buitengast Hospital and her work obviated the need for the positions of the steward and matron, who probably did not support the rigorous changes. ${ }^{77}$ The number of White Cross exam graduates significantly increased. Whereas in the first five years 25 nurses graduated, in the next ten years, between I884 and I893, a total of I88 nurses passed the exam. A large number of them had completed their training in the Buitengast Hospital..$^{8}$

In 1892 , the Amsterdam initiators of hospital nurse training organized a prestigious "Conference on Nursing the Sick", the first conference on nursing held in the country. The goal of the conference was to develop a unified system of nurse training and examination.79 Like the Buitengast Hospital, most Amsterdam hospitals had begun some form of training system, and associations of nursing also offered a variety of training programs that varied in length, depth, and quality. Control over training standards became a matter of debate. Both the medical and nursing leadership began to discuss the need for a new organizational body for the regulation of training. The White Cross Association could no longer process as many applicants as the number that applied, and physicians believed each hospital should have its own exam committee, all meeting the same standards.$^{80}$ Anna Reynvaan and Jeltje de Bosch Kemper organized the conference, with influential physicians such as Van Deventer and medical professor W. M. Gunning on the organizing committee, all of whom were members of the editorial board of the Journal of Sick Nursing. ${ }^{8}$ During the two-day conference, which was held in the lecture hall of the renovated Buitengast Hospital (now called the Wilhelmina Gasthuis), about 150 hospital directors, deputy directors, head nurses of the Buitengast Hospital, and other prominent citizens gathered. As a result of the conference, the Nederlandse Bond voor Ziekenverpleging (Dutch Nurses Associa- 
tion [NBZ]) was founded in I893, with Jeltje de Bosch Kemper as its secretary. $^{82}$

As its first accomplishment, the NBZ designed a unified regulation for nurse training and examination. Requirements for the NBZ exam included completion of a nurse training course and three years of nursing experience, with at least one year of experience in a general or children's hospital. ${ }^{83}$ Reflective of the values nurse training sought to inculcate in the new nursing recruits, demonstration of "good moral behavior", "a healthy status", and "general civilization and schooling" were checked as part of the application. Hospitals could join the NBZ and adapt their training according to the new regulations. If they did so, the nursing diplomas they granted became NBZ certified. The NBZ became a powerful organization, dominated by physicians and hospital administrators with nurses having little independent control. Their role continued to be legitimized based on female, moral duty.

\section{Female Influence}

In a complementary role to male medical authority, women attracted to nursing articulated their work in moral terms. Older notions of religious commitment were reconceptualized in secular terms and mingled with new rational, medical legitimizations.

Van Deventer's wife, Antonia Stelling, was a living example of a middleclass woman engaged in voluntary social reform activities. Working with her husband, she provided informal leadership as matron in the Buitengast Hospital. Once her husband moved on as medical director of Meerenberg, she informally functioned as Meerenberg's deputy director to supervise the new mental nurse trainees. When, in I9I0, Stelling presented a paper on her work for the (philanthropic) Association for After-Care of Discharged Epileptic Patients in Amsterdam at the International Congress on Insanity Care in Berlin, she explicitly stated that she believed that this was a task in which women could do beneficial work. She emphasized that this belief had been her inspiration to found the association in 1907 with a group of like-minded women at the request of the physician A. Bonebakker, the former director of the Institute for Epileptics in Amsterdam. Moreover, she noted that she had been able to learn about the problems facing the mentally ill while working at the side of her husband for twenty-five years, first at the Buitengast Hospital and later at the Meerenberg asylum. She indeed considered the moral influence a women could have complementary to male authority; she concluded the paper - a very thoughtful and knowledgeable discussion of the problems epileptic patients faced in social life - with an expression of hope that her dis- 
cussion had illuminated "how women, under psychiatric leadership could do beneficial work and indeed could contribute to maintaining recovery of the poor mentally ill" ${ }_{4}$

Reynvaan, who worked closely with Van Deventer as deputy director at the Buitengast Hospital, was equally dedicated to the moral influence of women. She believed a well-bred female nurse, who acted out of calling, love, and higher principles, would be an "angel of comfort", especially in asylums. The care of incontinent patients was burdensome, she agreed, but would be done more diligently if it were based on a higher principle and love. Pertaining to the situation on insanity wards, she argued that as a result of the sophisticated tone of the well-bred nurse, rudeness and violence would disappear from the ward, the disheartened would cheer up, the agitated calm down, the hot-tempered grow patient, and the dull act more quickly. ${ }^{85}$ Nurse training, she believed, was an important measure to bring about the proper (female) atmosphere and order on the wards.

In similar terms, in I89I Anna Reynvaan and Gerritje Kuyk, who was a former head nurse of the Buitengast Hospital, challenged, in the Maandblad voor Ziekenverpleging (Journal of Sick Nursing), a statement by psychiatrist Van der Chijs that middle-class women would be too refined for asylum work. Kuyk, by that time director of her own institution (a private home for nervous patients) noted that a well-bred and sophisticated female nurse would never be too refined to devote herself to the most desperate, because it was her calling. Moreover, she believed good training would make her take up her task with even more compassion and love. Kuyk's comments underscored how nurse training legitimized the work of sophisticated women and enhanced their moral role. In the Buitengast Hospital, she argued, the women "in training", devoted to the suffering patients, increased their pleasure and involved them in productive activities. Women who worked for pay, she noted, would never have been able to achieve such an accomplishment. ${ }^{86}$

\section{Hospital Hierarchy}

The new hospital-based nurse training provided women with basic medical knowledge and a limited period of practical experience acknowledged by a diploma, rather than a lifelong commitment and protection in a motherhouse system. The idea that nursing could be a respectable paid occupation for women legitimized hospital training and began to replace the traditional conception of nursing as charitable work. This proved a revolutionary change in nursing. ${ }^{87}$ It provided new avenues to independence for women and, as demand increased, generated a much larger supply of trained nurses. After 
the practical training, graduate nurses could make an independent living from fees or salaries directly paid to them in private duty nursing.

Nursing work, as a paid occupation and an institutional, diploma-based training system, attained a different character compared to the former smallscale charitable associations of nursing. If religious orders, deaconess organizations, or associations of nursing took over the management of an institution, they had their own hierarchy into which they incorporated novice nurses through apprenticeship. In the hospital training system, nurses were appointed as student nurses on a personal contract, under the authority of doctors, and became part of a hierarchical structure over which they had little control. As nurse historian Cora van der Kooij argues, the early form of nursing work that emerged in the wake of nineteenth-century social movements and philanthropic reform was completely different to the new linkage of nursing with medicine, in which nurses became the assistants of physicians. In the early associations of nursing, nurses were to some extent able to use the new social arena for women to their own advantage. During the late nineteenth century, however, the linkage with medicine moved nursing into a new phase of more hierarchically structured relationships ${ }^{88}$ Furthering this argument, it could be stated that in the medically controlled, hospital-based training system that emerged, nurses in many ways lost control over the domain of nursing as a field of women's work.

The work and way of living that the nurse training system entailed - obligatory living-in, long hours of hard (domestic) work, and usually very low pay soon made nursing unattractive to better educated upper middle-class women who were initially attracted to the work of nursing because of its socially respected role in reform work. ${ }^{89}$ The rhetoric of female ethics played an important ideological role in the evolution of nurse training as a disciplinary system that sought to instill middle-class values and behaviors in a nursing workforce that increasingly came from the lower middle and working class. Creating a student nurses' workforce in hospitals never resolved the longstanding problem of high turnover among hospital attendants, despite the promise of training. The wards were consequently left with many young, inexperienced nurses. Nevertheless, for lower middle- and working-class women hospital training had a different, yet probably similarly liberating meaning as it had initially had for their upper-class counterparts. It provided an opportunity, even if seen as a temporary investment to be endured, towards a career in which they could improve themselves. ${ }^{\circ}$ Because of their class background, these young women were more used to hard work, and the link with medical science increased their status within their own families and community. ${ }^{9 r}$ Hospital nurse training provided an "entrance ticket" to inde- 
pendent roles for graduate nurses outside of the hospital in preventive and social work within district nursing organizations or in private duty.

When psychiatrists decided to opt for a mental nurse training system in I890, they faced many of the same aspirations and frustrations that characterized general hospital nurse training. The problem of recruiting nurses in sufficient numbers and of a "satisfactory" class background was even more dominant. In many ways, this made the inherent class and gender contradictions of the training system stand out even more sharply.

The ideal of female-oriented mental nurse training brought together various threads of nineteenth-century culture. It helped to raise the status of psychiatry to that of general hospital medicine, it provided an educational structure to restructure the class base of asylum attendants' work in a new field of middle-class women's work, and it channeled the philanthropic aspirations of upper middle-class citizens to uplift the poor and to improve the care of the insane by means of raising the morality of asylum personnel. The gendered assumption that middle-class women had a special moral compassion that equipped them for nursing work encompassed all of these threads in the efforts of the initiators and creators of mental nurse training, both psychiatrists and middle-class women.

\section{Raising the Status of Psychiatry: The Introduction of Mental Nurse Training}

Within the "Nederlandse Vereniging voor Psychiatry" (Dutch Association of Psychiatry [NVP]), Van Deventer ardently promoted the system of White Cross nurse training among his colleagues and advocated for the attraction of middle-class women to improve asylum care. ${ }^{92}$ As a psychiatrist, he felt strongly about the introduction of nurse training for asylum personnel. It can be assumed that he had some authority on the matter within the NVP because of his experience with nursing reform in the Buitengast Hospital. His argument for the improvement of asylum personnel was intertwined with the desire for more authority for asylum doctors. He believed that only if the medical director had ultimate authority in asylums over both medical and administrative matters, including control over attending personnel, would medical care in asylums reach the appropriate standard of contemporary psychiatry. ${ }^{93}$ Psychiatrists' first and foremost motivation in arguing for a gendered nurse training system was their interest in an assistant over whom they had control. Nurse historian Eva Garmanikow has pointed out how the shared interest in nursing reform of female social reformers and physicians was based on very different definitions of a woman's role. While female nurse reformers argued that nursing should be pursued by women because of their caring qualities, 
they also claimed the right to work. They regarded femininity as a powerful resource in developing nursing as an occupational field for women. The interest of physicians in nursing as women's work, on the other hand, was grounded in a patriarchal view of female subordination and the need to strengthen their own professional dominance through the creation of disciplined subordinate assistants. This view implied a more restrictive definition of femininity and emphasized women's subservience. ${ }^{94}$

A more in-depth look at the reason the personnel question was raised once again in the NVP in the late I880s confirms Garmanikow's observation. ${ }^{95} \mathrm{At}$ that time, NVP members were quite troubled by the outcome of a conflict that had arisen in 1887 in the Roman Catholic Voorburg asylum between the physicians, the College of Regents, and the religious order of the "Broeders van Onze Lieve Vrouwe van Lourdes" (Brothers of Our Lady of Lourdes). Voorburg's first physician, A. O. H. Tellegen, strongly felt that he should have more control over asylum management and participate in regular meetings with the Regents and the brother-prior about matters of patient care. His regular quarrels with the brother-prior over what he felt was incompetent behavior of the brothers brought him to the point where he asked the College of Regents to replace or fire the brother-prior. The Regents' response was clear. They were willing to expand Tellegen's involvement with patient management in matters such as feeding, bedding, and clothing, but they expected Tellegen to acknowledge them as primary directors of the asylum, and they refused to fire the brother-prior. On hearing this decision, Tellegen resigned. NVP members strongly supported Tellegen in his decision; to them the conflict underscored the idea that supervision of personnel should be put more firmly into medical hands..$^{96}$ They must have felt that further action was needed, and they put the issue on the NVP agenda. ${ }^{97}$

In the next year's meeting of the NVP, in I888, Van Deventer introduced the topic and summarized his viewpoint in a paper..$^{9}$ He mapped out how the asylum physician should be entrusted with unlimited authority to treat patients and to direct personnel, preferably as medical director. Patient care, he argued, could best be assigned to nurses, preferably to women "uit de beschaafde stand" (from the middle class), who would need to be properly trained and, although he did not state so explicitly, would come under medical control. 99 The discussion following the presentation of the paper reflected how his colleagues struggled to conceptualize the implications of this point of view. Some doubted whether physicians would have time to teach personnel, but proponents emphasized they would. Others were skeptical whether middle-class women would be willing to do such work. Van Deventer argued that he had good experience with middle-class women in charge of patients in the 
Buitengast Hospital, even on male wards. As he explained elsewhere, those women had the right philanthropic morality and calling to affect patients. Male attendants were more tempted to abuse patients, he believed, whereas women had a natural calming influence on patients. ${ }^{\text {100 }}$

Various NVP members were hesitant about the role of middle-class women in asylums. They underscored the antisocial behaviors and indigence of the majority of asylum patients and feared that middle-class women would feel uncomfortable with the care of those patients. ${ }^{\text {ror }}$ Moreover, some colleagues wondered whether it would be appropriate to appoint women to work on male patients' wards and whether middle-class women could be recruited. Despite this reluctance they approved the general intention of Van Deventer's ideas. ${ }^{102}$ In their I 889 meeting the NVP appointed a special committee consisting of the psychiatrists Jacob van Deventer, A. O. H. Tellegen, and State Inspector W. P. Ruysch to design a proposal for improvement of asylum personnel.

The next year, I890, the committee presented their report. Clearly employing the notion of "progress", they presented a brief historical account highlighting how at various points in history psychiatrists had attempted to teach personnel and how low morality and high turnover rates among attendants had been the concern of asylum physicians all along. They believed that at that point in time the discussion on personnel had reached a historical turning point. ${ }^{103}$ The committee saw this evidenced in a "social consciousness on care of the sick [that] had been awakened" ${ }^{104}$ Most likely they felt that the rising medical prestige was on their side. The committee argued that the asylum paralleled the general hospital in that medical changes required the improvement of personnel. ${ }^{105}$ The care of the sick, they noted, could no longer be trusted to the hands of ordinary servants with no particular skills for the job and, more importantly, with improper, immoral behavior that made them unfit for the work.

A strategical citation of the esteemed medical professor W. M. Gunning, who along with Van Deventer was on the board of the newly established Journal of Sick Nursing (1890), reflected how the committee still had to convince many of their colleagues of the new views. But it also underscored the committee's belief that they were facilitating an important step forward in history. By citing Gunning, they put the plea for the training of personnel in the broader context of medical advancement. In the first issue of the new nursing journal, Gunning pronounced that the advancement of scientific and practical medicine had fundamentally changed the standards of care for the sick. Meeting these standards, he argued, required "a considerable level of general civilization, and theoretical and practical knowledge," and particularly "a relatively long period of preparation" ${ }^{106}$ Special nurse training schools, Gunning 


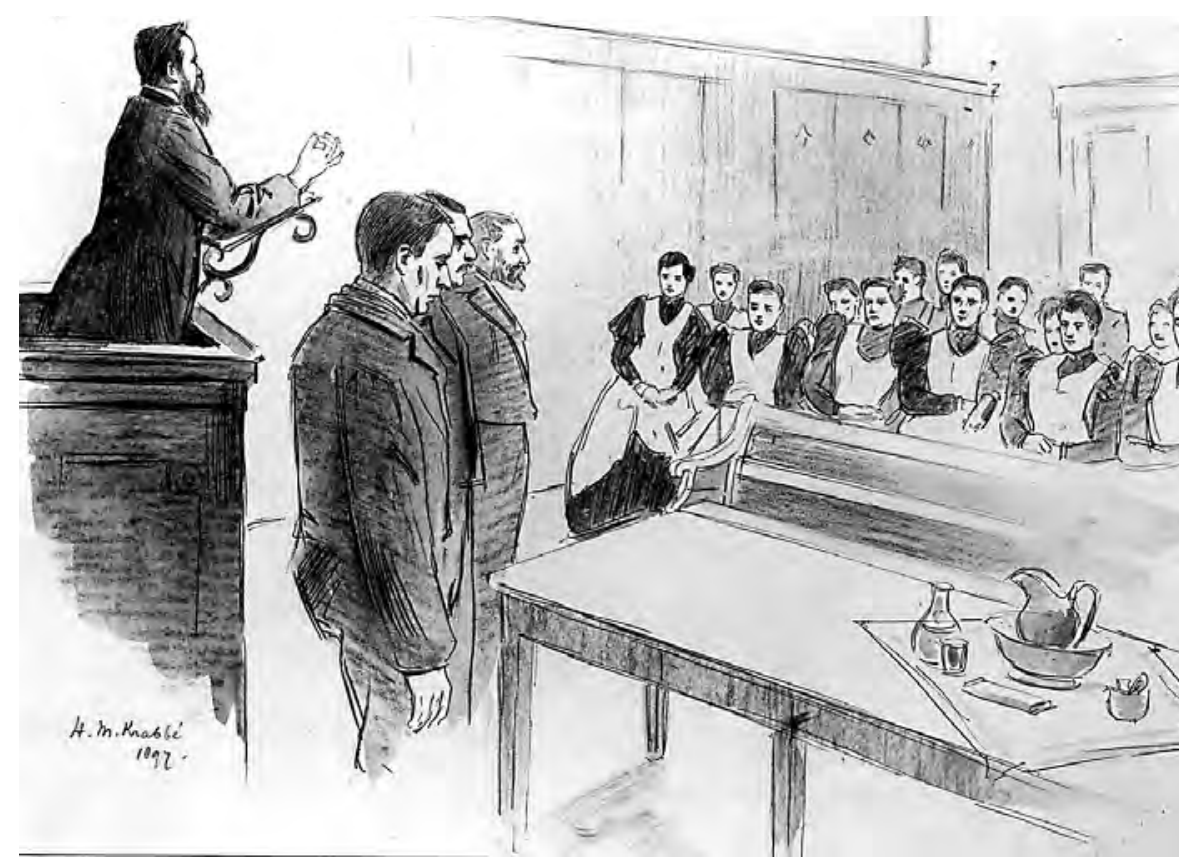

5. Jacob van Deventer lecturing mental nurses about three patients, Meerenberg Asylum, I897.

argued, had been established to teach this knowledge and skill, and, considering the special nature of the work, nursing had evolved as a socially respected occupation, particularly for women. ${ }^{107}$ In this way the outlines of the new mental nurse training idea were sketched. The NVP committee considered exactly the same reorganization - that is, introducing medical training of attending personnel - imperative for care of the insane.

The conclusions of the committee, obviously influenced by Van Deventer, proposed that the asylum boards and medical directors should join their efforts in a reorganization of attending personnel such that attendants would be replaced by nurses adequately trained in sick nursing. Nurse training should therefore be made a requirement for all asylum personnel, including the religious nursing orders in Roman Catholic asylums. The teaching would be the responsibility of the asylum physician. Asylum boards could facilitate the recruitment of capable trainees by improving work conditions and salaries. The medical director, they argued, should direct the reorganization and the establishment of a training course. Finally, the committee proposed to appoint an NVP examination committee to design training regulations and 
an exam that the new mental nurses could take on completion of a training course. These measures, reflecting both the need for more skilled personnel and the ambition to increase medical authority, would turn asylum work into a respectable occupation, the committee believed, thereby attracting reasonable nurses. ${ }^{108}$

The committee had not included Van Deventer's ambitious idea of having a female nursing deputy director assist the medical director in supervising nurses, nor did they recommend a female head nurse on the male wards. ${ }^{109}$ The notion of attracting middle-class women for asylum work was still controversial, and only a few medical directors fully supported the idea. Medical director Van der Chijs, for example, argued that such refined women would probably not be a match for disturbed, indelicate, and often filthy patients. He felt that respectable domestic servants were much more appropriate for this work. ${ }^{\text {IIo }}$ Medical director Schreve of the Rotterdam asylum, who proudly announced the reorganization of his attending staff in I890, admitted that the male wards were still functioning under the old regulations. Only on the female wards had he instituted a nursing staff separate from the domestic servants and under the supervision of a White Cross graduate. ${ }^{\text {III }}$ Despite these hesitations, the NVP approved the proposal and the committee, reappointed as the NVP's mental nursing exam committee, went on to design exam regulations and requirements for a training course.

In developing their regulations, the NVP exam committee took the nurse training system of the Buitengast Hospital and the White Cross exam, developed by Jacob van Deventer and the White Cross graduate nurse Anna Reynvaan, as their example. ${ }^{\text {II } 2}$ The new NVP regulations prescribed that applicants for a mental nurse training course had to be aged twenty or older, and in addition to being in good physical condition, they had to have a refined character and a respectable morality, which should be confirmed by recommendations from at least three sources. A theoretical course, taught by the medical director or asylum physician, should cover the subjects of human anatomy and physiology, health education, nursing the sick, including surgical and medical patients, training on bandages and dressings, and nursing the insane. Moreover, practical training should entail two years of practical nursing experience, including one with insane and nervous patients. The committee designed both the training model and a standard for the exam, but the NVP only intended to give the exam; the training course had to be provided by the asylum. An exam committee would hold the exams, which included written and oral components, annually. The candidates would receive a diploma and a badge of the NVP on passing the exam. ${ }^{113}$

By general approval the NVP accepted these regulations and the preparato- 
ry committee became the NVP's exam committee in i891. The first exams were held in November I892. ${ }^{\text {II }}$ The committee carefully checked the candidates' moral and civic qualifications. The candidates had to complete a questionnaire on their personal background information prior to the exam, and the medical director of their institution had to send in an appraisal of the candidate's competence and proper moral standing, a health appraisal, and confirmation of a satisfactory two-year practical training requirement. In addition, the candidate had to submit a birth certificate and a vaccination statement. ${ }^{\mathrm{II5}}$ The rigorous selection process reflected the psychiatrists' intention to set high moral standards.

In I893, after three rounds of exams, the exam committee proposed extending the practical training to three years, because they felt the practical knowledge of most candidates was insufficient. The change was probably also a response to the new nurse training regulations issued for the general hospital at that time; psychiatrists probably wanted their candidates to meet the same standards. The exam committee was perturbed that some asylums sent candidates who had not rotated through various departments, but had instead served on the same ward for two years. Such practical training was insufficient to produce a comprehensive understanding of the care of insane patients, the committee argued. Sufficient practical training should at least entail practical experience on the sick ward, the observation station, the quiet ward, the disturbed ward, the bath room, the isolation cells quarter and, if applicable, the higher social class department. ${ }^{\mathrm{II} 6}$

The exam committee's expectation, however, that mental nurse graduates of the NVP exam would be considered to be of the same quality as graduate nurses from general hospitals, thus confirming the similarity between mental and general hospitals - and, indirectly between psychiatry and general medicine - was soon disappointed. Once the physicians within the Dutch Nurses Association (NBZ) established a national standard for general nurse training in 1893 , they did not regard their standards as exchangeable with those of the NVP. Graduates of the NVP exam were excluded from NBZ certification. The controversy is probably an indication of the relatively low status of psychiatric medicine as compared to general hospital medicine. When, about fifteen years later, university hospitals expanded with clinics for mental and nervous patients and demand for mental nurses in private duty increased for nervous and mental patients, the interest on the part of the NBZ in certified mental nurses may have increased. In I907, the NBZ and the NVP finally agreed on a joint regulation for the exchange of their diplomas. ${ }^{117}$ Many mental nurses used this option as a chance to enhance their career opportunities by continuing their training in the general hospital. 
The gendered notion of female compassion, which was at the heart of psychiatrists' efforts to improve asylum care, came out most saliently in the foundation of the Wilhelmina Vereniging (Wilhelmina Association [WV]). Changing the asylum into a respectable mental hospital partly depended on the advances made in attracting "refined" female nurses for patient care. ${ }^{\text {II } 8}$ Inspired by high ideals, the exam committee of the NVP, consisting of state inspector W. P. Ruysch, A. O. H. Tellegen, and Jacob van Deventer, sought ways to attract a "better grade" of nurses for asylum work. In I897 Ruysch initiated the foundation of the reputable WV, a philanthropic middle-class society for the enhancement of the care of the insane and the promotion of the cause of mental nursing. The WV was named in honor of Queen Wilhelmina's ascension to the throne in 1898 . One of the initiatives of the new society was the foundation of a preparatory training period for female nurses, denoted vooropleiding (preschool). The WV opened the mental nurse preschool, the Wilhelminahuis (Wilhelmina Home), in I90. ${ }^{\text {II9 }}$

In order to improve the care of the sick, Ruysch noted, various philanthropic associations of nursing had been founded - for example the NBZ - but no such association existed for mental care. The WV was very prestigious. Women had an obvious role in creating this new organization, yet it was a role complementary to male medical authority. The WV established a provincial committee and local branches in every province, attracting members from the local aristocratic elite and middle classes such as lawyers, judges, members of the provincial councils, and, obviously, psychiatrists. The executive board consisted of Ruysch, Tellegen and Van Deventer, as well as the aristocratic ladies W. Haitsma Mulier-Baroness van Sytzama and Freule (Lady) S. Schorer. ${ }^{\mathrm{I20}}$ Both ladies already had an active role in philanthropic work at Meerenberg as chairperson and secretary, respectively, of the Meerenberg Association, a benevolent women's society founded in 1893 that occasionally

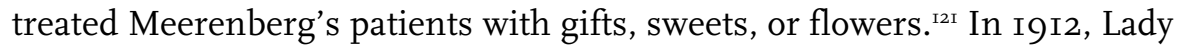
Haitsma Mulier became the first female board member of the Meerenberg asylum. ${ }^{122}$ Antonia Stelling, Van Deventer's wife, joined the Wilhelmina committee of the province of North Holland, together with various board members of Meerenberg.

The WV was active until the end of World War I. The association was then dissolved as a result of financial trouble and conflicting views as to where it should focus its goals. Although the bylaws of the WV addressed both male and female nurses, in reality the WV was only interested in ameliorating the status of asylum nursing by attempting to attract middle-class women. Men- 
tal nursing, secretary Van Deventer emphasized once more in his opening address at the first meeting of the WV, required women motivated by higher principles and devoted service who, under the leadership of the asylum physician, would be able to affect patients through their pedagogical influence. ${ }^{123}$ The enhancement of mental nurse training and the creation of rest homes for mental nurses, as well as providing support to nurses in the event of sickness, invalidity, and old age also were related goals. ${ }^{124}$ But nurses had no representation in the association. Psychiatrists dominated the discussions and controlled the agenda, occasionally using the leverage of the association to influence broader policy debates in psychiatric care. ${ }^{.25}$

Not surprisingly, the association's stance towards nursing always supported the official point of view of the NVP and underscored the policy of the State Inspectorate. With regard to a policy to support nurses in invalidity and old age, the WV issued advice in 1904 that nurses should be included in insurance funds through existing insurance companies, both for invalidity and a pension. ${ }^{126}$ In the same year the NBZ had issued a similar statement on this matter. However, the WV never took any initiative to establish relationships with insurance companies on behalf of nurses. Most of its statements and plans remained theoretical in nature. Moreover, the WV had no financial means to do anything different; its modest funds came from membership fees and donations.

The WV created two new institutions to realize its goals: a rest home and a preparatory training school. In 1899 , one of the aristocratic WV members made her cottage in the wooded Veluwe area available to the WV for female nurses to spend a few weeks during the summer. Initially she acted as the director of the home but stopped doing so in $1903 .{ }^{\mathrm{I} 7}$ As of I900 the WV rented "De Leemkolk", a large mansion owned by another family from its network, on a more permanent basis each summer. Creating a rest home fitted with middle-class culture at large, but it was also an indirect acknowledgment of the strenuous work conditions of nurses. Taking a rest cure or vacation to recuperate from strenuous work or overstrained nerves in a relaxing and healthy wooded area or at the seaside grew increasingly popular among the (upper) middle classes during the late nineteenth century. ${ }^{128}$ But the transition between a cure and a vacation was fluid. WV board member Lady Schorer was aware of the impact strenuous work conditions had on nurses. The Leemkolk, she noted, although maybe somewhat remote in its location, brought recovery to exhausted, weak, overstrained, and often anemic female nurses. ${ }^{22}$ The WV board felt that female mental nurses should be provided with an appropriate environment to recover from their hard work or to spend a vacation. ${ }^{130}$ Under supervision of a director, initially ten to twenty, and 
beginning around I9I0 over fifty, female nurses from various asylums spent a few weeks' vacation at the home annually.

\section{Het Wilhelminahuis (The Wilhelmina Home)}

From the outset the WV board favored the idea of a preparatory training school for mental nurses. They hoped that this would help to resolve the ongoing problem of the high turnover of asylum personnel and uplift their moral level and civilization. Psychiatrists noticed how turnover remained high among asylum nurses, and in their eyes nurses often lacked the proper moral characteristics for asylum work. Van Deventer kept emphasizing that mental nursing required a high level of refinement and a respectable, irreproachable character, which apparently were characteristics many asylum nurses were lacking. A preparatory training home would provide ample opportunity for an experienced, knowledgeable director to judge the character of the applicant female nurse and inculcate expected behaviors such as decency, punctuality, discipline, and refined manners prior to the beginning of training within the asylum. After a probationary period in the Wilhelmina Home the applicant could be placed in an asylum. The home, chairman Ruysch noted, would serve as a zedelijke zeef (moral sieve). ${ }^{\text {.3I }}$

The Wilhelmina-huis (Wilhelmina Home) opened in Amsterdam in Igor. The home was not linked to a particular asylum. Most likely the traditional example of a disciplined nursing order or an association of nursing, in which a group of nurses lived in a house while providing service to patients at homes and in hospitals, had resonated in the psychiatrists' minds when they designed the plan. The school of home economics that De Bosch Kemper had founded may also have been an inspirational example.

The Minister of Internal Affairs himself gave the address at the opening of the Wilhelmina Home. Reiterating the rhetoric on women's ethical influence, he emphasized how the sick room belonged to the women, as did the ward for the insane. Female nurses, he argued, knew the needs of the patients better than their male counterparts. ${ }^{132}$ Six to twelve pupils lived in the Wilhelmina Home at a time, usually staying for about three months, after which they were placed in an asylum for continuation of their nurse training. The student nurses received no salary, but had free board and lodging. Lady Haitsma Mulier together with Van Deventer and medical professor Tilanus formed the overseeing committee of the home. Another feature of the Wilhelmina Home was a small-scale nursing bureau, where families could request the address of a private duty nurse for mental or nervous patients. With about thirty to forty-five families using the bureau for information or mediation 
annually, this service remained a small-scale endeavor. ${ }^{\mathrm{I} 33}$

For the sake of their training the pupils were involved in housekeeping, kitchen work, and cooking. The board considered this training in home economics, similar to girls' education in general. It would properly prepare the women for ward work. To enhance the nurses' level of civilization they were occasionally taken to a concert or a museum and encouraged to read literature, and during dinner the directors' supervision was supposed to prevent the applicant nurses from gossiping by involving them in an animated conversation on general cultural topics. ${ }^{134}$

During their stay at the Wilhelmina Home, a teacher gave the pupils a repeat course in elementary education, so they could take the first part of the NVP exam. But, in contrast to nurse training in the asylums, the nurses at the Wilhelmina Home had no involvement with patients. Although it was the WV's aspiration that the Wilhelmina Home would become a preschool model of training for all asylum nurses, this never happened. ${ }^{135}$ Limited finances and a somewhat restricted design prevented the school from developing in that direction. It therefore had hardly any effect on the evolving institutional mental nurse training structure.

The actual interest in training at the Wilhelmina Home preschool was low. The sophisticated model of training did not appeal to the majority of asylum nurses who belonged to the lower middle- and working-classes. The highest number of nurses placed in asylums through the Wilhelmina Home preschool was fifty-three in I907, and after I9I0, when the preschool was extended to six months, only about twenty nurses were placed in asylums annually. In I9I3 this number decreased to a low of nine placements. The number of applicants was always about twice or three times more than the number accepted, but most of them withdrew as soon as they learned that they had to pay an entry fee of ten guilders plus about eighty guilders for a proper outfit, which was quite a sum of money for a respectable, lower middle-class family. ${ }^{136}$ Most of the applicants simply could not afford the training. Moreover, the board noticed, other work opportunities for girls in trade and industry increased, and owing to the growing number of asylums most nurses could be placed in asylum training directly, ${ }^{137}$ where they received a salary right away.

During World War I the WV institutions were in decline, but only partly because of financial difficulties and decreasing membership. The idea of a preschool based on philanthropy and character training alone turned out to be a concept that no longer fit the context. In I9I5, a profound reorganization of the Wilhelmina Home was proposed by the energetic and innovative psychiatrist Schuurmans Stekhoven, who had joined the board in I9I3. 
Stekhoven had been the director of one of the VCV asylums from I895 until I90I, when he was appointed as a state inspector. One of his major points of criticism of the school was that nurses had no exposure to patients. He felt that the Wilhelmina Home should take in some patients in order to provide nurses with practical training from the outset. He also proposed that the nursing bureau should take a more active role in providing private duty mental nursing, presumably to improve the WV's financial basis. ${ }^{1{ }^{13}}$ But economic conditions during the war were unfavorable for such a new concept. It can be assumed that the existing WV board refused to accept the new proposal. In I9I6, three of the four members resigned, including Lady Haitsma Mulier, and the Wilhelmina Home was closed the next year. ${ }^{139}$ The home continued to exist as a nursing bureau for private duty mental nursing and a home for convalescent nervous patients who could afford the fee, but the link with asylum nurse training was lost. ${ }^{\mathrm{I} 0}$

The evolution of the WV illustrates the large gap between reformers' ideals and the reality of asylum work. Many of the preschool graduates dropped out of training once they were placed in the asylum. Miss Bodel Bienfait, the Wilhelmina Home director in I9I6, framed their dropping out in moral terms ascribing it to a lack of earnestness and perseverance on the part of the nurses. ${ }^{\text {I4I }}$ In all likelihood, however, the Wilhelmina training did not fit the class background of the majority of mental nurses nor did it prepare nurses for the reality of patient care in asylums. Within the institutional structure of the asylums, mental nurse training took on quite a different meaning.

\section{Conclusions}

When psychiatrists adopted ideas from hospital medicine to establish mental nurse training, nursing had already changed profoundly. During the midnineteenth century it emerged as a socially respected occupation for middleclass women, paid and un-paid, in the context of religious revival and social reform. Public debate of women's moral role in society and the women's movement's initiatives to improve work opportunities for women provided a context in which nursing work evolved into a respected paid occupation based on the gendered image of female compassion. The civilizing role and respected reputation of respectable women experienced in the care of the sick became attractive to liberal-minded physicians who sought to reform hospitals. Increased demand for experienced nurses generated a new model of nurse training, initially established within an association of nursing, that precipitated a revolutionary change in nursing. Not only did it provide women with an avenue towards independent work in a salaried occupation, it also 
increased the supply of trained nurses. Once nurse training developed as a hospital-based program, the number of nurse graduates rapidly increased. At the same time, nurses lost much of the independent control they had once had over their work when training moved into the hierarchical, medically dominated hospital structure.

The NVP took the hospital nurse training model developed within the White Cross Association of Nursing and the Buitengast Hospital in Amsterdam as their example to initiate nursing reform within the asylums and create a system of mental nurse training that would attract a "better grade" of nurses to the asylums. Jacob van Deventer, who played a central role in the establishment of the hospital nurse training program, also had a great deal of influence on the acceptance of a similar model by the NVP. In particular, he argued that the role of trained female nurses would be crucial in creating a mental hospital, although, at the same time this was a controversial issue within the NVP. In I892, the NVP accepted a training scheme and began to hold annual exams. Women, who had an obvious role in the reform, operated within the limited space they were able to carve out. There was a large gap between the high ideals of female care and the reality of asylum work, as the limited success of the WV demonstrated. 



\section{CHAPTER IV}

\section{The Burdensome Task of Nurses}

Uw' hand, uw' zachte hand, moet zeker zijn en vast,

Door geen gebaar van die gij helpen moet, verrast.

Grijp moedig aan, maar wil 't niet overdrijven,

Doortastend moet ge zijn, maar nochtans VROUWELIJK blijven.

[Your hand, your tender hand, must be confident and firm,

Not surprised by any gesture of the person in your care.

Take up the matter bravely, but do not overact,

Vigorous you have to be, while still remaining FEMININE.]

Maria E. Beets ${ }^{1}$

Henriëtte Koffijberg, head nurse at the Veldwijk asylum, used these poetic words of her colleague Maria Beets to explain to her female pupils the behavior that was expected of them on the ward. She quoted the poem in an instruction booklet on mental nursing, which she had written for the purpose of training at Veldwijk. The booklet strongly emphasized the importance of female character traits and a respectable morality. ${ }^{2}$ It reflected the idea that disciplinary nurse training enhanced the female qualities that would bring about the cleanliness, rest, and order expected on the wards. It was most likely the first lecture book written by a female mental nurse.

Koffijberg, who was born in Amsterdam in I879, began her career as a nurse at Veldwijk in 1898 , at age nineteen. She soon became a head nurse (housemother) of a pavilion for disturbed patients, initially of a lower-class pavilion but later of one for first- and second-class patients. In I9०9 the board appointed her to direct "The Boschhoek", a new preparatory training school for female nurses at Veldwijk, which was a unique endeavor. The boundaries between nursing and other female leadership tasks were indistinct, however, and in I9I4 she succeeded her colleague Mrs. M. Th. Kassies-de Buisonjé as the housemistress of household affairs. In I9I8, she died suddenly after a short illness. ${ }^{3}$ Koffijberg was a religious, bright, and sophisticated woman with an open mind. She loved poetry and language. She was a member of the Dutch Christian Literary League and translated books she thought were inter- 
esting for nurses. Her position reflected the career opportunities for middleclass women opening up in asylum nursing. ${ }^{4}$

Koffijberg embraced the same ideology underlying the psychiatrists' ideal that with a refined attitude the nurse would be able to meet all medical expectations, both in terms of applying somatic treatments and in guiding quiet patients in work and leisure. Her booklet reflected the somatically oriented medical explanation of insanity that dominated psychiatry at the time. It gave guidelines to pupils on the care of patients on bed rest, and it provided the basic rules of hygiene, skin care and decubitus prevention, sick nursing, and administering medication. These skills were of crucial importance considering the weak physical state of many patients in Veldwijk. In I9I3, almost 60 percent of Veldwijk's patient population was diagnosed as demented. ${ }^{5}$

As important as these practical skills was the refined, compassionate morality of the nurse. Koffijberg was not alone in this opinion. Physician David Schermers of the VCV noted in the widely used nursing textbook he wrote in 1898 that nurses had to treat patients with kindness and compassion while maintaining an affectionate atmosphere and keeping a spirit of helpfulness and forbearance, always keeping in mind the patient's welfare and adapting their attitudes to the mood of the patient. ${ }^{6}$ Similarly, in the nursing textbook that medical director Van Deventer wrote in 1897 for the nurses in Meerenberg, he stated how nurses had to be empathetic to patients in order to gain their trust and guide them in the right direction. ${ }^{7}$ As nurse historian Rafferty has argued, "the perceived correlation between social class, moral rectitude and the self-control associated with "civilized" behavior condensed into a notion of "moral" training which in turn fulfilled a variety of objectives. Not only did it legitimize the gentrification of the occupation, it also provided a psycho-social theory of nursing care." ${ }^{8}$ In the absence of any explicit psychological or pedagogical theory, the notion of a civilized attitude fulfilled that role. Rafferty emphasizes in this regard the parallel at that time between the supposed child-parent, pupil-teacher, and patient-nurse relationship. They were all characterized by moral stewardship. ${ }^{9}$ However, for mental nursing the link between a civilized attitude and moral preponderance was a very general notion considering the wide variety and often trying and demanding behaviors of mentally ill patients.

Koffijberg had the instruction booklet carefully designed to teach the pupils how proper nursing required appropriate and refined manners. The book's explicit instructions reflected how most nurses still had to learn these behaviors. For example, it included statements that nurses should sit straight at the table and look at their superiors when they were spoken to. But the civilized attitude did not just pertain to manners. The book also addressed appro- 
priate morality in terms of handling and speaking to patients. Patients were to be spoken to politely and admonished firmly but with kindness. Nurses needed morality, attentiveness, calmness, and a sense of cleanliness - all characteristics of a civilized attitude - not only to appropriately attend to the appearance of patients and keep the sick room airy, light, clean, quiet, and warm, ${ }^{\text {IO }}$ but also to keep moral dominance over patients - for example, in keeping confused patients firmly in bed and in attending to the food intake of manic patients. ${ }^{\text {II }} \mathrm{A}$ civilized attitude also facilitated the involvement of patients in appropriate work and leisure activities. Such an attitude included knowledge of needlework, literature, music, games, and daily newspaper reading - all things that would help the nurses to distract patients or involve them in a conversation. ${ }^{12}$ Koffijberg emphasized how nurses should spread homeliness in the living room in the pavilions. While doing needlework or during tea, the nurse should group the patients around her.

However, Koffijberg's booklet also showed "the other side" of asylum life. The booklet's careful instruction on wrapping patients in wet sheets or blowing the whistle in the event of emergencies betrayed the fact that nurses had to deal with disruptiveness, disorder, and unpredictable behaviors or aggression, which was antithetical to the serene atmosphere of rest and calmness nurses were supposed to keep. ${ }^{13}$ Koffijberg's booklet underscores the observation of historian Ellen Dwyer in her study of two New York asylums. She argues that the task of the nurses was beset with conflicting demands of guiding and befriending patients while at the same time maintaining discipline and order. ${ }^{14}$ The booklet shows how at the time the medical and nursing leadership felt that such conflicting demands could best be resolved if the nurse had the proper level of refinement. The middle-class ideology of the domestic role of women provided the framework for such a role. Disciplined training in female skills supposedly gave the nurse the right equipment to fulfill her role and influence patients in the right direction in similar ways as the good mother did in the family.

\section{The Invisible Role of Nurses}

To understand the high ideals of the mental nursing reformers against the backdrop of the day-to-day reality of patient care, nurse historians have little evidence available to them. Nurses were most intimately involved with patients but left almost no evidence of their work behind. Sources exposing how nurses performed their tasks or in what atmosphere patient care took place are lacking. Psychiatric nurses responded to the dependency of patients created by their mental illness, but we know little about how nurses managed 

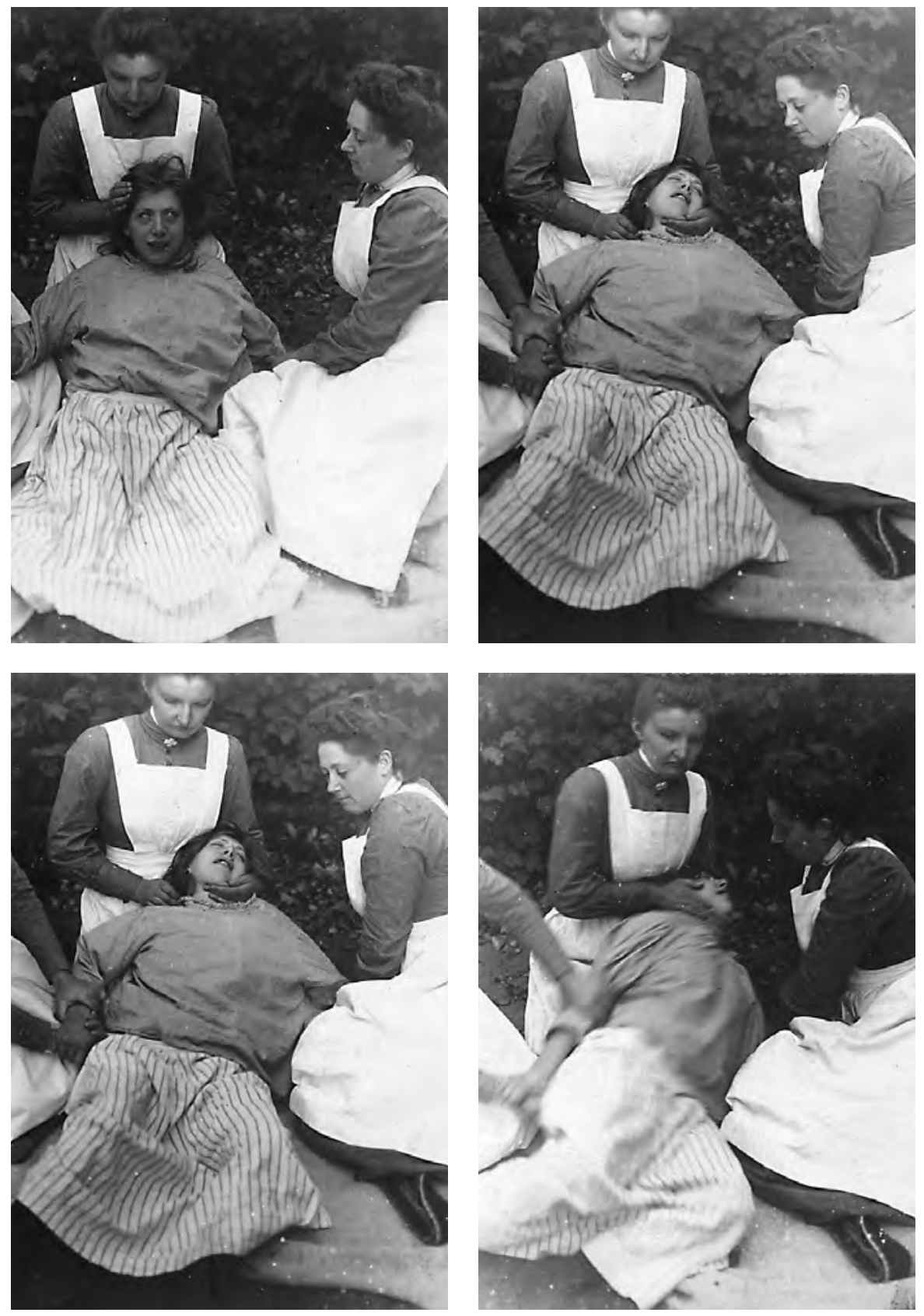

6. Three nurses attending a patient suffering an attack of hysteria, Pavilion III, Wilhelmina Gasthuis, Amsterdam, I907. 
the behavior of confused, agitated, or sick and incontinent patients. According to the medical rhetoric, nurses had to apply prescribed treatments, maintain discipline, and closely observe patients in order to be able to report patient behavior to the physician. Van Deventer explicitly stated that nurses should only report observed facts rather than opinions and be objective, not subjective. Making judgments, diagnoses, and decisions was clearly the domain of the physician; nurses lacked knowledge for those activities, Van Deventer noted, and therefore they should learn to write reports that were literal accounts of what really had happened with patients. ${ }^{15}$ Independent thinking was not encouraged within such an ideology. It rather instilled an antiintellectualism in nurses. ${ }^{16}$ Yet such rhetoric diverts attention from the continuous judgments nurses had to make. Koffijberg noted how nurses had to be prepared for unpredictable patient behavior. In situations in which controlling the behavior of others was extremely demanding, an emphasis on self-control and disciplined behavior seemed useful. Patients newly admitted to the observation pavilions, Koffijberg pointed out, required the care of at least two nurses because of potential disruptiveness or harm. Koffijberg warned nurses to remain friendly and polite in the face of patients who constantly climbed out of bed, who were annoying or fond of teasing, or who did not want to remain with the group on a walk. ${ }^{17}$ All nurses were equipped with keys and a whistle. Koffijberg explained how nurses should blow their whistle for help when a patient became aggressive. Then, with about three nurses to help, they should hold the patient down tightly to prevent kicking, beating, or biting by the patient, but not so hard that the patient was left with bruises. Using force such as pinching a patient's nose or hitting the patient with the keys was not allowed. If necessary nurses should lock the patient outside in the garden and shortly thereafter put the patient on bed rest. ${ }^{18}$

Koffijberg's instructions included a great deal of physical care of the patients, such as decubitus prevention, taking vital signs, or administering medication. She also gave instructions on treating constipation with dietary measures or purgatives, such as administering an enema. But Koffijberg noted how the latter could also be used to prevent patients from smearing their surroundings with feces, by just taking away "the material". ${ }^{19}$ The transition was easily made from using measures for reasons of physical care to applying them as a way of controlling or restraining behavior. The use of wet packs is another good example. Koffijberg's detailed description of soaking the sheets in hot water, laying them on blankets and then rolling them around the patient, who first had to be undressed, sounded like just another efficient physical procedure a nurse had to learn. The careful instruction to only use safety pins and never a rope to tie the blanket, and to apply the pack for no 
more than two hours seemed to underscore the professionalism of the procedure. But the instruction to reapply the pack after fifteen minutes if the patient was still restless revealed the measure's dual purpose. ${ }^{20}$

Sources that might reveal how these textbook ideals tallied with the day-today reality of nursing work are largely absent. A few scarce sources from the I920s and the I930s, which therefore fall outside the scope of this study, indicate that nurses initially responded with fear when they began their job. In an interview, nurse Solinger recalled how she hardly slept out of fear when she started her job as a student nurse in the asylum, which she began at age nineteen. Her bedroom was adjacent to a large sleeping ward for restless patients. However, once she overcame her initial anxiety she learned to appreciate the patients, some of whom she noted had a particular sense of humor. ${ }^{2 \mathrm{I}}$ Male nurse A. Zondag wrote a booklet on his career as a nurse in which he recalled how he felt shy and uncomfortable at first when he began his duty on an observation ward in I925. He was "overcome with trembling and fear" the first time he was in the proximity of an allegedly very dangerous patient, wrapped in a wet pack, who looked at him with "hate in his eyes" and spat in his face. Nurse Zondag was startled when he witnessed a change of that patient's wet pack for the first time. He clearly remembers the feeling of relief once the patient was packed in the sheets again. ${ }^{22}$ The initial fear and confusion of these nurses probably reflect a broader social embarrassment and uneasiness with deviancy and irrational behavior, and represents the stigma attached to working with "antisocial" patients.

\section{The Nurse as the Object and Agent of a Disciplined Asylum Routine}

Patient supervision, and with that maintaining discipline and the daily rhythm, was a major responsibility of nurses. Nurses woke the patients in the morning and helped them to get ready for meals, which they gave at set times. Nurses watched whether patients went to work on time, or whether they received their physical care and treatments as scheduled. Nurses kept the wards, beds, and materials clean and in order. Competent nursing facilitated the introduction of a medical regimen, characterized by cleanliness and order. It built on the disciplinary system of close supervision and inspection already introduced in the era of moral treatment.

Nurses themselves were subjected to a rigorous work discipline, in line with the introduction of disciplinary work habits among the working class in society at large. ${ }^{23}$ Detailed instructions prescribed nursing duties. ${ }^{24}$ When medical director Van Deventer introduced a night duty for nurses to watch patients on the new observation wards at Meerenberg, he also established the 
use of a newly obtained "control watch" that nurses had to push at set times as a means of observing whether they had taken their prescribed walks. ${ }^{25}$ Punishment, or in the worst cases dismissal, awaited nurses if they did not adhere to regulations. In Meerenberg, until Van Deventer began his directorship, a regularly used form of punishment to discipline personnel was canceling leave. In I89o female attendant Anna Kroon could not go home for leave three times because of the rude treatment of a patient, leaving the ward, and impudence towards her superior, while male attendant Maas van Drie had to stay in about twice annually, in I89o because of rudeness to a patient, in I89I because of insobriety and returning late, and in 1892 because of fights with fellow attendants. ${ }^{26}$ But even after the reorganization of personnel into a nursing hierarchy, Van Deventer regularly dismissed nurses who disobeyed regulations, although significantly these were predominantly male nurses. ${ }^{27}$

For their part, nurses subjected patients to close supervision. When a patient arrived in the asylum, a nurse usually picked the patient up from the admission room. Once on the ward, a nurse gave the patient a bath, which was a new experience for most of them. Regular bathing was not only part of the asylum routine, both for patients and nurses, but the bath on admission was also used for careful inspection and prevention. During the bath nurses examined all the bags and belongings of a patient for sharp or other "forbidden" objects with which patients could hurt themselves or others. Patients were inspected for existing wounds, bruises, or other physical abnormalities. After admission any contact between patients and the outer world was subjected to supervision. Nurses had to carefully inform the physician of any request for family contact, the sending of letters, or the exchange of belongings with other patients. ${ }^{28}$

Due to the impact of the somatic treatment model, nurses put newly admitted patients to bed on the new observation or sick wards, usually for about two weeks. Doctors subsequently decided on the transfer of patients to other wards based on their behavior, and nurses transferred patients to the quiet, semi-quiet, or disturbed wards. Sick and weak patients usually remained on the observation or sick ward. In I89340 percent of Meerenberg's patients were on the quiet wards, 20 percent were on the sick wards, and 45 percent were on the semi-quiet or disturbed wards. ${ }^{29}$

\section{Threat, Repression, and Abuse: The Division of Wards as a Control Mechanism}

The separation of space remained in existence during the time of somatic treatment. Paying patients had their separate quarters, in accordance with their social background. Voorburg and Veldwijk had special "villas" for these 
patients. Quiet paying patients read literature, listened to music, or did needlework. They went for walks regularly and were free to invite their relatives to visit. At Meerenberg paying patients had a dinner of several courses in the evening..$^{30}$ Disturbed paying patients had their own rooms for bed treatment separate from indigent patients.

Wards for indigent patients were much simpler in design and much larger. These patients could have visitors, but only if permitted. ${ }^{3 \mathrm{I}}$ The number of nurses on these wards was lower than on wards for paying patients, and patients usually had to help nurses to get the work done. The indigent patients had simple and routine meals at noon, usually one-pot meals during the week, and only on Sundays did they have meat, vegetables, and potatoes as separate dishes. These patients received uniform asylum clothes. ${ }^{32}$

The separation of space according to social class reflected class distinctions in society at large, but the division of wards into quiet, semi-quiet, and disturbed wards was useful as a control mechanism. Despite the somatic model, wards for chronic, quiet working patients remained highest in status. Transfer to these wards represented an improvement in patient behavior. Helpless, bedridden, incontinent, and disturbed patients took part in neither work nor leisure activities. The greatest stigma was attached to the semi-quiet and disturbed wards. However, semi-quiet wards were still somewhat higher in status than the disturbed wards and were particularly designed for those patients who were dependent and sometimes dirty or incontinent, but some of whom could work occasionally. ${ }^{33}$ Because of the awareness among both patients and personnel of such a hierarchy, instilling patients with fear that they would be transferred to the disturbed wards or be put in seclusion belonged to the arsenal of disciplinary methods that nurses used to enforce patient compliance. ${ }^{34}$

Patients reported use of such threats and also of physical abuse by nurses in an inquiry of state inspector W. M. van der Scheer in I9I7/I8 on patient abuse by nurses in the Reinier van Arkel and Voorburg asylums. The report stated that nurses not only threatened patients with transfer or seclusion, they also treated patients very rudely, including occasionally beating, shaking, or withholding food to enforce compliant behavior. ${ }^{35}$ The inquiry was undertaken in response to physicians' complaints about patient abuse and the supposed inadequacy of the religious nursing staff at these Roman Catholic asylums. Although the medical complaints must be seen in the context of the existing tension between physician staff and nursing orders in Voorburg due to the lack of authority doctors had over the nursing order, it is important to interpret such nursing responses and intimidation of patients carefully. 
In his analysis of life in asylums, Erving Goffman argues that social control inside the modern mental hospital was achieved through the system of wards, "graded for the degree of allowable misbehavior and the degree of discomfort and deprivation prevalent in them".$^{36}$ By improving behavior, the patient could "earn" promotion to better life conditions, Goffman argues, or the patient could be threatened with being sent back in case of misbehavior. Goffman considers the attendant to be the key staff member in a disciplinary system that was designed to manage a large group of involuntary inmates by a small staff. The attendant informed the patient of the regulations of award and punishment and arranged for medical authorization, Goffman reasons. Andrew Scull, following Goffman, underlines how a system of moral preponderance was invented in the era of moral treatment. In theory, the ward system effectively made patients aware that in many ways their treatment depended on their conduct. ${ }^{37}$

However, the analysis of Goffman and Scull suggests that the behavior of nurses was goal-oriented, based on a deliberate intention to maintain such a disciplinary system. It assumes that there was a direct, reciprocal relationship between patient behavior and nurse intervention. What remains obscure are the (social) factors that may have brought nurses to the point of using measures for instilling fear, threatening patients, or occasionally abusing patients. The way nurses behaved to patients was in many ways an effect of the asylum system at large and determined by the place nurses themselves had in the hierarchical structure. The resources available to them determined how creative they were in managing difficult patients in a humane way.

Nurses had to maintain order and discipline in an often unpredictable and disruptive environment. They developed their own informal ways to keep control over patients, ways that they had not necessarily learned in training or that had been approved by medical authority. Although nurses had little formal power in making therapeutic decisions on treatment, if they had no other resources available they could, as a control mechanism, instill fear in patients through the use of threats or other forms of punishment. However, if abusive disciplining by nurses occurred, it did not necessarily have to be a deliberate attempt to provoke compliant behavior from patients. It could as well have been an expression of excessive demands made on nursing personnel.

Historian Ellen Dwyer, in her analysis of two New York asylums, found that the harassment of patients and occasional abusive injuries were as much part of the asylum reality as dedication and considerate care. She explores the metaphor of the family to understand the interaction between patients and attendants in large asylums. Strenuous circumstances, a lack of resources, or contradictory demands could easily transform "good" attendants into "bad" 
ones, Dwyer argues. She notes that "several weeks on a ward for the noisy, incoherent, and incontinent" could easily change the dedicated attendant of less burdensome patients into an "irritable, harsh autocrat". Dwyer perceives the dual role of "loving parent and harsh patriarch" that nurses assumed as a reflection of the conflicting demands of their work: "Like parents, attendants sometimes loved, and at other times struck out at, their difficult children." ${ }^{8}$ She notes how in spite of the value doctors ascribed to the role of attendants in order to make medical therapies work, medical directors did not give much thought to the inherent contradiction in the demands they put on attendants - that is, "simultaneously to counsel and to clean, to befriend and to discipline, to follow and to lead". ${ }^{39}$

The patient abuse that occurred in Voorburg seems to illustrate this point, although in the case of Voorburg the medical complaints and the effort of state inspector Van der Scheer to point out to the College of Regents and the leadership of the nursing order that they had to hire more personnel, seemed a serious attempt to change what they considered to be an unacceptable situation..$^{\circ}$ Voorburg had the lowest nurse-patient ratio of all asylums in 1907 (I:IO); in most asylums the ratio ranged from $\mathrm{I}: 5$ to $\mathrm{I}: 8 .{ }^{4 \mathrm{I}}$ Whereas in other asylums more nurses were gradually appointed due to shortening of working hours and improvement of working conditions, in Voorburg the nursepatient ratio remained at about $\mathrm{I}: 8$ until the late I9IOs. ${ }^{42}$ In comparison, the nurse-patient ratio at Meerenberg was about I:6 in I900 and about I:5 in I9I0.43 Understaffing and long working hours in an isolated environment probably were major factors in creating the nurses' abusive behavior.

The story of Voorburg was not an isolated one. In the other asylums, too, some of the nurses were dismissed every year because of rudeness or patient abuse. ${ }^{44}$ Particularly on the wards for disturbed patients, high tension often arose between patients or between patients and personnel if one or the other supposedly did not listen, deliberately defied someone, or disobeyed the rules. Nurses, who themselves were placed under strict supervision in a hierarchy, sometimes took out their strain on the patients. An impatient nurse might treat a patient rudely, while fights occurred regularly between men.

Usually, however, cases of patient abuse remained concealed, particularly if personnel stayed loyal to one another. Only when a patient complained about abuse to a third party ${ }^{45}$ or if personnel reported on each other because of disagreement did incidents of patient abuse come into the open. As the case of Voorburg demonstrates, not only did abuse represent complex staffpatient interactions, the act of reporting was itself an intrinsic part of a wider power struggle and negotiation over domains of authority between personnel. Such dynamics were mirrored in a reported incident of patient abuse in 
Meerenberg in 1898 , when medical director Van Deventer, who was not too popular among personnel because of his authoritarian attitude, was accused of abusing patients.

The incident came into the open after a quarrel between Van Deventer and male nurse Gatsonides, the only male head nurse left after Van Deventer had initiated nursing reform. When Van Deventer wanted to dismiss him because of incompetence, Gatsonides went to the board with the accusation that Van Deventer had abused two patients. The board began an extensive investigation, interviewing various staff members, and eventually concluded that Gatsonides was right. Van Deventer turned out to have beaten a patient and tightly gripped the neck of another. According to Gatsonides a male nurse would have been fired for such behavior. The board reprimanded Van Deventer, but one of the patients also filed charges at the court in Haarlem "because of being treated rudely by the medical director". Based on the report of the board, the prosecutor decided that Van Deventer could not be "held liable for abuse". The case blew over for Van Deventer, but Gatsonides was dismissed on another occasion. ${ }^{46}$

\section{An Analysis of Patient Records}

The use of patient records as a source for historians has recently received more scholarly attention, although the interpretation of these documents must be undertaken carefully. 47 One of the expectations of the historical scrutiny of patient records is that they provide insight into the application of medical treatments and interactions between patients and care providers in the past..$^{8}$ Information on patients and patient care in this chapter is drawn from seventy patient records from the four asylums that are the focus of this study. 49

The selection of patient records is too small to be representative of the asylum population..$^{\circ}$ The aim of the record analysis is to obtain more detailed information on patient behavior as an indication of the nursing work involved in patient care and of the dilemmas which nurses faced in managing patients. More specifically, the analysis focuses on the reason for admission, the type of patient behavior demonstrated on admission and the first weeks of treatment, the treatment regimen, and the outcome of treatment. The diagnosis, the length of illness before admission, and the length of stay as an indication of the acuteness or chronic nature of patients' afflictions were also examined.

All records followed the guidelines on record keeping set by the State Inspectorate at the time..$^{5 \mathrm{I}}$ Physicians wrote the notes. They addressed the 
treatment regimen only minimally, but the records provide insights into the reason and course of admission, the patients' diagnosis and state of behavior, the level of violence involved, the progression of the illness (particularly during the first few weeks), and the further stay in the asylum, including some information on the social situation..$^{2}$ The records reflect the invisibility of nurses in the treatment regimen. Their role is rarely mentioned, usually only if a patient acted aggressively to a nurse, and on occassion the records mention that nurses had to observe a patient closely because of suicidal behavior.

The records represent a group of patients that more or less encompassed the range of cases with which nurses were usually confronted (Appendix Table A.2). They contain all diagnoses of the state inspectors' classification, ${ }^{53}$ except alcoholism, which in many cases was a related problem. The asylum physician made the diagnosis on admission, usually following the account of the referring physician, although a diagnosis was not made in all cases. Eleven records ( $\mathrm{I} 6$ percent) describe the illness in terms of its most important symptoms such as "fixed idea", "hallucinations", "persecution ideas", or "quiet, dejected and tired of life". ${ }^{54}$ In one instance the patient's diagnosis seems to be a mixture of physical and mental symptoms: "encephalitis, dementia and head trauma". 55

About one-third of the patients were male and two-thirds were female. Most women were married, and some were widowed, whereas most of the men were not married. Male patients had often worked as laborers or artisans. A few had been sick since youth and had never worked, or were out of work because of their illness. Only two were educated men, one a teacher and the other an engineer. About a quarter of the women had an occupation. Most married women had worked prior to marriage, but subsequently took care of thire family, although some still worked as shopkeepers or music teachers. Unmarried women worked as servants or shop assistants, and one as a nurse. But most helped out in the family, although many could no longer work due to their illness. The age of the patients varied widely, the youngest being thirteen and the oldest eighty-four. The majority of the patients were indigent.

About 70 percent of the patients stayed in the asylum for no longer than two years, but not all of these patients recovered. About a quarter (27 percent) died within these two years. Of all the patients, 34 percent recovered, I9 percent were discharged "not cured", which usually meant transfer to another asylum, and 47 percent died in the asylum. The records confirm the broader picture that the majority of asylum patients were chronically ill and did not leave the institution once admitted. The records indicate that families requested confinement for their relatives because they did not know how to handle their behavior any longer, could not endure their behavior anymore, 
the family feared accidents, or sometimes the care had become too great a burden..$^{56}$ The length of illness before admission shows that families lived with the affliction of their relative for a long time before they eventually sent the patient to the asylum (Appendix Table A.3). Eleven patients ( $\mathrm{I} 6$ percent) had had a sudden onset of their illness only a few weeks before admission, and nine of those recovered. But the majority ( 46 percent) had been sick for several years and would remain so. Patients who stayed in the asylum for more than ten or twenty years had been sick for most of their lives. In the latter cases patients were admitted because the family could no longer care for their relative, usually because the patient's carer had grown old or died. ${ }^{57}$

\section{Responding to Dependency}

Only rarely can sources be found that indicate whether nurses at times enjoyed taking care of mentally ill patients. But the record of a 29-year-old female idiot, whose parents had sent her to the asylum in order to be placed in family care, indicates that nurses enjoyed having her around. A month after admission, the patient was placed with two nurses who led a home for family care associated with the asylum. Nurses worked quite independently in such a home. They reported on the status of the patients to the asylum physician on a monthly basis. This patient, the nurse wrote, "is always in a good mood, tractable and obedient. She is full of jokes, so she brings conviviality to her environment, and attracts the love of everybody." ${ }^{8}$ The patient came from a self-paying family who had put her in first-class care. It is not clear why the family opted for family care. At age eight her parents had placed the patient in private care in a home for nervous patients, where she had lived for twentyone years. Perhaps she needed closer supervision than the home could provide. If she was left on her own, she scratched her face and fingers. For that reason she had worn cardboard tubes around her hands in the private home, but such measures were not used in the asylum.

The records almost never refer to the personal impact patients had on their environment, and the nurse's comment about the joy this patient offered was exceptional compared to other records. Maybe the patient's relatively favored position in first-class care contributed to a more personal approach. ${ }^{59}$ More prominent in the records was a concern whether a patient could still work, and what type of "antisocial" behaviors a patient exhibited, which reflected a preoccupation with the common social interest rather than a concern with the patient as a person. ${ }^{60}$ Nursing textbooks merely underscored such an ambivalent ideology. On the one hand, physicians Van Deventer and Schermers depicted mental patients in the nursing textbooks they wrote as poor suf- 
ferers, dependent on devoted care because they could not take care of themselves. But on the other hand, when they described the sensations, mood, thinking, and actions of the insane, they both underscored how patients were merely controlled by their biological constitution, which could incline them to the most antisocial and dangerous behaviors. ${ }^{6}{ }^{6}$

Such ideology was reflected in the record of an indigent female idiot, who had been placed in the asylum by her brother in I900 when she was fortythree years old and both her parents had died of old age. ${ }^{62}$ On admission she was alert and could speak, albeit in a stammering manner. She said that she felt fine and she seemed satisfied, the record notes, but "she mastered only a very small part of the normal female skills". Only under supervision could she do some very simple activities, and she was unable to dress herself. While in the asylum it became apparent that she was unfit for regular work, and she developed the inclination to undress herself. After ten years of asylum care her symptoms were described as "very large intellectual defect, boisterous, inclined to harass and to destroy small things". She died in I9I9 aged sixtytwo. Although little is known about the ward where this patient was placed, less personnel were available for indigent patients compared to higher-class patients. If patients could not be involved in work, nurses were probably not able to pay much them personal attention. It can be hypothesized that the woman quickly lost her initial satisfaction and developed her symptoms partly in response to her dull existence.

In the I9Ios some psychiatrists began to argue that the eventual physical and mental deterioration of patients in the mental hospital was related to a lack of personal attention and nursing care and christened the phenomenon "asylum dementia". ${ }^{63}$ Some physicians noted that the disciplinary, dull asylum routine destroyed all initiative in patients and made them into apathetic, conditioned automatons. ${ }^{64}$ The emergence of such concerns should be seen in the context of a wider debate among psychiatrists, which had never been silenced, over the low efficacy of asylum care and the ever-growing numbers of chronic patients, which defeated the objectives of the mental hospital. During the I9IOs criticism arose against the single-sided biological notion of mental illness, and some psychiatrists began to perceive certain behaviors of the mentally ill as a response to the wrong psychological and social environmental influences and experiences. From this perspective, the lack of personal attention began to be seen as a possible cause of psychiatric symptoms. ${ }^{65}$

But the implications of this opinion for the role of nurses were paid little attention. The system of nurse training that emerged within the context of the transformation from asylum to mental hospital was oriented to somatic care and the maintenance of order. The way the nurses' work was organized, pre- 
dominantly coincidental factors determined whether or not nurses would be able to pay personal attention to patients: the type of ward patients were assigned to, the number of personnel assigned to them, the strenuousness of nurses' working conditions, and the nurses' level of experience.

\section{Growing Old and Demented}

An important nursing task was the care of vulnerable, often bedridden, demented elderly patients who essentially came to receive care in the last years and often in the last months of their life. ${ }^{66}$ In I9I3, 58 percent of the patient population at Veldwijk was diagnosed as demented. Voorburg placed demented elderly either on special wards or on the wards for the semi-disturbed. In I9IO they comprised 2I percent of the population. ${ }^{67}$ Ten of the selected patients were diagnosed with dementia (senility) and seven of them died within a year of admission. They had been sick at home for much longer, usually several years. Most of them were in their seventies at the time of admission.

The behavior of demented patients was not easy for nurses to handle. Communication was difficult because of the patients' forgetfulness and confusion and, as psychiatrists observed, demented patients lost their sense of altruism and decency. ${ }^{68}$ The records report that many of the demented patients were drowsy and sleepy during the day, unable to do any work, as some physicians noted, but at night they were usually restless, anxious, and agitated, and attempted to get out of bed, tear their clothes, and make a mess of their beds. Some patients had to be isolated occasionally to prevent accidents, one record reports, or to handle the trying, agitated behavior, another record states. ${ }^{69}$

One 76 -year-old demented woman, admitted in I9Io, had been cared for at home by her daughters for fourteen years, but when her husband died in I909, and his pension stopped, the lack of family income forced the family to commit her to institutional care..$^{70}$ The record reveals that her care at home had required a great deal of "devotion and accuracy", because the woman was incontinent and had also attempted suicide several times. For the last ten years she had been bedridden, and her loss of short-term memory had made her confused and sometimes desperate.

On admission nurses bathed the woman and put her to bed. She refused to speak or eat, and responded to everything the nurses did with loud, vehement cursing. Eventually she began to eat and, after a week, to speak. She confabulated and usually gave slow one-word answers, but she remained desperate, often cursing loudly. She was occasionally incontinent and developed an ulcer, of which the nurses apparently took good care as it eventually closed. After a month the woman suddenly died of a heart attack. 
Most of the demented patients were put on bed rest. Bed treatment was used in two ways, either to care for those who became progressively drowsy and physically weak, often incontinent and helpless, ${ }^{7 \mathrm{~T}}$ or to calm down anxious patients whose physical deterioration was accompanied by agitation, loud screaming, cursing or violence. One 72-year-old patient, admitted in I920, was completely disoriented and highly anxious, and was screaming loudly. He ate very little and could only be kept in bed with considerable effort. He eventually received sedative hyoscine-morphine injections, and his status rapidly deteriorated. He grew drowsy and stopped eating, and after ten days he died..$^{72}$ Another 84-year-old demented woman, admitted in I920, had occasional fits of paranoia and confusion but, after about a year, she began to be increasingly agitated to the point where she walked around cursing all day. As a result she could "no longer be out of bed", the record notes, and was put on bed rest with sedative medication (Luminal). A few days later she developed a fever, suffered heart failure, and died within three days. ${ }^{73}$

The records of these patients remain unclear as to whether there was any negotiation between the physician and nursing personnel over medical intervention and how nurses sought solutions for handling difficult patient behavior. But it can be hypothesized that nurses sought support to find a solution for the trying behavior of patients. However, their position was weak because they were dependent on the physician for every therapeutic measure they had to take. It is likely that they called for the physician if a patient became extremely agitated. Whether the physician decided to give medication based on the report of nurses remains unclear, nor do the records indicate whether the physician or nurses perceived a dilemma in the effort to calm an exhausted, agitated patient with bed rest and medication. It can be assumed that the medication in combination with the physical exhaustion and weakness of the patient accelerated the dying process. ${ }^{74}$

Nurses took care of many dying patients, although scholars know little about how they handled such care or how much opportunity they had to spend time with dying patients. The nursing textbooks of medical director Van Deventer and VCV physician Schermers briefly addressed help with dying and the care of corpses. ${ }^{75}$ Schermers instructed nurses on the bodily care of dying patients. He noted that they needed absolute rest and a relaxed position. Nurses should quench the patient's thirst, wipe off any sweat, and take any measures that would relieve patients in their final hour. If the patient had trouble swallowing the nurse should moisten the patient's lips with a piece of cloth. ${ }^{6}$ Once the patient died, nurses would lay out the corpse. It was best to transport the corpse to the mortuary in the evening, Van Deventer noted, after the remaining patients had gone to bed. Even in the care of the dead, 
a nurse came to be the focus of order and surveillance. It was extremely important, Van Deventer emphasized, that when the family came to see the corpse a nurse was present to see that the corpse was lying properly.77

Although gradually decreasing mortality rates demonstrate that the general state of health in the asylums improved during the early twentieth century, a result to which more competent nursing of the many bedridden patients may have contributed, by I9I0 eight to nine percent of the population still died at Meerenberg and Franeker each year. At Veldwijk these numbers were considerably lower, four to five percent, which probably was related to the fact that only a third of Veldwijk's patients were indigent (Appendix Table A.4). Not all chronic patients died in the final stage of chronic mental illness. Many chronically demented, epileptic, or paranoid asylum patients caught infections and died of pneumonia or tuberculosis. The number of patients who died of tuberculosis in asylums was considerably higher than in the population at large..$^{7}$ Crowded institutions, the high number of bedridden patients, and physical weakness facilitated the spread of infectious diseases.

\section{Sick since Youth}

The affliction of chronically ill idiotic, imbecilic, and epileptic patients is described in the records as an inevitable process of deterioration. This reflected the medical notion of predetermined degeneration. ${ }^{79}$ Particularly during the late nineteenth century, psychiatrists perceived deterioration of the brain as a progressive process eventually ending up in "secondary dementia", the final stage of psychosis, in which patients simply vegetated, while they became incontinent, greedy, and essentially helpless. ${ }^{8 \circ}$ The biomedical and degenerative notions of patient behavior legitimized the treatment of patients as human beings who would inevitably end up as antisocial beings or vegetating plants.

Idiotic, imbecilic, and epileptic patients were either born with their affliction or had developed their illness at a very young age. ${ }^{81}$ In I 890 one imbecile boy was placed in the asylum at the age of thirteen. He could not speak very well and was incontinent. Most likely his father placed him in the asylum after his mother's death. ${ }^{82}$ He went to the asylum's school class for mentally retarded children and was placed in family care at twenty-seven. But this boy was an exception; most of these patients came to the asylum when they were older. Many of them added to the number of vulnerable, often bedridden, patients admitted in their last months of illness. One 37-year-old epileptic patient was admitted in $1920 .{ }^{83}$ He was lethargic, incontinent, and disoriented and had regular seizures. His aunt had taken care of him after his parents 
had died, but at the time of his admission she was seventy-seven years old and probably could not take care of him any longer. Within a month this patient died.

Not all patients agreed to their confinement. Nurses had to deal with the resistance of many patients who never accepted their placement. One imbecile man admitted in I9I5, aged fifty-nine, had always worked as a farm worker, although he was "slow, greedy, pessimistic and paranoid" ${ }^{84}$ His parents had died and he became increasingly trying, sometimes aggressive, and had threatened suicide. In the asylum he did not want to do any work, was obsessed with sexual matters, sometimes touched the female nurses indecently, and had only one thing in mind - he wanted to go back home and marry. Once he tried to get the key from one of the male nurses, and he often asked for his own clothes so that he could get out. After a year of treatment, he suddenly became bedridden, had a stroke, and died within a month.

Epileptic patients were described as hot-tempered, unpredictable, and dangerous. Supposedly, during periods of decreased consciousness, they were inclined to start fires or even kill without any memories afterwards. ${ }^{85}$ Nursing textbooks explicitly warned about the trying nature of these patients. ${ }^{86}$ Because they could injure themselves during their seizures, nurses had to watch these patients carefully, to prevent accidents and fights. Patients with regular seizures at night had special solid pillows and were placed on a ward for close observation in order to prevent suffocation..$^{87}$

The record of a 27-year-old epileptic patient, who was admitted in 1900 after the death of his mother, reflects the supposed inevitability of the degenerative process. The patient had seizures approximately every three days. ${ }^{88}$ According to his brother he had been slow, haughty, and difficult since youth. He had worked on and off as a shoemaker, but after his father's death he had developed the delusion that he was a doctor in theology. He was calm when admitted, but every now and then he became "heated", and sometimes he claimed "to be a king". During the first years of admission he was often aggressive, the record notes, picking quarrels with the male nurses and with patients, particularly when he was about to have a seizure. He received broom as medication, which diminished the seizures but did not eliminate them. Four years after admission, he was "drowsy" and "demented", but sometimes "angry" and "dangerous". Another eight years later one "could not have a conversation with him anymore", he was incontinent and treated with bed rest. By the time he died in I9I9, he had been bedridden, apathetic, and helpless for over three years. No remarks were made on the interaction with the patient except for his antisocial behavior. From a biomedical point of view more personal observations would have had no relevance. 
Patients admitted with acute mania, either as a one-off event or periodically, received similar treatment to that of chronically disturbed patients during their manic episodes. ${ }^{89}$ Fourteen cases (20 percent) had this diagnosis, including three men and eleven women. Almost all of them were treated with bed rest and sedative medication, and were put into isolation at times. These cases probably most explicitly illustrate how the new somatic treatments actually served as new forms of restraint. Cases of acute mania were known for their sudden onset and high cure rate after a relatively short period of admission. Sedation and isolation were predominantly applied to control behavior. Manic patients often arrived at the asylum in a state of total confusion. They talked rapidly and incoherently, with an unstoppable urge to move, destroy things, or tear their clothes. They often had difficulty eating or were aggressive or self-destructive because of their delusions. At home they had been restless; they had gone without sleep for several nights, or had been aggressive or suicidal. Two women developed mania after the birth of their children. ${ }^{\circ}$ Seven of the fourteen patients diagnosed with mania or manicdepression had been admitted before, some for the sixth time. Three patients, two of whom eventually died in the asylum, stayed for a considerable length of time, ${ }^{91}$ and one elderly patient died within five months, ${ }^{92}$ but all others were discharged as "cured" within a few months to about a year.

Obligatory reports on the use of restraints and seclusion tell us little about the contemporary reality of their application. ${ }^{93}$ The records do not indicate with what intention such measures were used or how nurses approached patients who were manic, trying, aggressive, or self-destructive. During the period of this study, from I 890 until I920, both the State Inspectorate reports and annual reports of asylums demonstrated a decrease in the use of restraint, particularly mechanical restraints and cells. ${ }^{94}$ Psychiatrists were proud that the new bed treatment had almost entirely replaced the use of isolation cells. ${ }^{95}$ However, no register had to be kept of the many new forms of restraint that developed within the context of somatic treatment, for example, hydrotherapeutic wrappings or "holding down" patients on bed rest. The use of medication was also not subjected to registration. This makes the extent of the use of restraint difficult to evaluate, but it is clear from the records that the new medical measures nurses applied in response to patient behavior created as many risks as previous forms of restraint and could easily end in disastrous situations.

Manic patients required close supervision by nurses, and all of the thirteen patients were placed on bed rest either on the observation ward or in isolation. 
It can be assumed that it was not easy for nurses to keep agitated patients in bed. Bed rest could only be applied successfully to very disturbed, trying, and dangerous patients with ample use of deep cribs, hydrotherapeutic wrappings, and sedative medication. Isolation and sedative medication were the most important measures used to calm these patients. Eight of them were put in isolation immediately on admission or during the course of their treatment, ${ }^{6}$ and in one other case regular hydrotherapeutic wrappings were used, or nurses occasionally subdued this patient in bed. ${ }^{97}$ Five records note the use of sedative medication, in some instances for a considerable length of time..$^{8}$ One woman who kept tearing her clothes apart had to wear a "tearing vest". 99

Occasionally the use of restraints had disastrous consequences. In I905, one 46-year-old married woman developed mania after an operation on her bowels. Although the wound healed well, after a week in the general hospital the woman became fearful, paranoid and frenzied at times, and she feared death. She had been in the hospital as a child when, after lightening had struck her, she had suffered from paresis for six months. Because her behavior could not be handled at the hospital, she was transported to the asylum. There she was put to bed with a sedative powder. In the evening she became restless, undressed herself, and overturned objects in her surroundings. In response, nurses brought her to a seclusion room. When she calmed down early in the morning, she was brought to bed again, "firmly wrapped". A few hours later "she had deteriorated", and the physician who was called in "found her dead". ${ }^{\text {100 }}$ Although the record reported "collapse" as the cause of death, reading the record definitely gives the impression that something had gone wrong with either this "wrapping" or the observation of this patient, and she may have suffered from congestion, which had been described as a risk of hydrotherapeutic wrappings. ${ }^{\text {Ior }}$

\section{The Care of Paralyzed and Handicapped Syphilis Patients}

Similarly to demented and epileptic patients, physical and mental deterioration was the inevitable characteristic of paralysis. The selected records included three cases of "dementia paralytica", or paralysis due to syphilis infection, and one patient who had encephalitis as a result of syphilis. ${ }^{\text {Io2 }}$ Although the physical cause of this disease gradually became accepted during the late nineteenth and early twentieth centuries, the disease held its strong undertone of moral degeneration and remained beset with social taboo. ${ }^{\mathrm{103}}$ The mental and physical deterioration, initially expressing itself in character change and a loss of decency, sometimes went along with increasing indifference but most often with excessive manic behavior and aggression. ${ }^{\text {104 }}$ 
One 42-year-old patient, admitted in 1890 , behaved quite typically of paralytic patients. ${ }^{105} \mathrm{He}$ had worked as a driver, had been married for fourteen years, and had always been a heavy drinker. But about eight weeks before admission he had developed ideas of grandiosity, that he was very rich and had a large herd of cows. He walked out of home, sometimes naked, and harassed other people. Eventually the police brought him to the asylum in handcuffs. He walked like a drunk, spoke with a stammer, and was extremely confused, immediately wanting to sell things. For the rest of his stay he remained confused and demented, always repeating the same stories and eventually deteriorating physically. He died after nine months. Another 43year-old patient was very well aware of his affliction, having been to the general practitioner before admission several times, but he never gave up the hope of recovery. ${ }^{106} \mathrm{He}$ grew increasingly apathetic and became incontinent. Eventually he had to be admitted because his wife was not able to care for him anymore. She seemed not to be aware of the cause of his illness, probably reflecting the social taboo that surrounded the disease. In desperation she wrote to the medical director asking whether there was any hope for her husband, because sometimes, she said, she had the feeling he seemed demented. In her letter she implored the director to treat her husband with kindness as he really could not help being incontinent, and very humbly she stressed the kindheartedness of her husband. He died about two years of after admission.

Patients with this affliction required intensive nursing, as the progressive paralysis eventually resulted in incontinence, difficulty swallowing, and physical weakness, finally leading to death. It can be assumed that the care of these patients was physically strenuous and exhausting. The work implied much lifting and shifting of patients, cleaning of beds, and long-term artificial feeding. In most cases bed treatment had to be applied because of physical weakness. However, although the state of deterioration of paralytic patients required competent nursing, psychiatrists made little reference to the care of physically weakened patients in their plea for more competent nursing. ${ }^{107}$

\section{They Wished to Be Dead: The Risk of Suicide}

Watching melancholic patients was a complex task for nurses. ${ }^{108}$ At the time of admission most melancholic patients were anxious and agitated, and often cried, walking around wringing their hands or screaming loudly. Communication with these patients was complicated. Many hardly spoke or only answered when they were asked a question. They were dejected, inclined to isolate themselves and to avoid company. The treatment of melancholic 
patients took place on the observation ward or the ward for disturbed patients. Of the twelve cases diagnosed with melancholia, one was treated with continuous bed rest and opium medication, ${ }^{109}$ while four were put on bed rest for the first few weeks and then gradually began to work. ${ }^{\text {IIO }}$ It was not clear whether bed rest was used for the other cases, but they were taken care of on the wards for restless, disturbed patients. Only one highly dejected but quiet patient was put to work right away. ${ }^{\text {III }}$ These patients usually did not sleep well at night. Often they were noisy or restless, sometimes to the point where nurses put them to bed in a single room or an isolation cell. ${ }^{\text {I2 } 2}$

The records give a detailed account of the severe desperation, fears, and deep sorrow that had overcome the melancholic patients. Some of them felt they were sinners ${ }^{\mathrm{II} 3}$ or miserable beings who had made everybody unhappy, ${ }^{\mathrm{II}}$ whereas others felt "somebody would come and get them", or "the police were looking for them" ${ }^{\text {II5 }}$ Others feared they would die of a terminal illness. ${ }^{\mathrm{II}}$ Often their fears grew to the stage where they became illusionary, thinking that their body was "empty" and "already dead", "had dead arms and legs", or was "destroyed and shrinking". ${ }^{\text {Ir }}$ Many other melancholic patients wished they were dead. ${ }^{\mathrm{I} 8} \mathrm{~T}$ The wish to be dead or hypochondriac fears made them disinterested in their bodily hygiene or careless about food intake. ${ }^{\text {II }}$ They had no appetite or they refused food completely. Nurses had to closely food intake observe and encourage patients to eat. In some cases refusal of food was counteracted by forced feeding. ${ }^{20}$

Melancholic patients remained in the institution for a relatively short time. ${ }^{\text {22I }}$ The most important reason for their admission was the threat of suicide. Of the selected records nine of the twelve melancholic patients had been admitted because of the inclination to commit suicide or an actual suicide attempt. Nurses had an important role in preventing suicide. When they put new patients in baths they had to inspect the patients' clothes and belongings for any "dangerous" objects, and they always had to be watchful, closely observe suicidal patients day and night, keep doors closed, keep dangerous objects out of reach, and never let suicidal patients out of their sight. ${ }^{122}$

Suicide in the asylum was a threat to the institution's reputation and was perceived as a failure of the management. A careful investigation usually followed after a suicide, and nurses were held responsible if a suicide occurred. Schermers explicitly warned nurses in his textbook about which times of the day nurses were most at risk of allowing suicidal patients out of their sight. At dusk, during dinner, or when changing shifts, patients could most easily take advantage of a moment of distraction. ${ }^{\mathrm{I} 23}$

Occasionally personnel were dismissed if the hanging or self-poisoning of a patient could be related to neglect or lack of supervision. ${ }^{124}$ At Veldwijk two 
patients escaped and subsequently killed themselves in 1898 . One escaped out of the garden of one of the pavilions. After the board's investigation, they decided to dismiss the married couple who headed the pavilion. An aspirant student nurse was fired when one of the patients escaped his attention and jumped from the roof. ${ }^{\mathrm{I} 25}$

But even close watching could not always prevent suicide. One patient, admitted in I895, was obsessed with illusions that she had done things wrong in the past. She believed that she had caused the death of a child of the man who had bought her family's business. She thought that there was no hope for her anymore. On admission, after her husband had left, she amenably went with the head nurse to a pavilion for first- and second-class patients. Although she mentioned that she did not exactly feel at ease with all these crazy people, she calmly went to bed at eight o'clock. When the nurse checked fifteen minutes later, she lay in bed quietly, but ten to fifteen minutes after that the nurse found the patient dead. The patient had hanged herself with a scarf on one of the bed knobs. The nurse called the head nurse, who quickly fetched the physicians, but their attempt at resuscitation remained fruitless. ${ }^{126}$ In this case the board did not feel that personnel could be held accountable for the incident.

It is significant that the annual statistics on suicide, which the asylums had to report, were always very low. A large institution such as Meerenberg (with over I,300 patients) reported five cases of suicide between I904 and I9I $6 .{ }^{127}$ Most likely these numbers not only reflect underreporting because institutions feared for their reputation, but the numbers were also kept artificially low. Patients who were on trial leave or had escaped and then committed suicide off the asylum grounds were not counted as a suicide. In Meerenberg, for example, one patient committed suicide in 1905 while on trial leave, while in I9IO at Voorburg one patient who had escaped was found dead the next morning on the railway track nearby. Both Meerenberg and Voorburg reported no suicides for those years. ${ }^{\mathrm{I} 2}$ Moreover, the increased social willingness to define suicidal behavior as an illness, typical of the nineteenth-century expanding definitions of deviant behavior as mental illness, left suicidal patients within an institutional setting that responded with as much uneasiness and ambivalence to such behavior as society at large. ${ }^{22}$ The dismissal of nurses in reaction to suicide was probably at best a reflection of that ambivalent attempt to seek control. 
Overcome by Delusions: The Risk of Refusing Food, Self-Mutilation, Violence, and Escape

Patients suffering from vecordia, paranoia, hallucinations, chronic mania, or dementia praecox, or who those were generally described as suffering from delusions or hallucinations formed the largest group among the selected cases. Nineteen patients ( 27 percent) were admitted with these diagnoses. ${ }^{130}$ Eight of them died, five recovered, and six were discharged "not cured". Half of them stayed about a year or shorter, and four for over ten years.

In these cases in particular nurses were regularly confronted with violence and aggression. Fights and abuse were a substantial part of the daily experience on wards of disturbed patients. Driven by the voices or visions of their hallucinations, or by delusionary fears of paranoia, poisoning, or persecution, these patients could become tense, anxious, extremely restless, trying, and often violent. One 35-year-old patient became increasingly nervous after several eye operations that he believed had ruined his career. He smelled chloroform everywhere he went; he traveled from hotel to hotel, always sleeping with open windows, but this failed to dissipate the smell. He finally ended up with his family, where he became suspicious that they had tried to poison him with broom. With time, his family could not handle his unrest, scolding, and unreasonable arguments anymore and arranged for his admission. ${ }^{\mathrm{I3}}$ Another patient, a young girl of fifteen, was driven into a frenzy by voices that told her to do wrong. Eventually she had almost daily outbursts of anger, kicking, and beating. At one point she forcefully tied a scarf around her neck, after which her parents requested her admission..$^{132}$

Some delusional patients completely refused food and drink, or hurt or neglected themselves in other ways. Out of desperation some smashed a window with their bare hands or mutilated themselves by other means. Mental nurses learned how to take care of wounds, and their training included first aid and the application of bandages and dressings. ${ }^{133}$ Attacks of violence could come unexpectedly. One patient, aged forty-five when admitted in I890, was always quiet, deep in thought, and never spoke to anyone. He had visionary hallucinations of angels and devils. He was involved with housekeeping, but often when he had to make the beds he ended up sleeping in them. Occasionally and unpredictably he would suddenly attack somebody. ${ }^{134}$

As with melancholic patients, the refusal of food weakened the physical condition of paranoid patients. This was the case with one patient, who was admitted in I9I0. He heard voices scolding him, and he beat nurses, behaving aggressively for over a month. He stayed on the ward for disturbed patients and often refused food. The nurses regularly force-fed him. He 
calmed down, probably due to physical exhaustion, but he also grew weaker. He was transferred to the quiet ward after three months, still refusing food. After a few weeks he began to eat but his physical weakness may have made him prone to infection. Five months after his admission he caught pneumonia and died within a week. ${ }^{135} \mathrm{~A}$ 27-year-old patient suffering from delusions of persecution was admitted after a suicide attempt. He thought he should not eat because he did not make any money. On the ward he was restless, anxious, and fearful, and he often cried. Although he began to eat eventually, he remained irritable, quiet, and sometimes trying. One and a half years after admission he died of tuberculosis. ${ }^{136}$

The treatment of these patients took place on the observation ward or the ward for disturbed patients. Bed rest was an important component of the treatment in most cases, sometimes in combination with isolation. ${ }^{\mathrm{I} 7}$ Most patients were put on bed rest for the first weeks, and then some became involved in work, but many were too restless for focused activities. If bed rest was applied because of extreme restlessness, it often took several nurses to subdue these patients. ${ }^{13^{8}}$ One 35-year-old woman who thought that God had doomed her forever was put on bed rest. Anxiously she frequently left her bed and eventually received hydrotherapeutic wrappings to calm her down. ${ }^{139}$ She also had difficulty eating because she thought that she had pins in her throat and that her food was poisoned. Only after a few days did she begin to eat, but she remained emotionally labile. The fifteen-year-old girl mentioned above was treated with occasional isolation, and she was given cold showers for frenzied screaming. After three months of treatment she was placed in family care..$^{140}$

These cases reflect how nurses' work was risky and perilous at times. For safety reasons the windows, doors, and furniture on wards for disturbed patients were of solid construction, designed to prevent destruction, violence, suicide, and escape. But aggression could not always be prevented, and nurses remained at risk of violence. They regularly became victims of smacking, punching, or kicking, and occasionally their hair was pulled. ${ }^{\mathrm{II}}$ At one point a patient at Meerenberg knocked three teeth out of a male nurse's mouth. ${ }^{\mathrm{I}{ }^{2}}$ One patient at Veldwijk smacked one of the house fathers with a piece of lead pipe. The board of Veldwijk felt relieved when the house father found another job as the steward of an orphanage, since he suffered from steady headaches and nervousness because of the accident. ${ }^{\mathrm{I} 3} \mathrm{~A}$ female nurse had to stay at home, incapacitated for months, after a patient hit her on the head with a chair. ${ }^{144} \mathrm{~A}$ very sad accident occurred at Veldwijk when an otherwise quiet patient impulsively attacked a house father who came to pick up the patient from the carpentry workshop. The patient stabbed the father in the chest with a chisel, and he died several days later in the hospital. ${ }^{145}$ 
Escape was another supposedly dangerous type of behavior that nurses were to try to prevent. One paranoid patient who had developed feelings of persecution after a family fight and eventually became violent against his family members was admitted after a suicide attempt. On the ward he was very anxious, would not stay in bed, and refused food. Although he gradually adjusted, the record states that at times "he suddenly wanted to escape again and again". ${ }^{146}$ Another demented, paranoid patient, often restless at night and avoiding contact with others, made several attempts to escape. ${ }^{\mathrm{I} 77}$ In his textbook Schermers warned nurses that some patients had a continuous "urge" to escape. Better than doors or fences, he recorded, the "watchful eye of the nurse" could prevent such an "unpleasant event". Escape demonstrated inadequate supervision, he argued, and it encouraged other patients to do the same. Moreover, it threatened the asylum's reputation, alarming families and the public in general, and it was often fatal to patients. ${ }^{1{ }^{18}}$ If patients did escape, nurses had to go out and look for them. Occasionally they faced consequences if one of their patients escaped. Male nurse Beimer from Veldwijk recalled how he had been fined more than a week's salary when one of his patients escaped.

Like suicide, escape had to be registered by law and reported to the State Inspectorate. Cautious about their reputations, asylum boards tried to keep the reported numbers of escaped patients as low as possible. The board of Veldwijk, for instance, decided in 1893 that patients who had escaped but returned to the institution within twenty-four hours did not have to be reported. As a result there were no escapes in that year. ${ }^{\mathrm{I} 49}$ Because of their asylum clothes escaped indigent patients were easily recognized by the public, and most of them were found within a day. ${ }^{150}$ Sometimes escape ended in suicide, ${ }^{\mathrm{ISI}}$ but most escaped patients fled home to their families. Some were quite creative in surviving and ridiculed the framing of escape as proof of antisocial "urges" or deviant behavior. In fact, considering the outcome of some escapes, they sometimes proved patients' strengths rather than their weaknesses or supposedly sick inclinations. One patient safely walked over a hundred miles home, overcoming both hunger and cold. Another patient turned out to do so well at home that the family requested he stay there. He recovered and was able to provide for the family as before. ${ }^{152}$

\section{Nervous Afflictions and Brain Trauma: Rare Cases in the Turn-of-the-Century Asylum}

Patients with nervous afflictions usually came from the middle- or upperclasses and attempted to avoid the stigma associated with admission to an 
asylum for which a certification of madness was required. Psychiatrists supported the idea that these patients could be better treated, just like physically ill patients, in facilities for voluntary treatment. ${ }^{53} \mathrm{As}$ a result several sanatoria and private homes for the voluntary treatment of nervous patients emerged during the late nineteenth and early twentieth centuries. In part these separate facilities contributed to the stigma attached to asylums as institutions for involuntary treatment. In response, in I9I5, the state inspectors suggested that a change of the insanity law of 1904 , which had facilitated voluntary treatment in university clinics, should also be applied to asylums. Thereafter asylums began to request state approval to use certain "designated wards" for voluntary treatment, and admission of nervous patients within asylums gradually increased. ${ }^{154}$

Until that time nervous patients had hardly ever been treated in the asylums. ${ }^{155}$ The two cases of patients diagnosed with insania neurotica or insania neurasthenica included in the selected records seem to confirm this situation. ${ }^{156}$ These patients did not receive treatment typical for nervous patients, such as bed rest, baths, or dietary and electric treatment, but were admitted because of their out-of-control behavior, which families could not handle anymore. One 48-year-old male patient, admitted for the second time at the request of his wife, was diagnosed as hysteria neurasthenia with an intermittent "urge to drink". Although detailed information on treatment during the second admission is missing from the record, it can be assumed that the drinking problem was as important a reason for admission as any nervous complaints. ${ }^{157}$ In the other case a 23-year-old female patient was not admitted to the asylum until after her behavior had gone out of control. She had a history of nervous complaints such as stomach pains and slow digestion, and felt unhappy and homesick in her position as a schoolteacher, but only during the last months prior to admission did the patient develop manic behavior. At home she had occasional attacks of frenzy and aggression, tore her clothes and bed linen, and eventually threatened suicide. At that point the family decided to admit her. ${ }^{158}$ In these cases nurses faced the same behaviors as in the treatment of other manic patients and probably responded in similar ways.

One last record that did not fit any category probably illustrates the erratic nature of psychiatric afflictions and the often unforeseeable effect of asylum treatment. This patient's history of nervous and behavioral symptoms and subsequent treatment seemed quite extraordinary, although nurses probably did not notice any abnormal behavior in this patient. At the age of twentythree, the patient had been treated at an out-patient clinic for nervous disease after he began to suffer from seizures. ${ }^{159}$ It was found that his scalp had been 
damaged during a trauma at age three, as a result of which his "character had degenerated". The physician related the patient's history of deviant behavior such as stealing and desertion from military service to the trauma. After a successful brain operation in I9I7, during which splinters from the skull were found and removed from the brain tissue, the patient's deviant behavior initially continued and in I9I9 he was admitted to the asylum. But once admitted, the patient turned out to be highly cooperative, and neither seizures nor abnormal behavior were ever observed. He became a dedicated working patient who eventually was placed in family care and six months thereafter was discharged "cured".

\section{Conclusion}

The stories about mentally ill patients obtained from the patient records illuminate the reality of patient behaviors that mental nurses faced. Although the records remain silent about the experiences of nurses, their interaction with patients, and the negotiations that went on between nurses, patients, and doctors, it is clear from the records that nurses' tasks were strenuous and complex. They had to respond to out-of-control patient behavior with treatments that were predominantly somatically oriented but also served as measures of restraint. Bed rest, wet packs, isolation, forced feeding, and administering medication often involved force, if not violence. Nurses had to maintain the rhythm of asylum life in the midst of an often unpredictable and disruptive reality. Within the biomedically oriented model, nurses had to be competent and adhere to a general humane attitude, but their interaction with patients was intended to be predominantly oriented toward controlling antisocial patient behaviors. Nurses, for their part, lived in a strict hierarchy that created its own tensions. Asylum boards held nurses accountable for close observation and keeping patients safe. The suicide or escape of patients, accidents, or rudeness could end up in the dismissal of nurses. Patient records reflect the invisible role of nurses as agents of order and discipline. 


\section{CHAPTER V}

\section{Negotiating Class and Culture}

An analysis of the introduction of mental nursing in asylums reveals the inherent class and gender contradictions of the training ideals. Training provided a metaphor for negotiating a new hierarchical structure, which facilitated the creation of a disciplined, respectable lower middle- and working-class nursing workforce, a process quite similar to changes simultaneously occurring in industry, such as the adherence to regular work routines and stricter time schedules. The process forged new gendered work relationships and new understandings of care shaped according to the cultural and religious context of the various groups involved. Female compassion and a civilized attitude were the antidote to supposed unruly behaviors such as theft, drunkenness, and disobedience among personnel, behaviors generally associated with lower-class morality but considered incompatible with the new somatic routines. Complaints about such lower-class behaviors were not new and had been expressed in similar terms during the era of moral treatment. However, nurse training provided a structure and language through which a definite break with the past could be made. In a manner typical of Dutch culture, this process resulted in a training pattern that differed between the various "pillars" yet adapted to similar social and medical changes. A detailed look at the training system reveals the characteristics and behaviors the "new nurse" was supposed to embrace within the asylum. The domestic ideology fit perfectly the re-creation of a "mistress-servant" relationship within a nurse training hierarchy of head nurse and student nurse. As nurse historian Rafferty identifies, the rhetorical call for "civilization" represented the new values and attributes desirable within a new scientific medical order: enlightenment, rationality, science, Christian purity, innocence, virtue, youth, freshness, gentleness, hygiene, sobriety, gentility, and intelligent obedience. ${ }^{2}$

\section{A Gendered Structure}

Women played a crucial role in creating the hierarchy and norms of women's work in which nurses were socialized within asylums. The evolution of the Dutch mental nurse training structure furthers Martha Vicinus' argument for British nursing that hospital nurses did not create real communities of 
women that were run and financed by women, as schools, colleges, and settlement houses often were. Complicated struggles with doctors and the traditional structure of nursing, Vicinus argues, prevented nurses from controlling their own situation. ${ }^{3}$ Rather, in the hierarchal hospital organization nurses lost much of the relative independence that they had gained in earlier associations of nurses. In the asylums, female nurses obtained leadership positions over day-to-day care, but always under the paternalistic supervision of doctors.

The inherent purpose of the training structure of transforming the lowerclass morality and behavior of asylum workers and attracting a "new nurse" presented itself most saliently in Van Deventer's ambitious reorganization of personnel in Meerenberg. On his appointment as medical director in I892, he immediately set to work reorganizing the asylum's attendant staff. At that time Meerenberg housed I,300 patients and about 270 personnel: six physicians; thirty-three officers, including a book keeper, the steward and matron, and various overseers; 135 attendants responsible for patients; 75 artisans, who also oversaw patients working with them in workshops, laundry, kitchen work, or gardening; and 32 servants in housekeeping and kitchen work managing day-to-day care. ${ }^{4}$ At the time of Van Deventer's arrival, dissatisfaction among physicians had increased to the point where they had just sent a letter to the board outlining a number of complaints, such as the delapidated condition of the building, the lack of work opportunities for patients, and the poor work conditions for personnel, including themselves. The physicians requested better training and research opportunities, more freedom to prescribe treatments, and better salaries and housing. ${ }^{5}$ Such an occurrence had never happened before. Their initiative reflected the physicians' growing medical self-consciousness and increasing professional awareness. Using the upheaval to his advantage, Van Deventer immediately backed the physicians' request; he presented a list of necessary repairs and improvements to the board, which was apparently convincing as repair work began in I893.

From I893, Van Deventer continued lecturing on psychiatry in Meerenberg. It is likely that the asylum physicians profited from the seminars since very little psychiatric education was available. A year later, the board approved the replacement of the old mortuary for research in pathology by a new, more spacious one. The youngest physician, responsible for dissection, and some of his colleagues performed extensive post-mortem examinations. They published at length on their research in brain pathology and developed new methods for preparing microscopic specimens. ${ }^{6}$ The professional ambitions of the physicians underscored the scientific context, which prompted Van Deventer in 1892 to request the reorganization of the attendant staff. ${ }^{7}$ 
Van Deventer reformed Meerenberg in a similar way to the Buitengast Hospital. He appointed trained nurses in positions that opened up when regular attendants left. Moreover, he transformed the attendant staff, both male and female, into a nursing hierarchy of male and female student nurses, nurses, first nurses (who oversaw one ward) and head nurses (who oversaw a department consisting of several wards). They all fell directly under the authority of the physicians. Artisans and housekeeping personnel still reported to the steward and matron. In terms of salaries, the operation would not be too costly, Van Deventer assured the board, because a sliding scale of annual salaries would not differ much from the traditional attendant salaries. ${ }^{8}$

The reorganization separated the new nursing staff from the traditional attendant staff. Nurses now came directly under medical authority. Furthermore, in perhaps the most revolutionary change, he attracted middle-class graduates from the Buitengast Hospital training program to fill the new head nurse positions, thus replacing traditional attendant-supervisors, in each of the six departments and the pavilion. The first female White Cross graduate to be appointed was Miss J. C. Roucan. She was placed on the wards for upperclass male patients. ${ }^{9}$ Never before had a female nurse been put to work on male wards. A few of the traditional supervisors who Van Deventer considered capable continued as new head nurses, but all the others left. By I9०0, female graduates filled all head nurse positions..$^{\circ}$

Van Deventer believed that trained nurses would spread the right morality and refinement, while being strictly subordinate to the physicians in charge of the various wards. This change made the physician the main authority in each department. Since the physicians had also begun to teach the nurses in the theoretical training course, the physicians had considerably increased their control over personnel. Other asylums eventually followed the same gendered pattern, albeit more hesitantly and driven by economic forces above all else. Physicians in particular pushed for such changes. In Franeker, the state inspectors pressured the board for changes. During the late i 890 os they supported Franeker's medical director, J. de Vries, in persuading the board to attract some trained nurses and establish a new, more appropriate sick ward, and "observation room" where patients could be watched and put on bed rest. ${ }^{\text {II }}$ The inspectors even sent a list of possible candidates the board could hire. ${ }^{\mathrm{I2}}$ The appointment in $\mathrm{I} 897$ of a new second physician, A. H. Oort, may have expedited decisions. Oort had a particular clinical interest in mental illness and apparently he had aspirations of a further career. ${ }^{13}$ In 1902 he left for a position at a prestigious new sanatorium for nervous patients connected with the University of Leiden. ${ }^{\mathrm{I}}$

Financial considerations, always an issue in Franeker, made the board hes- 
itant to shift towards nurse training. A trained nurse cost almost twice as much as a servant. ${ }^{15}$ But in 1898 the board appointed two trained nurses, one for the male and one for the female department. ${ }^{16}$ Simultaneously, it submitted a formal request to the government to change one of the wards into an observation quarter. ${ }^{17}$ Baukje van Zuylen, a reasonably experienced female trained nurse from the asylum in Delft, filled the position in the female department. She had recently passed the NVP exam in $1897 .{ }^{18}$ Van Zuylen, born in Leeuwarden in I866, was thirty-one years old when she came to Franeker. Before her work and mental nurse training in Delft, she had been a female attendant in the Meerenberg asylum for two years from I888 to I890. ${ }^{\text {I9 }}$ She remained in Franeker for eleven years until I908, when she became severely ill and resigned on the advice of the medical director. ${ }^{20}$ Significantly, the board first opted for a trained male nurse, P. N. Bras, for the male department. His co-attendants did not seem to accept his more exclusive position, and he left within a year. ${ }^{2 \mathrm{~A}} \mathrm{~A}$ year later, a female graduate nurse from the Delft asylum, Cornelia Wesselman, was selected for the male department. Most likely Van Zuylen and Wesselman knew each other from Delft;

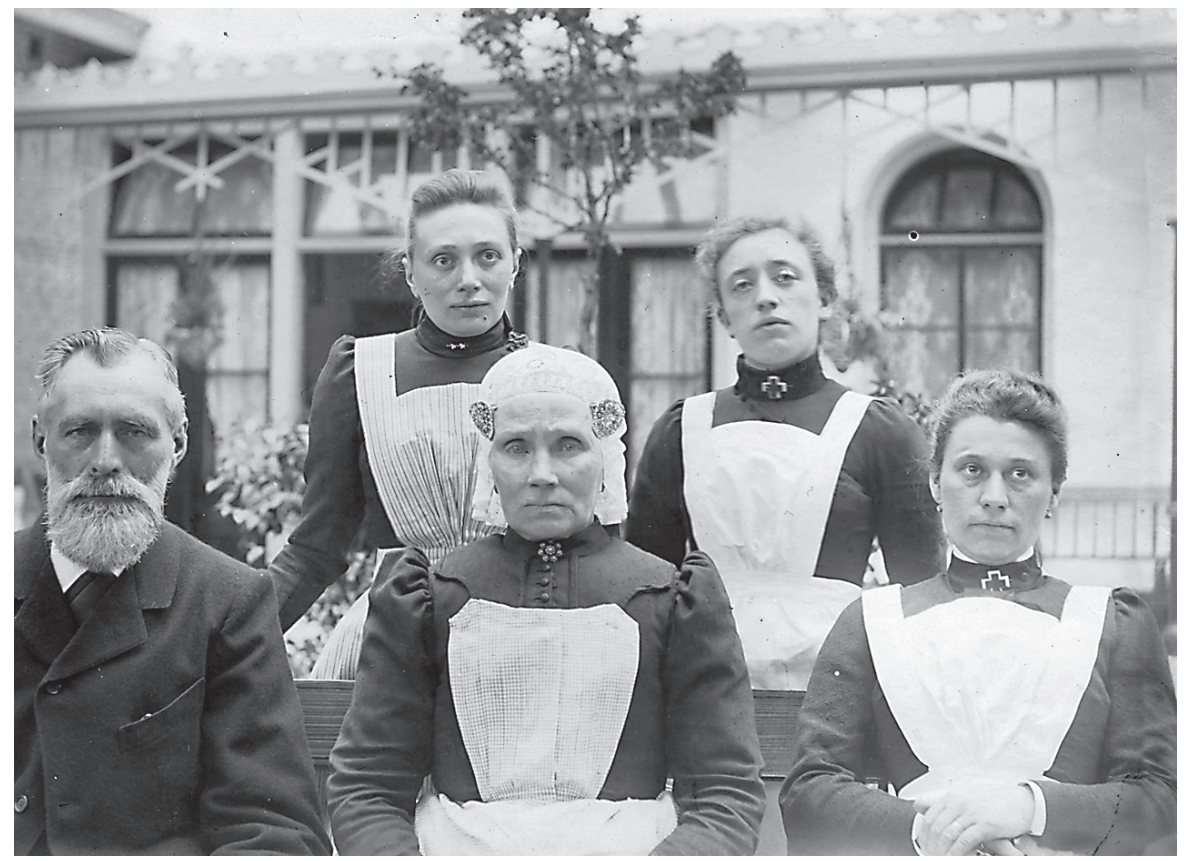

7. Father and mother Vos, the steward and matron of the Franeker Asylum, their daughter, and the head nurses of the male and female departments, Franeker Asylum, ca. I9०o. 
they had both taken the NVP exam in $1897 .{ }^{22}$ After a year of absence in I903, Wesselman stayed in Franeker for almost twenty years. ${ }^{23}$

By the end of 1900 , the board had hired five young women from respectable middle-class families as student nurses. ${ }^{24}$ Within the next decade a nursing hierarchy developed, including two head nurses, assistant head nurses, and staff and student nurses. The assistant head nurses were soon selected from the asylum's own graduates. By I9I0, when it had become more and more difficult to attract male nurses, female nurses also filled staff positions on the male sick ward. ${ }^{25}$ Despite most asylum boards' hesitance in appointing women on male wards, mental nurse training facilitated gendering of the traditional division of labor in all asylums. ${ }^{26}$

In Meerenberg, Van Deventer strategically put his wife, Antonia Stelling, in charge of the supervision of nursing personnel. In this informal position as deputy director, Stelling had major influence on the reorganization of the nursing staff. In the Buitengast Hospital, Stelling had informally served as matron, while Reynvaan was in charge as deputy director. Stelling now may have aspired to such leadership herself. Significantly, she joined one of the first groups of candidates from Meerenberg for the NVP exam and graduated as a mental nurse in $1893 .{ }^{27}$ Her informal leadership fitted the pattern of middle-class women engaged in social reform in a complementary role to men. She enhanced Van Deventer's authority over personnel considerably.

Stelling played a major role in structuring mental nurse training according to women's work and education for girls. ${ }^{28}$ The conflicting notion of a higher female calling and the lower prestige of nursing as a less valued domestic task was mediated through the training rhetoric. Nurse training gave nursing work a promise of higher status and prestige. ${ }^{29}$ According to the rhetoric, a good understanding of housekeeping duties would equip nurses with proper moral characteristics. Based on this idea, the work in the asylum's female workshops was included in the nursing domain. The seamstresses and the laundry maids all became nurses. Moreover, the inclusion of menial duties in the nursing domain legitimized the incorporation of home economics in nurse training.

Interestingly, in this way Stelling restructured domestic tasks that were traditionally part of the asylum economy into a new mental nurse training system. Previously these had been the tasks of attendants, and one could argue that in this way nursing was in many ways a replacement of former servant work. However, Stelling did more than just that. Very much influenced by middle-class domestic ideology, she organized the training into a female hierarchy of supervision in such a way that, theoretically, Meerenberg's new female student nurses first came for some time in apprenticeship in the sister 


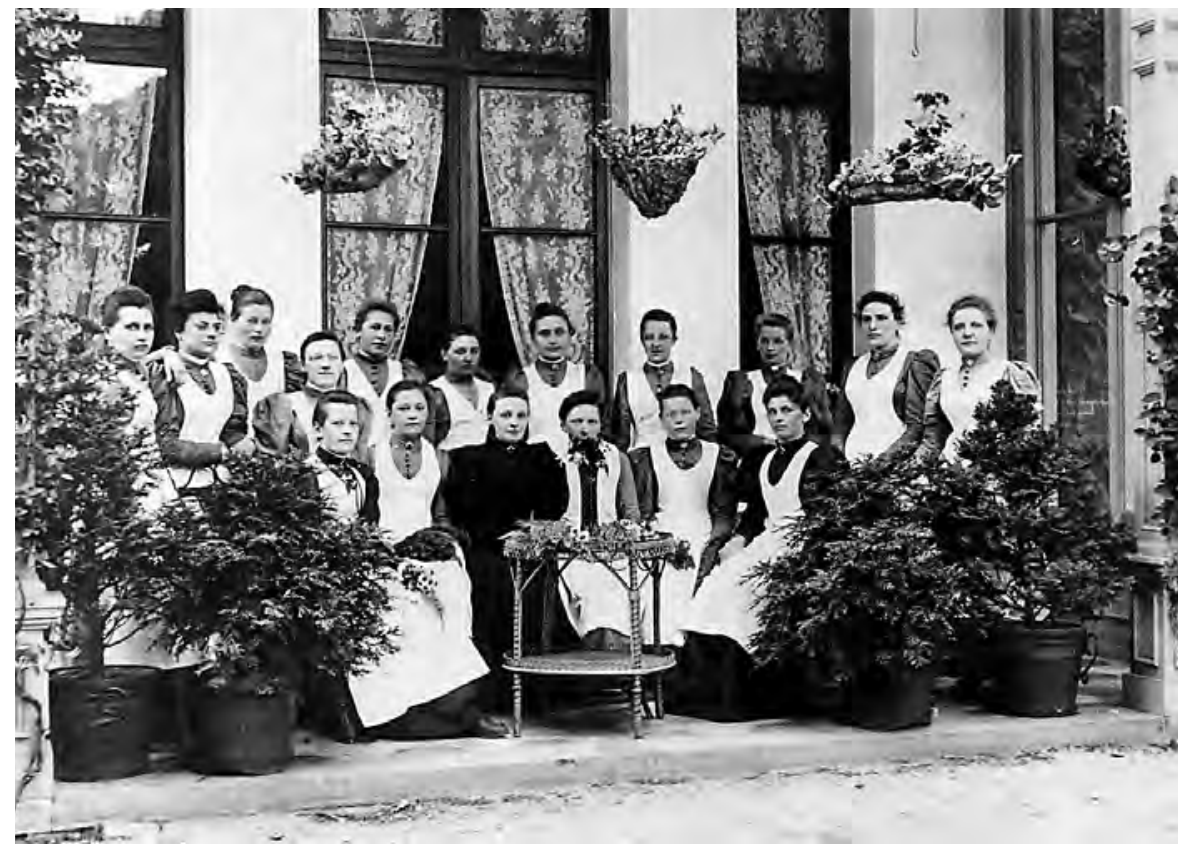

8. Early graduating class of the mental nurse training course at the Meerenberg Asylum, ca. I893. Antonia Wilhelmina Stelling, van Deventer's wife, is seated in the center in dark clothing.

house, which included a sick ward for nurses, and in the female workshops prior to starting work on the wards. They could learn domestic work, sewing, and cleaning according to the principles of home economics under the supervision of a head nurse. In this training they were supposed to obtain the discipline, punctuality, and obedience that would prepare them for work on the wards..$^{\circ}$ On the wards, the training continued under strict female supervision in a hierarchy with female head nurses at the top, which allegedly enhanced the development of cleanliness, punctuality, and subordination, as well as female domestic skills and a refined character. Importantly, as Abel-Smith has argued for British hospitals, the newly trained nurses spread the values and opinions of their own class. ${ }^{3 \mathrm{I}}$ The initial head nurses Van Deventer hired were White Cross graduates from the Buitengast Hospital, where he had previously been director. By placing them at the top of the new mental nurse training hierarchy, while Stelling herself served as the (informal) director of these nurses, she created a new structure in which the new student nurses could easily be disciplined in a new middle-class morality. The hierarchy thus 
created reflected a mistress-servant relationship: head nurses transmitted values of discipline, punctuality, and obedience to the lower middle- and working-class girls who eventually filled the ranks as student nurses.

It is likely that the school of home economics founded by De Bosch Kemper was an inspiring example to Van Deventer and Stelling when they reorganized the personnel in Meerenberg. Such a model, in which learning and working were not strictly separated, could easily be applied to the asylum. However, the gap between asylum life and the middle-class home ideal of the home economics school was considerable. Not only was the asylum much larger in design, the work was of a completely different nature as analysis of the patient records revealed.

\section{A New Discipline and Morale}

The new hierarchical training structure and regular hours of instruction aimed to increase the level of sophistication of the nurses and to instill in them a more refined morality while adjusting them to a new medical discipline. But the new morale was not restricted to course work and instruction. Both training and profound changes in the work and living situation subjected nurses to a whole new set of norms, which were intended to accentuate a civilized attitude appropriate to the new medical discipline. Strict supervision, a new appearance, and a rearrangement of living conditions ensured a distinction between the new nurses and the servant staff. A new dress code, disciplined work habits, a clearer distinction between nurses and patients, and an emphasis on self-control served to transform the supposed lowerclass morality into identification with a middle-class work ethos and the internalization of presumed civilized values such as punctuality, cleanliness, industriousness, self-discipline, responsibility, and devotion. Rules were enforced through supervision and consequences, or at worst, dismissal.

A uniform was part of the new regulations for student nurses at Meerenberg. Once they were accepted, the pupils had to buy a uniform that gave them a respectable, clean, and disciplined outlook, usually by means of installments withheld from their salary. Women wore a white apron over a blue dress. There were slight differences in color: blue for the students and the nurses, dark blue for the first nurse, and black for the head nurse. The uniform symbolized the hierarchical structure and enhanced discipline. Men wore black pants and a gray jacket. All had a student badge. To emphasize their respectability, they were not called by their first names, but addressed as "sister" or "brother".32

Architectural and social adjustments represented the new status of the 


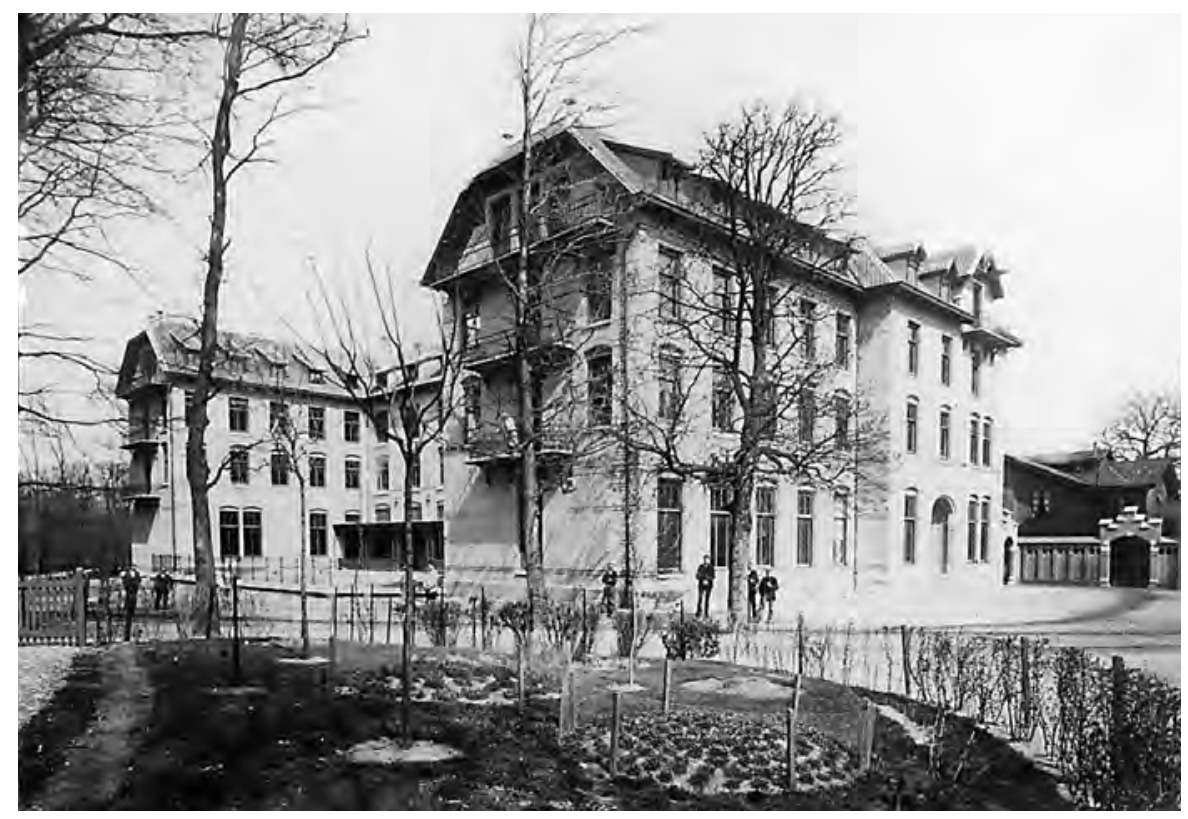

9. The Meerenberg nurses home for female mental nurses, Meerenberg Asylum, I904

nurses. Living in was obligatory for nurses. Traditionally, attendants had shared their lives with patients and slept on the same wards. In Meerenberg, Van Deventer considered this situation to be inappropriate for the new female nurses. They obtained sleeping quarters separate from those of the patients, to provide them with proper rest and leisure. In 1898 , a prestigious nurses home for female nurses was created. It illustrated the new status and prestige of the female nurse within Meerenberg. ${ }^{33}$ Significantly, Van Deventer considered such measures unnecessary for male nurses; their sleeping quarters remained on the same wards as the patients' quarters. In I904, Van Deventer's successor, Van Walsum, created a male nurses home for single male nurses. ${ }^{34}$ Similarly, the new middle-class nurses in Franeker no longer slept on the patients' wards and were eventually given their own conversation room. ${ }^{35}$

Strictly regulated working hours with set break and mealtimes reinforced discipline. A regular working day from 7:00 a.m to 9:00 p.m. had two halfhour breaks for breakfast and supper, and a one-hour break at noon for dinner. Nurses had to be punctual, and to leave the wards or the grounds, they had to request permission from the head nurse. After work, two hours of leisure remained, and the lights had to be switched off at eleven o'clock. The hierarchical system facilitated the enforcement of such regulations, and the 
neglect of duties, being late, or leaving without permission could result in dismissal. ${ }^{6}$ The supervision of the new night schedule entailed special measures. Nurses had to rotate in night shifts. To make sure nurses stayed awake, Van Deventer bought special watches that had to be checked at regular times. Similarly, night nurses had to mark several "check books" on their rounds, which were placed at specific "stations". This measure forced nurses to actually make the rounds because missing marks were treated as misconduct. ${ }^{37}$ The work routine in the new observation room in Franeker also included steady night care duties..$^{8}$ One attendant in the male department and a nurse in the female department had to closely watch the patients in the observation quarter at night, while another attendant made rounds through the asylum.

New habits had to support refined manners and a disciplined character. In Meerenberg, student nurses had to have dinner separately from the servants under the supervision of new table nurses in new diningrooms both in the male and female departments. The food improved. Nurses now ate the same food as third-class rather than indigent patients. 39

The subjection to discipline and training supposedly made the nurses better educated and thus more civilized beings, who could in turn spread the right morality and order in the asylum. Medical training, which, for example in Veldwijk, went along with religious training, served the dual purpose of instilling knowledge and higher values. It would bring devotion, sympathy, and much needed self-control to patient care. A case in point was the dismissal of one of the housemothers in Veldwijk. Mother van der Heyden served as a head nurse at several pavilions in Veldwijk in the early i89os. She not only turned out to be verbally abusive to patients, but also treated the staff nurses in a way "a respectable lady would never treat her servants" medical director Van Dale noted. Because of her scolding, hot-tempered nature and inappropriate leadership, she was eventually fired in $1895^{40}$

New cultural and leisure clubs for nurses, such as a theater club and a music band in Meerenberg, or a club for boys and girls, a music band, and a choir in Veldwijk, cultivated a more sophisticated character among personnel. ${ }^{4}$ Veldwijk's director Van Dale strongly encouraged personnel who had aspirations to engage in cultural activities such as organ lessons or a foreign language course in order to provide themselves with some distraction. Moreover, these clubs provided nurses and patients alike with entertainment so that asylum life would look more attractive. Clubs usually gave an annual performance, and the asylum band gave regular concerts to patients. The personnel's social life remained bound to the asylum and was subject to supervision and discipline. The leisure activities were strictly separated by gender and nurses were not allowed to socialize with those of the opposite sex. Sufficient 
leisure time and the opportunity to relax was part of the measures used to make asylum work more suitable for female middle-class nurses. The new regulations in Meerenberg included a fortnight of vacation and one day off every other week. ${ }^{42}$

As a result of the increase in free time, night shifts, and more labor-intensive somatic treatments, the total number of nurses in Meerenberg grew by 48 percent, from 133 to 198 , between 1892 and $1898 .{ }^{43}$ Soon female nurses formed the majority. By I 898 female nurses formed 75 percent of the nursing workforce. The sister house had a central role in the enhancement of the women's discipline and proper conduct. It placed female nurses under the continuous supervision of the head nurse of the nurses home. During offduty hours the nurses stayed in the nurses home, and they also went there for their meals. The head nurse carefully enforced appropriate behavior during their off-duty hours. She also oversaw the nurses home's ward for sick nurses. ${ }^{44}$ New student nurses usually started work in the sister house. The head nurse made them familiar with the work routine and taught them basic domestic skills.

In Meerenberg, the nurses' salaries did not differ much from those of the servants. Student nurses earned even less. ${ }^{45}$ By I9I0, the hierarchy of student nurse to head nurse was expanded by one rank through the creation of the position of applicant-student nurse..$^{46}$ The social position of the candidate student nurses, as expressed by their wages, was lower than that of a servant. Whereas a servant would earn 150 guilders, a candidate student nurse would receive Ioo guilders a year. ${ }^{47}$ Despite their new outlook and new work routine, neither the (candidate) student nurses' duties nor their subservient position differed much from the work hitherto regarded as servant work. ${ }^{4}$ This may explain the low efficacy of the new measures. The improvements had not lowered turnover rates. In I900, turnover was still 9I percent per year. ${ }^{49}$ With the economy expanding it remained difficult to attract a sufficient number of competent personnel.

\section{Culture Shock}

The rapid changes Van Deventer implemented came as a culture shock to the organization. The board almost immediately felt that their traditional authority had been threatened. The unrest the changes caused among the asylum attendants was demonstrated in very high turnover rates: 134 percent in 1893 and 96 percent in 1894 . They had never been so high, Van Deventer noted. $5^{\circ}$ Soon Van Deventer, who in his previous position had proven to be an extremely authoritarian personality,,$^{5 \mathrm{I}}$ came into conflict with the board over his rigor- 
ous plans for reorganization. In particular, his argument that the steward should report to him rather than to the board, which fitted with his belief in medical authority over the organization, was not received well. The board may also have feared the financial implications. In response, the board convinced the Provincial Council to formally split the management of the asylum into a department for administration and one for medical and internal affairs. The medical director would be in charge of the latter, whereas a financial manager would head the former, reporting directly to the board. $5^{2}$

Van Deventer's ideal of a professional organization with more rationalized working relationships was quite different to the traditional organization with which the board was probably still satisfied. In the traditional household-like organization of the moral treatment era, the physician had a much more managerial role, predominantly relying on his moral authority, as did the board. ${ }^{53}$ But in Van Deventer's opinion the new scientific psychiatric view on patient care and the use of new somatic treatments dictated the transformation of the organization into a medical hierarchy with the physicians in charge. The transformation implied the introduction of a managerial hierarchy and a disciplined work ethos, in many ways similar to changes in industry at the time. ${ }^{54}$ But Van Deventer's authoritarian attitude probably exacerbated the tension that the organizational transition created. Although the board members supported the scientific changes Van Deventer introduced, their personal relationship remained riddled by conflicts. 55

For different reasons, the reform effort also created tensions in Franeker. After the appointment of the first two nurses, the board made it clear that any further steps in nursing reform were dependent on raising patient fees. In I900 when the contract with the province came up for renewal, the board proposed an increase of the fees and wished to use some of the surplus for the expansion of the nursing staff. However, the Municipal Council did not agree and argued that any surplus should be returned to them. The board was deeply divided over the issue and, as a result, three of the five members resigned. ${ }^{6}$ In response, the Provincial Council increased patient fees by Io cents a day. ${ }^{57}$

Franeker shifted to a professional organization more gradually and later than Meerenberg, but the changes resulted in an essentially similar restructuring. As in other asylums, the "household" of the Franeker asylum was traditionally headed by a married couple, called the "father" and "mother", who managed daily patient care and supervised the attendants..$^{8}$ The asylum was run like a large, partly self-sustaining middle-class household, in which the patients shared a substantial part of the daily duties. Van Zuylen and Wesselman took over the supervision of patient care from the father and mother, par- 
ticularly on the new observation ward, and supervised the new nursing staff of student nurses. The mother remained in charge of the household affairs. The new student nurses started to work in the female department, and initially the shift towards nurse training was only made in that department.

When the father and mother retired in I909 after more than twenty years of service, the separation between the nursing staff and housekeeping staff was given a more definite character. Van Zuylen and Wesselman, who had taken over many of the traditional tasks of the matron in the area of patient supervision, did not become responsible for housekeeping. A deputy director, Miss J. W. E. de Boer, and a "chief of service", Mr. J. Th. Jansen, the second trained male nurse appointed in Franeker in 1902,59 replaced the father and mother as the heads of the household affairs. ${ }^{60}$ An assistant housekeeper was added in I9II. These three formed a stable group of officers in charge of household affairs. They, as well as the head nurses, remained in service for a long period of time, which may indicate that their positions met their aspirations and consequently they formed a solid network.

The feminization of ward work and the increased authority of middle-class women challenged traditional work relationships. A major source of tension in Meerenberg was the informal leadership of Antonia Stelling. Her relationship with the supervisors of the kitchen and household affairs and of the female workshops was not clear. This created tension, particularly since Van Deventer claimed that all those divisions were actually part of nursing work. The board was dissatisfied, because they believed it created a great deal of confusion as to who was responsible for the female staff. ${ }^{61}$ They felt that a female deputy director, probably similar to the previous matron, should be in charge of the female nurses. This issue remained unsettled for over a decade. The physicians did not want to share their authority over the head nurses and nursing personnel with another female authority figure. But the board felt that a respectable woman needed to be in charge of the female nurses in order to enhance the recruitment of young daughters from respectable families. They argued that parents would not send their daughters to work in the asylum if it was not clear who was in charge of them. ${ }^{62}$ Clearly the board feared for the asylum's reputation and felt frustrated over the inability to attract sufficient qualified personnel. Significantly, when Van Deventer and his wife left in I904, his successor, Gerardus C. van Walsum, turned out to be a strong opponent of the idea of formally appointing an deputy director of nursing. ${ }^{63}$

Eventually Lady Haitsma Mulier, who had joined the board in I9I2 as the first female member, pushed the issue. ${ }^{64}$ In April I919, the board finally appointed Miss G. Büller, who was the former deputy director of the Utrecht asylum. She immediately experienced strong opposition from the physi- 
cians, who hindered her rounds on the wards and demanded that she report to them rather than meet independently with the head nurses. After a while she turned to the board for help in establishing her position. ${ }^{65}$ The resistance of the physicians demonstrated the ambivalent response of the medical profession to the new trained nurses and their primary interest in the creation of compliant assistance. On the one hand, doctors needed better skilled assistants, but on the other hand their autonomy was threatened by the authority of (upper) middle-class women. ${ }^{66}$

The Orthodox Protestant Perception of Mental Nurse Training: A Family Ideology

From the outset, the board of the VCV utilized the older notion of Christian calling as the appropriate motivation for nursing work. In a lecture to the general VCV meeting in 1890 , chairman Lucas Lindeboom outlined that the VCV needed personnel who were faithful to the Reformed practice, devoted to Christian virtues, dependable, healthy, and motivated to dutiful service out of a belief in God. ${ }^{67}$ The board actively recruited like-minded personnel within the Reformed Protestant parishes. ${ }^{68}$ Congruent with the modest origins of the Dutch Reformed Churches' membership, the personnel who came to work in the VCV asylums were predominantly from working-class, farming, or lower middle-class families. They usually had a very modest educational background and had yet to acquire many of the respectable behaviors expected of them in their daily work with patients. ${ }^{69}$

The VCV distanced itself from the mental nurse training model of the NVP. Veldwijk had no aspirations of attracting middle- or even upper middleclass trained nurses, nor was its design based on the principles of the general hospital. Paradoxically, the VCV's eventual adoption of a system of mental nurse training that came close to the NVP model reflected their struggle to remain faithful to their Protestant, reformed identity in the midst of a modernizing society. As discussed in Chapter II, the VCV's aspirations to develop its own Christian psychiatry was an attempt to blend the contradictory demands of realizing its Christian mission of benevolent care and adapting to modern materialistic medical views. The design of mental nurse training that the VCV developed mirrored the same tensions.

When it opened the first two pavilions at Veldwijk in I886, the VCV leadership organized care based on a Christian, family-based philosophy. For each pavilion it hired a lay married couple and two attendants. From the outset the VCV called them "nurses", and addressed them as "sister" and "brother" .70 The VCV board sent this first group of lay personnel to the large Deacon and Deaconness Bethel Institute of Pastor Friedrich Von Bodelswingh in Biele- 
feld, Germany, just across the border, for six weeks to familiarize them with Christian care of the insane..$^{7 \mathrm{I}}$ The board considered that institution to be a good example for instilling their personnel with proper work ideals.

According to VCV ideology, in each pavilion a group of patients and personnel lived together resembling the faithful family. The (childless) married couple served as the housefather and housemother. Asylum treatment was to resemble the presumed healing function of the devoted Christian family. ${ }^{72}$ In I888, VCV board member Oosterwijk Bruijn outlined the VCV ideals of family care to the general meeting and emphasized the asylum's emulation of the healing function of the family, which he believed ideally mirrored heaven on earth. If a family neglected God's order it could easily become a breeding ground for insanity. It could result in family fights, lack of discipline, an immoral lifestyle, but also in overburdening the brain and in too much education, which in turn could cause insanity. But a normal, faithful family would have all the necessary characteristics to keep heart and senses healthy, he argued. Nineteenth-century paternalism fluidly harmonized with Oosterwijk's Christian family view. The faithful Christian family, he argued, respected the man's authority over the woman and parents' rule over their children and servants. Adherence to prayer, reading of the Scriptures, and religious services were the "soul" of family life. A harmonious family practised virtue, not sin, and would thus "suppress the germ of insanity". ${ }^{73}$

Faith and family bound nurses to the institution. The nurses' appearance was congruent with the family idea: they did not wear a uniform at first. ${ }^{74}$ Like attendants in other asylums, the nurses shared a great deal of intimacy with their patients. The married couple had their own room, but the nurses usually slept on the same wards as patients, which were essentially the pavilions' attics. The daytime quarters mirrored the family living room. The day began early, at 6:00 a.m. with a prayer or Bible reading for personnel, after which they helped patients out of bed. Breakfast was at 8:00 a.m. During the day nurses shared both patient care and domestic tasks very similar to those performed as part of the traditional role of a woman in the family. In the male pavilions, the housemother guided the domestic work of her "sons", the male nurses. The prayers and readings from the Bible at mealtimes were an integral part of pavilion family life. The daily schedule was grounded in strict discipline and subservience to authority.75

\section{Gendered Nursing Leadership in Veldwijk}

The gendered way in which the nursing leadership structure unfolded in the Veldwijk asylum revealed more explicitly how the social respect of female 


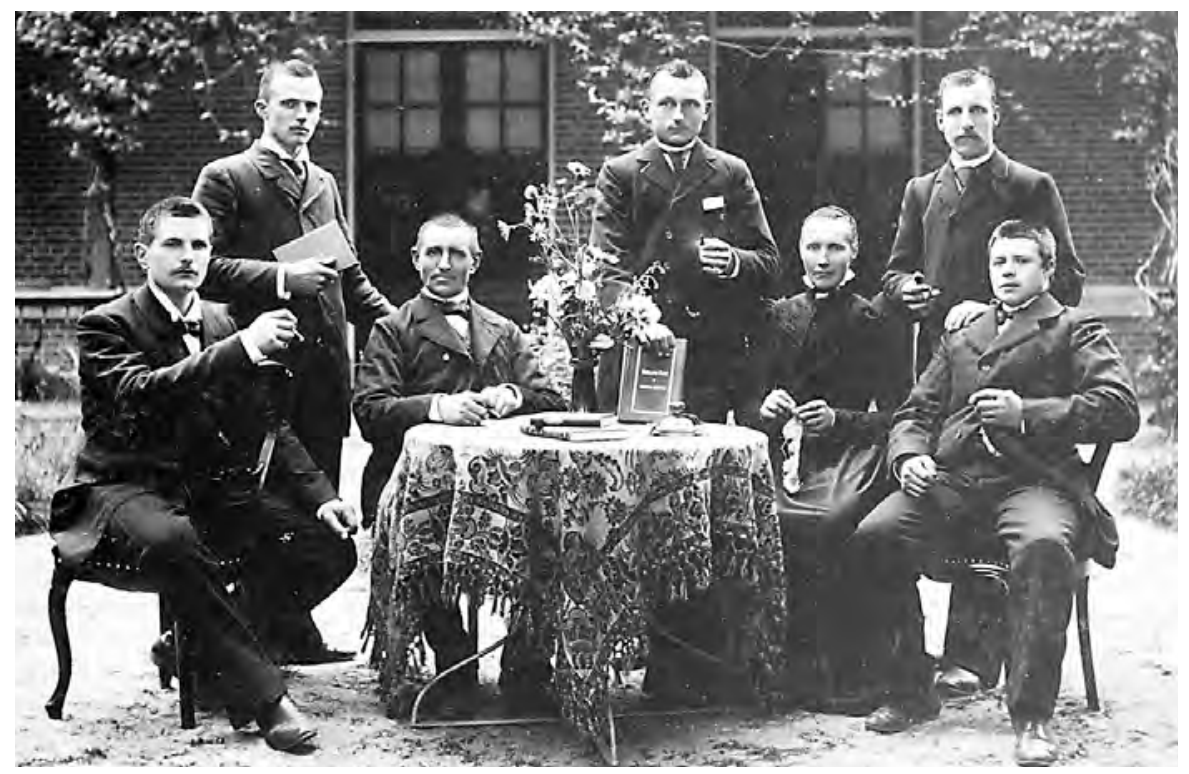

Io. Pavilion father, mother, and five male nurses, Veldwijk Asylum, ca. I89o

nurse training was essentially connected to single womanhood. The Asylum Council, consisting of the medical director, the economic administrator, and the asylum minister, quickly discovered that it was difficult to find dependable and competent lay couples to head the pavilions. As a solution, the board decided in I 887 that female pavilions could also be headed by a "mother/head nurse", a single woman with experience in nursing or charitable work. ${ }^{76} \mathrm{Mrs}$. Kassies-de Buisonjé, who started her career in Veldwijk in I889, may be typical of the women who the Asylum Council sought to attract for these positions. Kassies-de Buisonjé had been a teacher at a women's prison before she came to Veldwijk, where she began as a nurse and soon obtained a position as housemother/head nurse. In I892 she accepted the office of housemistress, in which she served for twenty-two years before retiring in I9I4 because of illness. She had a daughter who stayed with her at Veldwijk and who, in Kassiesde Buisonjé' later years, was appointed as her assistant. Her husband had probably died at an early age..$^{77}$

Once mental nurse training was established, Veldwijk soon recruited its housemothers/head nurses for the female pavilions from its own trained nurses, and the female pavilions were eventually all headed by trained female nurses. They were interchangeably referred to as "mother", "head nurse" or "sister", a confusion that was settled by I9Io when the board decided that the 
head of a female pavilion should be called "head nurse" and addressed as "sister".$^{8}$ The title "head nurse" may be symbolic for the gradually professionalizing role of nurses. In their leadership position, head nurses could gain considerable informal power to negotiate changes or mold the organization their way, supporting the idea that the new ideology was embraced by women as they sought ways to make a career and improve their working conditions. Yet patriarchal male authority had to be carefully respected in such negotiations. Mother Hendrika Gierveld, for example, a nurse at Veldwijk since its opening in I886, eventually moved into a head nurse position and stayed in service for thirty-eight years. Early on, she had successfully convinced the medical director that it was impractical for nurses to work all day and then to sleep in one room with patients at risk of self-mutilation. In response, director Vermeulen allowed nurses to alternately sleep in their own room for one fortnight and with the patients for the next.79

By I9I5, fifteen of the twenty-six pavilions and two of the three villas were for female patients and had a female head nurse as director. Mother Gierveld had no diploma, but all the others did. These trained nurses formed a stable group of personnel. In I9I5, the fifteen female pavilion heads had been in service for an average of fifteen to sixteen years. ${ }^{80}$

The situation was different in the male pavilions. Placing a single woman in charge of a male pavilion was socially unacceptable to the board. In I898 medical director Schermers, dissatisfied with the lay couples' leadership, which he felt lacked competence, and eager to implement changes, suggested an alternative of putting a single (trained) male nurse in charge, but neither single male nurses nor unmarried female head nurses seemed admissible as heads of the male pavilions. ${ }^{81}$

As a physician, Schermers may have trusted the competence of trained male nurses and considered the problem from a professional perspective. Appointing male head nurses seemed an attractive way of meeting the need for competent assistance. Asylum minister Van der Hoogt in I898/99, on the other hand, defended the capabilities of lay couples. They were appropriate for the male pavilions because the womanly influence could not be missed there, Van der Hoogt noted, clearly in defence of the VCV's family ideology. ${ }^{82}$ The healing function of the family was particularly dependent on the role of women and the conviction that women were the guardians of family morality and protectors against sin and decay. Yet in the VCV's religious beliefs male authority overruled female authority. Consequently female influence could only be spread through women's traditional role as wives in a male environment. The independent roles single women were apparently able to carve out were acceptable in a separate female community. Consequently, single 
women were acceptable as heads of female pavilions within the VCV. But the liberal idea, for example promoted by Van Deventer, that a (single) trained female nurse could have such a womanly, civilizing influence on the male wards was antithetical to the VCV's basic philosophy. In the liberal medical view, lay steward and matron leadership became an outdated concept. In the VCV asylums, however, a married couple helped to create acceptable leadership in the male pavilions that bridged two conflicting opinions.

Married couples continued to manage the eleven male pavilions and one villa for male patients. During the first decade it was difficult recruiting capable couples to Veldwijk, but in I9I5, married couples had an average duration of service of fifteen years, with two couples having been in service for almost twenty-five years. ${ }^{8}$ By then most of the housefathers had taken their training as a mental nurse and obtained their nursing diploma at Veldwijk. The married housemothers did not participate in training, thus remaining in line with the gendered VCV family ideology that a woman should never overrule her husband. While the housefather followed the nurse training, the housemother brought female influence to the male environment.

\section{Implementing an Educational Structure}

The new nurses entered into a training structure. In Meerenberg, Van Deventer carefully selected applicants for student nurse positions based on the NVP criteria of decency, health, good moral behavior, and a refined character. A questionnaire on their personal background, including their father's occupation, family situation, and education, as well as a personal interview and the checking of three references had to support the judgment on the nurses' suitability. Although the NVP prescribed a minimum age of twenty for entry into training, many student nurses were younger when they started. ${ }^{8}$ Van Deventer preferred to recruit applicants who had education beyond basic elementary education, such as a diploma in home economics or an extended elementary education certificate; the knowledge of foreign languages or music was an advantage. Van Deventer's expectations were high; most of his colleagues in other asylums set lower standards. In none of the other asylums did the commencement of training require any special preparation of the student nurses other than a history of irreproachable conduct. Most directors adhered to NVP standards in recruitment, but no special diplomas were sought. ${ }^{85}$

After a three-month probationary period the applicants became student nurses for the first year of their contract, after which they were promoted to the status of nurse. The first two years of work entailed the necessary practical training for the NVP exam. If at all possible, nurses had a chance to work in 
several departments and various wards, although initially there was no systematic way of dividing pupils over the wards. If there was an opening, competent nurses were subsequently appointed as first nurses in charge of a ward. The head nurse supervised all nurses in a department. During their two years of practical training (three years after I896) the physicians gave a theoretical course, usually one hour once or twice a week after work, often between 8:00 and I0:00 p.m., while the head nurse and department physician gave practical instruction on the wards ${ }^{86}$ In $\mathrm{I} 893$ the first ten candidates from Meerenberg passed the NVP exam. ${ }^{87}$ The asylum physicians all shared part of the theoretical course work, which included anatomy and physiology, medical and surgical nursing, and nursing of the insane. ${ }^{88}$

From a pedagogical perspective, the courses and practical training were quite limited and characterized by continuous repetition of the same material. Head nurses provided "repeat hours" in which they went over the material taught by the physician. Over time, training gradually adapted to the educational background of the majority of the nurses. After 1904, when the NVP changed its exam and training regulations, Meerenberg shifted to a three-level system of training with an exam at the end of each year. During their first year, pupils took a repeat course of elementary education for around two hours a week. In the second year, physicians taught anatomy, physiology, nursing of the sick, hygiene, and the application of dressings in a seven-week, one hour-a-week course. This course was repeated three times before students took the second year exam. This pattern was repeated in the third year, with a course on the nursing of the insane. ${ }^{89}$

In Franeker, the new female pupils received practical training from the head nurses and took a theoretical course quite similar to that in Meerenberg. Second physician Oort, who had already begun to teach the male attendants in his own department in 1898 , developed this course into a training course for male attendants and female student nurses. It is significant that only the female students could prepare themselves for the NVP exam. ${ }^{\circ}$ Similarly, medical director Van Dale, who taught the first courses to nurses at Veldwijk, initially only gave classes to the female nursing staff. Not only did he lack the time to teach male nurses, he argued, they were less also interested in learning. ${ }^{\text {I }}$

But in I907, for the first time, one of the male attendants in Franeker took the NVP exam, and in 1908 six male student nurses were appointed..${ }^{22}$ The shift may have been related to the economic situation. The annual report described I907 as a bad year financially, and the board, despite its initial fears over the high costs of hiring trained nurses, may have thought that hiring male student nurses was essentially cheaper than hiring traditional atten- 
dants. Furthermore, personnel began to participate in the municipal pension fund in I906. The pension fees were probably higher for experienced attendants than for student nurses. ${ }^{93}$

The course content in Franeker consisted of basic anatomy and physiology, and care of the sick and the insane. Oort used the textbook for mental nurses written by VCV physician Schermers and which had just been published in I898. Oort may have appreciated his new role as a teacher of nurses; although the board did not pay him any extra salary, it approved the suggestion of the medical director to give Oort permission to leave the asylum daily from 3:०० to 5:00 p.m. ${ }^{94}$ Like Meerenberg, in 1908 Franeker made the NVP exam a requirement on completion of the nurse training course. ${ }^{95}$ The NVP had probably encouraged this measure. By that time, Franeker prepared nurses for the first year exam by means of a repeat course of elementary education, taught by one of the town's elementary schoolteachers twice a week from 8:30 to 9:30 in the evening for female nurses, and one hour a week in the evenings for male nurses. Those who passed this exam moved on to the second year program. By then, classes in medical matters were taught by the second physician during the day, for two hours a week for female and one hour for male nurses..$^{9}$

The courses, which assumed a low educational level, seemed designed to keep nurses in the institutions as students for as long as possible, rather than provide any profound training. Course work was only vaguely connected to the nurses' work on the wards. Student nurses did not obtain lessons on the care of the insane until the third year. By that time they already had several years of experience. They learned the details of their work by word of mouth from colleagues, or possibly by instruction from the head nurse. There is no evidence, however, that such instruction, if it happened at all, occurred in any systematic way.

Despite the training rhetoric, the link between work discipline and educational requirements was weak. Until ı9o8, when medical director Van Walsum systematized the training program and established a rotation system, course work was voluntary and promotion into higher ranks was not dependent on passing exams. Many nurses never took the exam or quit their job before completing training. ${ }^{97}$ Student nurses became nurses after about one year's work regardless of whether they had taken the exams. Physicians taught nurses a few hours in the evening after work. Since the days were long and the work strenuous, class work at that time of the day was not ideal. Physicians soon began to resist the extra time they had to invest in teaching nurses. Once Van Walsum had reorganized the training and passing the exam was a prerequisite for promotion, physicians gradually started to teach 
their lessons during daily work time. This occurred in part because physicians began to resent the extra tasks expected of them in addition to their responsibility for patients. ${ }^{8}$ In I9I3 Meerenberg appointed an extra physician to the staff who became responsible for all teaching of nurses. By I9I5 physicians taught all their classes during the day. 99

\section{Mental Nurse Training at Veldwijk}

Finding sufficient and capable nurses was a persistent problem in Veldwijk. ${ }^{100}$ The consistently high turnover of staff nurses prevented the development of a stable, experienced corps of personnel. The VCV soon felt it had to provide some training in order to create a competent workforce, ${ }^{\text {,oI }}$ yet it struggled to conceptualize a model that would conform to the VCV ideology of Christian care. In 1890 the board appointed a committee consisting of board member Wielinga, medical director Vermeulen, and the newly appointed asylum minister Notten to develop a policy regarding the training of personnel. ${ }^{102}$ They clearly sought a compromise between religious and medical course content. They proposed a monthly lecture series by the physician and a monthly meeting with the minister for personnel. Significantly, in accordance with the VCV philosophy that insanity was predominantly a result of sin, the minister took on the responsibility of teaching the nurses about the symptoms and treatment of the insane. Notten wrote a textbook for this purpose, which he gave a catechism-like format with questions and answers concerning psychiatric knowledge. The physician's lectures were restricted to anatomy and physiology, and instruction on somatic treatments. ${ }^{103}$

Within a few years, however, this division of labor had reversed. The influence of the medical model grew and the use of bed rest increased, which counteracted the lay family model and the strong emphasis on religious training. In 1907 five of the eleven male pavilions and ten of the sixteen female pavilions had rooms or wards for bed-based treatment, close observation, sick patients, or a combination of these. ${ }^{\mathrm{T} 04}$ These treatments required more complex nursing skills. Another factor prompting the demand for trained nurses and exposing the deficiencies of the lay-based system was the rapid growth of the organization itself. In 1892 the VCV opened its second asylum, Bloemendaal, and in I895 a third, Dennenoord. ${ }^{\text {1os }}$ The expansion of the VCV created the need for a more structured way of generating trained and skilled personnel. The organization chose to design a unified system for training nurses for all its asylums.

The professional medical model overruled the ideologically highly valued lay model of training. The physicians had clearly gained influence. In the new 
training policy for personnel, designed in 1895 and taking effect in 1896 , the course content taught by ministers was reduced to church history, knowledge of the Bible, and catechism training. Physicians taught all of the medical content, including the psychiatric material. Moreover, a systematic repeat course in elementary education was established not only in the first year, but throughout the three years of training stipulated by the new training model. Attendance at the theoretical courses was mandatory for nurses. For the women the course included additional training in needlework, sewing, cooking, and diet. ${ }^{106}$ By I9I4 the model included practical training in medical matters such as taking vital signs, administering injections and enemas, giving baths, dressings or hydrotherapeutic wrappings, and moving patients into other beds. ${ }^{107}$ As a result of the VCV ideology, the training schedule at Veldwijk was more elaborate than that at other asylums and included religious education and lessons on the care of the insane from the outset. But the predominant pattern of teaching in the evenings was similar to that in other asylums. ${ }^{108}$ Practical training remained the primary responsibility of the pavilion heads. Schermers, the medical director of the VCV Bloemendaal asylum, wrote a textbook for the new training program. In layout and content it was similar to the textbooks written for nurses by physicians that were generally available at the time. ${ }^{109}$ But the religious influence had not disappeared. The

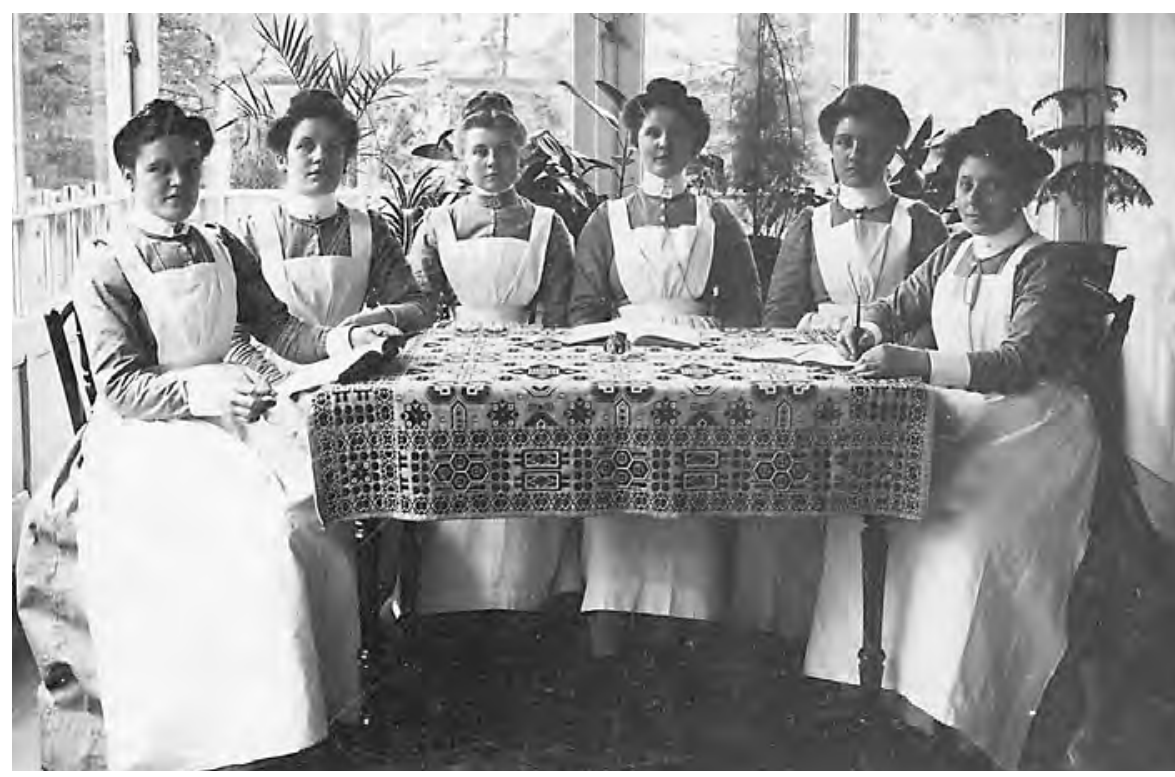

II. Female mental nurses at the Veldwijk Asylum, ıэıо. 
student nurses first had to pass their exam on the religious material before the exam on medical matters could be taken. On graduation nurses received a diploma that was valid within the VCV institutions only. ${ }^{\text {I10 }}$

The appearance of the nurses at Veldwijk changed on the board's acceptance of the new training regulations. The nurses now obtained a uniform just like their colleagues in other, traditional asylums. Difficulty attracting sufficient personnel may have contributed to this compromise with family ideals. In competition with other institutions Veldwijk sought to provide the same opportunities. ${ }^{\text {III }}$ The lay family structure gradually gave way to a professional, medically oriented model, although the VCV remained faithful to its Orthodox Protestant identity. The VCV nurse training remained separate to the mainstream model of NVP nurse training, just as the Protestant Free University provided its own medical training independently of state universities.

The morality that the training in Veldwijk sought to instill in its pupils focused on the training of character and decency, as in other asylums, but the emphasis included an appeal to religious rather than secular, scientific values. The training, just like VCV asylum life in general, was deeply entrenched in its Reformed ideology. It was geared towards the modest background of the Reformed community and strictly enforced discipline and obedience through obligatory attendance and close supervision, as well as regular meetings with the minister and daily prayers. For example, on one occasion it came to light that a female student nurse had stolen a small artificial bouquet from one of her fellow nurses in order to decorate her hat. Medical director Van Dale and minister Notten spoke with the girl in person. Once she had admitted her fault and shown repentance, minister Notten prayed with her. ${ }^{\text {II }}$

\section{Debate over The Boschhoek}

The undefined nature and ambiguity of the new "trained status" compared to the previous servant position continued to convolute the debate over the makeup and appropriate preparation of a "good nurse". The debates over nurse education and the measures taken within the VCV community with regard to the training of personnel reflected the broader tensions also felt in other asylums. Although the training discipline was intended to improve the level of personnel, turnover problems remained a pressing issue at Veldwijk. About 30 percent of the nursing staff had to be replaced each year. ${ }^{\mathrm{II} 3}$ One of the major reasons for the high turnover was the poor social position of the personnel. In accordance with VCV philosophy, the board, particularly its founder and chairman Lucas Lindeboom, argued that Christian devotion and philanthropy should motivate the attendants rather than the need to make a 
living. ${ }^{\mathrm{II}}$ This ideology was the source of much tension, particularly when personnel grew more aware of their socio-economic position. Salaries at Veldwijk were low compared to other asylums. In I90 a male graduate nurse in Veldwijk earned I25 guilders plus a savings allowance, whereas in Meerenberg in that same year a male graduate nurse earned I 50 to 200 guilders, and in some other asylums they earned 200 guilders (Utrecht), or 250 guilders (Endegeest). ${ }^{115}$ For a long time the VCV could not decide on a pension plan, and when disabled by sickness, most personnel had to leave without much of an allowance. ${ }^{\mathrm{II}}$

VCV physicians and ministers, who were confronted with the responsibility of day-to-day patient care and the daily pressure of a shortage of personnel, disagreed with the board's dogmatic adherence to a family ideology of devoted service. In the face of continuous high turnover, the question of personnel remained a widely debated issue and the resistance of nurses to stay was often explained in terms of a "lack of morality". In I900 medical director Johan H. A. van Dale and pastor Drenth presented the board with a report on the personnel. ${ }^{\text {Ir7 }}$ They suggested various measures to improve working conditions, such as an increase in salary, the involvement of local pastors in personnel recruitment, the improvement of training, and better facilities for taking care of sick personnel. Sickness among the personnel was a pressing problem and they felt that the VCV should provide some facilities. In the pavilions, where the personnel shared their daily life with patients, space and time were lacking to care appropriately for sick nurses. ${ }^{\mathrm{II}}{ }^{8}$ The acknowledgment of the many sick nurses indirectly underscored the strenuous working conditions that nurses endured.

Inspired by the example of the Wilhelmina Home preschool, Van Dale suggested that Veldwijk should establish a preparatory training school. ${ }^{19} \mathrm{Howev}$ er, he immediately linked character training and instruction with practical work. In his view, a preschool should be a home in which a few patients were admitted of whom student nurses could take care as part of their learning experience. The home could take in new aspirant nurses for three months to work with the patients in the morning and have ample time for study in the afternoon and evening. Although at that time the board was not ready to approve such a rigorous plan, they did agree to establish a rest home for sick nurses in one of the villas. They designated the Boschhoek Villa as a nurses home for sick nurses. In a festive and religious opening ceremony, Sister Hidding, one of the housemothers, was inducted as the head of the new Boschhoek Home, which opened in 1900. ${ }^{\text {I20 }}$ It would serve as a hospice for about six sick female nurses, as well as a place where female nurses could spend their days off. In this way, the board believed, the housemothers would 
be relieved from the care of sick personnel in the pavilions, while they apparently also improved leisure conditions for the personnel. Such a measure was thought unnecessary for sick male nurses. For them Van Dale and Drenth proposed to arrange a lounge with a veranda for about six beds in one of the quiet male pavilions. ${ }^{\mathrm{I} 2 \mathrm{I}}$

The VCV leadership was explicit about the aims of creating this facility for their female personnel. The opportunity for the recovery of their nurses allegedly fitted the stated VCV policy of looking after the interests of their personnel, but the nurses home also served as a means of propaganda. The board hoped that it would improve the reputation of the VCV so as "to attract young daughters of Christian principles" for work in their asylums. ${ }^{122}$

Soon the nurses home was filled with sick nurses. About twenty-six nurses used its service in I90I, most of whom suffered from weakness and exhaustion. Although all recovered, some remained too weak to return to the strenuous work of nursing. ${ }^{\mathrm{I} 23}$ Nervousness and overstrain were common complaints, while quite a few nurses suffered from tuberculosis. ${ }^{\mathrm{I2}}$ But the board soon found the operation of the house to be very expensive. The board considered closing down the nurses home just five years after its opening. The home had not brought down turnover rates as they had hoped. To prevent sickness among the personnel, the board adopted a new policy in 1906 that a physical exam should be part of the hiring procedure, and the next year the board closed the hospice for sick female nurses. ${ }^{\text {I25 }}$

\section{The Boschhoek Revisited}

In 1907, possibly in response to the closure of the nurses home, higher salaries, improved working conditions, and better preparation for nursing work were brought up again by yet another committee assigned to inquire on the state of personnel. ${ }^{\mathrm{I} 6}$ Pastor Bootsma, who presented the point of view of the VCV ministers, vehemently argued that more reasonable salaries and more time off, like the regulations in other asylums, were but one way to attract sufficient personnel for the tiresome and strenuous work of nursing. More important, he noted, would be the preparation of nurses for their work with several years of study prior to the beginning of their work, just like schoolteachers. The committee did not follow through with such an almost revolutionary idea, but they did recommend a salary increase.

Both the board and the physicians disagreed with the idea of a four-year "normal school" for nurses. Like their colleagues in the NVP, they clearly wanted to retain control over the nurses within the VCV asylums. In I907 Veldwijk's second physician H. Sap delivered a speech to the Christelijke 
Bond voor Ziekenverpleging (Christian Nurses' Association), founded in I9O2 as the Protestant counterpart of the NBZ. He argued that both the idea of comparing training of nurses with that of teachers and the practice in some asylums of requiring the command of at least one foreign language as a prerequisite of their applicant nurses were totally out of context. Years of intellectual schooling would not prepare anyone for swabbing, scrubbing, making beds, or cleaning and washing patients, but would only create dissatisfaction, if not an insupportable financial burden. But when someone in the audience suggested that maids could be hired for such work, Sap disagreed with this as well. Sap argued that mental nurses needed domestic work in the interest of their physical and mental health, since it gave them a necessary distraction from taking care of insane and nervous patients. ${ }^{127}$

Sap regarded the fact that new pupils were put to work in the pavilions under the supervision of a housemother who had no prior knowledge of their character as a disadvantage in the training of nurses. Neither did the student nurses receive any preparatory guidance or prior adjustment to the asylum discipline. Similarly to the suggestion Van Dale had already made in I900, Sap proposed a preschool where nurses would receive preparatory training and learn discipline. A graduated, experienced nurse could supervise them and, obviously under the direction of the medical director, teach them the beginnings of nursing skills. This would allow the asylum leadership to first get an impression of the potential and character of the student nurse, while the student would gain some experience before starting work on the ward. ${ }^{\mathrm{I} 28}$

At this point, probably in desperation, the board approved the physicians' long-standing plan to create a probationary training period for new applicants. The asylum council felt frustrated over the low morals and level of refinement of the applicants and expected that the Boschhoek would effectively counter such behavior. ${ }^{129}$ Of the twenty-two applicants hired in I908, for example, eight were fired because of unreliability, nervousness, imprudence, or incompetence, and one because of theft. In I909 the board reopened Boschhoek Villa as a preparatory training school. Medical director Van Dale considered it an appropriate solution to the ongoing difficulty not only of attracting but also retaining good personnel.

It is significant that the preparatory training school was designed for female nurses only. Van Dale's colleague, medical director Schermers, was explicit about the gendered nature of nursing. He clearly assumed women were most suitable for nursing. To start nurse training, he noted, student nurses needed no preparation other than the expectation one would have of every young daughter's upbringing: elementary education, sufficient housekeeping skills, and a satisfactory knowledge of the catechism, in addition to 
proper character traits such as compassion, gentleness, trustworthiness, punctuality, and attentiveness. ${ }^{130}$ The Boschhoek preschool, Schermers argued, was purposely established in order to create an opportunity to judge whether a woman had the right character for nursing, while simultaneously giving her some preparatory training. ${ }^{13 \mathrm{I}}$ His idea sounded very similar to the notion of the "moral sieve" that State Inspector Ruysch used to explain the function of the Wilhelmina Home.

Henriëtte Koffijberg became the director of the new home, which had aspirations similar to the preschool established by the Wilhelmina Association but was much more practical in its orientation. From the outset, the villa took in a few private, first- or second-class invalid patients, who the new student nurses cared for as part of their practical training. As the supervisor of the young girls who attended the Boschhoek for a three-month probationary training period, Koffijberg played a key role in instilling the class-based expectations in her pupils. She supervised the aspirant nurses and trained them in working methodically, teaching them basic patient care. In addition, the pupils had two hours of courses a day, one hour of either biblical history or elementary education plus one hour of nursing, taught by Koffijberg. ${ }^{132}$

With almost military methods, the new pupils were introduced to obedience, cleanliness, and discipline. On their arrival Koffijberg inspected and registered their belongings and assigned them a closet, which she maintained the right to inspect. Then the new student had to take a bath before putting on her new uniform. ${ }^{33}$ Subsequent bathing was required weekly. Each day was strictly regulated from hour to hour with prescribed tasks, meals, lessons, and some leisure time from 8:00 to 9:30 p.m. Ten o'clock was bed time, after which no reading, sewing, or letter writing was allowed. Moreover, during the preschool period the pupil had no days off and permission for running an occasional errand had to be obtained from Koffijberg. During the preschool the pupil received only ten guilders of pocket money for the whole three-month period and no salary. If a pupil turned out to be unsuitable, she had to leave immediately. ${ }^{134}$ Such methods were in line with similar approaches in schools and factories alike, and reflected contemporary beliefs among the middle class about how a respectable workforce could best be created. ${ }^{135}$

In I909, the year of opening, thirty-one student nurses went through the preparatory training period of two to three months. Of the first three pupils, two had to leave immediately. One was "dirty and shoddy", the other "rude and unrefined". The next three were of "a better grade", both in "appearance, attitude and manners". Of the remainder of the pupils, three more were sent away because of unreliability, dirtiness, or immorality. Two years later a total of ten out of thirty-three pupils had had to leave the preschool. ${ }^{136}$ Clearly, the 
adjustment to class expectations that they had never been exposed to was quite a shock to predominantly working-class girls with usually only minimal education. Yet the model of preparatory training developed at Veldwijk turned out to be a lasting concept. Most likely this was due to the practical training it provided to nurses in a relatively protected environment. Various hospitals introduced similar models of preparatory training for nurses during the I9IOS. ${ }^{137}$

\section{Roman Catholic "Resistance"}

The distinct view of Roman Catholic nursing orders at Voorburg on how to best provide care for the mentally ill created its own tension and disagreement over the nature and competence of nurses. The nursing orders at Voorburg were not prepared to easily accept a new health order grounded in medical science. An organically oriented, materialistic medical view was antithetical to the congregations' religious understanding of human suffering and to the belief in Christian charity and apostolate in which their philosophy of care of the insane was rooted. The religious orders saw their work as a Christian mission, an evangelical assignment to magnify God's glory in the world by means of benevolent works. ${ }^{1{ }^{8}}$ Faith, spirituality, and Christian community were the premises on which their constitution and daily rule were built. As with the missionary zeal of the Protestant religious movement, the many new active congregations founded as part of Roman Catholic revival facilitated the spread of Catholicism through charitable works. Congregations developed their identity as self-reliant Christian communities aimed at the spiritual welfare of their members and their charges. ${ }^{139}$ According to them, the order and discipline and the regularity of prayers and religious practices that regulated their own daily life and that of their charges exemplified God's order in the world and underlay their notion of healing.

The brother and sister orders of the Brothers of Our Lady of Lourdes and the Sisters of Good Works were founded in I830 and I845, respectively, by E. H. Stefanus Glorieux, who had been appointed as an assistant priest in the Belgian town of Ronse in I825. Confronted with the town's devastating poverty resulting from a long period of war and economic recession, Glorieux instituted a charitable workhouse for the poor. He founded the religious orders in order to staff the house, which soon expanded its charitable works to education in several schools and to managing homes for invalids, the elderly, and orphans. In I850 the congregation formally split into two separate organizations overseen by one board. ${ }^{\mathrm{I} 40}$

When the sister order contracted in 1853 for fourteen of their sisters to 
manage the Reinier van Arkel asylum in Den Bosch, they had some experience with the care of the insane. At that time, their charitable institution included about 249 orphans, 152 elderly women, most of them chronically ill, I30 poor women placed with the sisters by the poor board of Ronse, and 54 mentally ill women. ${ }^{\text {I4I }}$ The presence of these diverse groups of poor in the institution indicated that the sisters' charitable philosophy of care encompassed a broad category of poor sufferers entitled to mercy, including the insane. This inclusive view was quite different to late nineteenth-century medical philosophy, which regarded the insane as primarily organically ill patients. ${ }^{142}$ For their part, the sisters developed their organization into a flourishing endeavor in the second half of the nineteenth century, particularly involving themselves with the development of schooling for girls. ${ }^{\mathrm{I} 3} \mathrm{As}$ historian Annemieke Klijn argues, this is not a surprising focus for an active female congregation, considering the fact that in addition to the family, the school is one of the most important social institutions in which a new generation could be instilled with Roman Catholic tradition and faith. ${ }^{\mathrm{I} 4}$ Moreover, within the nineteenth-century domestic morality, education and caring tasks such as nursing were considered the natural role of women; the increasing number of female religious orders that involved themselves with such work was but one expression of this phenomenon. ${ }^{445}$

In I885 the College of Regents of the Godshouses in Den Bosch negotiated a contract for fifteen sisters to staff the wards of the female department in the newly opened Voorburg asylum. At that time, the order counted over six hundred members divided between twenty-nine institutions. Mother Catherine, described as a very capable and intelligent woman, headed the management of the female department for thirty-four years until I9I9. ${ }^{\text {I46 }}$ Under her strong and stable leadership the religious sisters formed a steady group, gradually expanding to sixty-nine sisters who in I9IO cared for over five hundred patients. ${ }^{147}$ The sisters' life in the institution was sober and the work strenuous. They probably saw their hard work as congruent with their self-sacrificing adherence to obedience, poverty, and purity. ${ }^{\mathrm{I} 8}$ The sisters shared their daily lives with the patients and slept on the same wards. They felt that the asylum was a charitable rather than medical institution. The College of Regents shared this perspective and did not invest much money in the working and living conditions of the sisters.

The nursing order was hesitant to agree to increased medical influence over their management of patients. Because of their different worldview, (medical) nurse training of their sisters was not the primary concern of the order. They resisted the attempt of the asylum physicians in the late nineteenth century, who were strongly supported by the state inspectors, to estab- 
lish a medical nurse training course. It can be assumed that one reason the order resisted medical control was that it wanted to uphold its own novitiate as the means of introducing its members to work and religious duties. In the novitiate, the sisters (the same is true for brothers) were disciplined in the ground rules and values of the congregation. They learned to be sober and obedient, and to practice Christian virtues and religious practices under the supervision of a novice mistress, who functioned as their spiritual mother, essentially replacing their family ties. The novitiate was an exercise in discipline, abstinence from sin and immoral inclinations, and preparation for charitable work, which consisted of practical training in the field of work the sister was assigned to. ${ }^{\text {I49 }}$

The premiss of such training completely differed from the ideas of medical nurse training. It can be hypothesized that the physician's insistence on medically controlled nurse training paradoxically delayed the order's acceptance of the idea that their nurses needed better professional preparation for their work. The sisters involved in education, for instance, obtained state-approved normal school diplomas by the end of the nineteenth century, and the order itself even founded an approved normal school. ${ }^{50}$ But in nursing there was no system of legal certification that could have created an interest on the part of the nurses themselves to establish schools for nurse training.

The state inspectors regularly pressured the College of Regents to support the physicians' proposal to establish a nurse training course. ${ }^{55}$ After a time, in I904, the General Prior of the order in Ronse approved regulations for a training course that would prepare the nurses for the NVP exam. ${ }^{152}$ The course was set up along the lines of the NVP model, with an initial repeat course of elementary education and a subsequent medical course covering the subjects of anatomy and physiology, hygiene, and the nursing of the sick and mentally ill, taught by the physician for about one or two hours a week. One of the sisters who was a graduate in education taught the repeat course. ${ }^{\mathrm{I} 33}$ The prior held the right to determine which sisters would attend the course and the College of Regents became responsible for all costs. Lecture hours were not supposed to interfere with the individual and communal religious practices of the sisters, and the prior had to approve the course content and books. ${ }^{154}$

Physicians had very little say in determining which nurses qualified for training. Since the prior assigned the sisters to training, the only control the physician had was over access. The College of Regents explicitly pointed out to the prior that physicians could refuse access to the course to a sister they found unfit for training, so that they only invested energy in those sisters who would be able to obtain the diploma. It is apparent that the physicians feared that the prior would deliberately undermine medical authority by withhold- 


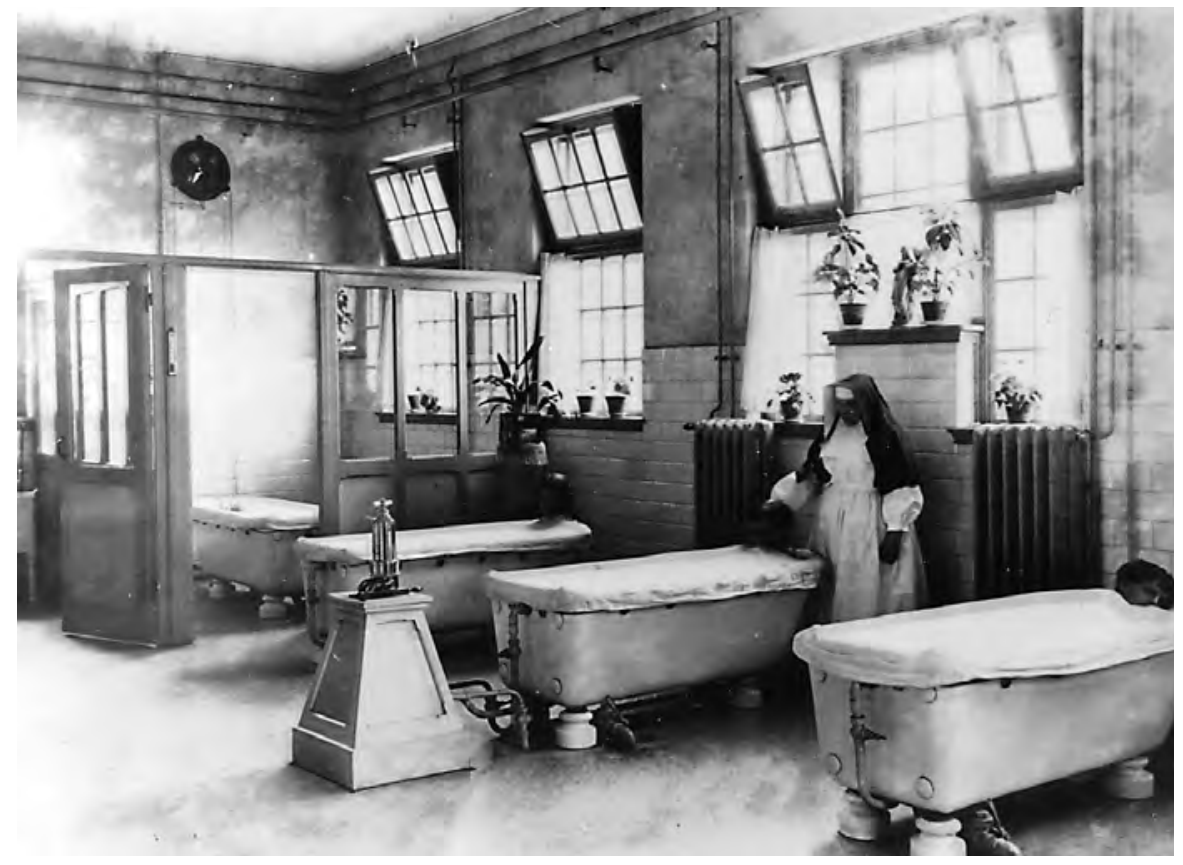

I2. Female nurse attending patients receiving prolonged bath treatment, Voorburg Asylum, i928.

ing the most capable sisters from training, only approving those who would consequently not be of much help to the physicians. ${ }^{155}$

The physicians' relationship with the brothers' order was riddled with considerably more conflict. From the beginning there was a power struggle between the physicians and the brothers, even to the point that the physicians resigned in $1888 .{ }^{156}$ Again, the differing philosophies of treatment of the mentally ill contributed to the tension, but divisions within the order itself complicated the picture.

In the mid-nineteenth century the male order numbered about eighty brothers and gradually expanded to almost two hundred professed brothers by I886. Most of the brothers were from modest family backgrounds, many coming from farming and artisan families. ${ }^{157}$ During the directorship of Father Hilarius, who was General Prior of the congregation from i 886 until I9I9, the order again more than doubled its membership to 442 brothers, 25 novices, and io postulants. By then the brothers staffed thirty-four institutions, including seventeen schools; nine orphan and elderly homes; three sanatoria; three insane asylums, including the Voorburg and Reinier van 
Arkel asylums; and two homes for physically ill patients. ${ }^{158}$ Because of their rapid expansion into more institutions, the order may have had difficulty meeting the growing demand for more brothers at Voorburg, which rapidly expanded. The wards of the asylum suffered from continuous understaffing, which was a source of great dissatisfaction on the part of the physicians who felt that their treatments could hardly be applied under such circumstances. Supported by the state inspectors, they pressured the College of Regents for more personnel. ${ }^{159}$

However, conflicts of authority within their own order and with the local church seemed to be more problematic to the brothers than conflicts with the physicians. For several decades the administration was dominated by the bishop who controlled the order. ${ }^{160}$ The brothers felt their self-reliance restricted both in their spiritual practice and in the administration of their institutions. Father Hilarius, a zealous proponent of the new spiritual orthodoxy, encouraged a strict, pious discipline among the brothers. He helped them to develop their own Rule, so that they could apply for papal rights that would place them directly under the control of the Church of Rome and make them independent of the local bishop. ${ }^{161}$ Despite a great deal of resistance from the local church officers, the rights were eventually granted in $1892 .{ }^{162}$

The order itself was internally divided. About half the brothers were Belgian and the other half were Dutch. Since the early I 880 os the Dutch wing had attempted to separate at several times. They wanted to have their own novitiate training home in the Netherlands, and in 1892 a few Dutch brothers began a home for paying nervous patients in the Dutch town of Dongen, which they sought to turn into their independent brotherhouse. Soon, however, the General Prior replaced them with Belgian brothers, although the order approved the Dutch novitiate home in I896 ${ }^{163} \mathrm{~A}$ subsequent proposal in I905 by another group of Dutch brothers to split the congregation into two parts, one Dutch and one Belgian, became the acceptable solution. Great instability within the order was generated by the conflict-ridden atmosphere and by the often unexplained, sudden replacement of staff, which was sometimes used by the order's leadership as a disciplinary measure. In this context, the conflicts with the physicians were just another source of tension that added to the turbulent atmosphere among the brothers in the Voorburg asylum.

The order had strong ideas of their own about the care of the insane, which were religiously inspired rather than medically oriented. In I892 Johannes Bernardus Tervoert (brother Dorotheus) confidently wrote and published a booklet on care of the insane. ${ }^{164}$ Tervoert began his work at the Reinier van Arkel asylum in I870 at the age of 3I and moved to Voorburg in I89I, where he stayed for another four years before being transferred to the order's main 
residence in Dongen. ${ }^{165}$ Significantly, this was the newly approved Dutch novitiate. He may very well have been part of this innovative group.

In 1905 Tervoert wrote a second book on the prevention of insanity. ${ }^{166} \mathrm{He}$ carefully avoided challenging the authority of the physician, who, he noted, should always be consulted as soon as possible in most cases. ${ }^{167}$ But in all likelihood Tervoert did not agree with the then accepted materialistic medical explanation and treatment of insanity. As did his Protestant counterparts, he saw good, faithful Christian (Roman Catholic) family life as the best prevention of insanity, which he believed resulted from immorality and lack of faith. ${ }^{168}$ He clearly sought support for a Catholic point of view on the care of the insane, for he sent his first book to all the Dutch bishops, the brother-prior of the neighboring Roman Catholic asylum Huize Padua, the College of Regents of the Reinier van Arkel and Voorburg asylums, but also to the state inspector. ${ }^{169}$

In Tervoert's view, asylum life should reflect and reproduce Roman Catholic faith. The religious practices, the daily prayers and the faithful order that the Roman Catholic nursing order practised and integrated within asylum life were a natural extension of the healing, faithful Roman Catholic family, and thus best for patients. Most likely his booklets were a response to the growing influence of a materialistic medical view on patient care. Tervoert's thoughtful writings show that he was an informed, educated man with intelligent ideas about the care of the insane, albeit ones very different to those of the medical establishment.

After a long series of negotiations between the state inspectors, the College of Regents, the order's General Prior, and the physicians, a contract regulating the brothers' participation in a training course leading to the NVP exam was signed in I900. ${ }^{170}$ By that time the physicians had already begun to teach the brothers. In the first lecture that physician J. C. J. van de Hagen gave to the brothers at the Reinier van Arkel asylum in September of 1896 , he congratulated the brothers and their congregation for their decision to enhance their competence in the care of the sick by establishing training. He praised their decision as a milestone, since they were finally taking part in the improvement of nurse training already achieved within the NVP and also in the Protestant VCV asylums. He seemed relieved that the physicians in Roman Catholic asylums could finally follow in their footsteps. Although he publicly acknowledged the brothers' dedication in the care of patients, the tone of his lecture clearly betrayed his view that the brothers lacked sufficient understanding of their work..$^{17 \mathrm{I}}$ It underscored the social and cultural gap between his perspective and that of Tervoert. ${ }^{172}$ 
As training evolved within the asylums, the central focus was on somatic care and the disciplinary nature of the nurse training system and in a sense fit the care of large numbers of physically weak patients. In Meerenberg, Van Deventer designed the mental nurse training program with military precision, and the female trained nurse obtained a central place in the asylum's regimen. Yet the initial aims of nursing reform were only reached in part. Similarly, Franeker developed a new nursing hierarchy of a handful of experienced nurses and a large group of continuously changing student nurses. In both institutions, restricted living situations and high turnover compromised the development of a stable workforce. The undefined nature and ambiguity of the new "trained status" as compared to the previous servant position continued to convolute the debate over the class background and the appropriate, gendered preparation of a "good nurse". Within the conservative atmosphere of Veldwijk, the establishment of training was initially antithetical to the VCV belief in lay, family-based care. But as the organization grew, the VCV leadership molded training in congruence with their own philosophy rather than with the dominant, liberal NVP model. Poor working conditions compromised Veldwijk's effort to attract capable workers in many ways. Rooted in the Roman Catholic tradition, the Voorburg asylum was even more reluctant to accept a materialistic medical view. After a great deal of pressure from the state inspectors, the nursing orders eventually adhered to a medically controlled training model, although in a sense it hindered the order nursing's own potential.

Mental nurse training remained limited in its potential both theoretically and practically.The system evidently brought much needed order and discipline to the organization, yet it remained ineffective in attracting a reliable, experienced workforce to the asylums. The psychiatric leadership continued to perceive the supposed problem as a lack of the right morality among personnel, and consequently they sought a solution to the pressing problem of attracting more refined and, therefore, more qualified personnel. Considering the gendered notion that women were the carriers of civilized influence, the training system became grounded in the values and expectations of women's work and the education of girls. This situation created tension among male nurses. The next chapter examines their marginalization in depth. However, many nurses, male and female, rejected the system. Administrators and physicians saw the continued high turnover as a reflection of a persistent lack of morality, which they related to the class background of the nurses. The structure and discipline underlying the training structure that 
psychiatrists developed was first and foremost an attempt to restructure the class base of the asylum workforce. Yet as the final chapter will demonstrate, nurses themselves developed a different perspective on their own social and working conditions and subsequently sought different solutions. 


\section{CHAPTER VI}

\section{The Marginalization of Male Nurses}

\section{Nursing, a Respected Occupation - but not for Men}

The conceptualization of nursing as women's work generated a gendered system of training and favored career opportunities for female nurses. This gendered ideology of nursing functioned as a selective mechanism that excluded male nurses. The process, however, was not only an ideological matter but also a result of the way the labor market developed. Men apparently had more options in the expanding labor market. In all asylums filling the positions for male nurses turned out to be more complex than hiring female nurses. Both Meerenberg and Franeker had to advertise the vacancies for male nurses, whereas they usually had enough spontaneous applicants for female positions. ${ }^{.}$A gendered division of labor enhanced the influx of women into nursing, which was a reasonable career opportunity within the small range of work options for women.

Implicit in the social definition of nursing as women's work was the assumption that these women would be single. Paid employment for middleclass married women had not yet been debated, let alone accepted. The notion of a respected social position for men was different. Aspirations and social respect for working- and middle-class men included marriage, a home, and an income high enough to support a family. The gendered structure of nursing work prevented men from reaching such goals; traditionally, the social and economic aspects of the attendants' work in asylums implied living in, a low income, and no opportunity for marriage or supporting a family. This had been the case since asylum reform had begun. The social position of the poor lower-class attendants reflected these characteristics, and the floating, often seasonal group of workmen and maids never stayed long in their positions.

Introducing nurse training was in part intended to raise the social position and aspirations of the lower class and in part to create a stable and disciplined workforce. This process was in many ways comparable to creating an industrial working class at that time. ${ }^{2}$ Yet for male nurses the aspiration to earn an income large enough to marry and sustain a family, and to attain a working day similar in length to that which their counterparts aspired in industry was difficult to realize. It took activism on the part of the workers similar to that in industry before asylum boards began to provide the conditions that made 
nursing work more attractive to the respectable male workers they were looking for.

The nurses all lived within the institution, which interfered with the opportunity to marry, but boards feared the cost of measures that would enhance the social life of male nurses outside the asylum. As in industry, the regularization of work, such as with shiftwork, was not easy to apply in residential institutions, in part because personnel had to be immediately available. The night care that was established on the observation wards entailed only a relatively small number of nurses and was designed to facilitate close observation, rather than creating an opportunity for nurses to live outside the asylum. Boards were hesitant to allow their nursing personnel to live out of the asylum grounds. Living in, being available day and night was part of the traditional asylum culture, in which attendants, like (single) servants in (middleclass) families or farm workers on larger farms, lived in a family structure. Improvements in transportation and the availability of the telephone enhanced the possibility of "living out". Yet when the board of Meerenberg eventually began to build family housing for their personnel in the I9Ios, they built the homes adjacent to the institution so that personnel remained easily available. ${ }^{3}$

The lack of opportunities and the gendered structure of nursing work was a bitter disappointment for male nurses. In I903 male nurse Reijnders, angry and frustrated, brought up the "verplegerskwestie" (male nurse question) in the Journal of Sick Nursing. He felt that male nurses were severely disadvantaged as compared to women. ${ }^{4}$ The inability to marry or sustain a family was not the only limitation for male nurses, Reijnders argued. Far more important was the lack of social respect for male nurses. They were treated, he bitterly noted, as if they did not have the same level of refinement and compassion as female nurses; some institutions did not even train male nurses. There were no rest homes for male nurses and, more importantly, no opportunities to become head nurse. Many male nurses experienced this as a humiliation and it generated great resentment of the female nurse workforce, although, Reijnders assured, he personally had nothing against female nurses. ${ }^{5}$

\section{Squeezed out}

For male nurses the development of nursing based on assumptions of women's work and education was unexpected, if not alienating. Before the introduction of nurse training, male and female attendants covered the work in the asylum's male and female departments, respectively, in equal num- 
bers. Once nurse training was established, male nurses were marginalized, not only in terms of numbers but also in terms of value and status. Particularly in Meerenberg, Van Deventer's reorganization of the nursing staff resulted in a rapid decrease in the number of male nurses.

In I892, at the start of nurse training, male nurses at Meerenberg formed about half of the nurses, with that proportion decreasing to i9 percent over ten years. Within a decade, from 1892 to 1902 , the number of male nurses at Meerenberg fell by about a third, from 62 to 44 , whereas the number of female nurses more than doubled, from $7 \mathrm{I}$ to 184 . The total number of nurses grew about 70 percent, from 133 to 228 , partly due to a shortening of working hours. In this same decade the number of patients increased only 5 percent, from $\mathrm{I}, 285$ to $\mathrm{I}, 353 .{ }^{6}$

In addition, the status and prestige of male nurses declined because of their exclusion from career opportunities. By I900 Meerenberg had filled all supervisory positions with female head nurses. When medical director Van Deventer began his nursing reform, he initially attracted a trained male nurse to the asylum. In 1892 he appointed trained male nurse E. Meuleman, ${ }^{7}$ who was a graduate of the White Cross training course in the Buitengast Hospital in Amsterdam, previously established by Van Deventer. Meuleman had a respectable background. He was a deacon of the Christian Association for Epileptics, which had an institution for epileptics close to Meerenberg. ${ }^{8} \mathrm{He}$ represented the new image of a properly trained nurse of good social standing, and he came to Meerenberg at the request of Van Deventer. ${ }^{9}$ But despite his good standing Van Deventer did not give him a similar leadership position to those he gave to the female graduates of the White Cross. They became head nurses, whereas Meuleman was appointed as a first nurse on the fifthclass quiet division of the male department. After a year he opted for a position outside the wards as supervisor of the male workshops. That position became the only career opportunity left for male nurses.

Similarly in Franeker women filled the supervisory positions in nursing. When Franeker began its nursing reform, the board initially appointed a trained male nurse, P. N. Bras, to the male department, along with a trained female nurse in the female department. Unfortunately, Bras' appointment as a male nurse was not a success. According to the medical director's report over I898, the appointment created tension because of Bras' ambiguous position among the servants, who were hierarchically of the same rank. ${ }^{\text {to }}$ Significantly, in 1902 the Franeker board appointed another male graduate nurse, J. Th. Jansen. He moved to a position as supervisor of housekeeping seven years later, when the traditional house father and mother retired. It is likely that it was the only position from which he could make a career. ${ }^{\text {II }}$ Notably, 
Jansen had obtained the prerogatives of living outside the asylum and was also married. In all probability, he would not have stayed otherwise. ${ }^{\text {I2 }}$

Because of the Roman Catholic tradition of order nursing, Voorburg was less affected by the feminization of nursing work and training. The Brothers of Our Lady of Lourdes remained in charge of the male department. In Veldwijk a different, but also gendered, criterion prevented single male nurses from attaining leadership positions. Whereas single female nurses could move into the leadership positions of housemother and head nurse, male nurses usually only attained similar positions when married. Ironically, the poor income and living in severely compromised the likelihood of marriage.

The restricted work and career opportunities for male nurses devalued the mental nurse diploma for them. At Meerenberg, medical director Van Deventer argued that for male nurses it was most important that they had experience and skills in artisan jobs, so they could guide patients in their work. ${ }^{13} \mathrm{He}$ believed that attaining the diploma was less important for them. At Meerenberg, the number of male nurses attaining a diploma was always much lower than the number of graduating female nurses. Of the 70 nurses who graduated before I 897 , only I4 (20 percent) were men, and between I 898 and I9O2 only 7 percent were men. The slight increase in numbers in the period I907 to I9IO may have been due to the new exam regulation of the NVP, which made the course more feasible for less educated nurses. But the number of male graduates did not really increase until after I9I2, when the Meerenberg board had decided to build houses for male nursing personnel so that they could marry. Between I9I2 and I9I6, 387 nurses graduated, I23 (32 percent) of whom were male. Graduation was one of the criteria for qualifying for a house. ${ }^{14}$

In Veldwijk the number of male student nurses was lower than that of their female counterparts. In part this was due to the lower number of male pavilions compared to female pavilions, but it was also harder to attract male nurse applicants. ${ }^{15}$ To enhance recruitment, the Veldwijk board approved a regulation in 1896 allowing male nurses to marry. Compared to Meerenberg, which did not accept male nurse marriage until I904, this was a relatively progressive step. ${ }^{16}$ But in both institutions the conditions for marriage remained restricted. Male nurses at Veldwijk were given permission to marry after eight years of correct and continued service on receiving the diploma, which in itself took three years to obtain. The youngest possible age to be accepted for training was eighteen years, so the board required several years of maturation before granting the privilege of marriage. ${ }^{17}$ In Meerenberg male nurses needed to have a satisfactory work history of five years within the institution, and a minimum age of twenty-six..$^{18}$

Most likely because of the early acceptance of a regulation for marriage, the 
percentage of male nurse graduates at Veldwijk was higher than in Meerenberg. Usually about 40 percent of the graduating nurses were men. In the period I9I2 to I9I6 the number of male graduates decreased to 23 percent. ${ }^{19}$ This was partly due to mobilization as a result of World War I. However, the board had also begun to appoint female staff nurses on male wards because of the inability to attract male nurses, ${ }^{20}$ who clearly had other employment options. As with female student nurses, male student nurses often left long before graduation. ${ }^{2 \mathrm{~T}}$

The feminization of work on the wards dictated that male nurses would be more or less restricted to areas of work that could not be covered by female nurses and as a consequence had less prestige within the new female conception of nursing work. Initially in Meerenberg, and later in the other asylums, female nurses were put to work on male sick wards. In particular, the increase of bed rest, which gave wards the character of sick rooms just like in a general hospital, justified the use of women for nursing work in all departments. Male nurses were needed predominantly for their bodily strength. The care of the severely disturbed male patients, for instance, remained the domain of male nurses. ${ }^{22}$

\section{Nurse Artisans}

Traditionally, before the introduction of mental nurse training, the asylums contained two groups of male workers responsible for overseeing patients. One group had more stable positions as skilled artisans in the male workshops and in maintenance positions. They were charged with overseeing patients involved in work. In Meerenberg, artisans had a considerable responsibility in patient supervision. In 1896,58 percent of the male patient population - over three hundred patients - were involved in work; a third of them had housekeeping duties on the wards, but all others were supervised by artisans in workshops and maintenance. ${ }^{23}$

Direct patient care was usually covered by a second group of predominantly lower-class unskilled laborers, often including workmen, seasonal workers or former farmhands. They left as soon as they could find a better position elsewhere. One of the implicit intentions of asylum nursing reform of the late nineteenth century was to replace this latter group of men or restructure them into a male nursing workforce. But it was difficult to conceptualize the new role of a trained male nurse. Should he be a nurse experienced in the care of the sick or should he be an artisan overseeing patients in work? Was the latter a nursing role or an artisan role? Or was the new nurse an artisan? Or, conversely, a position strongly promoted by medical director Van Deventer, 
should the traditional artisan be subjected to nurse training? Since in theory the new nursing tasks that had been generated from somatic treatments were predominantly women's work, the male nurse role was unspecified. The new notion of male nursing reflected an ill-defined compromise of skilled artisan work and direct patient care. Male nursing did not seem a "real" occupation, but at best a temporary trade on the road to a more definite, more respected position as a nurse artisan.

This indecision contributed to the ambivalent position of the male nurses. Male nurses gained little support from medical directors, who were be divided in their opinions as to how to conceptualize the role and competence of the male nurse. They judged male nurse competence by different standards to of female nurses. Women were judged in terms of character, decency, and a healthy outlook, ${ }^{24}$ but in the case of male nurses, directors looked more precisely to an applicant's record as a workman. In a survey conducted in I90I, most directors underscored that they preferred to hire male nurse applicants who already had a specific skill or trade. ${ }^{25}$ Presumably they felt that these men had proven their competence in respected, regular work. ${ }^{26}$

Van Deventer, who presided over the survey committee, held an even stronger opinion. The question of male nurses, he argued in I899, would not be resolved until male nurses were provided with homes and the opportunity to marry, just like the artisans. He proposed recruiting the asylum artisans, including shoemakers, bleachers, and garden workers, from the male nurse graduates. Consequently, he continued, the mastery of such artisan skills should be a prerequisite for enrolling in nurse training. ${ }^{27}$ On graduation, male nurses could then move into a position as "nurse artisan" and marry. Apparently Van Deventer did not consider direct patient care an occupation for male nurses, despite the fact that on certain male wards patient care was dependent on male nurses. Actual nursing, he stated, should be assigned to women. ${ }^{28}$

It was very difficult to recruit artisans under such conditions. Moreover, Van Deventer's attempt to define male workshops as nursing work was not very successful. Artisan work fitted less easily into a training discipline for male nurses than domestic work and home economics did in the preparatory character training of female nurses. It could be argued that women were used to combining their domestic artisan work with caring roles. ${ }^{29}$ Whether the work in the male workshops - the work of the shoemaker, the bookbinder, or the bleacher - should be considered nursing work and therefore require nurse training remained unclear. The Meerenberg asylum advertised for these artisans together with student nurses in one and the same advertisement on an ongoing basis. ${ }^{30}$ 
It was also unclear, particularly at Meerenberg, whether artisans should be incorporated into the medical hierarchy, under the responsibility of the medical director, or whether they should remain part of the administrative staff. Eventually Van Deventer created a nurse artisan training route for the workers in the patient workshops, such as the shoemakers. They could opt for an appointment as assistant male nurse, which implied that they had to share in ward duties on Sundays, but they also attained the privilege of free housing outside the asylum grounds. However, they earned less than a graduate male nurse and may, for this reason alone, have been attracted to nurse training. But most artisans appointed at Meerenberg had socially higher valued skills, including carpentry, gardening, smithery, and other maintenance crafts. They were part of Meerenberg's administrative service over which Van Deventer never attained control. These artisans lived outside the asylum grounds, earned more than male nurses, and neither fitted into a nurse training routine nor were involved in ward work. ${ }^{3 \mathrm{I}}$

The psychiatrists' preference for hiring men who had artisan skills as nurses must be understood as an attempt to attract workers from the respectable lower middle- and working- classes, rather than from the lower working class. Although late nineteenth-century society was characterized by a distinct division of social standing, the social layers were not homogeneous categories, and they were in transition as a result of industrialization. Gradually a broad category of industrial laborers emerged, while at the same time the number of workers in trade, transport, and service jobs increased. ${ }^{32}$ Contemporaries regarded skilled laborers, workmen, manual workers, and artisans as part of a broad category of lower middle- and working-class people in regular jobs, including schooled or skilled industrial workers and service personnel. Small shopkeepers and small farmers also belonged to this group. This group was distinguished from a lower working-class group of unschooled, unskilled irregular workers such as (seasonal) farm workers, porters, navvies, or other free (that is, not in regular service) workers. ${ }^{33}$ However, the preference for the former group does not explain the subsequent difficulty in conceptualizing the role of the male nurse.

It can be assumed that the subtle differentiation in status between the workshop and maintenance workers, and the undefined position of the nurse was also related to the level of intimacy they shared with patients. The more intimacy workers shared with patients, the lower their status, and the more difficult the patients, the less attractive and therefore aspiring the work. Traditionally the status of male attendants who worked on the wards was lower than those who supervised patients in the workshops. In turn, work in those workshops, which were specially designed to involve patients in work and, 
more importantly, to produce material for patients - that is, making and repairing patients' shoes (shoemaker) or clothes (tailor) - was probably less valued than workshops for skilled artisan work for the maintenance of the physical plant, such as carpentry, painting, or smithery, and, once electricity and central heating were introduced, the work of the engineers. The latter positions has the least involvement with patients - often only a few patients were put to work under the supervision of these artisans, and often patients in these jobs were skilled in such work. ${ }^{34}$ The combination of lower valued, more intimate work with patients on the wards and artisan work created a status conflict in the role of the male nurse. The female definition of nursing work exacerbated this conflict.

The combination of nursing and artisan work for male nurses was not unique to Meerenberg. Veldwijk followed a similar pattern of a nurse-artisan career for its male nurses. One of the first male nurses appointed in Veldwijk, Hendrik Beimer, began his career in nursing on the opening of Veldwijk in I886. Originally he had been a carpenter, but in military service he obtained some practice in nursing as a military hospital soldier. This experience, and his faith in God's guidance, motivated him to reply to an advertisement for the VCV for nurses at Veldwijk in I 885. For four years, he worked as a nurse in Veldwijk's first male pavilion. In every way, Beimer noted in an interview on the occasion of Veldwijk's fiftieth anniversary, personnel had to manage on very little during the early years. Pay was low and the rules very strict. Nurses had to go on regular walks with all of the patients, Beimer recalled. If one of them escaped, the nurse in charge had to pay for the costs of getting the patient back. As pointed out in Chapter IV, once he had to pay 2,50 guilders out of a weekly salary of only 2 guilders. ${ }^{35}$ But Beimer appreciated the dutiful lifestyle, the earnest prayers, and the devoted work. With time he obtained a position in the apothecary that the medical director initially ran out of his home. Beimer married in 1890 ; he kept the position of apothecary attendant for another forty years. ${ }^{36}$

The board and Asylum Council's expectation that personnel adhere to disciplined conduct and skill was not often met. In response they regularly discharged personnel because of "misbehavior" or a "bad character". One male nurse appointed at Veldwijk in December I893 left in April I895. He was considered to be a "childish, unreliable" character. Another male nurse, appointed in I894, left after a year because he was "careless" and "dirty". And a salesman who was hired as an aspirant nurse in I9Io was fired due to "misconduct". ${ }^{37}$ But the fact that many other male nurses left by choice, often within a year or even a few months, may indicate that many nurses were disappointed or had opportunities elsewhere. $3^{8}$ 
For financial reasons Veldwijk did not fill all male nurse positions with married nurses. As a result Veldwijk lost many experienced, competent nurses. Some of them, just like their female counterparts, were forced to look for other opportunities because they could not stay after engagement or marriage. ${ }^{39}$ Male nurse Teunis Boone, who came to Veldwijk in I892, had to leave after his engagement to a female nurse in 1895 , even though he was thought of as a "good, reliable" nurse..$^{\circ 0}$ Similarly, graduate nurse Reint Wieringa, who had obtained his diploma at one of the other VCV asylums, left Veldwijk after a year of service in 1905 because of his marriage. ${ }^{4 \mathrm{I}}$ But some male nurses did stay and found careers as housefathers or "married nurses".

The nurse artisan positions apparently lent themselves best to the purpose of married positions for male nurses. Shoemaker Lambertus van Oene began as an aspirant nurse in I89 at the age of twenty-two. He obtained his diploma at Veldwijk, married in I899, and had six children. After twenty years of service as a married nurse, he became supervisor of the male workshops, where he had probably already worked as a nurse-shoemaker. Here he remained until his retirement in I93I. ${ }^{42}$ In I9I5 Veldwijk had eighteen married male nurses on its staff. Quite a few followed the pattern of nurse artisan work and held positions such as nurse-painter, nurse-farm worker or nurse-carpenter while they supervised patients at work. Nurses did not just move into artisan roles related to patient supervision. Several of Veldwijk's personnel, such as the office worker, apothecary assistant, porter, and guard, were graduate nurses. At times nurses may also have aspired to move into artisan or administrative positions in order to escape from the often burdensome intimacy of the wards, the long work hours, and the low status associated with ward-based work. 43

\section{The Home of a Married Nurse: A Place of Family Care?}

The early acceptance of the marriage of male nurses at Veldwijk was not solely driven by idealism. Medical director Van Dale favored married nurses with families because they could participate in a network of families at Veldwijk who took patients into family care. Veldwijk took a leading position, compared with other Dutch asylums, in the application of family care - that is, boarding chronic quiet patients with trustworthy members of the asylum personnel and their families or with other families living in the surroundings of the asylum. Van Dale also utilized family care to board out patients for a few months prior to discharge as part of their recovery and transition to home. ${ }^{44}$ Patients remained under the institutional guidance of the asylum physician. Family care fitted into Veldwijk's Christian family ideology on asylum care. ${ }^{45}$ 
The almost mythical but powerful example of family care in the Belgian town of Gheel kept the idea attractive and alive. For centuries the families of this community had boarded insane patients, ever since it had developed as a place of pilgrimage of the legendary miraculous healer Dymphna. ${ }^{6}$ Since the middle ages (1286) the Saint Dymphna Guesthouse and Church have existed there, later with a separate sick room for lunatic pilgrims. Clerics, and later on canons, oversaw their care. But as the influx of lunatics grew, the clerics placed more and more patients with families in the area, and many lunatics stayed in Gheel for the rest of their lives. ${ }^{47}$ In the mid-nineteenth century, as the influence of government on insanity care evolved, governmental authorities transformed the guesthouse into a formal medical institution, with an asylum-infirmary for acutely mentally ill patients. Nevertheless, a large number of chronic patients continued to be boarded with families in the area..$^{8}$

During the I89os some Dutch asylum psychiatrists, and the state inspectors in particular, grew enthusiastic about this form of treatment. They saw it as a solution to the rapidly growing number of chronic asylum patients. ${ }^{49}$ Other European countries had also applied the model - in Britain, for instance, during the 1850 s and I 860 s when doubts about the growing size of the asylum system grew. ${ }^{\circ}$ Medical director Van Dale of Veldwijk was one of the proponents of this model in the Netherlands. He was in regular correspondence with the medical director of the Gheel asylum. In I902 they initiated a conference on family care, which was held in Antwerp. ${ }^{\text {II }}$ The idea caught on with medical director Van Deventer in Meerenberg. Both doctors brought up the issue in the NVP, who appointed them to a committee to report to the NVP on the prospect of such treatment in the Netherlands..$^{52}$

In I894 Van Dale placed eleven patients from the Veldwijk asylum in family care. Some were upper-class patients, placed in a family along with a private nurse to provide for their care. But gradually Van Dale placed patients from all social classes in family care. He selected families carefully according to the social standing of the patients. First- and second-class patients, for example, stayed with Veldwijk's pastor, with one of the office clerks, or with the head of the Christian school at Ermelo. Third-class patients usually stayed with the asylum's artisans or married nurses. By I897 the number of patients in family care had increased to thirty-three, while around i9ıo Veldwijk had seventy to eighty patients placed with neighboring families, who included both families associated with the asylum as personnel and non-personnel families..$^{53}$

Initially this system could only be designed for private paying patients because neither the poor law nor the insanity law provided any opportunity to have municipalities pay for care of the indigent mentally ill outside of asylums. This may in part explain why the system grew so popular in Veldwijk, 
because first- and second-class paying patients formed a third of the patient population. ${ }^{54}$ In order to resolve this problem, Van Deventer and Van Dale proposed and drafted a national regulation on family care, which they sent to the state inspectors for approval. In 1904 the insanity law was changed in order to make family care possible for indigent patients. 55

In Meerenberg, Van Deventer had initially applied the idea of family care to some upper-class patients, ${ }^{56}$ but in 1902 he placed the first five indigent patients with families in the surrounding community. His initiative failed, in part because at that time there was not yet a judicial base for placing patients outside the asylum, but also because boarding patients provoked strong resistance from the surrounding community. Some families in the surrounding area immediately left once they learned that a number of insane patients were going to live in their neighborhood. Van Deventer's successor, Van Walsum, saw little future for this form of treatment and the three patients still boarded out in 1905 returned to the asylum in 1906.57

Both in Veldwijk and Meerenberg the opportunity for male nurses to marry was initially linked with the condition that they should board one or two patients with their new family. ${ }^{8}$ Van Dale preferred to place patients with the families of Veldwijk's personnel because they were familiar with the care of mentally ill patients.59 In I897 eleven families at Veldwijk had taken in patients. ${ }^{60}$ Married nurses usually had one or two patients placed in their homes. VCV physician Leendert Bouman emphasized the importance of married nurses in family care. Not only the male nurse, Bouman noted, but also his wife should be competent and qualified before a the marriage of a male nurse could be approved, because her role was equally crucial in taking care of boarding patients. ${ }^{6 r}$

The moral obligation to support family care at Veldwijk must have been strong, particularly because personnel with long service records were usually loyal to the institution. Many may have liked the extra income from boarding fees, since salaries at Veldwijk were low. But not all of the nurses appreciated the moral obligation of taking in patients. In I909 married male nurse De Vries expressed strong objections against the implications of family care for personnel. He argued forcefully that it was impossible for his family, and probably for many families, to take in patients. His objections reflected a growing awareness during the early twentieth century among nurses regarding their social position. He asked the board for a salary increase and the freedom not to accommodate patients. The board immediately defended its position, based on the exisiting financial burden posed by married nurses on the asylum's budget as they were provided with family incomes and housing. ${ }^{62}$ The resistance of male nurse De Vries to the appeal based on loyalty and 
moral obligation that underlay the system of family care represented a broader process of changing work relationships between employers and personnel. Similarly, another male nurse argued that, after a working day within the asylum that was already too long, married male nurses should not be forced to continue their work at home, jeopardizing the happiness and leisure of their family life. ${ }^{63}$

\section{Growing Class Consciousness}

The right to privacy at home, a distinction between work and family life, limited work hours, relaxing leisure time, an adequate salary, and spending time with the family comprised the aspirations of an increasingly class-conscious new working class. The increasing dissatisfaction among male nurses about their undefined, ambivalent social position reflected this consciousness. ${ }^{64}$ Both class and gender relationships shaped their growing awareness. On the one hand, influenced by an increased level of organization of workers and union activism, they identified with the inequalities and contradictions experienced by workers in general. On the other hand, male nurses felt their professional aspirations threatened. Male nurses saw their inferior status in part as being the result of the gendered privileges of their female counterparts. ${ }^{65}$ The image of trained female nurses resonated with the respectability of sisters devoted to care, even of angels of mercy. To their frustration the newly trained status did not give such an image and prestige to male nurses. Instead, it seemed that their positions remained associated with the same inferiority and disgrace as the poorly respected lay attendants. They began to resist the devaluation to some sort of "secondary rank nurse" with a more or less inferior status. But they perceived little support for their professional interests within the predominantly female nursing organizations.

\section{Male Nurse Activism and the Career of P.N. Bras}

The career of male nurse P.N. Bras reflected the ambivalent experience of male nurses. Disappointment, growing self-consciousness, and professional pride alternated in the often contradictory incidents that shaped Bras' life. His career illustrates how a growing level of organization among nurses provided them with a context in which they could emancipate themselves, shape their ideas, and strengthen their social status.

In I893 Bras took the NVP exam as a student nurse in the Medemblik state asylum. He continued his career in the Rotterdam asylum. He then obtained a position as (the first) male head nurse in the Franeker asylum in 1898 . The 


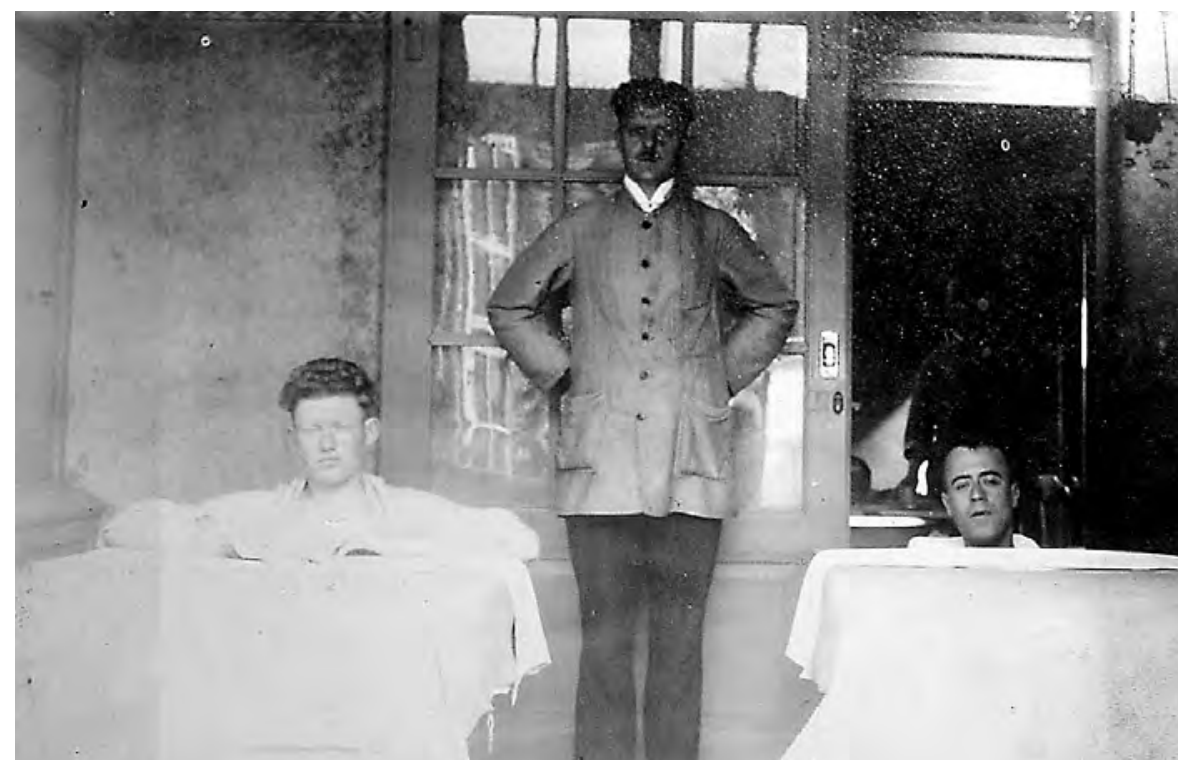

13. Male nurse attending patients receiving prolonged bath treatment, Meerenberg Asylum, ca. I9ıо.

initiative of Franeker to appoint a graduate male nurse on the male wards was not successful: the other attendants did not accept this position. ${ }^{66}$ Bras left Franeker within a year and took a position as a first nurse on one of the wards at Meerenberg. As was typical of the career pattern of male nurses within asylums, Bras moved into the only leadership position available to male nurses. In I900 he was appointed as "head nurse-supervisor over the male workshops". ${ }^{67}$

Bras soon felt bitterly disappointed about the lack of support and appreciation he received for his work. In particular, he felt humiliated by the authoritarian attitude of medical director Van Deventer. In desperation, Bras spoke to one of the board members, and in an accompanying letter he explained that his conflict with Van Deventer had begun after the latter had ordered Bras to become preceptor in the church, a job Bras had refused. From then on Bras often could not take his day off and requests to leave the grounds for a night were rejected. Van Deventer often humiliated him in front of patients.

The final unacceptable event for Bras came in I902, when an article signed by twelve male nurses complaining about female nurses taking care of male patients appeared in one of the Amsterdam newspapers. Shortly thereafter a brochure was published with similar criticisms. Bras was called to the direc- 
tor's room and in the company of two other physicians and the steward, Van Deventer accused Bras of being the author of the brochure and of having initiated a plot with other male nurses against Van Deventer's campaign for female nursing. To defend himself against such accusations and ill treatment, Bras eventually turned to the board for help..$^{68}$

Bras' malaise was no isolated event. The ambiguous position of male nursing created a great deal of tension in many institutions and should be understood as a major cause of the high turnover of male nurses. Activism among male nurses increased and may indeed have formed the background of Van Deventer's suspicious accusation of Bras. In 1906 a group of twenty alarmed male nurses founded the Nederlandse Verplegers Vakvereniging (Dutch Male Nurse Professional Association [NVV]). It explicitly presented itself as a professional organization and not a union. Bras was on the founding board of the NVV and participated in establishing a local branch of the organization in Meerenberg in the same year.

The goal of the NVV was to create a qualified and respected corps of male nurses, whose interests would be represented by the NVV. ${ }^{69}$ If they had a chance to regain control over nursing of male patients, male nurses argued, they would be able to have similar training and similar careers to female nurses. It would enhance the value of their diploma because they would have experience with all types of patients. But putting male nursing back in the hands of male nurses was not the NVV's only goal. Male nurses also campaigned for more social freedom. They argued that "monasterial repression" in asylums severely limited their motivation for devoted care. ${ }^{70}$

The activism that grew among male nurses to defend themselves against what they saw as gendered inequalities blended various sources of their frustration. They resented their competitive position with female nurses and were frustrated about the lack of social respect they had. Moreover, they perceived the alleged encroachment of women as an intrusion into a traditionally male domain of work - that is, the care of male patients. The tension that arose among male nurses illustrated their increasingly vulnerable position in a rapidly changing labor market.

Male nurses were a minority in the nursing profession. In around igio male nurses in hospitals formed about Io percent of the total number of nurses, whereas 36 percent of the nurses in the asylums were male..$^{77}$ With the economy expanding, the supply of male nurses did not meet the demand. Asylum boards experienced difficulties in attracting male nurses and often had to accept men who were not well qualified, which in turn threatened the reputation of trained male nurses. The NVV responded to this threat by attempting to close the ranks to unqualified persons. In 1906 it established an informa- 
tion bureau, with the aim of mediating in the placement and recruitment of nurses. The NVV members tried to gain the support of asylum directors to hire male personnel through their bureau. ${ }^{22}$ The bureau, however, received little support.

With the private duty market expanding in the early twentieth century, male graduate nurses sought to secure their position in private duty. The absence of opportunities on graduation in both hospitals and asylums favored the outflow of nurses to private duty. But in private duty, male nurses experienced strong competition from their female counterparts. Many male nurses who attempted to sustain themselves in private duty could only take cases with male patients, whereas women served all groups, including children. The nursing bureaus of the nursing organizations also competed with male nurses for male patients.

In response to the alleged intrusion of women into their domain, some of the NVV members developed a strong resentment against female nurses who took care of male patients. Some male nurses exploited the still prevalent cultural ambivalence to a public role for middle-class women. Although the aura of higher principles and devotion that surrounded female nursing protected and legitimized the work of female nurses, the image of immorality and fornication attached to women in public roles had not disappeared. Some male nurses argued that it would be "whorish" to have female nurses take their places in the military hospitals. Others argued that female nurses taking care of male patients aroused too much sexual excitement in the male patients, the female nurses, or both. Yet others felt that women should be protected against disgrace and shame and should not be put on the road to prostitution. ${ }^{73}$ These arguments soon died down, however, as male nurses quickly sensed that such denigrating comments about women could easily be used against them.

Among the founders of the NVV were a considerable number of private duty nurses who aspired to establish their own male nursing bureau. But the investment in founding and managing such an organization was a big challenge. Who of the male nurses, one of them angrily noted, lives in such a position that he would have a telephone and waiting room available, could take calls, or would have 300 guilders available for initial investment? And more importantly, would the public and physicians support such an organization?74

Yet by I 909 the NVV had opened its first Centraal Adresbureau (Central Address Bureau) in Amsterdam. Shortly after this another bureau was opened in The Hague. The bureaus flourished in these two large cities, although their organizations remained small. 75 The expanding service market for nervous patients was another area in which male nurses could make a living, quite comparable to their female counterparts. In I907 one of the NVV 
members, male nurse B. Muis, opened Huize Veelhorst, a rest home for male nervous patients in which a physician provided consultation and treatment. NVV member Johannes M. Luyten managed a sanatorium, Villa Germania, in the popular resort area along the North Sea coast at The Hague. ${ }^{76}$ But only a few male nurses could sustain themselves in such positions. The majority of NVV members were asylum nurses. ${ }^{77}$

In August, I907, the NVV held its third so-called "propaganda meeting" at Meerenberg in the nurses home. Van Deventer's successor, Gerardus C. Van Walsum, approved the meeting and even gave an entertaining and amusing speech to the male nurses..$^{7}$ He was more supportive of male nurses at Meerenberg than his predecessor had been and favored various improvements in their social position. Immediately on beginning his directorship in I904, Van Walsum increased the opportunity for nurses to leave the asylum in the evening and supported a regulation for the marriage of male nurses. He also arranged a "brother house" or male nurses home for the male nurses in the former director's residence, since he himself opted for a house outside the asylum grounds. Bras was appointed as supervisor of the brother house. ${ }^{79}$ Bras must have felt proud on the evening of the meeting. Most likely arranged by himself, but formally offered by Van Walsum, the male nurses home held a festive dinner for the entire group of about forty NVV male nurses. All members felt it to be a gesture of sympathy to their cause..$^{80}$

Bras made quite a contribution to the development of the NVV. In I907 he was appointed as an administrator of the editorial board of the NVV's journal Maandblad van de Nederlandse Verplegers Vakvereniging (Monthly Journal of the $N V V)$. Five years later he became the chairman of the association. The most important measures the NVV took to fight its "battle", as Bras called it, in the same way as other nurse organizations, were sending petitions to official and influential bodies and national and local authorities, and organizing propaganda meetings ${ }^{81}$ The local Meerenberg branch affected the politics of the asylum itself by approaching the director, the board, and the provincial council requesting living out and better rooms for the male nurses, the promotion of male nurses into leadership positions, and the improvement of the quality of the food.$^{{ }^{2}}$ If they felt it to be necessary, the NVV did not hesitate to personally visit politically influential people.

In order to keep control over their own professional interest, Bras ardently advocated for a politically neutral viewpoint of the organization, meaning that he wanted to keep the organization independent of the unions. Smaller professional organizations such as the NVV encountered great pressure and competition from larger unions to become loyal to "the class struggle" in general. Although Bras favored the work of the unionist Algemene Nederlandse 
Ambtenaren Bond (General Dutch League of Civil Servants [ANAB]), and he even helped to found a local branch of the ANAB at Meerenberg in I9IO, he believed that such a labor organization of civil servants could not fight the cause of nurses. Bras and many of his colleagues feared that if the NVV joined a union, "unqualified" people would take control over nursing and make uninformed decisions. The NVV leadership therefore cautiously tried to avoid such "political infection". ${ }^{8}$

As with the rivalry with the ANAB, the male nurse organization was in continuous debate with their female counterpart Nosokómos. In the campaign for the improvement of their social position, the issues of male nurses closely matched the interests of female nurses. The state regulation of nursing exams and licensing, strongly pursued by the female nurse organization Nosokómos, was supported by male nurses. In order to close the ranks to unqualified personnel, they felt that the government should approve the state regulation of nurse training. NVV male nurse C. Drosterij was on the board of the association to obtain state registration, founded by Nosokómos. ${ }^{8}$ Both groups also shared an interest in the campaign for higher salaries, a better protected legal status, and better working and living conditions within hospitals and asylums. Moreover, both the NVV and Nosokómos were relatively small organizations that competed for members with unions and the much larger medically dominated NBZ.

The intense personal investment of nurses in their organizations generated strong reactions if conflict and rivalry arose between the groups. Bras, for example, took it personally when he learned that during the summer meeting of the ANAB at Meerenberg in I9I3, the majority of Meerenberg's NVV members withdrew their membership from the NVV and switched to the unionist ANAB. Most likely this maneuver was related to the pending Provincial Council's approval of new regulations on the social position and legal status of provincial civil servants, which included all of Meerenberg's personnel. The ANAB strongly influenced this political battle, and the new regulations were indeed accepted. They entailed a ten-hour working day, one day off a week, and a salary increase. But the split was a painful experience for Bras. He felt that all his hard work to uplift the male nurse and increase his self-consciousness seemed to be wasted. Still, he was proud to learn that many of the requests for improvement made during the last address to the Provincial Council, which he had helped to prepare, were indeed implemented.

The new regulations entailed increased salaries, which became the same for male and female nurses. Already augmented in I9I0, salaries rose another 20 percent for unmarried, male graduate nurses, from 325 to 390 guilders including board and lodging, and for female graduate nurses another 40 per- 
cent from 275 to 390 guilders ${ }^{85}$ Opportunities for living out increased, particularly for male nurses, which reduced turnover among male nurses from 54 percent in I9Io to Io percent in I9I4. ${ }^{86}$ Moreover, the I9I3 regulations prescribed a ten-hour working day and one day off a week. Because this measure implied an enormous increase in the demand of nurses, the weekly day off for nurses was not implemented until I9I4, and the ten-hour working day in I9I $6 .{ }^{87}$ The regulations demonstrate that nurse activism gradually began to bring about some results, particularly in a provincial institution such as Meerenberg, where the personnel were actually civil servants. An eight-hour working day for nurses, similar to their counterparts in industry, did not materialize and would not for several decades. ${ }^{88}$

Bras himself, however, could not enjoy the fruit of the new regulations. Quite unexpectedly, due to unexplained "special circumstances", he left Meerenberg and the NVV at the beginning of I9I3. He had moved to the land of dreams and aspirations, and wrote about the politics of nursing at Meerenberg to his friend and former NVV colleague C. Drosterij in a letter from Grand Rapids, Michigan, in the summer of I9I4. ${ }^{89}$

During the late I9IOs the many shared interests between female nurses and the NVV overruled the gendered rivalries. In I9I8 the NVV opened up its organization to women. $9^{\circ}$ Yet the NVV's negotiations with Nosokómos to merge their organizations failed. Nosokómos kept its independent stance, particularly since in I9I9 the NVV joined the larger Algemeen Nederlandsch Vakverbond (General Dutch Federation of Trade Unions). Nosokómos refused to merge with a unionist-oriented group. ${ }^{9 \mathrm{I}}$ In the end, the organization of male nurses was too vulnerable to survive as an independent group, despite the dedication of its founders to establish an independent community of male nurses.

\section{Gendered Politics versus Expertise}

For the NVV male nurses it was difficult to legitimize their role. As Reijnders pointed out quite rightly in his article on the male nurse question in 1903, male nurses did not attain the same social respect as women, $9^{2}$ whose role in nursing at the time was legitimized by a domestic ideology on women's work. From the writings of female nurse leaders such as Antonia Stelling, Henriëtte Koffijberg, or Anna Reynvaan, it becomes clear that these women derived their professional identity from their role as women. Acting in a female, refined, and competent manner were the prerequisites for female nurses to do the job well.

Such a female nursing ideology did not work for male nurses. The liberal 
male nurses of the NVV were not attracted to a traditional, Christian perception of the caring role as one of devotion and self-sacrifice either, despite the fact that such legitimation had traditionally provided nurses, including male nurses in religious orders and deacon associations, with a great deal of social respect. ${ }^{93}$ Moreover, whereas physicians very much supported the perception of nursing as women's work, they did not provide much support to male nurses in developing a rationale for the role of men in nursing.

It is therefore interesting to look in more detail at how the NVV male nurses attempted to legitimize their role. Because of their gendered position, male nurses had to come up with some alternative to the womanly construction of nursing work. And they did.

Nurses were not merely objects of medical reform. Despite medical control, nurses were increasingly able to develop some independent thinking concerning their work. Nurses, both male and female, contributed to the new definitions of their role, albeit in a limited way due to the social position they occupied. Nursing formed a new occupational field in which knowledge and experience was renegotiated and new social meanings of nursing formulated. Even though doctors claimed and defined nurses as "their" object of change, at the same time nurses reflected on the social circumstances they experienced and developed their own strains of thought, not necessarily restricting themselves to what doctors told them.

In part, doctors controlled the socialization of mental nurses through the new mental nurse training. Physicians wrote the first textbooks for the purpose of nurse training and instruction. The books contained instructions and rudimentary explanations of (mental) patients' illnesses in accordance with the organic explanatory medical model of the time. The books predominantly contained the knowledge physicians felt important for nurses to gain. Nurse historian Peter Nolan highlights that asylum doctors began to write these medical textbooks for nurses only once psychiatric training for doctors had begun to develop. But most often, Nolan notes, the formal medical knowledge was not helpful to nurses who had to deal with patients in practice, and nurses developed their own informal knowledge and rules, often transmitted by word of mouth. 94

The way mental nurse training was structured in Dutch asylums confirms this observation. In the system of nurse training developed by the NVP, and quite similarly by the VCV, the first year of training focused on the repetition of elementary schooling, the second year on general medical knowledge taught by doctors, and the third year on the medical care of insane and nervous patients. By the final year of training, nurses had already worked in the asylum for about two or three years and presumably had developed their own 
ways of handling and managing mental patients.

Although the training provided little encouragement, nursing organizations in particular provided a forum for nurses to develop independent ideas. A written culture among nurses emerged within their organizations' journals, in which their ideas were traced. The articles in the new nursing journals did not reflect a mere reproduction of the dominant asylum culture: from time to time nurses wrote about their work, and came up with some innovative approaches towards patient care.

The NVV journal reflected how male nurses, like their female counterparts, reacted against their strenuous work circumstances. The majority of the articles in the journal were devoted to the campaign of improving the nurses' living and working conditions. These writings clearly demonstrate how nurses resisted a system that made them disciplinary executors of a custodial regime, with little individual, independent space. But the journal also gave some of them a chance to express some independent thinking about their contribution to patient care. Occasionally there was an article devoted to reflection on the content of their work.

In I9I2 the secretary of the NVV and a private duty mental nurse, G. H. Bouwmeester, wrote an article on "Paedagogiek en verpleging" (pedagogy and nursing). He argued that "the more nursing is based on pedagogical principles, the more it would show to full advantage". ${ }^{95}$ Pedagogy, a field of knowledge for teachers, he explained, also had an important role in nursing to. Just like children, psychiatric patients needed to learn and become aware of their responsibility as members of society. They needed teaching and guidance. Just as a teacher understands and educates a child, Bouwmeester reasoned, a nurse must use a "pedagogical element" in helping an alcoholic patient, for example, to understand the difference between good and bad..$^{6}$ Nurses could give such patients insight into the consequences of their afflictions. Bouwmeester believed that the nurse could make a useful contribution to society in helping to resolve the "social question" of fighting alcoholism. He carefully distinguished between the task of the doctor and the nurse. After medical therapy had done its work, he noted, nurses could guide neurasthenic patients to regain interest in work, subdue hysteric patients, or distract melancholic patients and convince them of their value. ${ }^{97}$

Bouwmeester clearly felt that nurses had a role in the recovery of patients, and that the "pedagogical element" was most important in this role. It is important to note that Bouwmeester formulated the role of the nurse in pedagogical, communicative terms, moving away from the organic notion of mental illness. Bouwmeester believed that because nurses were in contact with the patients all day long, they were in an important position to let the peda- 
gogical element play an important role in patient care..$^{8}$

Another male nurse, $\mathrm{H}$. van der Bor, similarly reflected on the nursing care of mental patients. In I9I 6 he wrote an article called "Iets over de verpleging van krankzinnigen" (On the nursing care of the insane). ${ }^{99}$ In the opening sentence of the article Van der Bor explicitly stated that his did not pretend to be a scientific article. For the advances made in psychiatric care based on scientific study, one should read the medical nursing textbooks, which psychiatrists had written for nurses, he advised. ${ }^{100}$ But, he continued, long and sometimes trying work experience had taught him that the medical nursing books had a major flaw in the comprehensive training for the mental nurse. They lacked advice as to how to handle or associate with mental patients.

In his attempt to formulate what it meant to communicate with patients and how nurses should associate with patients, Van der Bor emphasized that nurses had to be empathetic to patients and their families. He advised nurses to "imagine the situation of the patient". ${ }^{\text {Ior }}$ Because of their illness, asylum patients were torn from the coziness and comfort of family life. He warned nurses not to let themselves be affected too much by the "daily milieu" of the asylum, but to keep the "human feeling and compassion" that they had brought with them when they began their work. These were the qualities they needed - to treat patients with friendliness and politeness and to give them back some of what they were missing. The "cold environment of the asylum" with all its "degenerated and demoralized elements" could easily transform a person into the "kind of nurse who, without any contact with their patients, would only take care of their physical well-being". And patients needed much more, Van der Bor noted. "Make it your responsibility," he advised nurses, "to notice yourself and to imagine the situation of the patient every now and then"; otherwise "no warmth, civilization, attention will radiate from you to your environment". ${ }^{\text {I02 }}$ Apparently Van der Bor sensed that physical well being alone, which was essentially the core assumption of the biomedical approach to mental illness, did not sufficiently address the situation of the mental patient.

These two graduate male nurses of the NVV were highly articulate about the fact that they had expertise and a point of view on patient care that was not necessarily similar to that of physicians. They clearly struggled to define their role independently from medical authority and to develop self-reliant ideas about their work with patients. They considered their contribution to patient care to be part of a larger process of social betterment. Using neither religious faith nor medical concepts nor a feminist ideology, they turned to psychological and pedagogical notions to clarify the responsibility and expertise of the nurse. 
Bouwmeester and Van der Bor reconceptualized the social meaning of nursing within the moral terms and liberal philosophy of the time. They framed the responsibility of nurses as a moral force, a pedagogical element that brought human feeling and compassion to their environment. In a sense they revitalized the notion of a traditional, religiously based commitment of the nurse to human suffering, but in secular terms.$^{103}$ They reframed moral compassion and empathy towards patients as a "personal force to radiate to the environment". ${ }^{\text {104 }}$ Bouwmeester and Van der Bor gave new meaning to what it meant to watch and share intimacy with patients constantly. ${ }^{105}$ Rather than sharing that intimacy in a passive, self-sacrificing way, merely enduring what happened to patients, as the traditional religious philosophy had prescribed, Bouwmeester and Van der Bor thought that nurses had an active, pedagogical influence that would help patients to change. In this way these male nurses legitimized their work and responsibility in new terms, reframing their role in such a way that it included the male nurse. They avoided referring to this moral force as a particularly "womanly" influence. The metaphor of the pedagogue was not necessarily female, and the psychological ability and skill to imagine the situation of the patient could hardly be denied to men.

\section{Conclusion}

The development of nursing as women's work created tension among male nurses. Their position was marginalized, both in terms of number and status. Career opportunities diminished. In addition, improvements in social position such as the opportunity to marry or to live off the asylum grounds were initially out of the question for male nurses. Within the asylums, their contribution to patient care had little status, and artisan work rather than "real nursing" seemed to be their domain. Their situation provoked a strong reaction among male nurses: they founded their own professional organization to fight for their cause and improve their social position. The debates within the NVV reflected their struggle to relate to the gendered image of the female nurse. The NVV provided a forum in which male nurses attempted to conceptualize the social meaning of nursing as a role that legitimized and included male nursing. But the niche that male nurses were able to carve out for themselves reflected the early twentieth-century economic and social constraints on caring work as a man's job. 


\section{CHAPTER VII}

\section{Controversy and Conflict over the Social Position of Nurses}

\section{An Ambiguous Social Position}

Despite the promise of training, the social position of student nurses remained unstable and ambiguous. Although ideologically nursing had been reformulated as a respectable occupation, the actual working conditions rendered student nurses quite unprotected and prone to exploitation. Many nurses suffered from physical exhaustion as a result of the long working hours and strenuous working conditions. In Meerenberg, for example, the high turnover and continuous demand for personnel often prevented nurses from benefitting from a preparatory period in the nurses home. They were in a very vulnerable position as they usually came to work on the wards whilst young and with little experience. As discussed in Chapter V, high turnover was also a pressing issue at Veldwijk, and at Franeker, turnover rates remained high despite the increased status and training. During the first decades of the twentieth century, each year about a third to half of the nursing staff at Franeker were replaced by new applicants. ${ }^{1}$ Their salaries were about the same as those of the traditional attendants - I50 to 200 guilders in I9OI. A graduate nurse earned 250 to 300 guilders, and the first nurses, 300 guilders. Yet the number of graduate nurses remained low. ${ }^{2}$

The vulnerability of nurses became very clear in the case of the nineteenyear-old student nurse Elisabeth Johanna Van Steen at Meerenberg. In I897 she was sentenced to one month in prison after an accident involving one of the patients. She had allegedly caused a patient's death from burns in a bath that was too hot. ${ }^{3}$ Gerardus van Walsum, the physician in charge of the ward, reported to the court that the nurse had failed to check the bath's temperature properly. His impression was that this nurse was "somewhat loose", "just her age", and not one of the most meticulous nurses. ${ }^{4}$

The case stirred enormous debate. ${ }^{5}$ During the 1890 os the reputation of Meerenberg had already been severely damaged after two accidents leading to the deaths of patients, ${ }^{6}$ but in this case public indignation rose even higher. The case was widely discussed in the local newspapers and the Provincial Council's deputies began an extensive investigation after Elisabeth's appeal was upheld in a higher court.7 Amsterdam lawyer J. A. Levy volunteered to appeal against the conviction. After strong resistance from the Meerenberg 
medical and administrative staff, he eventually obtained permission to have the bathroom investigated, and he had two medical professors look into the medical status of the patient. ${ }^{8}$ It transpired that it was highly unlikely that the physically weak and mentally debilitated patient, who was in the last stage of epileptic disease, had died from burns. In addition, the technical investigation revealed a major defect of the machinery supplying water to the bath tubs, which accidentally caused a sudden influx of very hot, almost boiling water into the tubs. ${ }^{9}$ It seemed that the failure of the organization to provide safe care had been blamed on an innocent young nurse.

Levy angrily argued that nursing personnel worked long hours, with shifts of twelve hours among severely disturbed patients being common, for very little pay. Moreover, young girls with little experience were put to work on wards for the severely disturbed. ${ }^{\mathrm{r}}$ It is also significant that Elisabeth had resigned just before the accident took place because she could not bear the work load any longer. Even Lady Jeltje de Bosch Kemper expressed her indignation in the Journal of Sick Nursing. She noted that Elisabeth had worked in Meerenberg since she was seventeen, usually on the wards for the most disturbed patients. In defence of an acceptable and respectable social position for women, De Bosch Kemper found the case to be an illustration of the unjust working conditions for nurses. She felt that it was a humiliation and injustice that in the socially important work of nursing, women were severely overworked and often broke down at an early age, while at the same time an institution such as Meerenberg made a considerable profit on its yearly balance. Naively perhaps, she argued that nursing, particularly in the complex care of difficult mental patients, required an adequate supply of experienced personnel, sufficient pay, an adequate number of days off, and, in exchange for the physically strenuous work, appropriate insurance against old age and sickness. ${ }^{\text {II }}$ The growing discontent of nurses in general hospitals and asylums alike centered exactly on all of these issues, which nurses felt were not adequately addressed by either politicians or physicians. The physiciansteered Nederlandse Bond voor Ziekenverpleging (Dutch Nurses Association [NBZ]), to whom De Bosch Kemper expressed her criticism, did not seem receptive to the idea of a profound change in the social conditions of nurses. On the contrary, cases such as Elisabeth van Steen's seemed only to legitimize an even more profound attempt to improve the level of refinement of asylum nurses. Significantly, in the same year Van Steen was sent to prison, Van Deventer helped to found the Wilhelmina Vereniging. It is likely that the assumption was that if a higher level nurse could be attracted, the morality among asylum personnel would change almost naturally. Nurses, on the other hand, defined the problem of an "inadequate" and "ineffective" nursing 
workforce in quite different terms and made their dissent over low pay, strenuous working conditions, and - for some - the lack of legal protection the core of a political battle. Within the broader context of general social activism, organized nursing provided a forum in which nurses' social consciousness and professional identity could grow.

\section{Growing Social Awareness among Asylum Nursing Personnel}

The increasing influence of newly founded nursing organizations - the NBZ in I893, the professional nurse organization Nosokómos (Greek for "we care") in I900, the Christelijke Bond voor Ziekenverpleging (Christian Nurses Association [CBZ]) in I9O2, and the professional Nederlandse Verplegers Vakvereniging (Dutch Male Nurses Association [NVV]) in I906 - as well as the impact of trade unions on nurse organization both grew out of and shaped the social consciousness of nurses. Mental nurses participated in all of these organizations and in unions. Meerenberg, for example, had local branches of the NBZ, Nosokómos, the NVV and the union for civil servants. Nurses raised their voices via these new professional organizations, although how much autonomy they were able to achieve depended on the level of control they had within the organization. They saw themselves victims, exploited and subjected to inappropriate working conditions and they sought to improve their situation by means of organization and joint action. Both feminist ideas and identification with the labor movement influenced nursing activism, but at the same time differences of class, gender, and religion divided them.

The NBZ and Nosokómos both built on gendered ideas of female compassion to legitimize a new role for nurses, but they differed widely in their ideas of how such compassion should legitimize independent control and autonomy over practice and education. Quite radically, Nosokómos became an organization run by female nurses who distanced themselves from medical control. Male nurses organized themselves separately, as the gendered image of nursing prevented them from identifying with the female nurse organizations. Denominational groups formed their own Christian associations. Working-class interests and the aspirations of unionist groups remained antithetical to the professional ideals of many nurses, making the relationship between unions and nurses' organizations a difficult one. Differences between the various groups resulted in disagreement over strategies as to how to improve the situation of nurses and how to gain the social respect nurses felt was congruent with their social task. Nurse activism became a contested terrain of complex distinctions, alignments, and ambivalence over the social position and professional status of nurses. 
Increased activism among nurses was not an isolated event, as the labor movement gained considerable influence during the early twentieth century. As in Europe at large, progressive liberals, radicals, and laborers renegotiated the foundation on which the democratic state was based and claimed their right to vote. In the Netherlands, in I9I7 all male citizens obtained voting rights, followed by the women's right to vote in I9I9. ${ }^{\text {I2 }}$ The social-democratic labor party, founded in I894 by the socialist leader Pieter Jelles Troelstra, attracted many members from among the working class and became one of the dominant parties in Dutch socialism, eventually gaining a strong position in parliament by $1918 .{ }^{13}$

The fear of an organized, revolutionary working class, exacerbated by revolutions in Russia in I9I7 and in Germany in I9I8, resulted in government measures to ease social tensions. The foundations of a welfare state that protected workers against injury, invalidity, sickness, and unemployment were virtually in place in the Netherlands by the end of World War I. As of I9००, a series of social and labor legislation had passed parliament, among which were the Housing Act (I9OI), the Industrial Injury Act (I90I), and the Sickness Act (I9I3). By I9I9, the Labor Act had been passed, and entitled factory workers, but not nurses, to an eight-hour working day. ${ }^{14}$

However, the promise of training and increasing professional expectations made nurses as a whole ambivalent to a strong identification with labor activism. They intended to strengthen nursing's position as a profession as much as they attempted to improve working conditions. Probably in reaction to the conservative, medically dominated NBZ, in I900 a few progressive and socialist-minded nurses and physicians founded the nurse organization Nosokómos. This group had high professional aspirations. Their foremost aim was to establish an independent organization of nurses. Some of the Meerenberg nurses identified with this organization, and a branch of Nosokómos was founded at Meerenberg in I9II. ${ }^{15}$ From the outset Nosokómos distanced itself from the medically dominated NBZ, which had set minimal standards of training in I894. ${ }^{\mathrm{I}}$ Nosokómos affiliated with the broader organization of the International Council of Nurses (ICN) in I908 and represented the attempt of predominantly sophisticated, middle-class female nurses to defend an independent role for nurses. ${ }^{17}$ Jeanne van LanschotHubrecht, who joined the board of Nosokómos in 1904 and became its secretary in 1905, played a pivotal role in developing Nosokómos' international connection with the ICN. The international connection was an important resource for Van Lanschot-Hubrecht, who expressed her indignation about the abuse of nurses in Holland and the lack of initiative of the established nursing leadership within the NBZ in several letters to American nurse 
leader and suffragist Lavinia Dock, the secretary of the ICN. Dock, in turn, usually reported on the situation of Dutch nursing in the international section of the American Journal of Nursing based on the letters of Van LanschotHubrecht. Influenced by the international nursing opinions on independent nurse organization, the Nosokómos board members consciously decided to put the government of their organization in the hands of nurses; the socialist physicians who had supported the establishment of the organization were not elected to the board..$^{18}$

In this respect Nosokómos profoundly differed to the medical interest organization, the NBZ. ${ }^{19}$ The founders of the NBZ considered it to be a cultural organization furthering the advancement of the care of the sick and a reform initiative that more generally contributed to the improvement of cultural and social life. For them, the improvement of nurse training was part of that goal, but the well-to-do founders did not see themselves as an interest group for the promotion of working conditions of nurses. In this respect, it is noteworthy that the initial board of the branch organization of the NBZ in the province of Friesland, founded in 1902, included the influential physician Frederik van Eeden, Ladies Gevaerts and Foekema van Sytzema, and Aafke Gesina van Hulst, a descendant of an affluent family and the initiator of an association of district nursing for the relief of the poor in Harlingen in I896. Motivated to bring about a liberal and science-based approach to the care of the sick, the NBZ chairman pointed out that the bylaws should include the "somewhat tedious" but "indeed very important" rule prescribed by headquarters that at least two of the regular branch meetings be dedicated to a lecture on a scientific or socially relevant topic. ${ }^{20}$ In the branch organization of the NBZ in Haarlem this requirement was met by lecture topics varying from "the role of the district nurse" or "fighting tuberculosis" to "a report on a trip through the mountains of Austria" or "Vondel's literature". ${ }^{2 \mathrm{I}}$ From the perspective of furthering the cause of nursing these topics may seem wide-ranging and unspecific, but they reflect the organization's identity as a cultural organization. The lectures mirrored the cultural gap between the intentions of the NBZ founders and the interests of organized nurses, whose numbers soon grew both inside and outside the NBZ, in securing and improving the social position of nursing.

Its cultural orientation also showed that the NBZ had its basis in the liberal middle-class establishment, which was relatively influential and powerful. The physicians within the organization had the clearest ideas about the purpose that this general uplifting of the nursing of the sick could serve. They had the greatest interest in the reform of nursing care within the hospitals, and as a result their agenda soon dominated the organization. This was 
reflected in the membership of the NBZ branch organization at Meerenberg, which comprised many of the asylum physicians and head nurses and whose main authority was medical director Van Deventer. ${ }^{22}$

In the NBZ nurse leaders had little independent say and remained in line with the dominant medical opinion. ${ }^{23}$ The NBZ became the largest nurse organization once it began to establish bureaus for private duty nursing. Because of medical domination, the NBZ bureaus were in a powerful position to control the private duty market, in contrast to smaller organizations, such as Nosokómos, which were committed to setting high standards of training and reasonable fees. ${ }^{24}$

The limited power of the nursing leadership within the NBZ was reflected in the lack of influence of the Vereniging van Directrices en Adjunct-Directrices van ziekenhuizen en verenigingen voor ziekenverpleging (Association of Women Directors and Deputy Women Directors of Hospitals and Associations of Nursing), which was established from within the ranks of the NBZ in I899. When it came to international representation, the ICN rejected the NBZ as a proper national representative and accepted Nosokómos instead, as that organization was independent and directed by nurses, which was a major requirement for joining the ICN confederation of national nursing organizations. This probably contributed to the isolation of the Association of Women Directors and made them a powerless group. Many of them belonged to the first generation of upper middle-class women, who soon after their training had attained a position of deputy director in one of the many new small hospitals, out of touch with the lower middle- and working-class interests of the rank and file nurses. ${ }^{25}$ They had no independent control and were merely "adjuncts" to medical directors. Unlike the leaders of Nosokómos, who identified with more powerful British, American, and Scandinavian nursing organizations through their ICN membership, the annual reports of the organization of Dutch nurse directors illustrated their professional and political disengagement. The opening sentences of the annual reports of the Association of Women Directors reflected their lack of influence on any of the important issues in nursing at the time, be it with regard to professional regulation, education, or health and social progress. In I9Io "it had not much news besides the branch reports", in I9II-I9I2 there was "nothing to report about the previous year (I9II), nor much to report [about I9I2]". In I9I4-I9I5, when World War I had just begun and nurses had been internationally mobilized for war service, the report opened with "Unfortunately, my annual report will be brief, very brief actually, because there is not much to say", while I9I7 "was an uneventful year for the Association". ${ }^{26}$

The improvement of nursing's educational standards was at the heart of 
the doctrine of the female nurse organization Nosokómos. This organization closely reflected the feminist ideal of bettering the opportunities for independent living and working for women - independent of male (medical) domination, that is. It clearly saw itself as an interest organization for nurses and sought to protect them using high professional (educational) standards and licensing regulations through state regulation. Nosokómos wanted to close the ranks of nursing to "unqualified" personnel. Considering the large number of lower middle- and working-class groups in nursing, this gave Nosokómos a somewhat elitist character from the outset. ${ }^{27}$ Nosokómos felt that nurse training had deteriorated into a cheap way of staffing hospital wards and defeated its own objectives of making nursing a highly valued, refined, and skilled social service. The twin goals of female independence and contributing to society's progress, bound together by the domestic ideology of the role of women, framed Nosokómos' strivings. Training, Nosokómos argued, should be controlled by nurses, and state legislation in the form of a nurse practice act should guarantee protection against arbitrariness and the exploitation of nurses.

Nosokómos made a public stand against the restrictive rules and reported regularly on the strenuous working conditions and lack of freedom for nurses, both in hospitals and in asylums. ${ }^{28}$ As the case of Elisabeth van Steen demonstrated, nurses were regularly victims of exploitation. Many asylum nurses left their jobs because of physical exhaustion and nervous breakdown. ${ }^{29}$ Female nurses in particular, Nosokómos disconcertedly noticed, were "afgewerkt" (worn out) at an early age, with little social security awaiting them. ${ }^{30}$ If joint action with other activist groups strengthened Nosokómos' position, the organization did not hesitate to collaborate, even though it strongly emphasized its politically neutral stance. Nosokómos fought for its cause by means of sending petitions to political and hospital authorities, position statements in its journal, and responses to other nurse organizations' initiatives. In I9I7 a joint statement was published with the unionist Algemene Nederlandse Ambtenaren Bond (Dutch League of Civil Servants [ANAB]) on the changes they felt were imperative for nurse training and working conditions in university hospitals. The ANAB attracted many nurses who were civil servants in state, provincial, and municipal hospitals and asylums. A petition of the ANAB at The Hague to the municipal council in I9I5 illustrates the dissatisfaction nurses felt with the inhumane demands put on them. Being forced to follow classes after a long day of work, the petition stated, not only exhausted nurses but also inhibited any learning and affected nurses' responses to patients. Patient care eventually suffered due to this. The ANAB group argued that nurses should be entitled to the same freedom and 
respect as any other occupation, and should not be forced to physical and mental exhaustion under the pretense of devoted service..$^{3 \mathrm{I}}$ Indignant at the working conditions of nurses, the Nosokómos and ANAB boards cited the influential statistical report of physician Hecker on the overstrain of nurses, presented at the meeting of the ICN in I9I2. ${ }^{22}$ Under the guise of training, nurses felt they were abused and gained little social respect for their contribution to humanity. The ambivalent coalition between Nosokómos and the ANAB was an outgrowth of the politically divided, yet closely related, interests of the two organizations. The improvement of nurses' working conditions such as the shortening of working hours, higher salaries, pension, the right to live outside the institution, and a more secure legal status were common goals.

\section{Activism among the VCV Nurses}

Nurses working in the asylums of the Vereniging voor Christelijke Verzorging van Krankzinnigen en Zenuwlijders in Nederland (Dutch Association for the Christian Care of Insane and Nervous Patients [VCV]), organized themselves in Protestant organizations. They attempted to collaborate with other nurse organizations, although the VCV Christian ideology generated ambivalence about close involvement with secular activist groups. In I9O2 representatives of Protestant associations of sick nursing, the large VCV, the Christian sanatorium for nervous patients at Zeist, and other groups of Protestant nursing personnel founded the Christelijk Bond voor Ziekenverpleging (Christian Nurses' Association [CBZ]), the Protestant counterpart of the NBZ. The CBZ membership consisted of physicians, ministers, and nurses; the VCV physician Leendert Bouman was elected as chairman. ${ }^{33}$ Embedded in a patriarchal structure and opposed to both unionist activity and cooperation with non-denominational groups, the CBZ did not become an energetic organization, despite the relatively active role of nurses. ${ }^{34}$ When the Amsterdam branch of the CBZ dared to sign a petition to the municipal council for better labor conditions at the municipal hospitals, together with the NBZ, NVV, and Nosokómos, it stirred serious debate within the CBZ as a whole, and the branch received a firm reprimand from the more conservative headquarters. ${ }^{35}$ In I9II the CBZ was dissolved, since the larger Algemene Nederlandse Christelijke Ambtenarenbond (Dutch Christian League of Civil Servants), founded in I909, attracted several nurses as members. ${ }^{36}$

However, there was strong resentment among the Protestant nurses over their exploitative work situation. They had little chance to express their anger 
and frustration in public because any attempt to organize was vigorously suppressed by the VCV leadership. The conservative VCV board considered the idea of working for a living incongruent with the VCV's charitable, self-sacrificing nature. Moreover, the VCV expected strict subservience to authority by their members. Any attempt to the contrary was interpreted by the board as a dangerous and rebellious stand. Medical director Sap of the VCV asylum Bloemendaal immediately contacted the board when several journals of the Christian League of Civil Servants, directed to various nurses in person, arrived at the asylum. The VCV board and the board of Veldwijk agreed that such propaganda could not be tolerated, and personnel who chose to become members were to be advised to leave the VCV. ${ }^{37}$

In I9I8 a more militant group of Protestant nurses created the unionist Nederlands Christelijke Bond van Verpleegpersoneel (Dutch Christian League of Nursing Personnel). They joined the Nederlands Christelijk Vakverbond (Dutch Christian Union), founded in I909. The establishment of its first branch on the grounds of the VCV asylum Wolfheze and the preparations for founding a similar branch at Veldwijk caused quite an upheaval among the VCV leadership. The VCV leaders immediately used all their moral authority to suppress these initiatives, which they perceived as radical threats to their authority. In an almost revolutionary act, a nurse, in fact a female nurse, publicly presented her perspective on the nurse situation at the annual meeting of the VCV. The shortage of personnel, she boldly stated, was a result of unmet needs and poor conditions..$^{38}$ But the board did not want to see it that way. Their foremost worry was how to suppress such activism. They decided to found an organization for their personnel, drafting the bylaws without even consulting any nurses. VCV leader Lucas Lindeboom went to Amsterdam in person to talk to the rebellious nurses at the VCV clinic (Valeriuskliniek), who initially refused to join. The activism was silenced by the board's authority, and eventually most VCV nurses hesitantly joined the organization established for them. ${ }^{39}$

In order to ease the tension and fill the ranks, Veldwijk had to adapt its working conditions. In 1907 and again in I9I4 the VCV raised salaries, although they remained much lower than the wages paid at Meerenberg, for example. In I9I4 unmarried, male graduate nurses at Veldwijk earned 200 guilders per year, including board and lodging, whereas female nurses received 175 guilders, both with an annual savings allowance of at most 50 guilders. In the same year in Meerenberg an unmarried male nurse made 390 guilders in addition to board and lodging..$^{\circ}$ This may explain the continuing aggravation among VCV personnel. With the acceptance of the Labor Act in I9I9, which prescribed a 55-hour work week and one day off a week ( 36 
hours) for hospital and asylum personnel, the VCV eventually adapted its working hours for nurses to correspond with national trends. ${ }^{4 \mathrm{I}}$

\section{Seeking Legal Protection from the State}

In the early twentieth century, state registration of nurses became a political debate in all countries in Western Europe. The debate was a response to the growing activism among nurses, who increasingly sought protection from the state. In turn-of-the-century Germany, for example, the position of nursing personnel had provoked serious debates in parliament when nurses had gone on strike at a few hospitals. Politicians, as well as physicians and nurses, began to challenge the lack of legal regulations and the poor education of nurses..$^{2}$ The first law on nursing registration was passed by the Prussian parliament in Germany in 1907, but obligatory state exams were not instated until I92I. Nursing registration laws were passed at roughly the same time in Britain (I919), the Netherlands (I92I), and France (I922). The major influencing factors on the passing of registration laws in Britain - the unprecedented demand for nurses during World War I, the public sympathy for nursing created by the war, the introduction of the women's vote,43 and the government's attempt to control social unrest by further development of a welfare state ${ }^{44}$ - were relevant in Dutch nursing, although the war had less of an impact because of Holland's neutrality during the war.

Initially, Dutch physicians supported the standardization of nurse training within the NBZ, as well as nurses' interest in a registration regulation. ${ }^{45}$ But the physicians' idea of registration was to put the control of nursing practice in the hands of professional groups, themselves in particular, rather than state regulation. Physicians preferred to keep the exam regulations established by the NBZ, and for asylums, by the Nederlandse Vereniging voor Psychiatrie en Neurologie (Dutch Association of Psychiatry and Neurology [NVPN]). Hospital and asylum directors, already struggling with high turnover rates and problems staffing the wards, opposed any measures that they believed would further limit the supply of nurses.

Nosokómos, on the other hand, advocated legislation that would limit licensed nursing practice to graduates from state-approved training schools. In 1907 Nosokómos founded the Vereniging tot verkrijging van een wettelijke regeling van opleiding en examens voor ziekenverpleegsters en verplegers (Association to Achieve the Legal Regulation of Training and Exams of Nurses). ${ }^{46}$ One of the founders, board member Jeanne van LanschotHubrecht, was very clear about the intended goal. She argued that it was in the public interest, that the registration of nurses under state law, as with other 
professional groups, would guarantee and more clearly define the quality of professional nursing practice. Owing to the socially important role of nurses, their work demanded a respectable character and adequate training. The nursing diploma should be a guarantee that the nurse had indeed met these standards. ${ }^{77}$ Only this protection would end the abuse of students, Nosokómos believed, and safeguard the position of nurses in private duty. The NVV supported the idea of closing the ranks of nurses to "unqualified" personnel. $4^{8}$

On the founding of the Association for the Legal Regulation of Nurse Training in I907, Jeanne Van Lanschot-Hubrecht led Nosokómos' initiative to send two petitions, one to the Minister of Internal Affairs and one to the parliament, requesting a practice act for nurses similar to the regulations for physicians, dentists, midwives, pharmacists, and pharmacist-assistants. In response, the Minister of Internal Affairs sent the petition to the Central Health Council, a governmental advisory body on health affairs that was clearly dominated by physicians. The Health Council appointed a committee of four physicians, two of whom were psychiatrists: professor of psychiatry Cornelis Winkler and former VCV medical director David Schermers. The committee initiated an inquiry among all medical directors of hospitals and asylums on the situation of nurses and requested their opinions on the desirability of state involvement. ${ }^{49}$ Considering the slow response of the committee, the physicians probably had not put the legal regulation of nursing high on their list of priorities. In I909 Nosokómos and the NVV submitted another series of petitions..$^{5 \circ}$ The response of the Health Council finally came in I9II.

The (medical) committee made its viewpoint clear from the outset. ${ }^{5 \mathrm{I}}$ The notion of independent practice of nurses propagated by Nosokómos, the committee argued, was exaggerated at the least. Nurses were there to carry out doctors' orders and could never be more than assistants to the physician..$^{22}$ Moreover, the committee felt that conditions of training had to be responsive to the supply and demand of nurses..$^{53}$ The committee agreed with the majority of the medical directors that state regulation of training was unnecessary and that anything higher than elementary education was unreasonable as an entry level demand. ${ }^{54}$ The best way of guaranteeing a steady supply of nurses was to improve their working conditions, rather than imposing high educational standards. They argued that some preparatory adjustment to working on the wards by means of an initial period of domestic work in the institution seemed suitable to gradually adjust nurses to their work. ${ }^{55}$

In essence, the committee approved the existing training system that had been worked out in the NBZ and NVP. The committee emphasized that a preparatory period, such as the Wilhelmina school or the system developed at 
Veldwijk, seemed a good way of improving nurse training, but the idea of a two-year preparatory school of nursing, as proposed by Nosokómos, was out of the question. Suggestions by some medical directors to seriously consider the state taking over all nursing training, including the costs, was not approved by the majority of the medical profession.

When the reorganization of vocational education was debated in parliament in the early twentieth century, some members pondered the inclusion of nurse training in the state education system. But a state committee appointed by the Ministry of Internal Affairs to design new legislation on vocational education at the middle school level remained noncommittal concerning the place of nursing in such a system. The act on "nijverheidsonderwijs" (technical and home economics education) that was eventually passed by parliament in I9I9 did not include nursing..$^{56}$ According to educational historian Goudswaard, politicians of religious parties and physician parliament members at the time successfully exploited the argument that nursing as an act of Christian benevolence should not be governed by the state. Moreover, unlike the teaching profession, nursing did not find a place in the state regulation on higher professional education either. ${ }^{57}$

Despite the attempts of Nosokómos and the NVV, a nursing practice act never got off the ground, nor was nurse training incorporated in the state education system. Nurses remained divided over the issue within their own ranks. Nosokómos maintained its position that raising the standards of training was the most appropriate measure for improving the situation of nurses and should be the primary focus of nurse activism. ${ }^{8}$ But the membership counts of the nurse organizations by the late igios reveal that Nosokomos held a minority position. It had only around 800 members. An equal number of nurses had joined the unionist ANAB, whose primary focus was changing labor conditions. In the same year the NBZ attracted over 4,000 nurses. 59 Considering these numbers, it is not surprising that the Nursing Act that eventually passed though parliament in I92I, in the midst of an economic recession, followed the dominating opinion in nursing, which was that of the NBZ. ${ }^{60}$ This confirmed the powerful position of the NBZ, of which many nurses were members merely because of their dependency on physicians and hospital authorities in securing their position in private duty. ${ }^{6 \mathrm{r}}$ The law placed the accepted system of nurse training and exams under state inspection and required hospitals and asylums to seek state approval of their status as a nurse training institution. ${ }^{62}$

Furthermore, the law, which went into effect in I924, provided for a state register of graduate nurses based on the standards of training set by the NBZ. In the same year, the Minister of Internal Affairs approved a separate register 
for graduate mental nurses, accepting the diplomas issued by the NVP, the $\mathrm{VCV}$, and the two existing state asylums as meeting the requirements for state registration. ${ }^{6_{3}}$ All the state registers did was restrict the title of "(registered) nurse" and "(registered) mental nurse" to graduates of approved diplomagranting bodies without actually protecting nursing practice. Nothing prohibited those who did not meet these standards from practising, nor did the state provide any financial support towards the training of nurses. ${ }^{64}$ As the need for nurses continued expanding, nurses with lower qualifications remained in demand. Limited funding and the lack of political support resulted in an ineffective set of regulations that provided nurses with little protection. High turnover rates, the flight of graduate nurses from hospitals and asylums, unqualified personnel filling in, and the lack of security for nurses would remain characteristics of nursing practice for decades to come. ${ }^{65}$

\section{Controversy over Training}

While the organized response of nurses to their social position reflected dissent over their working and educational conditions, the prevailing view among psychiatrists was that the problem of recruiting an adequate nursing workforce resulted from a lack of morality and the problematic class background of nurses. Their discontent and ambivalence grew as the training system did not turn out to be as effective as they had hoped. The assumption, as initially framed by Van Deventer and taken up by the NVP, that nurses, particularly female nurses, would bring to the asylums the desired female morality and compassion if they had the right middle-class background became increasingly contentious. By the turn of the century, when the system had been in operation for a number of years, several developments defeated the psychiatrists' original intent and created numerous new dilemmas. Firstly, psychiatrists had a vested interest in creating capable assistants who could make their therapies work and enhance the still precarious status of psychiatric medicine. But nurses did not necessarily take up the training as psychiatrists had intended. If completed, the training provided nurses with career opportunities outside of the asylum, and so they left continuously. Even more left before completing the training. The mental nursing workforce became neither stable nor experienced. For some psychiatrists this phenomenon was only further proof of a lack of morality and motivation among nurses, but others argued that working conditions had to be changed. Secondly, the initial exam and training system was not very effective. The discrepancy between the educational level of the nurses and the expectations of psychiatrists was high. Within the NVP this created ambivalence over whether standards 
should be raised or lowered. Moreover, psychiatrists soon experienced their own involvement in nurse training as yet another burden that compromised their workload. But they did not want to give up control either. Finally, the somatic treatment approach grounded in physiological conceptions of mental illness, which had provided the legitimacy of the mental nurse training system in the first place, became increasingly controversial. The training and work of nurses, built on the premise of somatic care, reflected similar controversies. Gender figured as an important category in all of these dilemmas, each of which will be discussed in more detail.

\section{Ambivalence to Morality and Class Background}

In I898, about five years after the NVP exam had been established, Willem Hendrik Cox, medical director of the Brinkgreven Asylum, cynically noted that the "verpleegsters-kwestie" (female nurse question) turned out to be a chronic problem and a much debated issue among both German and Dutch psychiatrists. ${ }^{66}$ Cox was ambitious, with strong scientific interests, and he was a productive author of psychiatric medicine; during his lifetime he developed from a strong advocate to a strong critic of the biomedical approach to mental illness. ${ }^{67}$ As of 1892 he directed the Brinkgreven asylum, and was subsequently appointed director of the sanatorium for nervous patients in Arnhem from 1900 to 1902. In I9O2 he became medical director of the Utrecht asylum. In I9OI he succeeded Van Deventer as chair of the NVP exam committee. Determined to create the best possible circumstances for effective psychiatric treatment, he felt strongly about the necessity of qualified nurses in order to provide such treatment. Yet he also had outspoken ideas about the contemporary dilemmas in successfully attracting qualified nurses. ${ }^{68}$

The mental nurse, Cox firmly stated in I 898 , had to be a "beschaafde dame" (refined lady). ${ }^{69}$ Teaching a nurse the basics of anatomy and care of the sick and insane and providing her with practical training did not suffice. Before starting such training, she needed to be a refined woman, Cox emphasized. His view was quite similar to that held by the founders of the Wilhelmina Association. The stated subjects could be easily learned, Cox assured, but "algemene ontwikkeling” (general refinement) could not. Yet he sarcastically noted that not even Io percent of the asylum nurses reached such a level of sophistication..$^{\circ}$ While in the past, asylum physicians had had to work with whoever was unfit for servants' or maids' work, the new trend seemed to be that only women unfit for work as a nanny, pharmacist, or teacher applied for asylum nursing positions, Cox complained. He felt that the title "nurse" and a uni- 
form were in no way a guarantee of a high moral and intellectual standing. ${ }^{71}$ Because of the difficulty of recruiting well-bred women, standards had fallen greatly, Cox noted, to the point that nursing now seemed an avenue for female servants to improve themselves, learn some manners, and move on. That was all that was left of the call for civilization, Cox pointed out. Nurses should be able to have a "discourse" with these patients, an intelligent discussion about literature, history, or the political and social matters of the day, rather than just gossip or talk about ordinary matters. In the care of patients with typhus or pneumonia such ability was less instrumental, Cox noted, but a moralizing influence was of central therapeutic value in the care of "zenuwlijders- en lijderessen" (nervous patients) in psychiatry. Unfit, continuously changing personnel, without a high level of refinement, he argued, would not have the right psychological influence on patients and would only hinder the efforts of the "hogere beambten" (higher officers), which included the physician and the head-nurse, who had to constantly retrain new personnel..$^{22}$

Cox's views are illustrative of the criticism some psychiatrists had about nurses' supposed lack of refinement and sophistication. His views underscore the commonly held belief - for example within the Wilhelmina Vereniging (Wilhelmina Association) - that solutions to the problem of the supposed inadequate nursing workforce rested on the increase of the level of refinement of nurses. Significantly, Cox persistently focused on the characteristics of the female nurse and did not even mention male nurses. As demonstrated in the previous chapters, seeking to instill personnel with a more civilized attitude was a class-based concept and, considering the nineteenth-century viewpoint that women were the guardians of such civilization due to their moral compassion, also a gender-based concept.

Cox's frustration represented a number of unresolved dilemmas. He clearly linked female civilization with an innate, natural ability to have the right psychological influence on patients and could only see that as a reflection of class and gender. ${ }^{73}$ His understanding of civilization served as a psycho-social theory on therapeutic care, in which conversing with patients obtained a more central role. The nurse's role was crucial in making the physicians' treatments work, and Cox clearly began to see those treatments as a combination of physical and psychological approaches.

Paradoxically, Cox's new therapeutic ideas were geared to a particular malady, the afflictions of nervous patients..$^{74}$ It is likely that the needs of this most prestigious group of the mentally afflicted, who were relatively best able to communicate, legitimized Cox's requirement of high moral standards for nurses. When Cox, in the mid-I9ios, further developed his insights on psychiatric therapy and, under the influence of new psychological theories on 
mental illness, pleaded for a psychological and therapeutic approach to patients, he still had in mind the most communicative patients. ${ }^{75}$ Psychiatrists indeed derived most of their motivation and prestige from the care of this group. Cox's own career, which included the directorship of an institute for nervous patients, and his eventual strong criticism of the asylum system reflected this pattern. But as an asylum director, he was also well aware that the nervous patient he had in mind was not the average asylum patient at that time. Most asylum patients were indigent and had chronic afflictions such as dementia, epilepsy, idiocy, or chronic mania, for which Cox's intended "discourse" seemed to be of limited value.

More importantly, as Cox pointed out, refined middle-class women did not apply to asylums in substantial numbers. Current historical research by nurse historian Cora van der Kooij confirms this contemporary observation. ${ }^{76}$ Examining the class background of nurses from the Buitengast Hospital (later Wilhelmina Hospital) between I9I0 and I920, she found that the majority of nurses came from the lower middle- and artisan-classes, including farmers' families. For daughters from the respectable working class, nurse training was an opportunity for upward social mobility, and many of them successfully graduated from nurse training programs. Van der Kooij observed that in the initial decade, hospital reform attracted upper middle-class women, particularly in the Buitengast Hospital. However, between I890 and I900 the nurses' social class gradually declined. Nursing included several heavy menial tasks and in many ways did not differ from servant work, which made the occupation unattractive for upper middle-class women, she argued. ${ }^{77}$

My examination of the register of applicants for servant and nursing positions at Meerenberg from I 887 until I 9 II confirms this pattern for psychiatric care. The majority of nurse applicants had a lower middle- or artisan class background..$^{8}$ The information solicited from applicants on their personal background, including father's occupation, upbringing in the family, health of parents, education, health, religious denomination, and motivation to apply, provide insight into their social position. Moreover, applicants had to give three references, preferably from a teacher, minister, and general practitioner, which were indeed checked. ${ }^{79}$

For male nurse applicants, two-thirds consistently came from the lower middle- and artisan-classes and about a third were the sons of laborers. On rare occasions, the son of a manufacturer applied, but this was highly exceptional. Social mobility among female nurse applicants reflected more change. In 1895,74 percent came from the lower middle- and artisan-classes, and 9 percent were the daughters of laborers. Ten percent were the daughters of upper middle-class and manufacturers' families, including some daughters 
of lawyers, doctors, and ministers. Five years later, however, only 4 percent were upper middle-class, and these were all daughters of manufacturers. Seventy-two percent had a lower middle- or artisan-class background, and I4 percent were daughters of laborers. By I908, the majority, 89 percent, came from the lower middle- and artisan-classes. Only one applicant out of 68 was the daughter of a manufacturer, and only 7 percent (5 applicants) were laborers' daughters. Quite similar to Van der Kooij's findings, by I9IO daughters from upper middle-class families rarely applied.

Recent Dutch historical studies on social mobility in the nineteenth century observed how in the latter half of the century, when industrialization had had an impact, differentiation between the classes changed. ${ }^{8 \circ} \mathrm{A}$ broad middle class arose as positions for civil servants and employees grew and schooling among the working class increased. Roughly three layers are identified, which usually are each divided into upper and lower strata, yet great variation exists depending on whether urban, industrial, or rural areas are analyzed. The upper class were the urban aristocrats and "gezeten burgerij" (middleclass citizens). The upper middle class included learned professionals, large store owners, managers in companies, and high grade civil servants. The broad lower middle class included small shopkeepers, teachers, and lower civil servants. Depending on the area, farmers could also belong to this group, although if they were small farmers, they could belong to the lower class as well. The upper lower class entailed respectable working families of artisans and schooled workers. The lower stratum included unschooled laborers, servants, and farmhands in rural areas. Most fathers of the Meerenberg applicants were artisans, shopkeepers, civil servants such as policemen, army officers, employees or staff of transport and shipping companies, hotel owners, or teachers. Among both male and female applicants, 35 to 45 percent came from artisan families.

Most nurse applicants were unmarried. Only rarely did widowed or married people apply, and they were usually rejected. The accepted applicants were increasingly younger as time proceeded, particularly among the female nurse applicants. About half of the male nurse applicants were between twenty and twenty-four years old. Applicants older than thirty were usually rejected. Among the female nurse applicants in I895, twenty-five percent were younger than twenty, and by I 908 half of the accepted female nurses were not yet twenty years old. Eventually, in the early I900s the asylum appointed "aspirant" student nurses. They were young women of about seventeen or eighteen years old who had already begun working in the asylum before beginning their training as student nurses.

Most of the Meerenberg applicants had completed elementary education 
and a few years of extended elementary education or middle school. Many women had taken an additional course in needlework after their elementary education. As the class background of the applicants fell, so did the educational level of the nurses. In I895 and I900, about ten percent of the female nurse applicants were graduates from normal schools or industrial schools. ${ }^{8}{ }^{8}$ In I905, only one applicant out of eighty had such a diploma, and in I908 none of the pupils had graduated from these schools.

Although a few applicants had prior experience in nursing, the majority of female nurses came from home or had had a previous position as a servant. Some had experience in typical female jobs such as looking after children or assisting in teaching. Most male nurse applicants had worked in artisan or workmen's jobs. For male nurse applicants, a good working record was the most important measure of aptness for the job. Their police record was checked routinely as part of the application procedure. Important reasons for rejecting male nurse applicants were a criminal record, drinking, suspicion of weak health or a physical condition, the fear that the applicant only intended to stay for the winter, or a generally poor, untidy, or dumb and sluggish outlook. The appropriacy of female nurse applicants was judged on the basis of morality and character, with cleanliness and decency being the most important attributes. Female nurse applicants were usually rejected if they appeared too nervous or weak. Moreover, whereas men were checked for crime, women were rejected if they dressed too fancily, or if they looked too frivolous or possibly seductive - in short, if their decency or moral standing was questionable. For both male and female nurse applicants an important consideration of suitability was the physical strength and health of the candidate. A scrofulous outlook, a weak constitution, or a nervous impression were often grounds for rejection. Many applicant files contained comments such as "phtisis?" or "scrofulous?" in the margin, which may indicate that the medical director and officers feared hiring personnel who would soon be suffering from tuberculosis, one of the most threatening contagious diseases in the early twentieth century.

Considering the class background of the nurses, some psychiatrists' initial aspirations to recruit highly sophisticated nurses were not met in reality. Eventually the NVP felt compelled to lower its training standards, just to meet recruitment needs. Psychiatrists, especially the exam committee of the NVP but also Cox, considered this a dangerous dilemma. Lower standards would result in a downward spiral, they feared, ever lowering the level and reputation of the asylum. 
Physicians saw their reform efforts threatened not only with personnel matters within the asylum, but also with the growing private duty market for nurses in the care of nervous patients. Psychiatrists' control over nurses disappeared once nurses entered private duty and, most likely, nurses were in direct competition with physicians when it came to the care of nervous patients. Cox, for example, did not hesitate to depict the career aspirations of nurses outside of the asylum in a negative way, questioning their intentions, professional status and motivation as if they were only interested in making money. As Cox argued, the lower-class nurse would lack commitment and definitely leave the asylum on graduation to pursue positions in which she could earn more. If this happened, a stable, experienced staff would never be created. ${ }^{82}$ Graduate nurses did in fact usually leave the asylum after graduation. The training provided an avenue towards a further career in private duty or hospital nursing, particularly for the female nurses. ${ }^{83}$ In this way, the NVP exam and mental nurse training did not help achieve the goal of attracting a better class of personnel. Psychiatrists were not successful in recruiting and retaining the skilled "assistants" they needed and wanted to provide somatic care. As pointed out in Chapter IV, the strenuous work environment and complex patient care demands may have contributed to this situation.

Graduate nurses did indeed have many career opportunities outside of the asylum. Not only did they work independently in private duty, but particularly the early, upper middle-class graduates of the Buitengast Hospital also took the lead in opening and managing homes for nervous patients. A case in point was the career of White Cross graduate nurse Gerritje Kuyk, which illustrates the appeal of independent roles for middle-class nurses. Kuyk was one of the first generation of trained nurses who eventually found employment in the rapidly growing field of the private care of nervous patients in the late nineteenth century. Most of these patients were from the middle- and upper-classes and were usually cared for at home or in the newly established sanatoria or private homes. ${ }^{84}$

In I880 at age 34 Gerritje Kuyk began her nursing career as a student nurse and trainee of the White Cross nursing course in the Buitengast Hospital..$_{5}$ She was forced to find a way to support herself after her father's death in I88I. On graduation, she became a member of the White Cross association of nursing and worked in private care. Although hesitant, she eventually decided to accept Jacob van Deventer's offer to become a head nurse at the Buitengast Hospital and remained in this position for three years. Although she was interested in the care of insane and nervous patients, her position at the 
Buitengast Hospital did not meet her aspirations. It is likely that Kuyk preferred a more independent role, separate from the hospital system.

After one of her previous private patients had created a legacy in her name, Kuyk established a private home for female nervous patients and feebleminded children in Villa Christiania in Scheveningen, a seaside resort on the North Sea coast, close to The Hague. For ten years, until her early death at the age of forty-nine, she directed the home and gradually expanded her organization. In 189 I she opened a second home, Desideria, and a third, Perseveranza, in I892. The names of the homes nicely reflected the morality of the nineteenth-century middle-class women's culture in which she participated. Each home had room for eight patients and nursing staff, whom she herself supervised. As of 1890 medical care was provided by physician A. O. H. Tellegen, who had established himself as a private psychiatrist after leaving the position as superintendent in the Roman Catholic asylum Voorburg. ${ }^{86}$

Another former head nurse of the Buitengast Hospital, Sophia Genis, opened a home for female insane patients in Ede in I89.. Fifteen patients could be cared for in the home, for which Genis formally obtained approval from the State Inspectorate of the Insane. Two years later she opened two more homes for female nervous patients, which probably indicates that her endeavor was a flourishing business. ${ }^{87}$ Although these first-generation trained nurses usually had a higher class background than the average mental nurse who graduated after 1900 and were not representative of the latter group, they created a network of facilities outside the asylum that eventually attracted many mental nurse graduates.

\section{Tension over the NVP Exam Criteria}

Within a few years of its operation, the NVP exam committee noticed that many nurses had difficulty following the course work and only a few took the exams. Asylum nurses did not have the level of sophistication or educational background that the most ambitious psychiatrists desired. Despite increased demand for mental nurses, the NVP exam remained a small-scale endeavor for the first decade. Between I893 and 1902 the number of asylums grew from I9 to 22, while the number of nurses increased from about 750 to I,200, not including head nurses and first nurses. ${ }^{88}$ About io years later the total number of mental nurses had increased to about 2,000 , working in 29 asylums, including some smaller homes ${ }^{89}$ But initially only about 40 to 60 candidates applied for the exam each year, of whom usually about 30 to 40 obtained their diploma. During the first decade that the exam was held, I892 to I902, only 305 student nurses obtained a diploma, which was 62 percent of 
the total number of exam candidates, and half of these candidates came from only one institution, the Meerenberg asylum..$^{\circ}$

The exam requirements were high. Exam questions concerned equally the general level of "civilization" of the nurses as the candidates' medical knowledge of anatomy and physiology, the quality of the sick room, and the food requirements for the sick. The exam committee attempted to judge the character and gentility of the examinee through questions on general topics of literature, history, geography, or biology, reflecting the examiners' norms of a well-educated standing. ${ }^{9 r}$ However, the majority of the mental nurse candidates did not meet the high standards of the initial NVP exam committee, and within a few years the exam committee had to reconsider its norms. The exam committee, consisting of Inspector Ruysch, Van Deventer and Tellegen, probably held higher expectations than the average NVP member. Soon other members pushed for more realistic views, although some, for example Cox, remained persistent in their idea that the majority of asylum nurses did not reflect the right level of civilization.

In his I 898 statement, Cox was one of the first to propose a solution. He suggested that pay for nurses be raised considerably, since salaries in asylums were too low to attract better educated women. But secondly, clearly indicating his worry about the nurses going off to private duty, he felt that psychiatrists should increase their control over the intellectual level of nurses, especially of those who left the asylums and who, he believed, could threaten the reputation of psychiatry once they worked in private duty. One exam of a high standard was most desirable, he believed, but if necessary, a two-level exam system could be designed: one for nurses who remained within the asylums and one with higher standards for those nurses who would seek private duty. ${ }^{92}$

Cox's plan immediately received strong opposition from one of his colleagues, psychiatrist D. Schermers, medical director of the VCV Bloemendaal asylum. Schermers did not agree with Cox's elitist perception of the mental nurse. Schermers argued that a very good and devoted nurse could be created, out of the lower middle- and working-classes, who was responsible, tactful, and compassionate even if she did not have the high intellectual level Cox seemed to desire. Moreover, since the majority of the patients in asylums were from the lower social classes, a nurse from the artisan and respected working class would be highly appropriate. If the asylum organization itself properly valued nurses by providing fair living conditions, proper leisure opportunities, and a supportive, family-like work community - but not necessarily higher salaries - and encouraged nurses in their training to develop themselves and learn to think about what they were doing, a good nursing workforce could be recruited. ${ }^{93}$ 
According to Schermers the asylum should provide a moral and intellectual community in which nurses were valued. ${ }^{94}$ He argued that the VCV asylums had developed an integrated system of examination, salary, annuity, and career opportunities that bound the personnel to the institution. The lowest level of duties and domestic service was linked with the lowest level of training. This, Schermers noted, made it attractive to nurses to work their way up to more highly valued positions of greater responsibility. He saw the provision of elementary education within the asylum as crucial and preferred it to subjecting personnel to exam requirements that were too idealistic and therefore unreasonable. Schermers probably felt a need to compete against the liberal-oriented medical director Cox, and more importantly, Schermers defended the training system designed within the VCV asylums, which had just been established in 1896 separately from the NVP. From the outset, the VCV asylums had geared their nurse training to the level of the lower middleand working-classes, and strongly rooted it in an ideology of benevolence and religious compassion.

Divided by internal conflicts within the NVP, the initial exam committee had not been able to come up with new regulations for the mental nursing exam, despite an extensive review of the status of nursing personnel in I900.95 In I90I the whole exam committee was replaced and the new exam committee designed new regulations. Significantly, medical director Cox became the chair of the new exam committee, which included the psychiatrists S. Reeling Brouwer, L. S. Meijer, J. C. I. Van der Hagen, and Th. E. Frijlinck. ${ }^{96}$ After a number of internal battles, the NVP changed its training and exam requirements to parallel the suggestions made by Cox in I898. The NVP opted for two exam levels. An A exam was designed for asylum nurses who would remain within the institution. In addition, the committee designed a B exam, geared towards head nurses and those interested in private duty, which could be taken on completion of the A-exam and another year of training in the asylum.

The choice seemed a compromise between adaptation to the majority of asylum nurses' background and the desire to maintain control over private duty nurses. ${ }^{97}$ Significantly, the pattern of the new NVP A exam clearly followed the pattern of the VCV exam system, with a repeat course of elementary education in the first year, general nursing of the sick in the second year, and a focus on the nursing of the insane in the third year. ${ }^{8}$ The NVP also began to charge a fee for the exam. Previously, the NVP training and exam had been made available to nurses free of charge. However, since a high number of nurses left the institutions after graduation instead of remaining within the asylum to work, the committee felt justified in receiving payment for the 
training they provided. The B-exam never became popular and only a few nurses took it each year. 99 It was discontinued in I9I2. ${ }^{100}$ Considering the demand for nurses, most mental nurses who continued their studies opted for a general hospital diploma or went into private duty without the B certificate.

Along with the exam format, the NVP changed the exam procedure. The new committee members found it impossible to judge character, morality, and capabilities of the examinees based on a few hours of examination. They proposed decentralizing the exam and setting it twice a year. The physicians who provided the training should also set the exams jointly with two delegates of the exam committee, thereby leaving more authority over training to the individual asylums. ${ }^{\text {Ior }}$ Moreover, for the first time, the asylum doctors entrusted some of the exam preparation to deputy directors and head nurses, who were added to the exam committee, albeit without voting rights. ${ }^{102}$ Asylum physicians grew dissatisfied with the many administrative, teaching, and pharmaceutical responsibilities they had in addition to direct patient management without proper reimbursement. ${ }^{\mathrm{IO} 3}$ After the decentralization, the involvement of nurses, and the revision of the criteria, the number of examinees quadrupled within a few years. The number of candidates, which had never exceeded forty to sixty per year during the first decade, rose to about two hundred candidates twice a year by I9I0. ${ }^{104}$ The revisions of the NVP exam demonstrated the NVP's response to the continuing demand for nurses and to the class background, cultural level, and aspirations of the majority of the asylum personnel.

\section{Controversy over the Somatic Approach and Biomedical Footing of Psychiatric Care}

The controversial nature of the somatic approach was another dilemma that impacted on the status and prestige of psychiatric care and consequently the status and prestige of the work of nurses, who provided that care. As I have previously argued, the call for the education of nurses formed a secularized reframing of religious devotion, which for centuries had been the foundation for the care of the sick by nursing orders and was still maintained within the philosophy of care in the VCV and Roman Catholic asylums. The feminization of a compassionate attitude reflected a gendered understanding of the role of nurses. Nurses remained subservient to the patriarchal authority of the primarily male doctors. Furthermore, about a third of asylum nurses were male. As pointed out in the previous chapter, the preference for female breeding posed challenges for male nurses . 
In psychiatry, a civilized attitude was important as most patients' afflictions entailed behavioral and communicative difficulties. The idea formed a continuation of rather than a break with the previous era of moral treatment. Higher principles of devoted care, gentleness, and appropriate manners would assure that nurses approached patient behavior as symptoms of their illness. They would not scold them or, in the worse cases, abuse them. The training system's main function was to instill discipline, manners, and habits that enhanced a civilized attitude among personnel. Self-control in many ways guaranteed the appropriate control of others. ${ }^{\text {105 }}$ Moreover, good manners and a refined character would assure appropriate handling of the intimacy nurses shared with patients. Well-bred nurses would maintain decency and control their sexuality. ${ }^{\text {106 }}$

Gradually psychiatrists, including Cox, began to frame a civilized approach towards patients in less gendered terms and developed a more general psychological theory on the therapeutic nature of conversations with patients. Cox became a critic of the one-sided biomedical footing of scientific psychiatry. He perceptively noticed that when a patient's illness was conceptualized as an organic problem, like that of the typhus or pneumonia patient, the nurse's ability to communicate with that patient seemed irrelevant to the disease process. Cox probably understood that there was an inherent contradiction between the organic, biomedical explanation of illness and the theory that a personal and humane approach to patients was important in the recovery process. The biomedical view of illness assumed a causal relationship between an organic cause and a mental illness, irrespective of the therapeutic relationship and, consequently, of any moral or psychological approach to the patient. According to Cox, a biomedical perspective was too limited in the psychiatric context. Probably unintentionally, Cox revisited older notions of the patient-doctor relationship as conceptualized in the era of moral treatment. He sensitively noticed that "a discourse" was most important in psychiatry.

In the course of his career, Cox's understanding of the meaning of a "discourse" changed from an "intelligent discussion" into a "psychotherapeutic conversation", or as Cox stated around I9I5, "whoever wants to help another person, but more importantly, who wants to mentally support and heal somebody, must be able to listen and find what the other person thinks and feels important; [medical] education in the so-called 'objective methods' enhances an egocentric observation of others and only teaches to value their own thoughts and feelings." ${ }^{107}$ Cox's views represented the transition from an organic to a psychological understanding of mental afflictions. A civilized attitude formed the cornerstone of compassionate care and the ability of a psychological understanding of patients. 
But the call for refined nurses was double-edged. Refinement presumably formed the foundation of a humane attitude, while it also ensured the skillful and competent bodily care of patients. Purity was as much a moral notion as it underlay punctuality, cleanliness, hygiene, and eventually antiseptic and aseptic techniques. Considering the somatic approach, particularly the widely applied bed-based treatment; the large number of physically weak demented, epileptic or paralytic patients; and the threat of tuberculosis in the asylums, competent physical care was extremely relevant. From that perspective the nurse training system was effective. Probably as a result of more competent nursing care of the many bedridden patients, the general health of asylum patients improved during the early twentieth century, as evidenced by decreasing mortality rates. ${ }^{108}$ Between 1890 and I9I5, the annual mortality rate of the patient population in Meerenberg dropped from II.2 to 8.4 percent, in Franeker from I4.3 to 8.2 percent, and in Veldwijk from 6.5 to 3.8 percent (Appendix Table A.4).

However, refinement was also relevant because of the foundation it provided for a gendered, patriarchal nurse-doctor relationship that provided the physician with a competent assistant who would also be subservient. From the perspective of physicians feminine compassion was supposed to make nurses accurate, but not independent thinkers. As medical assistants, nurses were expected to observe and report relevant patient behaviors to the physician, but not make independent judgments. This anti-intellectualism was inherent in the nurses' role and was in some ways antithetical to the expectation of sophistication and a higher intellectual level that, for example, underpinned Cox's argument for the education of the nurse. ${ }^{109}$ As has been illustrated in the chapter on patient cases, nurses continuously applied somatically oriented scientific knowledge and made judgments and decisions when it came to patient care. However, within the training ideology, nurses obtained little independent autonomy to do so. Significantly, when nurses went into private duty with the scientific knowledge they had obtained to pursue a more autonomous role, physicians were the first to try to control that practice.

The lack of specificity of the somatic measures was probably what made the somatic approach most problematic and posed conflicting demands on personnel. As medical historian Charles Rosenberg argues, despite the growth in technology and science, the assumed link in psychiatric medicine between the etiology of a disease and its therapy remained persistently unclear. ${ }^{\text {IIo }}$ The linkage between pathological mechanisms and therapeutic remedies was largely unfounded in the era of somatic treatment in psychiatry. ${ }^{\mathrm{III}}$ Physical exhaustion provided some rationale for bed treatment, and to some degree 
unrest did the same for the application of bath treatment, yet in many cases the treatment became a means for controlling difficult behavior and evolved into means of restraint. Nurses, who actually applied the treatments, often saw their role restricted to the control of antisocial patient behaviors by means of somatically oriented approaches. When somatic treatments dominated as a restraining measure, the refined attitude only helped nurses to subserviently, but dutifully, complete the expected task and preferably not ask questions. According to contemporary observers, nurses' competent performance of such a role seemed to be a function of the moral attitude or gender-based compassion of the individual nurse. Yet it seems more appropriate to assume that such a role largely reflected the social position of asylum nurses and the social choice made to constrain difficult human behavior based on organic theories. The inherent contradictions of the work and the training of nurses restricted the potential of the role of nurses, and their tasks based on somatic approaches mirrored the therapeutic impasse of somatically oriented psychiatric medicine. Moreover, their social position and limited education hindered their ability to criticizehtheir situation or their therapeutic role.

Recently nurse historian Gunnel Svedberg reported on narratives of nurses who administered prolonged baths to psychiatric patients in Sweden during the I930s and I940s. ${ }^{\text {II2 }}$ Considering the similarities between the orientation on German models in Dutch and Swedish psychiatry at the turn of the century, her findings are a relevant addition to the evidence of this study. In Swedish psychiatry prolonged baths were given in similar ways to those described in this study, sometimes for weeks at a time, often with a canvas sheet placed over the tub. Patients remained in the water while they ate, slept, or defecated, with similar risks to the patients' skin as observed by Dutch contemporaries. Although one Swedish nurse described prolonged baths as "horrible" in retrospect, she emphasized that "at that time we didn't think like that, since it was part of the treatment... some patients did become calmer." ${ }_{\text {II3 }}$

Nurses found their work with baths tiresome and trying, and often a tremendous responsibility, Svedberg reports. Patients spat at nurses and called them names, and sometimes incidents occurred, one nurse revealed. Another noted that the duty was usually given to the youngest and least experienced staff members. Patients were either too ill to talk to, one nurse reported, or, as another remembered, conversations with patients in baths were not permitted. Svedberg found no supporting evidence that such patients could indeed not be talked to. On the contrary, contemporary Swedish nursing textbooks (1924) noted that baths should be given with kindness and consideration. Yet patients could be regarded as being beyond reach for various reasons, Svedberg hypothesized, which was probably consistent with the way inexperi- 
enced personnel handled a difficult situation. Furthering this thought, I would add that the younger and less experienced the personnel, the lower the chance that they would have read one of the textbooks or had any instruction in this aspect of nursing. Svedberg further notes that shutting off feelings may have been a common response for an unprepared and inexperienced person exposed to overwhelming and painful impressions, even though they may be eager to do their duty well and be responsible. ${ }^{\text {II } 4}$ She finds it clear from the accounts that the baths were "a way of controlling the patients' violence and agitation". ${ }^{15}$ Svedberg argues that the nurses' emphasis in their narratives on the impossibility of communicating with patients and the assignment of bath work to inexperienced personnel may be accounted for as a "product of the professional identity of nurses". The nurses referred to their experience as attending, untrained nurses in retrospect. By the time of the interviews, in the I980s and I990s, these nurses had developed a different understanding of their work and considered "the most important part of their caring to be relating to patients, [which] required experience and training," Svedberg notes. Her observation confirms the evidence in this study that nurses, who were inexperienced and largely unprepared, were exposed to tasks that posed conflicting demands on them. Only occasionally did individual nurses question their practice or propose alternatives, for example, evidenced by the thoughtful publications of two male nurses discussed in the previous chapter. The hierarchical structure and limited educational preparation at that time did little to encourage such sophisticated behaviors.

\section{Conclusion}

Organized nurses' responses to their complex position were divided along the lines of class, gender, and religion. Those groups who attempted to organize themselves independently from medical authority rejected the subservient, restricted social position of trainee nurses. Nosokómos, in particular, felt that student nurses were exploited, if not abused, and were the victims of inappropriate and unfair working conditions. The organization advocated high educational standards for nurses and professional protection through state registration. But the opposition from hospital authorities and the powerful influence of the NBZ hindered the attempt to set higher standards. Moreover, the lower middle- and working-class interests of the majority of nurses lay in securing their position and fair working conditions, rather than in higher professional standards. The increasing demand for nurses and the pressure to staff the wards defeated the effort to restrict access to nursing practice by maintaining high educational standards. 
By the turn of the century, the mental nurse training was incongruent with the designers' original intentions and created multiple new dilemmas. Firstly, the system did not produce the capable, compliant assistants who could make psychiatrists' therapies work and raise the status of psychiatry. Turnover remained high and graduate nurses had many opportunities in private duty. The mental nursing workforce became neither stable nor experienced. The gendered, class-based notion of civilized care only partially matched the training needs and work expectations of the largely lower middle- and artisan-class nurses. Secondly, the initial exam and training system was not very effective. The NVP responded ambivalently to the observed discrepancy between exam requirements and the educational level of the nurses. Finally, the somatic treatment approach grounded in physiological conceptions of mental illness, which had provided the legitimacy of the mental nurse training system in the first place, became increasingly controversial. The training and work of nurses built on the premise of somatic care reflected similar controversies. 


\section{Conclusion: The Politics of Mental Health Nursing}

The Disappointment of Somatic Explanations in Turn-of-theCentury Psychiatry

As was also true of hospital nursing, mental nursing emerged within a broader context of social and medical changes in the late nineteenth century. The mental nurse training system that psychiatrists established within the asylums reflected the ideal of raising the level of asylum personnel and oriented asylum care towards the achievements in hospital medicine. The promise of science, the improving image of the hospital, and the apparent success of organic explanations of diseases were so forceful that such explanations also gained strong social support in psychiatry. Psychiatrists, socialized in the cultural and scientific values of the time, were strongly attracted to the image of the general hospital and sought to transform the asylum into a mental hospital.

Placing the care of the mentally ill on a new scientific biomedical footing was a powerful motivation of liberal-oriented psychiatrists. At the Meerenberg asylum, which was rooted in a liberal tradition, the shift to this new somatic orientation was favored both by the physician staff and the asylum board, although the transition did create tensions. Most asylums, however, were more hesitant in making the transition. Franeker in particular feared the costs the new medical treatment implied, and the conservative Protestant and Roman Catholic institutions also had strong objections to it. ${ }^{I}$ Within these institutions the materialistic scientific notion of mental care threatened conservative religious beliefs and the transition to a medical model was less easily made. The transition sometimes provoked strong reactions - for example, from the VCV, which attempted to develop its own Christian psychiatry and philosophy of asylum care. Essentially the new science-based practice profoundly changed the organizational structure of the institutions and transformed longstanding traditions of institutional care based on a lay, middle-class household model.

The shift to a professionally based, hospital-oriented institution was made with the expectation that scientific principles and skilled, somatically oriented care would make the asylum a more humane and effectual place, and yet its success was limited. The implementation of more competent nursing care 
definitely had a favorable impact on the health of the many bedridden patients. The general health status of asylum patients improved during the early twentieth century, as evidenced by decreasing mortality rates. ${ }^{2}$ But the metaphor of fighting contagion and the reliance on organic explanations of disease, the basis of the new biomedical orientation, was ill fitted to the dayto-day reality of asylum care. In psychiatry the etiology of most mental illnesses remained obscure, leaving the relationship between therapy and a specific disease unclear. This lack of specificity adversely affected the status and prestige of psychiatry as a medical field, as well as the image of the mental hospital. ${ }^{3}$

Furthermore, the creation of the mental hospital did not solve the longstanding problems of asylum care. Psychiatric symptoms did not vanish as a result of better physical care and somatic treatment. The number of asylums continued to grow, as did the number of asylum patients. The majority of these patients' afflictions were of a chronic nature, and recovery rates remained low. In Meerenberg, for example, about seventy to a hundred patients were discharged annually as "cured" or "improved", which was only 5 to 7.5 percent of the population. At the turn of the century two-thirds of the Meerenberg population ( 66 percent) were chronically ill with paranoia (35 percent), idiocy or imbecility (20 percent), or epilepsy (II percent). ${ }^{4}$ They were subjected to an isolated existence, without much chance of ever returning to society.

The aspirations of psychiatrists to treat mental patients according to the principles of general hospital care were deflated within a few decades. Lack of alternatives may explain, at least in part, the appeal of somatic treatments. As one psychiatrist pondered in I923: "While [...] therapeutically, we asylum physicians, can do next to nothing, we have to try everything that still seems to be of some use." 5 The lack of a clear medical etiology gave the application of the new somatic treatments a very weak footing. The transition from using methods of treatment for reasons of physical care to applying them as a means of controlling supposedly antisocial behavior in patients was easily made. Although bed-based treatment did not seem out of context for physically weak and bedridden patients, for many others the new therapies turned into various new forms of restraint and coercion. The expectation that somatic approaches would increase the efficacy of the asylum was soon dashed. As a predominantly lower-class institution for indigent, chronically mentally ill patients, the asylum remained a stigmatized institution that necessarily attained a lower status than the general hospital. 
One of the central elements in creating the outlook of a mental hospital was the establishment of a mental nursing staff. Psychiatrists, who initiated mental nursing reform, derived the example for the organization of mental nurse training from the general hospital. The gendered notion of "civilized care" was central to the idea of a mental hospital. The image of refined, middleclass female influence, which had brought so much change in the hospital, had a strong appeal in psychiatry as well. The most ambitious asylum physicians believed that bringing middle-class women experienced in the care of the sick to the asylum would profoundly change the nature of the traditional attendant staff. The emphasis on character and civilized behavior in mental nurse training was congruent with the nineteenth-century middle-class view that women had a particular moral ability to affect society. Religious inspiration and missionary zeal formed a strong basis for women's activism and participation in the reform movement. The care of the sick was but one avenue for women to realize their desire for a meaningful social role in society. The notion of the refined nurse entailed both the idea of technical skill and female compassion. Character training and the strengthening of female skills were believed to enhance the ability of mental nurses to sustain discipline and order in the asylum. Competence as much as moral influence was ascribed to the women sought for mental nursing. Early mental nursing reformers clearly had daughters from middle-class families in mind, very much like the women who were attracted to the White Cross training program in its first decade. They would supposedly have the right moral attitude that psychiatrists were looking for to bring organization and skill to the asylum. However, just as in the general hospitals, where within a decade the majority of nurses came from the lower middle and working classes, the majority of women attracted to asylum nursing were from modest social backgrounds. This created a discrepancy between psychiatrists' desire for a well-bred, middle-class nursing staff and the class background of the actual nursing personnel. The training system became in part oriented towards instilling such values in nurses through a disciplined hierarchy of nurse training and supervision.

"Civilization", then, reflected a dual notion of control. Self-control, instilled in nurses by disciplined training, formed the necessary condition to control others. Yet it was also assumed that women would exercise control in strict subservience to male medical authority. On the one hand nurses were expected to develop the autonomy to attend to patients in a civilized, compassionate, self-controlled way; on the other hand they were incorporated into a strict hierarchy that left them little space for self-reliant care. They did not 
obtain autonomy over either their knowledge or their educational preparation. However, unexpected by the designers of mental nurse training, the grounding in civilized care and scientific knowledge, no matter how basic, provided lower middle- and working-class women with new opportunities for a respected career. After the training, many left to find employment in private duty or furthered their careers in general hospital care. Unintentionally this factor and the poor working conditions of asylum nurses prevented the development of a stable and experienced nursing staff.

The example of general nursing and the somatic treatment model generated new mental nursing tasks of disciplined performance of somatic interventions, and skillful assistance in medical observation and treatment. The new tasks included the close observation of patients, even at night, and reporting on their physical and behavioral symptoms. Moreover, nurses kept the newly arranged wards for bed rest in order and adhered to a strict discipline among themselves and their patients. But the unspecific nature of the new treatments such as prolonged baths, hydrotherapeutic wet packs, or forced methods of keeping restless patients in bed facilitated their potential use as measures of restraint. In that regard, nurses became the agents of a new regimen over which they had little control. Mental nurses' tasks remained oriented towards watchful, custodial care, and they were often confronted with violence and disruptive patient behavior in an unpredictable environment. This rendered the role of nurses complex. This study confirms Dwyer's observation that nurses in asylums had to respond to the often conflicting demands of guiding, disciplining, and befriending patients. It further reveals that the assumption was that such conflicting demands could be best resolved if the nurse had the proper level of civilization. ${ }^{6}$ The domestic ideology regarding women's special moral capacity formed the basis for such a view.

The gendered structure of mental nurse training contributed to the exclusion of male nurses from the nursing domain and reflected the gendered division of labor in an industrial society. It was difficult for men to identify with the feminine conceptualization of the nursing role. Female compassion and the combination of domestic artisan work with caring roles, sanctioned by the ideology of women's inclination towards motherhood and domesticity, did not fit with the legitimization of the role of men in nursing. The male nurses' position became increasingly controversial and provoked strong responses among male nurses. Moreover, economic demand, the impact of industrialization, and a gendered division of labor diminished the place for men in caring jobs.

As mental nurses gradually began to point out, the somatic orientation did not really help nurses to learn how to handle or associate with patients. With- 
in the biological notion of mental illness the question of how to relate to patients had little therapeutic relevance for the disease process. Yet the gendered ability to sensitively attend to patients was still seen as a capacity that was essential to competent patient care. The assumption was that this capacity naturally came with the proper level of refinement and social background, or with the right religious motivation. Significantly, according to the rhetoric, it seemed a capacity that women with respectable social backgrounds had already developed within the context of their own homes. Alternatives that framed attending to patients in any other way were not available. The notion that one could develop the ability to associate or communicate with patients as a therapeutic skill was a completely new concept at that time and was only hesitantly beginning to be made as psychological and sociological knowledge began to develop. As nurse historian Rafferty has argued, the call for civilization presumably served as a psycho-social theory of nursing care. It outlined the behavioral expectations of nurses and complemented competence in somatic care with a compassionate approach of patients. ${ }^{7}$ Nevertheless, this was a very class- and gender-based notion. To uplift the level of refinement of lower middle- and working-class nurses who came to work in the asylums, the training structure facilitated the incorporation of nurses into a hierarchical structure with a strict discipline and rigidly regulated work routine designed to inculcate in nurses the values and behaviors expected of them. After about a decade, the training scheme was adjusted to the basic educational level most nurses had.

\section{The Educational versus the Social Value of Mental Nurse Training}

The study confirms the observation made by Peter Nolan and by Robert Dingwall, Anne Marie Rafferty, and Charles Webster for British mental health nursing that the training raised expectations that were not met in reality. ${ }^{8}$ The strict hierarchy, rigid discipline, and poor working conditions forced nurses into shackles that they soon experienced as too tight. They eventually tried to improve their situation by organization and joint action. Their organized efforts were of limited success, however. From the outset, differences in class, gender, and religion prevented nurses from developing a unified system of nurse organization, and opposition from the mental hospital and medical authorities hindered them. Limited funding and a lack of political support resulted in an ineffective set of legal regulations that provided nurses with little protection and security. The ideal of close observation and somatic care that characterized the new mental hospital wards, as well as the handling of difficult patients, required a high level of skill and expertise and an ample 
number of personnel, considering the work and care involved with patients on bed rest. But neither stability nor expertise characterized the majority of the asylum nursing staff.

The increased number of patients on the sick wards at Meerenberg underscores how somatic treatments expanded. The number of such patients more than doubled between I893 and I9I2, from 77 to 148 in the male department and from 8I to 189 in the female department. In contrast, the number of patients on quiet wards decreased considerably in the same period, from 202 to 147 on the male wards and from I96 to III on the female wards. Patient numbers on the wards for semi-disturbed and disturbed patients remained roughly the same. ${ }^{9}$ Nurse-to-patient ratios give an indication of the increased number of nurses needed for the more labor-intensive treatments, although the numbers must be interpreted with caution because they varied widely and working hours gradually decreased between I890 and I920, which also affected the number of nurses. The nurse-to-patient ratios in Meerenberg illustrate the point. Between I892 and I900 they went up from about one nurse for every nine patients to one for every six. It must be noted that these ratios do not reflect the fact that usually a relatively higher number of nurses was assigned to paying patients. Most likely the increased ratio resulted from the introduction of bed treatment and the nursing reforms introduced by Van Deventer. Between I9Io and I9I6 the ratio went up from about one nurse to every five to one nurse for every three to four patients; the increase was probably related to the introduction of the ten-hour working day in I9I6. Whereas the number of patients increased between 1892 and I 916 from I, 285 to I, 378, not even Io percent, the number of nurses tripled from 139 in 1892 to 370 in I9I6. ${ }^{\text {Io }}$

But the increased demand for skilled nurses on the wards was met by young and inexperienced student nurses. They formed the bulk of the workforce. Moreover, the conditions under which training was established were ineffective. The limited nature of the training system allowed for a service of at least three years with minimal hours of education. In most asylums around half to two-thirds of the nursing personnel consisted of trainees, with relatively few experienced nurses around with time for instruction. As a result the climate for learning was poor, a situation that was exacerbated by high turnover among graduate nurses. The training was of a limited design that gave nurses little chance to reflect on their work with patients. The few hours of instruction, often late at night, had a marginal place in the work schedule. Furthermore, the formal medical knowledge taught to nurses had limited applicability to dealing with patients in practice, although the grounding in basic medical matters did provide nurses with a valuable career perspective. 
Most of the work and methods of asylum care the nurses learned through experience and by word of mouth from colleagues. ${ }^{\text {II }}$

Nevertheless, the social and cultural meaning of the training must not be underestimated. This study confirms historian David Wright's observation for British asylums that asylum work created important opportunities for working-class women to achieve social advancement, albeit modest. In Dutch asylums mental nurse training provided lower middle- and working-class women with some basic medical knowledge, nursing experience and a living that may have had a better social status than women's work in domestic service generally. Eventually it also provided them with career opportunities outside the asylum or with opportunities to further their career in the general hospital. ${ }^{\mathrm{I2}}$

In essence, mental nurse training, similarly to general hospital nurse training, sought to meet contradictory goals. On the one hand the training was designed to adapt to the educational needs of the pupils to prepare them for ward work, but on the other hand the demands of the institution were in many ways antithetical to such training. Student nurses were there to do the work. The increased nurse-to-patient ratios and statistics on the expansion of bed rest demonstrate that an increasing number of nurses had to be hired not only because of reduced working hours and more days off, but also because of the more labor-intensive work. Providing training was considered quite an investment of time and a financial burden for the institution. It was therefore extremely difficult to envision a system of nurse training that valued nursing expertise on its own terms.

The contradictory goals created tension both at the top and at the bottom of the organization. Directors felt frustrated that despite the investment to provide nurses with "free education", they showed little interest and left. Often this was seen as a further indication of low morality. Nurses, on the other hand, complained about the low pay, the long hours, the evening-based training, and the lack of personnel. Poor working conditions exacerbated high turnover and intensified the lack of mature, experienced nurses. Only gradually were turnover rates brought down as salaries went up during the igios. Yet as the costs of care rose in the I920s, costs seemed easiest to control by again bringing down wages and decreasing the number of employees. The costs of the maintenance and the upkeep of material and buildings were largely fixed. ${ }^{13}$ What seemed to be effective ways of controlling costs turned out to be ineffective in keeping experienced nurses in the asylums. 
Rising costs aggravated the growing dissatisfaction with the poor results of the somatically oriented model of treatment during the mid-I9Ios, both among physicians and municipal councils, who paid the patients' fees. The somatization of care and rising personnel costs drove up the cost of psychiatric care, although the increase in costs was only in part related to the laborintensive nature of somatic therapeutics. Statistics on personnel and economics at Meerenberg illustrate the point.

Somatic treatments required more nursing personnel. As a result the cost of care went up. Bath treatment, for instance, was expensive because of the considerable costs of water and heating, and was also more labor intensive. But the major increase in costs was related to increased salaries of personnel and the shortening of working hours. This change particularly pertained to nursing personnel because nurses had to cover shifts twenty-four hours a day. As a result even more personnel were needed.

In Meerenberg the total number of personnel doubled between I892 and I9I6, from 272 to 533 , mainly caused by an increase of I67 percent in nursing personnel between I892 and I9I6 (Appendix Table A.5). Moreover, half of the total increase of 223 nurses took place after I9I0, when working hours were shortened and the weekly day off was introduced. Not only in absolute numbers but also as a percentage of total personnel, the number of nurses went up from 49 percent in 1892 to 67 percent in I9I6. In the same period the number of officers, including physicians, ministers, administrators, and head nurses, only increased by 45 percent. The number of servant personnel rose 9I percent, while the number of administrative and technical personnel fell.

The tremendous increase in mental care costs due to higher salaries and the increase in personnel was exacerbated by skyrocketing costs of living during World War I. As in the country at large, employers had to pay cost-of-living allowances in addition to the salaries during the war years. Moreover, scarcity caused a phenomenal increase in food and fuel prices, and many of the male personnel had to be temporarily replaced because of the draft. Whereas the total budget had almost doubled in ten years between I904 and I9I4, in the next four years of war it almost trebled (Appendix Table A.6). The proportion spent on salaries rose from I6 to 28 percent between I904 and I9I9, but the salaries of medical personnel, which included nursing, proportionally rose even more. In I909 they comprised almost a fifth of the budget, whereas in absolute numbers the salaries of medical personnel more than quadrupled during the war.

As a result patient fees rose substantially. The annual fee for indigent 
patients at Meerenberg increased from 320 guilders in 1908 to 400 guilders in I9I7. ${ }^{14}$ In around 1920 fees again escalated as the administration of the budget changed. Asylum boards moved away from fixed patient fees and instead began to assess patient fees in terms of daily rates, based on the real costs demonstrated in the annual budget. This strategy meant that costs of nursing care were passed on to patient fees. This new financial management increased the financial burden of care of the mentally ill for municipalities, and patient fees were also a large expenditure on the provincial budget. Complaints from politicians about the high costs increased, which augmented social pressure to change mental care policy. ${ }^{15}$

\section{Ideals and Limitations}

The disappointment about the idea of a mental hospital, the institutionalization of predominantly chronic patients, and the enormous increase in costs caused an impasse in somatically oriented asylum care by the end of the I9IOs. Forced by financial difficulties and inspired by new understandings of physiological, psychological, and social factors in mental illness, psychiatrists began to look for alternatives to the somatically oriented treatment regimen. One of the critics of the biomedical model in psychiatry, Willem M. van der Scheer, the new medical director of Meerenberg appointed in I92I, was very influential nationally in introducing "active therapy" as an alternative to bed treatment. This was a new regimen of pedagogically oriented occupational therapy, which was in many ways a revival of the older moral treatment by means of regular work activity. It was modeled after similar examples in Germany. ${ }^{16}$

The emergence of a mental health movement in the late I9IOs and I920s provided alternatives to psychiatric treatment outside the asylum system. The Nederlandse Vereniging tot bevordering der Geestelijke Volksgezondheid (Dutch Association for the Promotion of People's Mental Health), the equivalent of the American National Committee for Mental Hygiene, was founded in I924. ${ }^{17}$ The large city of Amsterdam with its many new urban social problems was a receptive environment for the new ideas of social work for nervous and mental patients. As of I9I7 psychiatrists established preventive pre- and after-care services for the mentally ill. Within these services and the new bureaus of social work for mental and nervous patients, new roles for nurses ("social nurses") developed.

An assessment of the impact of these changes on mental nursing is beyond the scope of this study, yet it has become clear from the records that the emergence of new alternatives to the biomedical asylum model had little 
impact on the system of mental nurse training. This may indicate that once the mental nurse training system was in place, it was difficult to change its institutional basis or its essential function in staffing the asylum wards. The introduction of mental nurses skilled in the care of the sick within the asylums had been legitimized by new organically based scientific notions of mental illness and by the gendered view that women in particular were most suitable to taking up this task. The strong motivation of psychiatrists to create a body of capable, yet subservient medical assistants and to transform asylums into mental hospitals furthered the establishment of mental nurse training. By the late I9IOs the mental nurse training model had taken firm root in the asylum structure even though the treatment approaches that had legitimized its origin had lost their relevance as other alternatives became available.

The enduring nature of the system probably also reflected its attractiveness. For a new generation of lower middle-class and working-class women, somatically oriented asylum care created opportunities that seemed more rewarding than traditional domestic jobs. The largely experiential training provided women with skill and competence as well as a living and career opportunities. In a rapidly changing labor market for both men and women, the asylum's link with medical science trickled down to nurses through a limited but not necessarily meaningless system of training, and gave women from modest social backgrounds an increase in social status and opportunities not readily available to unskilled female workers. However, the attractiveness as an alternative to domestic service at the same time reflected its limitations. In its first decades the mental nurse training system remained ineffective in attracting a reliable, experienced workforce to the asylums. Complaints of a lack of morality persistently figured in debates on the supposed problems of attracting qualified personnel, which reflected the difficulty of viewing personnel problems in the asylums as more than a function of the moral and professional integrity of the individual nurse. Considering the central role of competent and compassionate nursing care in the daily guidance and care of the mentally ill, the social position of nurses limited the potential of the mental hospital, ${ }^{18}$ an argument soon pointed out by organized asylum nurses. Personnel problems in many ways reflected the social difficulty of caring for the mentally ill. The inherent contradictions of the work and the training of nurses restricted the potential of the role of nurses and mirrored the therapeutic impasse in somatically oriented psychiatric medicine. 
Appendix 


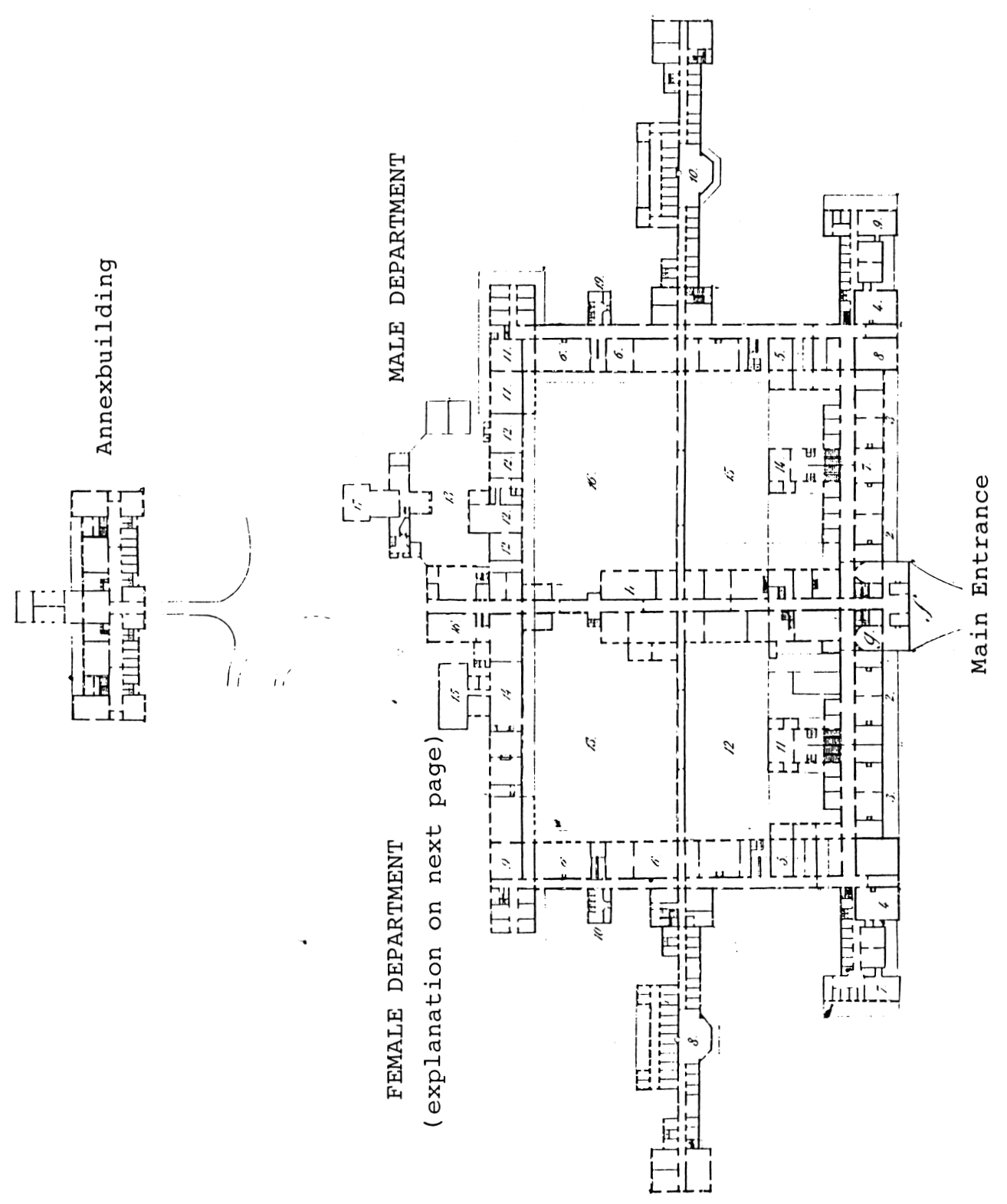

Figure A.I - Meerenberg Floor Plan, First Floor, I874.

Source: E. Gerdes, Meerenberg en de krankzinnigen (Sneek: Wiarda, I876), 398. 


\section{Explanation}

Female Department

I. Board and director's room

2-3. Ladies, first and second class

4. Quiet female patients, third class

5. Female patients, fourth class

6. Quiet female patients, fifth class

7. Disturbed female patients, first, second and third class

8. Disturbed female patients, fifth class, including cells

9. Sick and old female patients, fifth class

Io. Bathrooms

II. Bathrooms and servant rooms

I2-I3. Inner court, fourth and fifth class

I4-I6. Female workshops (laundry)

g. Steward's room

I. Kitchen, first, second and third class

II. Kitchen, fourth and fifth class

X. Anatomy and mortuary

Male Department

Mirrors the design of the female department

Annex Building

Pavilion for demented and epileptic patients, fifth class 
Table A.2

Listing of Diagnoses, $\mathrm{N}=70$.

Type of Diagnosis

Amentia

Dementia paralytica/Insania paralytica

Dementia praecox

Dementia (senilis)

Hallucinationes

Hysteric psychosis

Idiotia 2

Imbecillitas

Insania epileptica

Insania hysterica

Insania neurotica

Insania periodica

Mania acuta

Mania chronica

Manic depressive psychosis

Melancholia

Paranoia

Presbyophrenia

Vecordia

General state of psychosis (no diagnosis

Source: Seventy Selected Patient Records. 
Table A.3

Patients' Length of Illness prior to Admission by Length of Admission, $\mathrm{N}=70$.

\begin{tabular}{lllll}
$\begin{array}{l}\text { Length of } \\
\text { Admission }\end{array}$ & Ill for Weeks & Ill for Months & $\begin{array}{l}\text { Ill for Years } \\
\text { (range) }\end{array}$ & Unknown \\
\hline 0-6 months & 6 & I & $8(2-29 y)$ & 5 \\
7-I2 months & 2 & 7 & $5(2-4 y)$ & I \\
I3-24 months & 3 & 3 & $5(2-59 y)$ & 3 \\
25 months -6 years & - & 3 & $7(4-18 y)$ & 2 \\
7-IO years & - & - & - & - \\
II-20 years & - & - & 5 (II-43y) & I \\
>20 years & - & I & $2(20 y-u n k n o w n)$ & - \\
Total Patients & II (I6\%) & I5 (2I\%) & $32(46 \%)$ & I2 (I7\%) \\
& & & &
\end{tabular}

Source: Seventy Selected Patient Records.

Table A.4

Annual Mortality Rate among the Asylum Population at Meerenberg (M), Franeker (F) and Veldwijk (V), I890-I9I5.

\begin{tabular}{|c|c|c|c|}
\hline & M & F & $\mathrm{V}$ \\
\hline I890 & II.2\% (I35) & I $4.3 \%(34)$ & $6.5 \%$ (I4) \\
\hline 1895 & $9.7 \%(\mathrm{I} 27)$ & I3.5 \% (39) & $3.3 \%$ (12) \\
\hline 1900 & $7 \cdot 9 \%$ (I04) & 10.6\% (33) & $4.7 \%(2 \mathrm{I})$ \\
\hline 1905 & $8.0 \%$ (ІІо) & $6.4 \%(20)$ & $4.6 \%(24)$ \\
\hline I9Io & 8.०\% (109) & $9.5 \%(3 \mathrm{I})$ & $5.4 \%(27)$ \\
\hline 1915 & $8.4 \%$ (II5) & $8.2 \%(27)$ & $3.8 \%$ (I9) \\
\hline
\end{tabular}

Source: Statistics drawn from Annual Reports (JvMB, JvF, JvVCV, sectie "verloop der bevolking"). 
Table A.5

Total Number of Personnel, Percentages of Officers, Nurses, Servants, Administrative and Technical Personnel, Meerenberg, I892-I9ı6.

\begin{tabular}{|c|c|c|c|c|c|}
\hline & Total & Officers & Nurses* & Servants & Admin./Tech. \\
\hline 1892 & 272 & I $2 \%(33)$ & $49 \%$ (г33) & $\mathrm{I} 2 \%(33)$ & $27 \%(73)$ \\
\hline 1900 & 363 & I0\% (37) & $60 \%(2 \mathrm{I} 6)$ & $17 \%(60)$ & $13 \%(47)$ \\
\hline I9I0 & 404 & I $2 \%(47)$ & 6 г \% (249) & $\mathrm{I} 2 \%(5 \mathrm{I})$ & $15 \%(62)$ \\
\hline I9I6 & 533 & $9 \%(48)$ & $67 \%(356)$ & $12 \%(63)$ & $12 \%(66)$ \\
\hline \multicolumn{6}{|l|}{ Increase } \\
\hline I892-І916 & $96 \%$ & $45 \%$ & $167 \%$ & $91 \%$ & $-\mathrm{I} 8 \%$ \\
\hline
\end{tabular}

Source: JvMB I892, 20-27; 1900, 35-4I; I9I0, I-I9; I9I6, 24.

* Head nurses and assistant head nurses are not included in these figures. They are counted as officers.

Table A.6

Number of Personnel, Total Budget in Guilders, Total Salaries and Salaries of Medical Personnel (including Nursing Personnel) in Percentages of Total Budget and in Guilders, Meerenberg, I904 - I9I9.

\begin{tabular}{lrrrr}
\hline Personnel & & Total Budget & Total Salaries & Salaries Med.Pers. \\
\hline I904 & 375 & 527,206 & I6\%( 82,424$)$ & $7 \%(36,59 \mathrm{I})$ \\
I909 & 397 & 555,627 & I9\%(103,398) & $8 \%(46,776)$ \\
I9I4 & 487 & 959,338 & 2I\%(206,038) & I2\%( I I I,925) \\
I9 I9 & 58 I & $2,573,377$ & $28 \%(709,896)$ & I8\% (475,389)
\end{tabular}

Source: Jaarrekening (Annual budget), JvMB I904-I919. 


\section{Notes}

\section{Notes to Introduction}

I Van Drenth and De Haan emphasize how care is a highly gendered notion, commonly referring to activities connoted "feminine", but not intrinsically linked only to women. Men also played an important role in public care. Yet at the same time the authors purposely focus on women in their historical analysis of the rise of caring power in order to highlight the historical nature of the link between women and care. See Van Drenth and De Haan, The Rise of Caring Power, I2. For the relational dimensions of gender formation, see also McPherson, Morgan, and Forestell, Gendered Pasts, 5-6.-

2 Van Drenth and De Haan, The Rise of Caring Power, 23-36, 47-50.

3 Eijt, Religieuze vrouwen; Klijn, Tussen caritas en psychiatrie.

4 Ellemers, "Pillarization." For the term "segmental cleavages", see Lijphart, Democracy in Plural Societies, 3-5, 25-52.

5 For an excellent political history on the Netherlands, see Kossmann, De Lage Landen. For the political transformations in the mid-nineteenth century, see in this work, 2I6-98. For the naming of the pillars, see Lijphart, Democracy in Plural Societies, I5.

6 Ibid., 3-4.

7 J. E. Ellemers, "Pillarization", I29. For further discussion of the process of Verzuiling (pillarization), see Lijphart, The Politics of Accommodation; Stuurman, Verzuiling, Kapitalisme en Patriarchaat; Righart, De katholieke zuil in Europa.

8 Kossmann, De lage landen, 289-98.

9 Van Loo, Den arme gegeven, 28-30, 53-6o; De Jonge, Geschiedenis van het Moderne Nederland; idem, De Industrialisatie in Nederland; Van Tijn, "Het Sociale Leven in Nederland." Io Ibid.

II See Verslag van het Staatstoezicht, I888-90, I03-5. Artisans and workers were also involved in the supervision of patients who worked in workshops, the garden, or the kitchen. The term "nurse" (verplegende) began to be used in the I89os. See Verslag van het Staatstoezicht, I89I-93, I66-67.

I2 See, for example, Artikel 28 and 29, "Instructie voor het dagelijksch bestuur van het geneeskundig Gesticht voor Krankzinnigen te Franeker (I852)", in Instructiën en verordeningen, 1886.

I3 The most literal translation of krankzinnigenverplegende would be "nurse of the insane." However, "mental nurse" seems to be a more accurate and common translation. The term "mental nursing" was used by the British association of psychiatrists, the MedicoPsychological Association, which established a national training and examination scheme for asylum attendants in Britain in I89o. See Nolan, "Psychiatric Nursing Past and Present", 33-34, I23-25. The term "psychiatric nurse" (psychiatrisch verpleegkundige) was not common in the Netherlands until the second half of the twentieth century. See Goudswaard, Inleiding tot de geschiedenis van de verpleegkunst, I43; Kramer, Geschiedenis, I44. 
I4 Women's historian Joan W. Scott's seminal work Gender and the Politics of History (I988) had a significant impact on the study of gender history and the centrality of gender as a category of analysis. In a recent revised edition (I999) she reflects on the prolific scholarship on gender and politics that has appeared over the last ten years. For an overview of influential American literature in women's history, see Thurner, "Subject to Change." For an explanation of the nineteenth-century domestic ideology on women in the Dutch context, see Eijt, Religieuze vrouwen; Jansz, Denken over sekse; Waaldijk, Het Amerika der vrouw.

I5 McPherson, Morgan, and Forestell, Gendered Pasts, 5.

I6 Influential international works that analyze nursing history from the perspective of women's history include Reverby, Ordered to Care; McPherson, Bedside Matters; and Rafferty, The Politics of Nursing Knowledge. The predominant emphasis in these works, however, is on hospital nursing.

I7 D’Antonio, "Negotiated Care”; Digby, Madness, Morality, and Medicine; Dwyer, Homes for the Mad; Tomes, The Art of Asylum-Keeping.

I8 Porter, "Shaping Psychiatric Knowledge", 255.

I9 Deutsch, The Mentally Ill in America (I937); Hunter and McAlpine, Three Hundred Years of Psychiatry (1963); Van der Esch, Geschiedenis. For a review article on this debate for the Anglo-American literature, see Scull, "Psychiatry and Its Historians", and for the Dutch literature, Van Belzen and Vijselaar, "Dutch Psychiatry." Van Belzen and Vijselaar argue that until about 1975 most contributors to Dutch psychiatric history were psychiatrists who wrote the history of their field and their leaders.

20 Goffmann, Asylums; Szasz, The Myth of Mental Illness; Foucault, Madness and Civilization; Rothman, The Discovery of the Asylum.

2I Scull, "Psychiatry and Its Historians", 240.

22 Scull, Museums of Madness; idem, The Most Solitary of Afflictions.

23 Grob, Mental Institutions in America; idem, Mental Illness.

24 Grob, Mental Institutions in America, xiii.

25 See Castel, L'ordre psychiatrique; Dörner, Bürger und Irre; Binneveld, Filantropie; Scull, Social Order/Mental Disorder; Qvarsell, "Locked Up or Put to Bed."

26 Scull, "Psychiatry and Its Historians."

27 D’Antonio, "Negotiated Care", 34-35.

28 These studies include Digby, Madness, Morality, and Medicine; Dwyer, Homes for the Mad; D'Antonio, "Negotiated Care"; and Tomes, The Art of Asplum-Keeping.

29 D’Antonio, "Negotiated Care."

30 Moral treatment will be discussed in Chapter I. For the analysis of the work of attendants, see Digby, Madness, Morality, and Medicine, I40-70; Dwyer, Homes for the Mad, I63-85; Tomes, The Art of Asylum-Keeping, I79-87.

3I Van Belzen and Vijselaar, "Dutch Psychiatry." Many celebratory histories have been written on the occasion of an anniversary or jubilee of the asylum. These books usually follow a traditionalist perspective on asylum development. Some are exceptions to this tradition and include an historical analysis. See Binneveld and Wolf, Een huis met vele woningen; Kappelhof, Reinier van Arkel; Lindeboom and Van Lieburg, Gedenkboek; Vijselaar, Gesticht in de duinen; Blok and Vijselaar, Terug naar Endegeest.

32 Binneveld, Filantropie; Binneveld et al., Een psychiatrisch verleden; Binneveld and Van Lieburg, Psychiatric Reform; Binneveld and Wolf, Een huis met vele woningen; Vijselaar, "De zedekundige behandeling"; idem, "Egodocumenten"; idem, Krankzinnigen ge- 
sticht. Other important contributions to this line of literature include Hutschemaekers, Neurosen in Nederland; Jak, Armen van Geest; idem, Huizen van Barmhartigheid; Kappelhof, Reinier van Arkel; Klijn, Tussen caritas en psychiatrie.

33 Analysis of the role of mental nurses in the Dutch psychiatric historiography is limited to scattered chapters and sections in larger works on the history of psychiatry. They usually pertain to the introduction of mental nurse training as a psychiatric reform effort. Several master's theses focus on the history of mental nursing. Weisglas examines the transition from untrained attendant to trained mental nurse in asylums up to I920, whereas De Laat decribes the history of mental nursing from I920 to I980. See Weisglas, "Overgang van oppassers"; De Laat, "Van psychiatrisch verpleegkundige tot ...?" Van der Laarse-de Bruin analyzes changes in the content of mental nurse textbooks that mark a transition from a medical to a more psychological approach to patients. See Van der Laarse-de Bruin, "Veranderingen." See also De Boer, "Van arbeiders onder krankzinnigen."

34 Vijselaar, Krankzinnigen gesticht, I25-39; Kramer, Geschiedenis, IIO-I9, I44-49.

35 Vijselaar, Gesticht in de duinen; Blok and Vijselaar, Terug naar Endegeest. The latter has a strong emphasis on the patient experience in the history of the Endegeest mental hospital.

36 Davies, Rewriting Nursing History; Lagemann, Nursing History.

37 Davies, Rewriting Nursing History, IO-II; Lynaugh and Reverby, "Thoughts on the Nature of History", 4, 69; Reverby, Ordered to Care, 6-7; Rosenberg, "Review Article: Recent Developments"; idem, "Clio and Caring”, 67-68.

38 These works include, chronologically listed, Melosh, "The Physician's Hand”; Maggs, The Origins of General Nursing; Baly, Florence Nightingale; Reverby, Ordered to Care; Dingwall, Rafferty, and Webster, An Introduction to the Social History of Nursing (which includes a chapter on mental disorder and mental handicap); Lynaugh, "From Respectable Domesticity”; Rafferty, "The Politics of Nursing Education I860-I948."

39 Church, “That Noble Reform"; idem, "Emergence of Training Programs”; idem, "From Custody to Community"; Nolan, "Psychiatric Nursing Past and Present"; idem, "The Founding of Psychiatric Nurse Training”; idem, History of Mental Health Nursing.

40 Church, "Emergence of Training Programs", ro7.

4I Carpenter, "Asylum Nursing"; Dingwall, Rafferty, and Webster, "Mental Disorder"; Haw, “John Conolly's Attendants"; Hughes, "Country Boys Make the Best Nurses"; Peplau, "Future Directions"; Russell, "The Lunacy Profession.”

42 The articles emphasize the strenuous work conditions and the impossibility for attendants to marry.

43 Several authors record that work regulation of attendants usually included a system of fines to force attendants to follow regulations. See Haw, “John Conolly's Attendants”, 4I; Carpenter, "Asylum Nursing”, I38; Hughes, "Country Boys Make the Best Nurses", 92.

44 See Carpenter, “Asylum Nursing”; Dingwall, Rafferty, and Webster, "Mental Disorder”; Hughes, "Country Boys Make the Best Nurses"; Nolan, "The Founding of Psychiatric Nurse Training"; idem, A History of Mental Health Nursing; Peplau, "Future Directions." 45 Carpenter, "Asylum Nursing"; Dingwall, Rafferty, and Webster, "Mental Disorder"; Nolan, A History of Mental Health Nursing.

46 Hughes, "Country Boys Make the Best Nurses", Io०-Ior.

47 Wiegman, "Zusters in smetteloos wit." 
48 Bakker-van der Kooij, "Mara”, I93-22I; idem, "De maatschappelijke positie”; Van der Kooij, "I890-I990", I3-64; idem, Mans.

49 Spijker, Mooi en beschaafd verplegen; Van Gemert and Spijker, Verdichtsel en werkelijkheid. 50 Wiegman, "The Origins of Modern Nursing” and "Gij completeert zijn arbeid."

5I For a discussion of this trend in writing about social history, see Stearns, "Introduction"; Sharpe, "History from Below", 24-4I.

52 See Sharpe, "History from Below", 36-37.

\section{Notes to Chapter I: Asylum Reform Ideals}

I Vijselaar, Krankzinnigen gesticht, I3-I4; Ederveen, "Niet voor rede vatbaar", 22-30, 46-57.

2 Ederveen, "Niet voor rede vatbaar", 56-57. In this period the (local) government contributed only minimally to poor relief. Local poor boards and church boards usually owned stock or property such as land, farms, and houses, out of which investment they financed poor relief. See De Kruif, "De prijs van de armenzorg."

3 In Groningen, for example, the town council ordered the establishment of a "madhouse" (dolhuis) for five people in 1605 , annexed to a local poorhouse for the elderly (Pepergasthuis) founded in 1405 . For its management, the board appointed a married couple who were paid by the town council. Ederveen, "Niet voor rede vatbaar", 3I-46.

4 Vijselaar, Krankzinnigen gesticht, I3-I4. For a discussion of the history of poor relief, see Van der Valk, "Van Pauperzorg”, 9-27; Van Doorn, "De strijd tegen armoede"; Verdoorn, Het gezondheidswezen te Amsterdam.

5 Qvarsell, "Locked Up or Put to Bed", 86; Tomes, The Art of Asylum-Keeping, 3-5.

6 Tomes, The Art of Asylum-Keeping, xiv-xv, 5; D’Antonio, "Negotiated Care”, Io.

7 Tomes, The Art of Asylum-Keeping, 3-7; D’Antonio, "Negotiated Care”, 9-13; Strumpf and Tomes, "Restraining the Troublesome Patient", 5-9; Vijselaar, Krankzinnigen gesticht, I4; Binneveld, Filantropie, I6-20.

8 Tomes, The Art of Asylum-Keeping; Digby, Madness, Morality, and Medicine; D'Antonio, "Negotiated Care."

9 For the United States, see Tomes, The Art of Asylum-Keeping, 5; for Britain, Andrew Scull argues that lunacy reform was heavily influenced by social movements of evangelicalism (a conservative, humanitarian, and paternalistic crusade against religious indifference and immorality) and Benthamism (a utilitarianist attempt to create a scientific, expert-based style of governmental policy and administration). See Scull, The Most Solitary of Afflictions, 84-88. Roger Qvarsell makes the same argument for Swedish psychiatric reform. See Qvarsell, “Locked Up or Put to Bed”, 88. For Dutch psychiatric reform, similar roots can be traced. Joost Vijselaar argues that the founders of the Meerenberg asylum were involved in the positivist, hygienist reform movement and were closely connected with members of the "Reveil" circles, a Protestant revival movement quite similar to evangelicalist groups. Vijselaar, “De zedekundige behandeling”, I22.

Io D’Antonio, "Negotiated Care", IO-II; Tomes, The Art of Asylum-Keeping, 5.

II Tomes, The Art of Asylum-Keeping, xv. The emergence of moral treatment as a psychiatric reform movement in the context of a broader poor reform occurred in all Western countries during the nineteenth century. When this reform began, it was in part related to the transition from traditional society to a modern, industrial state and to the subsequent growing influence of government in each country. See Qvarsell, "Locked Up or Put to Bed", 86-87; Binneveld, Filantropie, 16-22.

I2 Suzuki, "The Politics and Ideology of Non-Restraint." 
I3 Binneveld, Filantropie, 59.

I4 Tomes, The Art of Asylum-Keeping, xvi-xvii; D’Antonio (“Negotiated Care”, II) argues that in the early nineteenth-century Friends asylum a moral regimen was at first a lay model of care, recreating a notion of the family. In the mid-nineteenth century, physicians played a more central role, in part to reduce the tension created by the contradictory expectations of the asylum as a family. Scull perceives the "medicalization" and "take over" of medical authority in asylums as a deliberate professionalizing strategy of doctors and a form of "moral entrepreneurship." See Scull, The Most Solitary of Afflictions, I75-2I6.

I5 Tomes, The Art of Asylum-Keeping, xiii.

I6 Ibid., xv.

I7 Ibid., xiii.

I8 Ibid., xv-xvi.

I9 Qvarsell, “Locked Up or Put to Bed”, 86.

20 Van Doorn, "De strijd tegen armoede”, 6-7; Binneveld et al., Een psychiatrische verleden, 94-Ioo; Scull, The Most Solitary of Afflictions, I-45.

2I Foucault, Madness and Civilization; Scull, The Most Solitary of Afflictions.

22 Binneveld and Van Lieburg, Psychiatric Reform, I9.

23 Ibid.; Van der Esch, Geschiedenis, I: I2; Binneveld et al., Een psychiatrisch verleden, I04-5; Van Doorn, "De strijd tegen armoede", 7.

24 Schroeder van der Kolk's view on moral treatment was similar to that of its designers at the York Retreat. For Van der Kolk's views and model of renovation, see Binneveld, Filantropie, 44-5I and Vijselaar, Krankzinnigen gesticht, I5.

25 Vijselaar, "Schroeder van der Kolk"; Binneveld, Filantropie, I3-77.

26 Van der Esch, Geschiedenis, I: 8I, no. 4.

27 Verslag over den Staat, I869-74, 3, 42; PB, I (I883): II.

28 Vijselaar, "Schroeder van der Kolk."

29 Binneveld, Filantropie, 67.

30 Van der Valk, "Van Pauperzorg", 9-27.

3I Jongmans, De Zusters van Coudewater, 50.

32 The state government contributed a fixed rate of forty guilders to the fee. See Verslag van het Staatstoezicht, I900-1902, 242. The province usually contributed the same amount to the fee as the state.

33 Querido, Krankzinnigenrecht, 265.

34 JvMB; JvF; De Groot, Veldwijk in verleden tijd, 99.

35 Vijselaar, "De zedekundige behandeling”, I43-48.

36 Vijselaar, "Schroeder van der Kolk."

37 Ibid., I22-23.

38 Figure I, floor plan of Meerenberg. The corridor system is discussed in Scull, Social Order/Mental Disorder, 23I-38, and idem, The Most Solitary of Afflictions, 267-333; see also Tomes, The Art of Asylum-Keeping, I29-87. For an analysis of the architecture in nineteenth-century Dutch asylums see De Boer, "Architectuur en krankzinnigen."

39 Vijselaar, "De zedekundige behandeling”, I34-35. A physician was put in charge of the new institution because of his moral authority rather than his medical knowledge. See also Tomes, The Art of Asylum-Keeping, 129-64 and Digby, Madness, Morality, and Medicine, 105-37.

40 JvMB, I887. 
4I Vijselaar, “De zedekundige behandeling”, I32-43.

42 Ibid., I3I.

43 Ibid., I43-49.

44 Verslag over den Staat der Gestichten, 1869-74, 20, 23-26.

45 Haw, “John Conolly's Attendants", especially 45-46; Hughes, "Country Boys Make the Best Nurses", especially 93-94.

46 RANH, ATC, archief no. I8I, inv. no. 294 "Huishoudelijke regelementen voor het Provinciaal Krankzinnigen gesticht Meerenberg I845-I894”, particularly "huishoudelijk reglement", handwritten by B. H. Everts, I849. "Instructie voor de bedienden in het krankzinnigengesticht te Franeker I850", included in Instructiën en verordeningen, 1850-1886, Medemblik Collectie, G30, Museum GGZ, Trimbos Instituut.

47 These turnover rates were reported in Meerenberg. See JvMB, I890, 20-25. During the I8gos the economy boomed, resulting in a high demand for laborers. But even in the I870 the state inspectors reported annual turnover rates of a third to over one-half of the asylum workforce. See Verslag over den Staat der Gestichten, I869-74, 2 I-22.

48 "Twee stukken van B. H. Everts over verbetering van het gehalte van het dienstpersoneel, I854." RANH, ATC, archief no. I8I, inv. no. 338.

49 "Instructie voor de bedienden in het krankzinnigengesticht te Franeker, I850", in Instructiën en verordeningen.

50 "Schets der volstrekten vereischten van een goed gesticht tot genezing van krankzinnigen en der wijze van beheer van hetzelve." J. Schroeder van der Kolk (1838), cited in Binneveld, Filantropie, 20I-II. For further discussion see Binneveld, Filantropie, 47-50 and Vijselaar, "Schroeder van der Kolk", 27I-85.

5I Binneveld, Filantropie, 2 II.

52 Bourgeois ethical values of calmness, quietness, control of emotions and behavior, selfcontrol, regularity, moderation, temperance, purity, discipline, order, accepted "natural" distinctions of social standing, paternalism, industry, piety, decency, and the disciplined devotion of a refined, Christian family were reflected in important documents, representing the core values of moral treatment, such as "Schets der volstrekte vereischten" by J. Schroeder van der Kolk (I838) (cited in Binneveld, Filantropie, 2OI-II), and in the behavioral code posted in the hall of the Meerenberg asylum for all Meerenberg residents, both patients and personnel. This code was entitled "Voorschriften voor alle bewoners van het gesticht Meerenberg" (I850). For a picture of the behavioral code and a discussion of it by Joost Vijselaar, see Kerkhoven, Beeld van de psychiatrie 1800-1970, $8 \mathrm{I}-82$. The opinion that in the moral treatment era the asylum was managed as a large bourgeois household grounded in nineteenth-century liberal "civilized" bourgeois ethics has been developed in collaboration with Joost Vijselaar. See also the discussion of moral treatment at the beginning of this chapter.

53 "Beredeneerd Verslag over het jaar I85I, omtrent het Geneeskundig Gesticht voor Krankzinnigen te Franeker, uitgebracht door Bestuurders dezer Instelling, ter voldoening van Art. II hunner instructie", JvF, I85I, 9, GAF, APZF, doos 5I3I.

54 Verslag over den Staat der Gestichten, 1864-68, 70-80; 1869-74, 20, 23-26; Verslag van het Staatstoezicht, I888-90, I03, I78; Vijselaar, Krankzinnigen gesticht, I25.

55 Vijselaar, “De zedekundige behandeling”, I25; Verslag over den Staat der Gestichten, I $869-74$, II-26.

56 JvMB, I887, 24; I889, I9.

57 Jansz, Denken over sekse, 42. 
58 De Regt, Arbeidersgezinnen en beschavingsarbeid, I7-33, I37, I50.

59 Rosenberg, The Care of Strangers, I33.

GoDonkersloot, Raadgevingen aan Oppassers. Other examples are Curwen, Handleiding voor Oppassers and Hecker, Gids voor de huisgenooten.

6r Donkersloot, Raadgevingen aan Oppassers.

62 It can be assumed that in the second half of the nineteenth century most attendants had elementary education, although it may have been minimal. The first three laws on public education for all children, including the poor, passed through parliament in I801, I803, and 1806, and prescribed education in reading, writing, language, and arithmetic. See Boekholt, "De Nederlander gaat naar school”, 208. However, throughout the nineteenth century truancy was high. School attendance was made obligatory by law (leerplichtwet) in I9OI (Boekholt, 2I3-I4). The registers of applicants for servant and nursing positions kept at Meerenberg (I887-I9II) reported that almost every applicant had elementary education. See Sollicitanten Registers I887-I9II, RANH, ATC, archief no. I8I, inv. no. 366-79.

63 For a discussion of similar developments in the American context, see Grob, Mental Illness and American Society 1875-1940, 7-29 and Dwyer, Homes for the Mad, I63-85.

64 Ellen Dwyer, in her study of two nineteenth-century New York asylums, argues that despite the late nineteenth-century medicalization and professionalization of asylums, the position of attendants remained ambiguous, and their status hardly improved. Although doctors expected kind and loving care from attendants, they did little to improve working conditions that would encourage such behavior. Often the (minimal) training doctors eventually provided to nurses was no more than an upgrade to make the work more attractive. See Dwyer, Homes for the Mad, I63-85.

65 Tweede stuk van B.H.Everts, I854, RANH, ATC, archief no. I8I, inv. no. 338 .

66 Ibid.

67 Verslag over den Staat der Gestichten, I869-74, II-26; I878-8I, I-I6; I882-84, I-I4; I885$87,5 \mathrm{I}-54, \mathrm{I} 24-25$.

68 Binneveld, Filantropie, repressie en medische zorg..

69Heemstra, Honderdjarig bestaan, 9-15.

70 Algra, Franeker stad met historie, I2 6-73.

7I Heemstra, Honderdjarig bestaan, I4-I7.

72 Ibid., I8.

73 Ibid., 24-30

$74 \mathrm{JvF}, \mathrm{I} 85 \mathrm{I}, \mathrm{I} 853$

75 The annual patient fee at Franeker was 2I9 guilders until I9o0 and had not been raised since I882. JvF, I882, 3, GAF, APZF, doos 5132. In I900 the fee was raised from 60 to 70 cents a day (255.50 guilders annually). JvF, I900, sectie "bestuurders", GAF, APZF, doos 5132. In other asylums the fee was higher. Meerenberg charged a fee of 270 guilders for indigent patients during the I880s and I89os. See Duyvesteyn, Historisch overzicht, 4I. The patient fee of third-class patients in Veldwijk was 300 guilders on its opening in 1886 . JvVCV, I9I9, 25.

$76 \mathrm{JvF}, \mathrm{I} 882,4$.

77 Nation-wide, indigent patients continued to make up the majority of the asylum population far into the twentieth century. In I909, 8I.7 percent of the asylum population was paid for using public funds. Of the new admissions between I909 and I9II, 77.6 percent were indigent. See Verslag van het Staatstoezicht, I909-II, 306, 322. In contrast, the 
socioeconomic status of the population in general improved during the late nineteenth century when industrialization had its biggest impact in the Netherlands. After 1890 the number of poor and dependent on relief in the general population decreased. See Van Loo, Den arme gegeven, 55-64.

78 This classification structure was common in Dutch asylums. For a discussion of this structure in the Voorburg asylum, see Binneveld and Wolf, Een huis met vele woningen, 46-49.

79 Ann Digby shows in her analysis of the York Retreat how a systematic nosology fell into disuse at the Retreat during the second half of the nineteenth century and mixed old and new treatments were applied pragmatically and eclectically. Digby, Madness, Morality, and Medicine, 135-39. See also Scull, The Most Solitary of Afflictions, 344-49.

80 This description of the class differentiation in Dutch society is based on Duyvendak and Kooij, Sociale Geschiedenis, 59-68. For the generation of the working class see Van Doorn, "De strijd tegen armoede" and Van Holthoon, "De armenzorg in Nederland."

8I JvMB, I890, 3I. By I89o indigent patients (fifth class) comprised I, oI9 out of a total of I,I72 patients in Meerenberg. Classes one to three numbered 90 patients and the fourth class included $6_{5}$ patients.

82 See Vijselaar, Krankzinnigen gesticht.

83 In her study of the architecture of the Duin and Bosch asylum (founded I909), Marjan Onrust describes how the design reflected the attempt to control difficult patients and the marginalization of the most difficult patients to the outskirts of the grounds. The pavilions for quiet patients were the most open and were at the front, whereas the buildings for the most disturbed patients were of a closed design, heavily constructed, and more remote. See Onrust, Waanzin gevangen, 92-II9.

84 JvMB, I889, 9-10.

85 Although cloisters, monasteries, and Roman Catholic orders had been banned during the French Revolution, Napoleon had, out of necessity, restored charitable congregations that devoted themselves to the nursing of the sick or education of the poor by law (I804). These laws also applied to the Netherlands and were maintained in the new kingdom (I8I5). See Eijt, Religieuze vrouwen, 47-50. For a listing of the many Roman Catholic religious orders established in the Netherlands during the nineteenth century, see Van Vught and Voorvelt, Kloosters op schrift. For a discussion of the re-establishment of nursing orders in Napoleonic France, see Weiner, "The French Revolution."

86 Righart, De Katholieke zuil in Europa, I89-98; Eijt, Religieuze vrouwen, 49-50.

87 Eijt, Religieuze vrouwen, 51. Eijt argues that the revival of Roman Catholic religious missions and the re-establishment of charitable orders is comparable to similar movements among nineteenth-century Protestants, such as the Inner Mission movement (Deaconess movement) (30).

88 Binneveld, Filantropie, I84-87; Klijn, Tussen caritas en psychiatrie, 3I-34.

89 Kappelhof, Reinier van Arkel, 9-I5. By the mid-eighteenth century the asylum housed about twenty-five patients. Ibid., I30.

9०Ibid., 9-I4.

9I Ibid., 46-52.

92 The funds of the hitherto separate charitable organizations were merged into one poor relief fund of the "Godshouses", as the combined organizations were called. Only the Dutch Reformed deacon board and the Jewish poor board remained independent. See De Kruif, “De prijs van de armenzorg”, 36. 
93 Kappelhof, Reiniervan Arkel, 65-70.

94 Ibid., 70.

95 Ibid., 70-74.

96 Klijn, Tussen caritas en psychiatrie, 40-47. Klijn demonstrates a similar tension between the views of the nursing orders and the state inspectors in her study of two charitable asylums in the (Roman Catholic) province of Limburg. See also Binneveld, Filantropie, 188-92.

97 See Jongmans, De Zusters van Coudewater, 20-27.

98 Binneveld and Wolf, Een huis met vele woningen, 40-52.

99 HDNP, VCV, no. 50I, inv. no. 52, SV, I27. Rapport door D. Schermers over het bezoek aan enige buitenlandse en binnenlandse gestichten [Z.d., waarschijnlijk rond I890].

Ioo Verslag van het Staatstoezicht, I89I-93, I22.

IOI Kraus, Krankzinnigheid in Nederland, 2. Compared to other countries these numbers were relatively low. In Britain, for instance, the rate per Io,000 was I6.49 in 1855 and 29.26 in I890. See Scull, The Most Solitary of Afflictions, 337.

IO2 Van der Esch, Geschiedenis, 8I; Van Cappelle, "Het toenemen der bevolking”, especially 9-II. The population grew from three to about four million in that period.

I03 JvMB, I899, 76-79.

I04 Ibid.; Binneveld, Filantropie, ıо9.

I05 Binneveld, Filantropie, I43.

Io6 JvMB, I899, 76-79.

I07 The medical director used the word bergplaats (warehouse). JvF, I882, 4.

Io8 JvMB, I882, I-2; I883, I-2; I884, I-2.

IO9 Van Cappelle, "Het toenemen der bevolking", 5-13.

IIо Kappelhof, Reinier van Arkel, 46-48; Binneveld, Filantropie, I25-29; Grob, Mental Institutions in America, 35-220; idem, Mental Illness, 46-I07. See also Scull, The Most Solitary of Afflictions, I75-266, 334-74 and Hutschemaekers, Neurosen in Nederland, II 8-57, 240-42.

III Verslag van het Staatstoezicht, I885-87, I-3. The certification implied a loss of civil rights. A patient had to be discharged "recovered" in order to regain these rights. Admissions without certification were only possible after the law was adjusted in I904. Then, to facilitate admission in new university clinics, which were legally not asylums, the opportunity of uncertified admission was created. See De Ridder, "Het ontstaan van de aangewezen afdeling", III-25.

II2 Binneveld, Filantropie, I5I-54.

II3 Verslag van het Staatstoezicht, I885-87, I5-I8.

II4 Van der Esch, Geschiedenis, I975, 8I.

II5 JvF, I882, I886.

II6 JvF, I882.

II7 Een eeuw krankzinnigenverpleging 1849-1949, 52.

II8 JvMB, I888, 8; I889, 3-4.

II9 Verslag van het Staatstoezicht, I888-90, 366-67.

I20 JvMB, I888, 48; I889, 36; I890, sectie "geneeskundige statistiek" (56 out of 27I admissions were diagnosed with dementia).

I2I Founded in I886, Veldwijk was the first of a wave of new asylum building by Protestant and Catholic groups until about I920. Between I 880 and I920 nineteen new asylums were founded, predominantly by denominational groups, including Roman 
Catholic orders. See Van Belzen, Psychopathologie en religie, 336-38; Binneveld et al., Een psychiatrisch verleden, Io9-16; Righart, De Katholieke Zuil in Europa; Stuurman, Verzuiling, Kapitalisme en Patriarchaat; Vijselaar, Krankzinnigen gesticht, I7.

I22 The English word "reformed" cannot really express the complex process of separation among Protestant churches in Holland during the nineteenth century, because it is a translation of both hervormd and gereformeerd, which mean two different things in Dutch. For a history of the separation movements that formed the Gereformeerde Kerken (Dutch Reformed Churches) in I892 see Van Belzen, Psychopathologie en religie, I3 and Lindeboom and Van Lieburg, Gedenkboek, I3-2I. For a summary of the founding story of the VCV, the Veldwijk asylum, and the leadership of Lindeboom, see Lindeboom and Van Lieburg, Gedenkboek, 23-4I. See also JvVCV, I884/85, I885/86, I886/87.

I23 See Introduction, this book, for a discussion.

I24 Lindeboom and Van Lieburg, Gedenkboek, I3-I5.

I25 The most popular leader of the Doleantie, Abraham Kuyper, was not only a theologian, but also a politician and publicist. He was one of the initiators in founding the (Protestant) Free University in I880 (of the Dutch Reformed Churches). See Van Belzen, Psychopathologie en religie, 338-39, 34I-42.

I26 See Introduction, this book.

I27 JvVCV, I884/85, 21, 65 .

I28 Lindeboom and Van Lieburg, Gedenkboek, 43-47, I09-26, I77-87; Binneveld, Filantropie, $160-84$.

I29 Van Belzen, Psychopathologie en religie, I4.

I30 Initially the VCV had no contracts for indigent patients, and only families who could afford the fee placed their family members in Veldwijk. Because of the demand for placement nationally, municipalities soon began to pay for placing indigent patients in Veldwijk, although about a third of Veldwijk's patient population remained private paying patients from higher social classes. Later institutions founded by the VCV were all for indigent patients. For patient numbers see JvVCV, I886/87, 45; I900, 54 The percentage of private paying patients has been gathered from the annual reports, section “Loop der Bevolking”, JvVCV, I886-1920.

I3I JvVCV, I884/85, 30 .

I32 JvVCV, I885/86, I3.

\section{Notes to Chapter II: The Ideal of a Mental Hospital}

I Binneveld, Filantropie, II3-I5; Grob, Mental Illness and American Society 1875-1940, 307 I. For a discussion of the rise of hospital medicine and the hospital system, see Rosenberg, The Care of Strangers.

2 Qvarsell, "Locked Up or Put to Bed", 94. Qvarsell describes the same development in Swedish psychiatry. Around I896, based on the argument that the mentally diseased should have the same treatment as the somatically diseased, "almost all patients were put to bed", light and airy sick rooms were created, and the pavilion system was preferred, Qvarsell notes. For the Netherlands, see Van Deventer, "Enige beschouwingen.” The emphasis of Meerenberg's medical director Jacob van Deventeron the hospital as a model for asylum treatment almost literally follows the line of reasoning of the German psychiatrist Neisser, although he gives no references. Neisser discusses his opinions on bed treatment in Neisser, Ueber die Bettbehandlung. Neisser (born I86I) was asylum 
physician at Leubus (1886-92) and medical director of the Lublinitz asylum and, after I904, of the Bunzlau asylum (biographical information from Lindeboom and Van Lieburg, Gedenkboek, I55). Neisser stated that the ideas on bed treatment that he discussed had been spreading for over a decade in various western European countries, including France, and were already propagated at the Tenth International Medical Conference in Berlin (1890). See Neisser, Ueber die Bettbehandlung, 3, 9.

3 See a discussion of how the medical model replaced a traditional, lay, bourgeois family model of care in D’Antonio, "Negotiated Care”, 219-90.

4 JvMB, I918, 7I.

5 Binneveld, Filantropie, I22; Qvarsell, “Locked Up or Put to Bed”, 93-94.

6 Late nineteenth-century and early twentieth-century Dutch psychiatry generally oriented itself on German psychiatric literature. See Van Belzen, Psychopathologie en religie, 228.

7 Vijselaar, "Neerlands eersten psychiater", 5-6. See also Grob, Mental Illness and American Society 1875-1940, 30-7I; Qvarsell, "Locked Up or Put to Bed", 93.

8 Rosenberg, "Florence Nightingale", II6-36; Temkin, The Double Face of Janus, 4I9-7I; Tomes, "The Private Side of Public Health."

9 Peters, "The German Classical Concept of Schizophrenia”; Sedler, "Concepts of Schizophrenia."

Io Digby, Madness, Morality, and Medicine, I05-39; Van Deventer, "Enige beschouwingen."

II In 1865 the law on state medical inspection was passed by parliament, and among other things brought medical licensing and education under national regulation. As of 1865 a license as a physician could only be obtained after training at one of the three university medical schools or at the Clinical School of Medicine in Amsterdam (which soon incorporated into a university), and after passing a state examination at the end of the university training. Since that time medical training has meant university training, although psychiatry had not yet developed into a medical specialization. Houwaart, De hygiënisten, 230-45; Van der Velden, "The Dutch Health Services."

I2 PB 8 (I890): I89-96; Feestbundel van de Nederlandse Vereniging voor Psychiatrie ter ere van haar 25-jarig bestaan, xi; Vijselaar, "Neerlands eersten psychiater."

I3 Blok and Vijselaar, Terug naar Endegeest, 27-32; Van der Esch, Geschiedenis, 3: 88-92.

I4 Peeters and Vos, "Historische fasen", I9-20; Vijselaar, "Neerlands eersten psychiater", 4-6.

I5 Verslag van het Staatstoezicht, I897-99, 38I-82.

I6 Binneveld, Filantropie, I23; Stockman, Geen rede mee te rijmen, 9I-97.

I7 Kerkhoven and Vijselaar, “De zorg voor zenuwlijders rond I900”, 28. For a history of neurasthenia, see Drinka, The Birth of Neurosis. For a Dutch history of neurosis, see Hutschemaekers, Neurosen in Nederland.

I8 Binneveld, Filantropie, I22-25; Blok, "Hersenverweking in Nederland", 47-53; Rosen, Madness in Society, 247-67; Scull, The Most Solitary of Afflictions, 324-29. Social-Darwinist thought generated the view that hygienic improvement and modern medicine enhanced the survival of a relatively large group of "degenerated", socially inferior people who in turn threatened modern civilization. Out of this train of thought, and in response to increasing numbers of (deviant) groups such as mentally ill people, a eugenic movement gained popularity in the late nineteenth and early twentieth century. For a discussion of eugenics in the Netherlands, see Noordman, Om de kwaliteit. 
I9 For a listing of common causes of mental illness used by the state inspectors in their annual reports, see Verslag van het Staatstoezicht, I89I-93, 46; Van der Bergh, "De oorzaken van krankzinnigheid", 57-64. The social causes were described by Jacob van Deventer in his annual reports. JvMB, I895, 71; I903, 69-73.

20 Binneveld, Filantropie, I22.

2I Ibid.; Scull, The Most Solitary of Afflictions, 325.

22 Mooij, Geslachtsziekten en besmettingsangst,79; Blok, "Hersenverweking in Nederland", 50-52; Rosen, Madness in Society, I79-94.

23 Qvarsell, “Locked Up or Put to Bed”, 94.

24 In I9I6 the medical director of Endegeest Asylum, J. van der Kolk, discussed bed treatment in the Psychiatrische en Neurologische Bladen (Psychiatric and Neurological Journal), the professional journal of psychiatry, and he referred explicitly to German developments as influential examples of the application of bed treatment. Van der Kolk, "Over bedbehandeling."

25 JvMB, I90I, 9-I4.

$26 \mathrm{JvMB}, \mathrm{I} 898$, I80-8I.

27 Van der Bergh, “De oorzaken van krankzinnigheid”, 5I-64.

28 Binneveld, Filantropie, 166-69.

29 Van Belzen, Psychopathologie en religie, 29-82, 32I; Van Os and Wierenga, Wetenschap en rekenschap.

30 Van Belzen, Psychopathologie en religie, 98, 355-59.

3I Some members of the Dutch Reformed Churches had strong sympathy for homeopathic medicine. This was in line with their rejection of materialist notions. See Wieringa, "Lotgevallen van de Valeriuskliniek", I5-I6. Similar antimaterialist views and the notion of insanity as a disease of the soul, caused by sin, can be found in the work of the German psychiatrist J. Heinroth. See Ackerknecht, Short History of Psychiatry, 6r.

32 In the VCV's first annual meetings several board members, both theologians and physicians, outlined the VCV's medical doctrine in numerous position papers on the cause and nature of insanity, the relationship between faith and science, and the meaning of faithful family life for the treatment of the insane. These papers summarized what would remain the dominant VCV ideology on insanity far into the twentieth century. See Van Belzen, Psychopathologie en religie, 32-33; Hermanides, "Het wezen."

33 Ibid., 83-9I.

34 "Verslag betreffende het Christelijk gesticht voor krankzinnigen 'Veldwijk' te Ermelo,"”, I893, I895, HDNP, VCV, no. 50I, doos I3 (handwritten Annual Reports of Veldwijk by medical director J. van Dale, I893, I895). The sections on the health status of the patients in these reports show that Van Dale applied similar treatments as in other institutions and interpreted insanity in medical rather than in biblical terms. Moreover, he used similar sedative medication. See also Van Belzen, Psychopathologie en religie, $275-367$.

35 "Rapport van de Geneesheer Directeur [Vermeulen] aan het Bestuur, II-I2-I89o,"”, HDNP, VCV, no. 50I, doos I3. Vermeulen could not build on much experience in asylum care. When he joined the board of the VCV on its founding, he was about to retire as a general practitioner but felt pressed to take over the medical directorship in Veldwijk's year of opening when the young graduate Reindert Klinkert (I857-86), recently appointed as medical director, suddenly died. Vermeulen must have felt relieved when yet another young, just graduated physician, Johan Hendrik Abraham van Dale (1865- 
I949), joined him in I890, although he did not have any experience with insane patients either. When Vermeulen died the next year, Van Dale succeeded him as medical director, where he remained until I924. He was a keen, very devoted, and scientifically interested physician who gave much stability to the organization for several years but also carefully listened to the advice of his more experienced colleagues.

36 Brief van J. H. A. van Dale aan het bestuur, I89I, HDNP, VCV, no. 50I, doos I3. In the same letter Van Dale requested the establishment of an operating room.

37 "Verslag betreffende het Christelijk gesticht 'Veldwijk',", I906 and I907, section "lijkopening" (autopsy), HDNP, VCV, no. 50I, doos I3.

38 Vijselaar, Krankzinnigen gesticht, 32-37; Qvarsell, “Locked Up or Put to Bed,"”, 94.

39 Vijselaar, Krankzinnigen gesticht, 33; Van Deventer, "Enige beschouwingen."

40 Van der Kolk, "Over bedbehandeling." For increased use of bed rest, see Verslag van het

Staatstoezicht, I897-99, 255. For a further discussion of bed treatment, see Kramer,

Geschiedenis, I05-8; Vijselaar, Krankzinnigen gesticht, 32-40, Io6-7. ì

4I Qvarsell, “Locked Up or Put to Bed.”â

42 Neisser, Ueber die Bettbehandlung. In his I9I6 article Van der Kolk identified J. van

Deventer as one of the first Dutch psychiatrists to have applied bed rest on the insanity wards which he did when he was still a physician at the Buitengast Hospital in Amsterdam in I879. See Van der Kolk, "Over bedbehandeling," 478.

43 Descriptions of bed treatment by other psychiatrists give similar listings. It was applied widely for all sorts of mental illness. See Van der Kolk, "Over bedbehandeling”, 477-87.

44 Neisser, Ueber die Bettbehandlung, 3-I7.

45 Van der Kolk, "Over bedbehandeling."

46 Neisser, Ueber die Bettbehandlung, I-20. For similar confidence in the working of bed treatment, see Van Deventer, "Enige beschouwingen”; and Van der Kolk, "Over bedbehandeling." A similar medical regimen was used for the treatment of nervous diseases, especially neurasthenia, which was developed by, among others, the New York physician George Miller Beard and the Philadelphian physician Silas Weir Mitchell in the late nineteenth century. See Drinka, The Birth of Neurosis, I84-209. The London physician William S. Playfair introduced the treatment in Britain (Drinka, 2I2). For its reception in Germany and the Netherlands, see Dr. A. Brosius, honorary member of the NVPN and medical director of the Bendorf and Sayn asylums near Koblenz, Germany. Brosius, "S. Weir Mitchell's Systeem Neurosen."

47 Neisser, Ueber die Bettbehandlung, I2-I3.

48 Rosenberg, "The Crisis in Psychiatric Legitimacy."

49 Van Deventer, "Enige beschouwingen"; ibid., "Isoleren of niet isoleren."

50 Verslag van het Staatstoezicht, I894-96, 245; Van Deventer, "Isoleren of niet isoleren", I9-23.

5I Verslag van het Staatstoezicht, I888-90, I77-78; Kerkhoven, Beeld van de psychiatrie 1800-1970, 109.

52 The description by one former patient of her experience in the asylum in the late I9Ios vividly portrays the ongoing unreston theward for bed rest, with patients talking, screaming, crying, jumping in bed, or climbing out of bed. See Dommisse, Krankzinnigen.

53 JvMB, I896, I30-34; I897, I7I-75.

54 Single rooms were one-bed rooms, which could be used either open or locked. In the latter case there was not much difference to a cell.

55 JvMB, I896, I7I-75; I897, I30-34; I903, I32-33. 
$56 \mathrm{JvMB}, \mathrm{I903}, \mathrm{I32}-33$.

57 JvVCV, I899/i900, 9; I901, 26.

$58 \mathrm{JvVCV}$, i9o6, 42 .

59 Sectie "geneeskundige en zielkundige behandeling" in "Beredeneerd Verslag over het jaar I9०0, omtrent het Geneeskundig Gesticht voor Krankzinnigen te Franeker, uitgebracht door Bestruurders dezer Instelling, ter voldoening van Art. II hunner instructie”, I907, I910, I918, including “Blauwboek", JvF, GAF, APZF, no. 5133. Franeker reported the application of bed rest for the first time in 1907 (I2 men and 22 women). In I9IO the annual report noted 25 men and 40 women on bed rest, out of a total of 3 I 8 patients ( 20 percent). In I9I 8 these numbers were 30 men and 45 women, out of a total of 299 patients (25 percent).

6oSee JvVB, I907, vraag 3, I7, 52, and I9I0, vraag I7, 52; SH, AG, Janora, doos I2, map blauwboeken I907-I9I7. From I907 through I9I0 about Io to 20 (I to 2 percent) of the almost I,००० patients were reported to have been treated with bed rest. In I907 two bedzalen (bed wards) were built in the male department. The JvVB (I9IO) reported that eight women were treated with bed rest on the observation ward.

6I JvVB, I9I5, vraag 29; I9I8, II. In I9I0 the reported number of patients on the "observatie kwartier, waakzaal, ziekenzaal en bedverpleging" (wards for observation, bed rest, and sick patients) was 99 (about Io percent) (see JvVB, I9IO, vraag I7), and in I920 this number had increased to I3 8 (about I5 percent) (see JvVB, I920, 4).

$62 \mathrm{JvVCV}, \mathrm{i904}, 35$; I905, 45.

63 Vijselaar, Krankzinnigen gesticht, I44-45.

64 Van Deventer, "Enige beschouwingen", 246-50; Van der Kolk, “Over bedbehandeling”, 486.

65 Koffijberg, "Lessen in de Beginselen”, 3I; Vijselaar, Krankzinnigen gesticht, II5.

66 Kramer, Geschiedenis, I05; Vijselaar, Krankzinnigen gesticht, II5.

67 Verslag van het Staatstoezicht, I903-8, 337.

68 Janssens, "De behandeling en verpleging."

69Ibid., 52I-34 (citation, 525).

70 JvMB, I9I3, III.

7I Benders, “De behandeling van krankzinnigen" (citation, 234).

72 JvMB, I9I3, III.

73 Janssens, "De behandeling en verpleging” (citations, 525, 532).

74 JvMB, I9I3, III.

75 Benders, “De behandeling van krankzinnigen”, 236-37.

76 Verslag betreffende het gesticht Duin en Bosch over het jaar 1910, 94 (Annual Report Duin en Bosch), RANH, ATC, archief no. I8I, inv. no. 587. The Duin en Bosch asylum, founded in 1909 , was one of the provincial asylums of the province of North Holland, similar to the Meerenberg asylum.

77 Stukken betreffende enige suicide gevallen, rechtzaak tegen verpleegsters I9I9, RANH, ATC, archief no. I8I, inv. no. 456.

78 JvMB, I903, II8-I9.

79 JvMB, I887-I918, sectie “werkverschaffing."

80 Meerenberg appointed its own minister and chaplain, and when, after 1880 , the number of Jewish patients increased, Meerenberg appointed a Jewish teacher. Veldwijk, too, had its appointed minister for "spiritual care", as opposed to medical "physical and mental" care. 
8I Rosenberg, The Care of Strangers, 8.

82 Ibid., 9, 212-36.

83 Neisser, Ueber die Bettbehandlung, I2-13.

84 Querido, Het Wilhelmina Gasthuis, 213-I8, 283; Van der Esch, “Jacob van Deventer”, 313. 85 Binneveld, Filantropie,I22-25; Van Deventer, "Bijdrage tot de leer", I73.

86The Buitengast Hospital had obtained this function after the closure of the old innercity asylum (Pesthuis) in the seventeenth century. After the opening of Meerenberg, the asylum never really closed down. Ideally, insane patients would be placed in the Buitengast Hospital only temporarily, awaiting placement in Meerenberg, but in reality, because of the overcrowding of asylums, the Buitengast Hospital continued to serve as an asylum for the city of Amsterdam. When psychiatry became a medical specialty within the university in 1896 , Buitengast adopted the function of university psychiatric clinic. There was one other asylum in Amsterdam, the Jewish asylum (Joods Krankzinnigengesticht), which was part of the hospital for the Jewish patients of Amsterdam. As of 1883 , when the Jewish asylum became too small, Jewish patients were also admitted to Meerenberg. In I 909 a new asylum for Jewish patients was built in Gelderland (Apeldoornse Bos), partly funded by the province of North Holland. See Oosterhof, Apeldoornse Bosch.

87 Querido, Het Wilhelmina Gasthuis, 213-I8.

88 Ibid., 245-6I, 283-86.

89 Van Deventer, "Eenige opmerkingen”, 28.

90 Ibid.; Van Deventer, "Enige beschouwingen."

9I Van Deventer, “De eischen."

92 Roger Qvarsell observed for Swedish psychiatry that an important new principle in turn-of-the-century psychiatric treatment was the continuous supervision of patients. "The nurses never left the patients' rooms and everything that happened was reported to the doctor and written down in special diaries." Qvarsell, "Locked Up or Put to Bed", 94 .

93 Cowan, "Over de verplegingsquaestie", 292.

94 For the aspirations of physician Cowan, see Verslag van het Staatstoezicht, I888-90, I79; for the introduction of S. Weir Mitchell's therapy in the Netherlands, see Brosius, "S. Weir Mitchell's Systeem Neurosen.” For the use of physical (massage and electricity) therapy in asylums, see Vijselaar, Krankzinnigen gesticht, I००-3. For a critical discussion of S. Weir Mitchell's treatment and for the perspective of a woman who actually experienced and criticized the treatment as denigrating for women, see Knight, "The Yellow Wall-Paper."

95 Stephan, De behandeling van sommige vormen van zenuwlijden met mestkuren.

\section{Notes to Chapter III:}

\section{Female Compassion: Mental Nurse Training Gendered Female}

I Jones, The Charitable Imperative, 9I-93; Nelson, "Entering the Professional Domain."

2 For a discussion, see Van Drenth and De Haan, The Rise of Caring Power, 29-36. They focus primarily on Protestant religious revival. For Roman Catholic developments, see Jones, The Charitable Imperative and Eijt, Religieuze vrouwen.

3 Eijt, Religieuze vrouwen, 50-94.

4 Eijt, "Zindelijkheid en Zuinigheid”; De Bie and Fritschy, "De 'wereld' van Reveilvrouwen." 
5 Van Drenth and De Haan, The Rise of Caring Power.

6 Ibid., 47-50.

7 Ibid., 45 .

8 Ibid., 47.

9 Ibid., 46-47. Van Drenth and De Haan's argument that in the latter movement both arguments of "equality" and "difference" of women were used, underscores Ulla Jansz's analysis of the first wave of feminism in the Dutch context. Jansz concludes that "the analysis of feminist publications (I860-I9I2) in terms of equality and arguments about differences shows that difference arguments were used more prominently by some groups and at certain times, and equality arguments by others and in other periods. Central to the feminism of the whole period, however, was a struggle against the socially constructed hierarchical relationship between men and women, against prejudices about women as women. First wave feminism should therefore be seen as a form of egalitarianism: an endeavor to achieve equal treatment despite recognized differences. See Jansz, Denken over sekse, 277-78.

Io Scott (Ed.), Gender and the Politics of History, I988, I8-24, 31-33.

II Vicinus, Independent Women, 2-5; Spijker, Mooi en beschaafd verplegen, 74-76; Eijt, "Zindelijkheid en Zuinigheid", 8I-82. For the percentage of unmarried women, see Eijt, “Zindelijkheid en Zuinigheid”, 82.

I2 Eijt, Religieuze vrouwen, 64-72; see also De Bie and Fritschy, "De 'wereld' van Reveilvrouwen."

I3 Eijt, "Zuinigheid en Zindelijkheid”, 83; Wiegman, "The Origins of Modern Nursing”, 88; Spijker, "Mooi en beschaafd verplegen", 76-77; Jones, The Charitable Imperative, I989.

I4 Van Drenth and De Haan, The Rise of Caring Power, 47-50. Reveil is French for awakening.

I5 Poplin, "Kaiserswerth Nurse Training School”, 40.

I6 Wiegman, “The Origins of Modern Nursing”, 89; Van Lieburg, Bronovo 1865-1990.

I7 Bakker-van der Kooij, "De maatschappelijke positie”; Van Gemert and Spijker, Verdichtsel en werkelijkheid; Wiegman, "The Origins of Modern Nursing”, 83-98.

I8 Over instellingen.

I9 Jones, The Charitable Imperative, 92-103.

20 Over instellingen, especially 46-53.

2I "Inrigting voor pleegzusters gevestigd te Amsterdam. Verslag van het bestuur der Vereniging voor Ziekenverpleging te Amsterdam”, July I853, I2, GA Archief Vereniging voor Ziekenverpleging, archief no. 920, inv. no. I30.

22 Wiegman, "The Origins of Modern Nursing”, 90.

23 Van der Kooij, "I890-I990”, 27-30; idem, Mans, I3-I7, 25.

24 For a discussion of this phenomenon in the United States, see Ginzberg, Women and the Work of Benevolence.

25 Van Drenth and De Haan, The Rise of Caring Power, 46.

26 Stuurman, Verzuiling, Kapitalisme en Patriarchaat, II4-I7.

27 Jansz, Denken over sekse; Waaldijk, Het Amerika der vrouw.

28 Jansz, Denken over sekse, 4I-44.

29 Van Essen, Opvoeden met een dubbel doel, 8-9.

30 Eijt, Religieuze vrouwen, 164-96; Jansz, Denken over sekse, 85-86; Rafferty, "The Politics of Nursing Education I860-I948”, 94-I02; Waaldijk, Het Amerika der vrouw, II5. 
3I During the second half of the nineteenth century different types of occupational training and education for girls emerged, varying from girls' middle schools to occupational schools both for working- and middle-class girls. The latter included industrial schools, schools for home economics, and vocational schools such as the normal school for teachers and, in the late nineteenth century, schools for social work. See Van Essen, Onderwijzeressen in niemandsland, 32. The first normal schools for female teachers were founded in 1836 and I850. Jansz, Denken over sekse, 42-44. Women entered high school and eventually university during the I870s. The first woman to enter university was Aletta Jacobs in I872. She studied medicine in Groningen. Jansz, Denken over sekse, 44; Waaldijk, Het Amerika der vrouw, I9.

32 Waaldijk, Het Amerika der vrouw, I05.

33 Ibid., 105-6.

34 Ibid., I06-7. The claim of women's duty to an ethical impact on social progress based on evolutionary thought was not unique for Mercier, but as Waaldijk argues, she articulated this view within the Dutch context and thus "inspired a generation of Dutch women" in legitimizing social work as a field of women's work and womanly characteristics. Waaldijk, Het Amerika der vrouw, 332. For such evolutionary thought in nursing, see Nutting and Dock, History of Nursing, especially r: 3-8.

35 Hamilton, "Constructing the Mind of Nursing." Hamilton analyzes the emergence of a modern, secular notion of compassion out of a religious tradition as a source of legitimization among early United States nurse leaders.

36 Van Deventer, "De eischen", reference to Mercier, 8.

37 Bakker-van der Kooij, "Mara”, 2II; De Regt, Arbeidersgezinnen en beschavingsarbeid, I43-98; Waaldijk, Het Amerika der vrouw, ro9.

38 Den Broeder and Schaap, "Het maatschappelijk moederschap"; Jansz, Denken over sekse, III-20; Waaldijk, Het Amerika der vrouw, 99-II6. For the battle against prostitution, see Mooij, Geslachtsziekten en besmettingsangst, 48-55.

39 Pleij, "Uit beschaafde nood geboren."

40 Jansz, Denken over sekse, 32-37.

4I Jansz, Denken over sekse, 42.

42 Borkus et al., Vrouwenstemmen, 25-35.

43 Jansz, Denken over sekse, 202-3.

44 Borkus et al., Vrouwenstemmen, 38; Jansz, Denken over sekse, 82.

45 Jansz, Denken over sekse, 82.

46 Borkus et al., Vrouwenstemmen, 39-40; Jansz, Denken over sekse, 82-85.

47 Jansz, Denken over sekse, 84-5.

48 Opportunities for independent medical practice for women protected by training, examination, and regulation existed only for midwives. Van Lieburg and Marland,

"Midwife Regulation"; Marland, Art of Midwifery, i92-213.

49 Wiegman, “'Gij completeert zijn arbeid””; Bakker-van der Kooij, “Mara”, I99-203, 220; Van der Kooij, Mans, 27-66.

50 Bakker-van der Kooij, "Mara”, I96.

5 I Ibid., I97.

52 Van der Kooij, Mans, I3.

53 Both the Amsterdam Association of Sick Nursing and the Haarlem Association of Sick Nursing, for example, regularly covered cases of nervous patients as well as mental patients. For examples see “Zusterboek" I849-64, inv. no. 33, various entries, Archief 
Vereniging voor Ziekenverpleging, archief no. 920, GA; Notulen van het bestuur van de Haarlemse Vereniging voor Ziekenverpleging (HVZ) I877-86, inv. no. 2, GAH, AHVZ, inv. map 52.

54 The board of the HVZ established a nursing bureau in I9I4, managed by a nurse-director. "De geschiedenis van de HVZ I87I-I976", 8I. GAH, AHVZ, inv. map 52. Nursing bureaus were established as of about I895. For a discussion, see Van der Kooij, Mans, 2O-2I.

55 Van der Kooij, Mans, II.

56 Querido, Het Wilhelmina Gasthuis, 72, 248-49; De Boer and Pley, Grachtenzusters.

57 Querido, Het Wilhelmina Gasthuis, I54-57.

58 Bakker-van der Kooij, "Mara”, I97; Van der Kooij, "I890-I990”, 24-3I; Querido, Het Wilhelmina Gasthuis, 245-6I; Wiegman, "The Origins of Modern Nursing”, 9I-92.

59 Rafferty, “The Politics of Nursing Education I860-I948”, 58. The incorporation of elements of girls' education in nurse training did not evolve into a school-based education for nurses, unlike women's education in other fields such as teaching, social work, or midwifery. Nursing remained an apprenticeship system of training in which the role of the student nurse was predominantly one of a paid worker.

6o Rafferty, "The Politics of Nursing Education I860-I948”, 75-100.

6I Houwaart, De hygiënisten; Van der Kooij, "I890-I990”, 24-26; Wiegman, “The Origins of Modern Nursing", 9I-92.

62 Wiegman, “The Origins of Modern Nursing”, 91-92; Van der Kooij, “I890-1990”, 24-26.

63 Querido, Het Wilhelmina Gasthuis, 67-85, 2II-42.

64 Similarly, in Germany the traditional "motherhouse" system grew outdated and was not able to meet the demand for nurses so that new ways were explored to increase the supply of nurses independent of the traditional system. For a discussion, see Boschma, "Agnes Karll."

65 Wiegman, “The Origins of Modern Nursing." For a contemporary history of the life of Jeltje de Bosch Kemper, see Naber, Het Leven en werken.

66 Jansz, Denken over sekse, especially 82, I50; Pleij, "Uit beschaafde nood geboren”; Naber, Het Leven en werken, I4-44; Wiegman, "Zusters in smetteloos wit”, especially I5-I6.

67 Naber, Het Leven en werken, I2I-50.

68 Ibid., I26, I33.

69Bakker-van der Kooij, "De maatschappelijke positie”, 459-6o; Wiegman, “The Origins of Modern Nursing”, 9 I.

70 Between I 890 and I900, Cora van der Kooij argues, nursing and philanthropy or poor relief became separate fields of work. Nursing became available for and oriented to all social classes. For a discussion, see Van der Kooij, Mans, I3.

7I $M v Z_{3}$, no. 6 (February I893): 123-24.

72 Van Gemert and Spijker, Verdichtsel en werkelijkheid, 40-4I.

73 Between 1879 and 1883 a total of 25 nurses graduated. See Bakker-van der Kooij, "Mara", I2.

74 Van Gemert and Spijker, Verdichtsel en werkelijkheid, 34-4I; Van der Kooij, "I890-1990", 2I-26; Wiegman, “Zusters in smetteloos wit”, 68-79; Querido, Het Wilhelmina Gasthuis, 245-68.

75 Rafferty, The Politics of Nursing Knowledge, 9-4I.

76 Deputy directors were indeed assistants to the medical director and had little inde- 
pendent authority over the nursing personnel. See Frederike Meyboom in RijpstraVerbeek, Dienend in het wit, 107.

77 Querido, Het Wilhelmina Gasthuis, 249, 286.

78 Bakker-van der Kooij, “Mara”, , 2.

$79 \mathrm{MvZ}$ 3, no. 2-3 (Oct.-Nov. I892):33-83.

80 Ibid.; Bakker-van der Kooij, "Mara”, 200.

8I Querido, Het Wilhelmina Gasthuis, 250-5I.

$82 M v Z_{3}$, no.7 (March I893): 138-39.

$83 \mathrm{MvZ}$ 4, no. Io (June I894): I4I-44.

84 Stelling, "Erfahrungen beim patronat", citation, Ir. Emphasis added.

85 Reynvaan, "Hoe de Nederlandse vrouw"; Van Deventer, "Reactie."

86 Kuyk, "Correspondentie."

87 Bakker-van der Kooij, "Mara”, i98.

88 Van der Kooij, "I890-I990”, 26; idem, Mans, 88-9I.

89 Bakker-van der Kooij, “Mara”, 2II.

90 Ibid., 2I2-I3.

9I McPherson, Bedside Matters, 26-72.

92 PB 9 (I891): 233-34.

93 Van Deventer, "Eenige opmerkingen."

94 Garmanikow, "Nurse or Woman”, especially ııо-ıі.

95 Verslag van het Staatstoezicht, I885-87, I24-25; Van Deventer, Ruysch, and Tellegen, "De verbetering", especially 222-29.

96 Binneveld and Wolf, Een huis met vele woningen, especially 53-62.

97 The debate within the NVP reflected the physicians' effort to establish their authority within asylums more firmly. Tellegen, "Het verleden, het heden." Peter Nolan observed about British psychiatry that psychiatrists did not begin to teach courses to nurses until they themselves began to receive university training in psychiatry. See Nolan, "Psychiatric Nursing Past and Present", I2 I-25, especially I22.

98 "Discussie over de stellingen", 28, I65-7I.

99 Van Deventer, "Eenige opmerkingen", 3I.

IO० Ibid., 20-3I; Van Deventer, “De eischen." Van Deventer noted that male nurses had to be assigned to the Buitengast Hospital wards for the most disturbed male patients, and also to the syphilitic ward.

IOI "Discussie over de stellingen”, I69; "Het gesticht te Zutphen”, I27-30.

IO2 "Discussie over de stellingen", I65-66.

I03 Van Deventer, Ruysch, and Tellegen, "De verbetering”, 222-25.

IO4 Ibid., 223 (translation GB).

I05 Ibid.

Io6 Ibid., citation of professor Gunning, 223, n. I (translation GB).

I07 Ibid., 223, n.I.

I08 Ibid., 230-34.

IO9 Ibid., 235 .

IIO "Het gesticht te Zutphen”; "Schrijven van den eersten geneesheer voor krankzinnigen te Zutphen, dr. S. A. van der Chijs [...] inzake de eischen eener goede krankzinnigenverpleging, met reactie van J. van Deventer", $M v Z$ I, no. II (July I89I): 3-4.[Note from first physician for the mentally ill at Zutphen, S. A. van der Chijs [...] regarding the requirements for good mental care, with a response from J. van Deventer] 
III "Het gesticht te Rotterdam: Uit het verslag betreffende het geneeskundig gesticht voor krankzinnigen te Rotterdam over I89o van de geneesheer-directeur F. H. Schreve" [From the annual report of the Rotterdam Asylum of 1890 by medical director F. H. Schreve], PB 9 (I89I): I3I-34; Verslag van het Staatstoezicht, I888-90, I79.

II2 Van Deventer, Ruysch, and Tellegen, "De verbetering"; Verslag van het Staatstoezicht, I89I-93, 8-I2.

II3 $P$ В 9 (I891): 233-34; 10 (1892): 76-87, 218.

II4 Verslag van het Staatstoezicht, I89I-93, 8-I2.

II5 Tellegen, Ruysch, and Van Deventer, "Rapport der Examen-Commissie", especially 66.

II6 Ibid., 68-69.

II7 PB II (I907):363-65; Verslag van het Staatstoezicht, I894-96, I4-20.

II8 Van Deventer, "Enige beschouwingen”, especially 232, 240, 246; Van der Hoogt, "Ons Zusterhuis 'De Boschhoek'”.

II9 JvWV, I898; I903, I5.

I20 JvWV, I898.

I2I JvMB, I893, I36-37.

I22 JvMB, I9I2, I.

I23 JvWV, I898, 24-25.

I24 JvWV, I900, 22-3I, bylaws of the Wilhelmina Vereniging.

I25 JvWV, I902, 3I-32; JvWV, I904, bijlage; JvWV, I906, 27-35.

I26 JvWV, ı904, bijlage.

I27 JvWV, I899, 6-7; I903, I7.

I28 Geneeskundige gids, 7-29. For a discussion of the use of resorts in the treatment of nervous afflictions, see Drinka, The Birth of Neurosis, I7-28, 210-38.

I29 JvWV, I9०0-I9I4, reports on “De Leemkolk." Schorer's comments JvWV, I900, I5; I902, I9.

I30 Cora van der Kooij argues that it was exceptional for nursing, as compared to other lower middle- and working-class jobs, to have an annual vacation, usually of two weeks. She suggests that the upper middle-class background of the first generation of trained nurses and the aspiration to attract this group to nursing prompted the granting of an annual vacation for nurses. See Van der Kooij, Mans, 67.

I3 I JvWV, I899, II.

I32 JvWV, I90I, I2.

I33 JvWV, I90I, 20. Various annual reports of the WV make reference to the nursing bureau.

I34 JvWV, I903, 34-35.

I35 JvWV, I910, 6-10.

I36 JvWV, I9I4, 9. Eighty guilders was quite a sum. In I9I3 the annual salary of a student nurse at Meerenberg was 234 guilders a year, whereas a general workman earned thirteen guilders a week at Meerenberg, which overall was one of the better paying institutions. See Een eeuw krankzinnigenverpleging 1849-1949, 266-67.

I37 JvWV, I913, 6.

I38 JvWV, I9I4, I7-18.

I39 JvWV, I9I7, published in De Wilhelmina Gids: Orgaan van de Wilhelmina Vereniging 3 , no. 5-IO (I9I8): 49-60, especially 53. Report of the General Meeting of the Wilhelmina Vereniging, June 3, I9I6, including the JvWV, I9I5, published in Maandblad voor 
het Krankzinnigenwezen I (І9І6): 98-І16, especially 99.

I40 De Wilhelmina Gids 3, no. 5-10 (I918): III.

I4I JvWV, i9i6.

\section{Notes to Chapter IV: The Burdensome Task of Nurses}

I This is a fragment of a longer poem written by Maria E. Beets (translation GB), cited in Koffijberg, "Lessen in de Beginselen", 9-Io. Maria E. Beets, a nurse and the director of the Protestant hospital in Nijmegen, also published the booklet "Harptonen", $M v Z$ 3, no. 2 and 3 (I892): 30.

2 See Koffijberg, "Lessen in de Beginselen", 2-5, 27. For a discussion of the early nurse training's emphasis on character and morality (rooted in domestic ideology) rather than training of intellectual skills, see Rafferty, "The Politics of Nursing Education I860-I948", 59-102.

3 Kappers, "In memoriam Henriëtte Koffijberg”, 76.

4 Ibid., 75-79.

5 JvVCV, I9I3, 54 .

6 Schermers, Handleiding, 202-8. The book was used at the VCV asylums, including Veldwijk, but also at Franeker and Voorburg. For its use in Franeker, see Verslag van het Staatstoezicht, I900-1902, II8. For its use in Voorburg, see JvVB, I9Io, vraag I9, SH, AG, Janora, doos I2, map blauwboeken I907-I7. In Voorburg the physicians used other nursing textbooks as well for their teaching of nurses. In I907 the medical library acquired J. C. Th. Scheffer, Voorlezingen over zenuwzieken en krankzinnigen en hunneverpleging and J. E. Stumpff, Voorlezingen over ziekenverpleging (JvVB, I907, vraag 47), and in I9Io the teaching material also included the nursing textbooks of A. N. Nolst Trenite, Handboek der ziekenverpleging and P. H. M. Travaglino, Leidraad bij de voorbereiding tot het examen in de krankzinnigenverpleging (JvVB, I9IO, vraag I9).

7 Van Deventer, Handboek, 72.

8 Rafferty, The Politics of Nursing Knowledge, 30.

9 Ibid.

Io Koffijberg, "Lessen in de Beginselen”, 2-5, 8-9, 2I-27.

II Ibid., IO-20, 23-24.

I2 Ibid., 27.

I3 Ibid.

I4 Dwyer, Homes for the Mad, I84.

I5 Ibid.

I6 Rafferty, The Politics of Nursing Knowledge, 38-4I.

I7 Koffijberg, "Lessen in de Beginselen."

I8 Ibid., 30-32.

I9 Ibid., 8-I5, 20.

20 Ibid., 3 I.

2I Interview with nurse Solinger, who undertook her nurse training in the late I930s at the St. Joris asylum in Delft. See Bakker, De Goei, and Vijselaar, Thuis opgenomen, 73-75.

22 Male nurse A. Zondag wrote an autobiography. He began as a student nurse at the Zutphen asylum in I925 and continued his training in the Franeker asylum in I927, where he stayed for the remainder of his career until I970. Zondag, Naar Franeker gaan, I6, 2I-23, 37 (citations, 23).

23 Suzuki, "The Politics and Ideology of Non-Restraint", I2-I4. 
24 Examples are Veldwijk, "Instructie voor de hoofden van paviljoenen, 28-5-I896", HDNP, VCV, no. 50I, doos 55, and for Meerenberg, "Huishoudelijk reglement voor het Provinciaal Krankzinnigengesticht Meerenberg I845-I894, gedeeltelijk concepten, gedeeltelijk gedrukt; met bijlagen I90I-I903", RANH, ATC, archief no. I8I, inv. no. 294.

$25 \mathrm{JvMB}, \mathrm{I} 893,45$.

26 Bedienden Register, no. 2 (I4 december I884-I4 mei I889), no. 290 Maas van Drie en no. 378 Anna Kroon, RANH, ATC, archief no. I8I, inv. no. 3I7.

27 See Bedienden Register no. 4 (Io februari I893-I mei I895), no. 45 leerling-verpleegster (female student nurse) Caroline Jansz dismissed because of unsuitability for the work; no. 47 leerling-verpleger (male student nurse) Petrus van Dam dismissed because of a late return from leave; no. 5 I leerling verpleger (male student nurse) Pieter de Haan dismissed because of insobriety; RANH, ATC, archief no. I8I, inv. no. 32I. Personeelsregister no. 7 (26 november 19005 mei I903), no. 9 Hermanus Maassen, leerling-verpleger (male student nurse) dismissed because of the refusal of duties, RANH, ATC, archief no. I8I, inv. no. 324 .

28 Van Deventer, Handboek, 2, 42.

$29 \mathrm{JvMB}, 1893, \mathrm{I} 46$.

30 JvMB, I894, 4; I899, 95, 99.

3I JvMB, I897, I64.

32 Verslag van het Staatstoezicht, I903-8, 330.Restless patients regularly tore apart their clothes, which made it more expensive for families to provide clothes.

33 JvMB, I903, 78.

34 In the annual report of I903 medical director Van Deventer of Meerenberg explicitly discussed the use of transfer to the "disturbed ward" as a disciplinary measure for "antisocial" or overly disruptive behavior of patients who could not be contained on the sick ward (with bed rest). JvMB, I903, 8I. In his textbook for nurses, however, he instructed nurses to never use force or threaten patients and to explain all their trying behavior as a consequence of their illness. See Van Deventer, Handboek, 90-9I. For a discussion of the use of threats as a disciplinary measure, see also D'Antonio, "Negotiated Care", 232-38.

35 See "Rapport betreffende de verpleging van patienten in het geneeskundig gesticht te Voorburg” (30-IO-I9I7), 2, supplement to letter B. no. 993, 28-I0-I9I7, from W. M. van der Scheer to Gedeputeerde Staten van Noord-Holland, in Map "Wantoestanden in de verpleging van Reinier van Arkel en Voorburg I9I7-I9I8", SH, AG, I900-1950, doos 20.

36 Goffman, Asylums, 36 I-62.

37 Scull, The Most Solitary of Afflictions, 169-74.

38 Dwyer, Homes for the Mad, I84.

39 Ibid. Dwyer felt that the late nineteenth-century medicalization of lunatic asylums and the attempt to raise their reputation by repositioning them as "state mental hospitals" neither improved the attendants' status nor clarified the ambiguities of their position. Nurses remained "frozen in their conflictual roles," Dwyer argued, of "children in the need of medical supervision", "surrogate parents of patients", and "domestic servants of all” (185). Dwyer noted that asylum doctors, like their counterparts in general hospitals, "never seriously considered redistributing internal asylum authority to accommodate their shifting mission" (I84). Although my study shows that the establishment of nurse training was an essential ingredient of the transformation of the asylum into a 
mental hospital and that this process could not just be considered a matter of "reframing”, I agree with Dwyer that the nurses' role remained ambiguous, if not predominantly custodial.

40 See Folder "Wantoestanden in de verpleging van Reinier van Arkel en Voorburg I9I7I9I8”, SH, AG, I900-I950, doos 20.

4I Opleiding en examens van verplegenden, I88. For Voorburg, see Blauwboek I907, SH, AG, Janora, doos I2, map Jaarverslagen Voorburg I907-I7.

42 Blauwboeken I9Io-I7, SH, AG, Janora, doos I2, map Jaarverslagen Voorburg I907-I7.

43 JvMB, I900, 35-4I; I9I0, I-I9.

44 See, for example, Rapport van de Geneesheer-directeur van Veldwijk over I894, I897, I902, sectie "mutaties", HDNP, VCV, no. 501, doos I3; JvMB, I900, 44-45.

45 During the I89os several patients disclosed their experiences with asylum treatment and abuse in publications that stirred a public debate among politicians and physicians alike. See Melster, Mishandelingen; Te Gempt, Mijne Ervaringen; Van Eijk-Osterholt and Bökenkamp, Wartaal van een Gek; Verslag van het Staatstoezicht, I89I-93, I24-33.

46 Notulen van de Commissie van Toezicht, 24 october I898, 3I october I898, 4 november I898, ro november I898, 30 december I898, I4 juli I899 (ontslag Gatsonides), Iı januari I900, RANH, ATC, archief no. I8I, boek I4, Notulen van de Commissie van Toezicht I895-I90I.

47 The first large-scale studies in the Netherlands using patient records to analyze historical shifts and trends in psychiatric patient behavior and treatment are Peeters et al., "Historische veranderingen" and Hutschemaekers, Neurosen in Nederland. For a methodological discussion of the use of patient records, see Digby, "Quantitative and Qualitative Perspectives", I53-74; Kappelhof and Wolf, "Patientendossiers"; Klijn, Tussen Caritas en Psychiatrie, 63-64; and Risse and Warner, "Reconstructing Clinical Activities."

48 De Goei, Notitie betreffende een reglement, 2.

49 Patient records were drawn with permission from the four institutions that are case studies for this study-twenty from each of Meerenberg, Franeker, and Veldwijk and ten from Voorburg-at five-year intervals between I885 and I920. Records of Voorburg (PZ Reinier van Arkel, Postbus IOI50, 5260 GB Vught) and Veldwijk (PZ Veldwijk, Postbus I000, 3850 BA Ermelo) are kept within the institutions. The patient records of Meerenberg and Franeker are located in the Rijksarchief Noord-Holland (State Archive of North Holland) in Haarlem (Archief van het Provinciaal Ziekenhuis nabij Santpoort I849-I99I, archief no. 366) and the Gemeentearchief Franeker (Franeker Municipal Archives) in Franeker (Archief Psychiatrisch Ziekenhuis Franeker), respectively. The year I885 was only included in the selected records from Franeker and Voorburg. To protect patient confidentiality, I have numbered the records from I through 70 . The key between records I to 70 and the individual patient records remain with the Gemeentearchief Franeker, the Rijksarchief Noord-Holland, and the psychiatric hospitals Veldwijk and Reinier van Arkel. The records are divided as follows: I 885 three records, 1890 nine records, I895 ten records, I900 ten records, I905 twelve records, I9Io eleven records, I9I 5 nine records, and I920 six records.

50 For practical reasons, in the present study the selection of records had to remain small, and the selection is not statistically representative.

5I The physician were legally obliged to keep daily notes for the first fourteen days after admission, which usually contained an extensive report on the reason for admission 
and patient behaviors in the first two weeks. Weekly notes followed for the next twentyeight weeks (six months) and monthly notes thereafter until discharge, with an annual note on the renewal of the court-approved certification of madness. Monthly statements were usually just one line, or one- or two-word statements. Some records included the full certification of madness and court approval of admission, which had to be requested within three days of admission. The records included personal information, the date and the reason for admission, usually the diagnosis, the date and status of discharge (recovered, not recovered, or died), a standardized account of information provided by the referring physician with questions regarding family background, state of health, upbringing, causes of insanity, course of the illness prior to admission, and signs and symptoms observed by the referring physician. They also included correspondence with third parties regarding admission, discharge, transfer, or trial leave. Letters from family members or the patient were rarely included. Not all archives have kept the complete records; sometimes they contained only notes of the first weeks or first six months of admission.

52 To protect patient privacy, no names or places of residence are used in the description of cases. Because the selection of records is too small to be representative either of the patient population or of the treatment regimen of each asylum, the records are taken as a group, which in a sense enhances privacy.

53 In I897 the NVP (Dutch Association of Psychiatry) revised an earlier classification from I885. The state inspectors took over this version (Verslag van het Staatstoezicht, I897-99, 38I-82), which contained twelve diagnoses: Mania, Melancholia, Amentia, Insania periodica, Insania epileptica, Insania neurotica, Insania toxica, Insania paralytica, Vecordia (paranoia), Dementia, Imbecillitas, and Idiotia. Further specification followed in I909 (Verslag van het Staatstoezicht, I909-II, 307): Mania, Melancholia, Insania periodica, Paranoia, Insania neurotica, Amentia, Insania toxica, Insania epileptica, Dementia senilis, Dementia paralytica, Dementia organica, Dementia praecox, Dementia secundaria, Imbecillitas, Idiotia, and Casus ceteri. After I9II the state inspectors stopped reporting on particular diagnoses, and asylum physicians began to follow new medical handbooks of psychiatry. Jelgersma, Leerboek der psychiatrie was widely used as of iوıı.

54 See, for example, records 34, 22, 30, 31, 43.

55 Record 50.

56 This observation differs from Andrew Scull's argument that the enormous growth of asylum admissions was the result of deliberate professionalizing strategies of doctors, which he calls "medical entrepreneurship." Scull, The Most Solitary of Afflictions, I7523I, 344-52. Increased admissions rose out of a broader process of medicalization, in which more social problems (including prostitution and the provision of birth control, but also to a certain extent criminal and deviant behavior) began to be perceived as medical problems rather than moral problems and thus fell within the domain of medical expertise. Of course, Scull is right that the medical profession played an active role in this reframing process. See De Swaan, "Het medisch regiem I, II, en III" in De mens is de mens een zorg, I5I-2I9, and Zorg en de staat; Hutschemaekers, Neurosen in Nederland, 240-42.

57 The referring physician (general practitioner) wrote the initial certification of madness, which had to be approved by the court before admission and had to be confirmed by the certification of madness of the asylum physician. The judicially approved requests for 
admission were made by pouse: I7; parents: І3; family: 24; officer of justice or mayor: 2 ; employer or hostess: 3; other asylums: I; physician: I; unknown: 9.

58 Record 54 .

59 First- or second-class patient records were more elaborate than those of indigent patients, and often included a life history of the patient, sometimes written by the patients themselves. Historian Joost Vijselaar, Dutch Institute of Mental Health, made a similar observation in describing I,००० patients' records of the Willem Arntsz asylum in Utrecht (I84I-I9I9). Personal communication, December I994.

6oSee Klijn, Tussen Caritas en Psychiatrie, I07. According to Klijn, in the late ninteenth and early twentieth centuries, confinement of the mentally ill was predominantly viewed from the perspective of social utility rather than concern for the patient as an individual.

6I Van Deventer, Handboek, 72-89; Schermers, Handleiding, I62-9I.

62 Record 27.

63 Vijselaar, Krankzinnigen gesticht, I44.

64 The term "automat" was used by medical director L. S. Meijer in I903. See De Goei, "I900-I924", 22, especially n. 55 .

65 De Goei, “I900-I924", especially 33-39; Van der Grinten, De vorming van de ambulante geestelijke gezondeihdszorg, 42-56. The context for such rethinking forms the emergence of psychoanalysis (I9I2) and the mental hygiene movement (which took root in Holland in the I9I0s). Brinkgreve, "De zorg voor zenuwlijders", I8I-205. For the United States, see Grob, Mental Illness and American Society 1875-1940, II4-I5.

66Records 3, 5, I4, I5, 38, 4I, 45, 52, 67, 69. A total of nine cases were diagnosed with dementia (senilis) and one case with presbyophrenia, which in the record was also described as "dementia senilis with characteristics of presbyophrenia."

67 JvVB, I9I0, vraag I7, SH, AG, Janora, doos I2. JvVB, I9I5, vraag I5, ibid., demonstrates that "half-disturbed" patients were predominantly elderly patients.

68Vijselaar, Krankzinnigen gesticht, 66. All records of demented patients reported confusion and forgetfulness, and most patients demonstrated behaviors such as tearing off of clothes, fits or cursing, which were considered indecent.

69 Records 5, 4I.

70 Record 45.

7I Records 3, 38, 45, 52. The first two patients were admitted in I 885 and I905, respectively, and the second two in I9ıo.

72 Record 69.

73 Ibid.

74 I have not come across evidence whether physicians, nurses, or family at the time saw the provision of sedative medication to the elderly as a dilemma or whether they made the link between the use of medication and the acceleration of the dying process.

75 Van Deventer, Handboek, I05-8; Schermers, Handleiding, I05. Significantly, these two textbooks were the only ones I found that addressed care of dying patients.

76 Schermers, Handleiding, I05.

77 Van Deventer, Handboek, ro8.

78 Vijselaar, Krankzinnigen gesticht, I45.

79 Records 26, 32.

8o Van Deventer, Handboek, 8I.

8I Idiotia: records 27, 54; Imbecillitas: records 7, 62; Epilepsia: records 26, 32, 68.

82 Record 7. 
83 Record 68.

84 Record 62.

85 Dwyer, “Stories of Epilepsy I880-I930”, 248-72.

86 Schermers, Handleiding, 258-6o; Van Deventer, Handboek, 82-83.

87 Schermers, Handleiding, 259.

88 Record 32.

89 Mania acuta: records I, 2, 8, I3, 23, 44, 57; insania periodica or manisch-depressieve psychose (manic depressive psychosis): records 39, 53, 56, 60, 61, 63. One case had initially been diagnosed as insania hysterica, but as the pattern became clear during the third admission, the patient was diagnosed as insania cyclica (record I7). One case of amentia is also discussed in this section (record 33).

90 Record I (I885) and record 8 (I890). Although these women were afflicted with what we would now call puerperal psychosis, they were diagnosed with acute mania.

9I Records I7, 23, 53 .

92 Record I3.

93 For a discussion of the use of restraints and the difficulty of evaluating statistics on restraint use, see D'Antonio, "Negotiated Care", 219-62.

94 JvMB, I894, I76. The state inspectors reported a decrease in use of mechanical restraints and cells (Verslag van het Staatstoezicht, I897-99, 280, 307; I900-02, I4748; I909-II, 350-54), although they noted that the registration of restraint use did not give a clear insight in real use of restraint because restraints were not clearly defined. Wrapping a patient in dry sheets, for instance, was usually registered as restraint, whereas wet packs were considered hydrotherapy and not registered. Verslag van het Staatstoezicht, I909-II, 354 .

$95 \mathrm{JvVCV}, 1909,23$.

96 Records I, 2, 8, I7, 23, 39, 57, 61.

97 Record 53.

98 Records I, 2, 39, 44, 53. Record 53 states that on admission in I9Io this patient received trional, later camphor and morphine injections, and subsequently camphor tablets, camphor powders, sulfonyl, choral, paraldehyde for over a month, and then in the next half year camphor, and paraldehyde every other day. From I9II until her death from heart failure in I9I6, this patient was treated in bed. For those years no use of medication was recorded.

99 Record 8.

I00 Record 33 .

IOI See Chapter II.

IO2 Dementia paralytica: records 4, I8, 59; Encephalitis luetica: record 50.

I03 See Thompson, "The Wages of Sin” and Blok, "Hersenverweking in Nederland.”

IO4 Blok, "Hersenverweking in Nederland", 9-I2; Vijselaar, Krankzinnigen gesticht, 6465.

I05 Record 4 .

I06 Record 18.

I07 This phenomenon underscores Gerald Grob's argument that sometimes it was professional and political concerns rather than patient needs that determined social and professional responses to mental illness. See Grob, Mental Illness and American Society 1875-1940.

Io8 Melancholia: records 6, IO, II, 20, 2I, 24, 37, 43, 46, 55, 58, 66. 
IO9 Record 6.

IIO Records 2I, 24, 46, 55 .

III Record II.

II2 Records 24, 37.

II3 Record 2I.

II4 Records I0, 43.

II5 Records 24, 37 .

II6 Records Io, 20, 66.

II7 Records I0, 37, 46.

II8 Records 43, 58 .

II9 Records 2I, 24, 46, 66.

I20 Record 58.

I2I Of the twelve melancholic patients, one was admitted for five years and died and another woman for one and a half years, but most stayed for about a year.

I22 Schermers, Handleiding, 243-45.

I23 Ibid., 245 .

I24 Stukken betreffende enige suicide gevallen en ongevallen I902-I937. Ongeval I902. RANH, ATC, archief no. I8I, inv. no. 456.

I25 "Verslag betreffende het Christelijk gesticht voor krankzinnigen 'Veldwijk' te Erme1o", I898, sectie "ongelukken", HDNP, VCV, no. 50I, doos I3.

I2 6 The details of this case were written in a report, read to the board the day after the accident, and written down in the minutes of the Asylum Council. Notulen Gestichtsraad, 20-3-I895, HAV.

I27 JvMB, I904-I6, sectie "ongelukken."

I28 JvMB, I905, I05; Blauwboek Voorburg I9ıо, vraag 85 en 86, SH, AG, Janora, doos I2.

I29 MacDonald, "The Medicalization of Suicide in England", 85-I03.

I30 Records 9, I2, I6, I9, 22, 28, 29, 30, 31, 34, 35, 40, 42, 47, 48, 49, 5I, 64, 65. Vecordia: records I6, I9, 29; Paranoia: 35, 48, 49; Hallucinationes: 28; Chronic mania: I2, 65; Dementia praecox: 64 ; generally described as suffering from delusions or hallucinations: 9, 22, 30, 31, 34, 40, 42, 51. One case diagnosed as hysterische psychose (hysteric psychosis) (record 47) is also included in this group. The fact that the patient was aggressive and hallucinating was the most important reason for admitting the patient.

I3I Record I6.

I32 Record 22.

I33 See, for example, Van Deventer, Handboek, 70 and Schermers, Handleiding, I25-46.

I34 Record 9.

I35 Record 48.

I36 Record 35.

I37 Record 5I: this patient was put in isolation at night because of immoral sexual behavior. Record 65: this patient was isolated because she was restless and frequently left her bed. Record 47: this patient had a long history of incarceration and asylum admission. Because of his aggression and hallucinations he was placed in isolation for the first two weeks of treatment. The medical director spoke with him daily and gave him paper and a pencil to write and draw (his notebook was included in record). After two weeks he remained on the ward during the day and was transferred to a state asylum after two months. 
I3 8 Record 3I.

139 Record 42.

I40 Record 22.

I4I Verslag van het Staatstoezicht, I900-I902, I43-44.

I42 JvMB, I893, 65.

I43 Rapport van de Geneesheer-directeur van Veldwijk over het jaar I893, sectie “mutaties”, HDNP, VCV, no. 501, doos I3.

I44 Notulen Centraal Bestuur, 2I-I2-I893, 9-5-94, book I, HDNP, VCV, no. 50I, doos I4.

I45 JvVCV, 1904, 36 .

I46 Record 35 .

I47 Record 49.

I48 Schermers, Handleiding, 236-38.

I49 See "Verslag betreffende het Christelijk gesticht 'Veldwijk', I893, HDNP, VCV, no. 50I, doos I3.

I50 See, for example, "Verslag betreffende het Christelijk gesticht 'Veldwijk”, I893, I896, I90I-5, sectie "ontvluchtingen en ongelukken”, HDNP, VCV, no. 50I, doos I3.

I5I “Verslag betreffende het Christelijk gesticht 'Veldwijk”, I894, sectie "ontvluchtingen en ongelukken", HDNP, VCV, no. 50I, doos I3.

I52 Ibid.

I53 Psychiatrist G. Jelgersma, later a professor of psychiatry and neurology at the University of Leiden, was a strong proponent of this idea. See, for example, Jelgersma, "Zenuw-inrichtingen."

I54 Meerenberg, for example, opened a ward for voluntary treatment, called "sanatorium", in I9I8. JvMB, I9I8, 72. For a discussion of the development of the "designated wards" for voluntary treatment, see De Ridder, "Het ontstaan van de aangewezen afdeling" and Legemaate, Rechtspositie, 31-60.

I55 See Hutschemaekers, Neurosen in Nederland, 66.

I56 Records 25 (admitted in I900) and 36 (admitted in I905).

I57 Record 36.

158 Record 25.

I59 Record 70.

\section{Notes to Chapter V: Negotiating Class and Culture}

I Rafferty, The Politics of Nursing Knowledge, 20.

2 Ibid.

3 Vicinus, Independent Women, 87.

4 JvMB, I892, 20-27, 35.

5 "Nota opgemaakt door verontruste geneesheren, juni I892", RANH, ATC, archief no. I8I, inv. no. 340 .

6 See JvMB, I877, 3-6; JvMB, I894, I8; JvMB, I897, I-7; for publications see Jelgersma, "Nieuwe proeven"; idem, "Het ontbreken"; Van Walsum, "Bijdrage”; idem, "Demonstratie."

7 NCvT, 25-II-I892, 9-I2-I892, RANH, ATC, archief no. I8I, inv. no. I3; JvMB, I-40.

8 I00, I50, and 200 guilders for the student nurse, nurse, and first-nurse, respectively. The salary of attendants at that time was 150 guilders. All of these salaries included board and lodging. JvMB, I892, 28; Een eeuw krankzinnigenverpleging 1849-1949, 266 67. 
$9 \mathrm{JvMB}, \mathrm{I} 892,3 \mathrm{I}$.

Io JvMB, I900, 37 .

II Notulen van de bestuursvergaderingen, 7-I2-I897, GAF, APZF, inv. no. 5090.

I2 Ibid., I-I2-I897, 2I-I2-I897.

I3 For an interesting photographic collection that he put together of several clinical cases, see fotoserie A. H. Oort, Historische Fotocollectie, Psychiatrisch Ziekenhuis Franeker, locatie Groot Lankum.

I4 JvF I920, GAF, APZF, inv. no. 5I33.

I5 The wage of the first trained male nurse was 300 guilders, and for the female nurse 250 guilders. In that same year a male servant earned I2O-I 60 guilders and a female servant IIO-I40 guilders. JvF, blauwboek, I898.

I6 JvF, I898.

I7 Missive boek, brief 473, I9-9-I898, GAF, APZF, inv. no. 5 II8.

I8 Notulen van de bestuursvergaderingen, I8-I-I898, GAF, APZF, inv. no. 5090.

I9 No. 29I, Bedienden register, 2 (I4-I2-I884 to I4-5-I889), Baukje van Zuylen, oppasseres, RANH, ATC, archief no. I8I, inv. no. 320.

$20 \mathrm{JvF}, \mathrm{I} 908$, sectie "personeel."

2I JvF, I898, sectie "personeel."

22 PNB 2 (I898): 243-48. For the appointment of Cornelia Wesselman, see "Loonlijst der bedienden", los vel ingelegd in Rekening Franeker over het dienstjaar I899, GAF, APZF.

23 “Loonlijst I9O2, I904", ingelegd in Rekening Franeker over het dienstjaar I902, I904. In JvF, I920, sectie "personeel”, Wesselman was still noted as head nurse.

$24 \mathrm{JvF}$, ı9००, blauwboek, Io.

25 JvF I9I0, GAF, APZF, inv. no. 5I33; Roode, "Verpleging in de afgelopen 25 jaar."

26 This argument is less relevant for the Roman Catholic asylum Voorburg, where mental nurse training did not change the traditional separation of nursing orders by gender.

27 JvMB, I892, 30-31; Verslag van het Staatstoezicht, I89I-93, I0.

28 Van Deventer, "De voorbereidende opleiding”, 153.

29 See Baer, “Nursing's Divided House”; O’Brien, “All a Woman's Life Can Bring.”

$30 \mathrm{MvZ}$ I3 no. 9 (I903): I52-55.

3I Abel-Smith, A History of the Nursing Profession, 34. Abel-Smith emphasizes that the new regimen in the hospital had consequences not only for nurses but also for patient behavior. For example, the new middle- and upper-class values did not allow smoking, drinking, or cursing.

$32 \mathrm{JvMB}, \mathrm{I} 892,28-29$.

33 JvMB, I892, 20-27; I893, 38-48; I898, I5-I7.

$34 \mathrm{JvMB}, 1904,23$.

35 The floor plan of I903 included separate bedrooms for nurses (verpleegsterskamers). Plattegrond van het Geneeskundig Gesticht voor Krankzinnigen te Franeker, I903, Losse stapel met bouwtekeningen en plattegronden, GAF, APZF. The floor plan of I935 included a conversation room and dinner hall (zusterszitje, zr. conv., zr. eetzaal) for nurses. Plattegrond (floorplan) I935, "Academiegasthuis, Psychiatrische Inrichting Franker”, Map plattegrond, doos 3, inv. no. 5133, GAF, APZF.

36 Van Deventer et al., "Rapport omtrent den actueelen toestand"; JvMB, I9०0, 44-45.

$37 \mathrm{JvMB}, \mathrm{I} 892,3 \mathrm{I}$.

38 JvF, I902, sectie “personeel." 
$39 \mathrm{JvMB}, \mathrm{I} 893,46$.

40 "Onderzoek van de gestichtsraad Veldwijk in opdracht van het bestuur naar aanleiding van klachten. Zaak van Mej. van der Heyden, 20 maart i895. Van Dale”, HDNP, VCV, no. 501 , doos 52 , SV, II3.

4I JvVCV, I887/88, I5; JvVCV, I908, 4I; Van Dale, “De toestand”, 56.

$42 \mathrm{JvMB}, \mathrm{I} 893,38-48$.

$43 \mathrm{JvMB}, \mathrm{I} 898,35$.

44 JvMB, I898, I5-I7; JvMB, I900, 40 (for numbers on female and male nursing personnel).

$45 \mathrm{JvMB}, \mathrm{1} 892$ 2, 20-33.

46 JvMB, I9IO, I, I4-I5.

47 Register houdende ingeplakte advertenties uit kranten wegens aanbesteding, levering [goerdern], oproepen voor personeel etc., I890-I922, RANH, ATC, archief no. 338, inv. no. I5. See in particular “Nieuws van de dag”, 26/27 January I9I2: an advertisement for two aspirant student nurses, aged I7-I9, at a salary of Ioo guilders and a few student nurses at a salary of I50 guilders. A few advertisements later, "Nieuws van de dag", I5 August I9I2: an advertisement for two female servants, aged ig or above, at a salary of at least I50 guilders. Whereas the student nurses would earn a salary similar to that of the servants, the aspirant pupils would earn roo guilders.

48 See Maggs, The Origins of General Nursing. In his analysis of the social origins of recruits in various British hospitals from I88I to I9I4, he concludes that the social position of newly trained nurses remained subservient and exploited.

49 Een eeuw krankzinnigenverpleging 1849-1949, II8-2I.

50 JvMB, 1893, 4I; 1900, 42.

5I Querido, Het Wilhelmina Gasthuis, 284.

52 Map “Reglement” I894-I902, no. I-II, RANH, ATC, archief no. I8I, inv. no. 336.

53 Van Persijn, "Ter Herinnering."

54 See De Regt, Arbeidersgezinnen en beschavingsarbeid, I7-49.

55 NCvT, IO-I2-I903, 2, RANH, ATC, archief no. I8I, inv. no. I5.

56 Notulen van de bestuursvergaderingen I8-I2-I900, I9-I2-I900, 2-I-I9OI, GAF, APZF, inv. no. 5091.

$57 \mathrm{JvF}$, I900 (sectie "bestuurders") reports an increase of the patient fee from 60 to 70 cents a day. GAF, APZF, inv. no. 5132 .

$58 \mathrm{JvF}, \mathrm{I} 85 \mathrm{I}, \mathrm{I} 853$.

$59 \mathrm{JvF}, 1902$, I909, sectie "personeel." Until I907 when male student nurses began to participate in taking the NVP exam, Jansen remained the only graduate trained male nurse at Franeker. He may have been needed in the male department as somatic treatments increased.

60JvF, I909, I9I0, sectie "personeel."

6I NCvT, II-7-I903, 6, RANH, ATC, archief no. I8I, inv. no. I5.

62 "Benoeming eener adjunct directrice", met vier bijlagen, (zie speciaal de memorie van toelichting), 29-9-I9II, RANH, ATC, archief no. I8I, inv. no. 38I.

63 Brief I6-6-I9I6 van Iste Geneesheer-directeur G. C. van Walsum aan Commissie van Bestuur PZ Santpoort, RANH, ATC, archief no. I8I, inv. no. 38I.

64 Lady Haitsma Mulier had a long-standing involvement with Meerenberg, predominantly in her position as chairperson of the benevolent women's society "Meerenberg." For her influence on the debate, see blad 3, NCvT, I2-4-I8I8, 8, Map "Afschriften, 
samenvatting notulen van bestuursvergaderingen aangaande de benoeming van een adjunkt-directrice”, RANH, ATC, archief no. I8I, inv. no. 38I.

65 Brief 4-I2-I9I8, no. 4/7 van Commissie van Bestuur aan Gedeputeerde Staten re benoeming adjunct-directrice, RANH, ATC, archief no. I8I, inv. no. 38I; Brief G. Büller aan Commissie van Toezicht, I8-I2-I9I9; Rapport door G. Bellar Spruyt betreffende de positie van de adjunct-directrice I9I9, RANH, ATC, archief no. I8I, inv. no. 342.

66The ambivalent relationship between doctors and nurses is well analyzed by Van Gemert and Spijker, Verdichtsel en werkelijkheid, 29-98. For the ambivalent response of British doctors to the new trained middle-class nurse, see Moore, A Zeal of Responsibility.

67 Lindeboom, “De betekenis", especially 49-52.

68 "Verslag betreffende het Christelijk Gesticht 'Veldwijk' te Ermelo”, I907, sectie "personeel”, HDNP, VCV, no. 50I, doos I3.

69Lindeboom and Van Lieburg, Gedenkboek, 130.

$70 \mathrm{JvVCV}, \mathrm{i} 886 / 87, \mathrm{i} 4$.

7I De Groot, Veldwijk in verleden tijd, 29, 79; Callenbach, Friedrich Von Bodelswingh, p.v.

72 Van Oosterwijk Bruyn, "Het huisgezin."

73 Ibid., 60.

74 JvVCV, I886/87, I5.

75 "Algemene voorschriften voor verplegers en verpleegsters in de Stichtting Veldwijk te Ermelo, i februari i907", HDNP, VCV, no. 25, doos 2, map 40.

76 JvVCV, I886/87, I4-I5.

77 See "Jubileum."

78 Notulen van het Centraal Bestuur, 3-3-I9I0, VCV, no. 50I, doos I4-I8, boek 3.

79 Moeder Gierveld aan't woord. "Veldwijk", 342-45.

80 JvVCV, I9I5, 6I-62.

8I Rapport over het personeel door D. Schermers, I5 augustus I898, VCV, no. 50I, doos 52, SV, I43, Nota no. I7 van de geestelijke verzorgers over het verpleegpersoneel door J. Bootsma, april I907, VCV, no. 50I, doos 5I, SV, 206.

82 Van der Hoogt, "Onze huisvaders en -moeders." In the annual report of I9I2 the married house mothers were included in the listing of personnel as "without theoretical training." JvVCV, І9І2, 31.

83 JvVCV, I9I5, 6I.

84 Sollicitanten registers, RANH, ATC.

85 Van Deventer et al., "Rapport omtrent den actueelen toestand", I2-29.

86"Omschrijving van Rechten en Plichten van het Verplegend Personeel, Gesticht Meerenberg”, I898, Museum Meerenberg, PZ Amsterdam, Santpoort, Depot diverse brochures; JvMB, I908, 28-30.

$87 \mathrm{JvMB}, \mathrm{I} 893,46-47$.

$88 \mathrm{JvMB}, \mathrm{r} 893,45$.

89JvMB, I908, 28-30.

9०JvF, I898, I907, sectie "personeel."

9I "Verslag betreffende het Christelijk gesticht 'Veldwijk' te Ermelo over het jaar I893", sectie "cursus", VCV, no. 50I, doos I3.

$92 \mathrm{JvF}, \mathrm{I} 907,3$; JvF, I908, 4.

93 Van der Kooij, Mans, 22.

94 Verslag van het Staatstoezicht, I900-1902, II8. 
95 Verslag van het Staatstoezicht, I903-8, 286.

$96 \mathrm{JvF}$, I907, blauwboek I907, 6.

97 Of the thirteen student nurses appointed in April I893, for example, eight left within a year, two within thirteen months, two after two years, and only one stayed for three years and six months. No. 4I-43, 45-47, 5I-57, Bediendenregister no. 4, IO-2-I893 to I-5-I895, RANH, ATC, archief no. I8I, inv. no. 32I.

98 Van Deventer et al., "Rapport van de commissie." Despite the improvement of education for psychiatrists, they remained dissatisfied over their social position. The many additional tasks in particular-teaching nurses, covering the pharmacy in the evening, or providing health care to personnel-caused resistance after I900. Moreover, physicians often had to live in just like nurses. In Meerenberg three of the six physicians were living in until I906, when the board created outside housing for all physicians. JvMB, I906, 2I. Not until the personnel regulation of I9I3 were physicians entitled to one Sunday off every fortnight.

99 JvMB, I908, 28-30; JvMB, I909, I40; JvMB, I9I3, 27; JvMB, I9I6, I05; Van Deventer et al., "Rapport van de commissie."

Ioo Lindeboom and Van Lieburg, Gedenkboek, I37.

Iо I Lindeboom, "De arbeiders onder krankzinnigen", 52-55.

Iо2 JvVCV, I890/9I, I7.

I03 Van Dale, “De Personeelquaestie”, especially I49-50; Notten, De geesteskranke.

I04 Bijlage "Toestand van de Stichting Veldwijk op I-I-I908", "Verslag betreffende het Christelijk Gesticht 'Veldwijk”, I907, HDNP, VCV, no. 50I, doos I3.

I05 Lindeboom and Van Lieburg, Gedenkboek, ro9-27.

Io6 "Rooster der lesuren voor het verpleegpersoneel van Veldwijk", ingelegd in "Verslag betreffende het Christelijk Gesticht 'Veldwijk'”, I901, HDNP, VCV, no. 50I, doos I3; "Reglement voor de Opleiding van Verpleeg-personeel in de drie gestichten der Vereniging”, Bijlage I, JvVCV, I895/96; Van der Hoogt, "Reglement voor de Opleiding."

I07 JvVCV, I895/96, bijlage I; Verslag van het Staatstoezicht, I900-I902, III-I2; "Verslag betreffende het Christelijk Gesticht 'Veldwijk”, I906, sectie “cursus”, HDNP, VCV, no. 50I, doos I3; Algemeen reglement voor het verpleegpersoneel I9I4, HDNP, VCV, no. 50I, doos 3I, Statuten, reglementen, en instructien van de VCV.

Io8 The Veldwijk board shifted training hours towards daytime after I950. Map tentoonstelling B-opleiding Veldwijk (I990), HAV.

Iog Schermers, Handleiding.

IIO Lindeboom and Van Lieburg, Gedenkboek, I29-48.

III Van der Hoogt, "Reglement voor de Opleiding", 9.

II2 "Onderzoek van de gestichtsraad Veldwijk naar aanleiding van de klachten van Mej. van der Heyden”, SV, II3, HDNP, VCV, no. 501, doos 52.

II3 In I896 turnover among male nurses was 32 percent, and among female nurses 35 percent. In I9OI, 44 (about a third) of the I50 personnel left that year. "Verslag betreffende het Christelijk Gesticht 'Veldwijk'”, I896, I901, sectie “mutatie personeel”, HDNP, VCV, no. 50I, doos I3.

II4 Lindeboom, "De arbeiders on der krankzinnigen", 49-52.

II5 Van Dale, "De toestand", 55; Van Deventer et al., "Rapport omtrent den actueelen toestand", 39-40.

iı6 Van Dale, “De toestand”, 56; JvVCV, I899/ı900, II; see also Lindeboom and Van 
Lieburg, Gedenkboek, I29-3I for a discussion.

II7 "Rapport over een regeling m.b.t. het personeel. Voorstel en advies aan het bestuur. Van Dale en Drenth, 2 maart I900", HDNP, VCV, no. 50I, doos 52, SV, I53.

II8 Rapport omtrent de verzorging van de kranken onder het personeel, I2-I-I9०0, VCV, no. 501 , doos 52, SV, I43. Voorstel van de gestichtsraad voor regeling voor verzorging van ziek en rust behoevend verpleegpersoneel aan het bestuur, I899, VCV, no. 50I, doos 52, SV, I5I.

II9 Van Dale, "De toestand", especially 57.

I20 De Groot, Veldwijk in verleden tijd, 99.

I2I VCV, no. 50I, SV, I53; JvVCV, I899/I900, I0; Van der Hoogt, “Ons Zusterhuis.”

I22 Van der Hoogt, "Ons Zusterhuis”, I49, citation I49. The asylum council that proposed the creation of the rest home/nurses home explicitly referred to the nurses home of the Meerenberg asylum, which had cost II7, ००० guilders. Consequently, the council convincingly argued to the board that a request of 7,000 for the Boschhoek would not be too much. Voorstel van de gestichtsraad, I899, VCV, no. 50I, doos 52, SV, I5I.

I23 “Verslag betreffende het Christelijk gesticht 'Veldwijk'”, I9OI, "verslag van de Boschhoek", VCV, no. 50I, doos I3.

I24 "Verslag betreffende het Christelijk gesticht "Veldwijk”, I907, sectie "personeel", VCV, no. 501, doos I3.

I25 "Verslag betreffende het Christelijk gesticht 'Veldwijk', I907, sectie "personeel", I906, o.a. bijlage "vragenlijst voor lichamelijk onderzoek van het personeel", VCV, no. 501 , doos I3.

I26 VCV, no. 50I, doos 5I, SV, 206, Nota no. I7 van de geestelijke verzorgers over de positie en toestand van het verpleegpersoneel door J. Bootsma, april I907, en SV, 207, Rapport der commissie uit het algemeen bestuur der VCV benoemd tot het instellen van een onderzoek naar de toestand onder het verpleegpersoneel, juli i907.

I27 Sap, "De opleiding", 39-47.

I28 Ibid., 44-45.

I29 "Verslag betreffende het Christelijk gesticht 'Veldwijk”, I9०8, I9०9, sectie "personeel", VCV, no. 50I, doos I3.

I30 Schermers, "Opleidingskwesties."

I3I Ibid.

I32 Sectie "vooropleiding, theoretisch en practisch", "Verslag betreffende het Christelijk gesticht 'Veldwijk', I909, VCV, no. 50I, doos I3.

I33 This was not unique to Veldwijk. The state asylum at Woensel had a similar policy. Physician Schoondermark wrote in an instruction booklet for new nurses that taking a bath was one of the first things a new student had to subject herself to: "In the asylum you will take at least a weekly bath, and put on fresh clothes." Schoondermark, Wenken, 9 (Museum GGZ, Medemblik Collection, G75). On the one hand the book reflected the expectation that pupils would be of a social class not yet used to taking regular baths. But on the other hand the measure reflected the disciplinary methods with which a middle-class asylum leadership subjected the new pupils to the bourgeois expectation. Care of the hands, feet, and hair was important too. All the washing and scrubbing a nurse had to do could damage the skin of the hands, being on one's feet so much could cause swollen and painful feet, and regularly combing the hair would prevent lice (ibid., 9-Io). The norms of physical hygiene, the social position and 
appearance of the decent middle class, and the strenuous work of the nurses were all reflected in the initiation ritual and rules for bodily care.

I34 "Regeling voor de vooropleidingsschool Boschhoek te Ermelo", appendix to "Verslag betreffende het Christelijk gesticht 'Veldwijk'”, I909, VCV, no. 50I, doos I3.

I35 For a discussion of instilling discipline in the industrial workforce, see De Regt, Arbeidersgezinnen en beschavingsarbeid. See also Rafferty, The Politics of Nursing Knowledge, 9-4I.

I36 "Verslag betreffende het Christelijk gesticht 'Veldwijk”, I9०9, sectie "personeel", VCV, no. 50I, doos I3; Verslag van het Staatstoezicht, I909-II, 292.

I37 A short notice on the preparatory training school from the annual report of I925 and a one-page article on the history of the preparatory training school at Veldwijk in the "Nieuwsbrief" (January I979), both in Map Tentoonstelling B-opleiding Veldwijk (I990), HAV.

I38 Boerrigter, Honderdvijftigjaar lang Broeders van Goede Werken, 44.

I39 Eijt, Religieuze vrouwen, I57; Klijn, Tussen caritas en psychiatrie, 32; Righart, "Moraliserinsoffensief."

I40 Boerrigter, Honderdvijftig jaar lang Broeders van Goede Werken, I4-37; Heyrman, Gedenkboek, 9 .

I4I Heyrman, Gedenkboek, 28-29. The numbers are for 1858 .

I42 See Klijn, Tussen caritas en psychiatrie, 3I-62.

I43 Heyrman, Gedenkboek, 43-6I.

I44 Klijn, Tussen caritas en psychiatrie, 32.

I45 Eijt, Religieuze vrouwen, I64.

I46 Heyrman, Gedenkboek, I65-68.

I47 JvVB, blauwboek Voorburg I9ıo, vraag I7, SH, AG, Janora, doos I2, map blauwboeken I907-I7.

I48 Eijt, Religieuze vrouwen, 40-51.

I49 Ibid., IIO-II; Boerrigter, Honderdvijftigjaar lang Broeders van Goede Werken, 87-9I.

I50 Heyrman, Gedenkboek, 55-57.

I5I Binneveld and Wolf, Een huis met vele woningen, 62-63.

I52 "Opleiding religieuze broeders and zusters Reinier van Arkel en Voorburg I903I905, met contract I904 en bemoeienis van de bisschoppen van Gent en Den Bosch", doos 24, no. 08.86, AG I900-I950, SH, AG.

I53 Ibid.; Binneveld and Wolf, Een huis met vele woningen, 63.

I54 "Ontwerp voor bepalingen omtrent onderwijs tot ziekenverpleegster aan zusters opgesteld door de Overste in Ronse, 2I-I-I904", in Map “Opleiding religieuze broeders and zusters”, doos 24, no. 08.86, AG I900-I950, SH, AG.

I55 Brief I-I2-I903, Brief College van Regenten aan Overste van Melle; Brief I2-I903, Antwoord van Overste van Melle aan de Regenten; Brief 3I-I2-I903, College van Regenten aan J. van Melle, directeur van de Congregatie der Barmhartigheid te Ronse, in Map "Opleiding religieuze broeders and zusters", doos 24, no. 08.86, AG I900-I950, SH, AG.

I56 Binneveld and Wolf, Een huis met vele woningen, 58-59.

I57 Boerrigter, Honderdvijftig jaar lang Broeders van Goede Werken, 5I.

I58 Ibid., 5I, 98.

I59 Binneveld and Wolf, Een huis met vele woningen, 56.

I60 Ibid., 6I-76. 
I6I Ibid., 78.

I62 Ibid., 83 .

I63 Boerrigter, Honderdvijftig jaar lang Broeders van Goede Werken, 92-93; Kerkhoven and Vijselaar, "De zorg voor zenuwlijders rond I9००”, 9I.

I64 Tervoert, Opmerkingen over de verpleging van krankzinnigen.

I65 Kappelhof, Reiniervan Arkel, 94.

I66 Tervoert, Nuttige wenken.

I67 Ibid., 7 .

I68 Ibid., 6-I2.

I69 Ibid., I-6.

I70 Binneveld and Wolf, Een huis met vele woningen, 63 .

I7I Eerste les over zieken- en krankzinnigenverpleging aan de Eerw. Broeders van O. L. V. van Lourdes in het gesticht "Reinier van Arkel" te 's-Hertogenbosch op 9 september I89 6 door Dr. J. C. J. van de Hagen, Iste geneesheer. SH, AG, Losse Documentatie, archief briefwisseling college van regenten, ingekomen stuk 73-77, I897.

I72 Religious nurses remained in Voorburg until the I990s, although there were only a few left by that time. The number of order nurses rapidly decreased in the second half of the twentieth century. In the I920s the asylum began to hire secular student nurses, initially men but as of I93I also women, in addition to the order nursing's staff, and during the late ig6os the order nurses shifted from a collective to a personal contract. See Zuster Adelbert, "De Godhuizen nemen afscheid van de zusters van barmhartigheid", 27-5-82, doos “Voorburg, Notities", door H. C. M. Geelen, personal collection Joke Leenders, Nurse-Administrator, PZ Reinier van Arkel; Verheij and Overmeen, Omzien in Zorg, 5-6.

\section{Notes to Chapter VI: The Marginalization of Male Nurses}

I "Beredeneerd verslag over het jaar I9II, omtrent het Geneeskundig Gesticht voor Krankzinnigen te Franeker, uitgebracht door Bestuurders dezer Instelling, ter voldoening van Art. II hunner instructie”, JvF, 7, GAF, APZF, inv. no. 5133; Van Deventer et al., "Rapport omtrent den actueelen toestand", io.

2 The creation of an industrial workforce went along with instilling a strict time discipline and routinization of the workday. A more punctual lifestyle was often forced on the industrial workers by a system of fines. De Regt, Arbeidersgezinnen en beschavingsarbeid, 26-30, 34-36.

3 JvMB, I9IO, 25, 240; I9II, 24-25; I9I2, 24.

4 Reijnders, "De verplegerskwestie."

5 Ibid., 77.

$6 \mathrm{JvMB}, 1892,24,35 ; 1895,34 ; 1898,35 ; 1902,63$.

$7 \mathrm{JvMB}, \mathrm{I} 892,3 \mathrm{I}$.

8 Associations for male nurses or deacons developed within the context of the Orthodox Protestant evangelical revival during the mid-nineteenth century similar to the deaconess institutions.As with their Roman Catholic counterpart for which during the boom in establishment of Roman Catholic orders female orders outnumbered the male orders, deacon associations were probably less common. As José Eijt argues in her study of female orders in the Netherlands, the bourgeois domestic ideology on the role of women enhanced the recruitment of women for caring tasks. This was no different in the deaconess movement. See Eijt, Religieuze vrouwen, I57-58, I64-65. 
$9 \mathrm{JvMB}, \mathrm{I} 892,3 \mathrm{I}$.

Io $\mathrm{JvF}, \mathrm{I} 898$.

II JvF, I900; JvF, I902; JvF, I909. Until I907 when male student nurses began to take the NVP exam, Jansen remained the only trained male nurse graduate in Franeker. He may have been needed in the male department as somatic treatments increased.

I2 JvF, I9०9.

I3 JvMB, I897, 39; I899, 40-4I; I901, 49.

I4 For the numbers of graduating nurses, see JvMB, I899, 33, 39-40; I900, 53; I90I, 5I; I902, 88; І916, 30; Een eeuw krankzinnigenverpleging 1849-1949, 66, 26I, bijlage I; "Dienstvoorwaarden en Omschrijving der Rechten en Plichten van het Personeel", JvMB, 1904, 34-35.

I5 By I899 Veldwijk had 26 pavilions (440 patients), II of which were male and I5 female. JvVCV, I898/99, 32-33; "Verslag betreffende het Christelijk gesticht voor krankzinnigen 'Veldwijk' te Ermelo over het jaar I90I”, HDNP, VCV, no. 50I, doos I3.

i6 JvMB, i904, 34-35.

I7 Artikel 2, I2, Reglement voor de Opleiding van Verpleegpersoneel in de drie gestichten der Vereeniging, JvVCV, I895/96, Bijlage I. On request this period could be reduced for example if age was an issue. Eventually the prerequisite for marriage was relaxed. By I9I4 male graduate nurses could request permission to marry from the board once they reached twenty-five. By then, they obtained the right to marry after six years of service, three of which had to be as a graduate nurse. See Artikel I7, Algemeen Reglement voor het Verpleegpersoneel, HDNP, VCV, no. 50I, doos 3I.

I8 JvMB, I904, 34-35.

I9 List of graduates I897-I92I, HAV, map Tentoonstelling Honderd Jaar B-Opleiding Veldwijk (I990).

20 Notulen van het Centraal Bestuur, I4-I8, boek 4, II-7-I9I3, 24-9-I9I3, 29-5-I9I4, HDNP, VCV, no. 50I, doos I4-I8.

2I VCV, no. 50I, doos I3, Verslag over I900, I906, sectie "personeel”; JvVCV, I9I2, 3I-32.

22 JvMB, I907, 77; Notulen van het Centraal Bestuur, 23-4-I9I4, HDNP, VCV, no. 50I, doos I4-I8, boek 4 .

23 JvMB, I896, 130-36. Out of the 579 fourth- and fifth-class male patients, 334 worked; 364 out of the 605 fourth- and fifth-class female patients worked.

24 See the discussion of the applicant nurse registers in Meerenberg in Chapter VII.

25 Van Deventer et al., "Rapport omtrent den actueelen toestand", 24.

26 Ibid., I4. The medical director of the Bloemendaal asylum reported in the survey that he preferred "country boys" as male nurses, whereas a service record as a domestic servant was sufficient for female nurses. For a similar argument, see Hughes, "Country Boys Make the Best Nurses."

27 JvMB, I899, 40-4I.

28 JvMB, I897, 39 .

29 I am indebted to Ellen Baer for furthering the argument in this direction.

30 In JvMB, I982-I904, sectie “personeel”, Van Deventer frequently stated that personnel in the male artisan workshops should be included with the medical personnel rather than with the administrative and technical personnel (and thus be within medical control). For the advertisements, see "Register houdende ingeplakte advertenties in kranten wegens aanbesteding, levering [goederen], oproepen voor personeel enz., ı89oI922", RANH, ATC, no. 338, inv. no. I5. 
3I For the salaries of male nurses compared to workshop artisans and maintenance artisans, see Een eeuw krankzinnigenverpleging 1849-1949, 266-67.

32 Based on a trade count of the working population of $\mathrm{I} 849$, in the mid-nineteenth century 44 percent worked in agriculture, 24 percent in industry (often not yet mechanized), and 29 percent in trade, transportation, and service. In I9o9 these percentages had changed to 28, 32, and 38 percent, respectively. De Regt, Arbeidersgezinnen en beschavingsarbeid, $\mathrm{I} 8$.

33 De Regt, Arbeidersgezinnen en beschavingsarbeid, I7. See also Berting, "In het brede maatschappelijke midden”, I26; and Van Holthoon, Mensen in Europa, II7-I8. The categorization given by De Regt, Van Holthoon, and Berting are informed by analyses of trade counts of the working population in the mid-nineteenth century (J. J. Giele and G. J. van Oenen) and tax assessments (H. van Dijk) as an indication of social stratification.

34 Of the 332 male patients involved in work at Meerenberg in I896, ten worked in the carpentry workshop, I with the joiner (schrijnwerker), three with the smith, two in the gas factory, three in the boilerhouse, and 4 with the painter. In total there were twenty-three patients (7 percent) working at these jobs. Seventy-one patients were involved with fieldwork and portering (2 I percent), sixty-four in the male workshops (tailor, shoemaker, mattress maker, bookbinder) (I9 percent) and all other I50 patients did domestic work on the wards (35 percent), or other domestic, kitchen, and laundry work (II percent). Twenty-four (paying) patients (7 percent) undertook upper-class activities such as music, art, etc. See JvMB, I896, I35.

35 The disciplinary system of fines to force laborers to keep their responsibilities, both in terms of time scheduled and task, was not unique to asylum care; it was also common in industry. De Regt, Arbeidersgezinnen en beschavingsarbeid, 26-3I.

36 "De oude garde vertelt: Veldwijk na 50 jaar, I886-1936", Refajah 35 (January/February I935/36):34I-49.

37 No. 313, 3I8, I386, Stamboek personeel (I886-I92I), HAV.

38 See, for example, no. IoII, I03I, I426, Stamboek personeel, HAV.

39 The reasons for leaving differed for men and women. Male nurses, if they did not obtain a position as a married nurse, had to leave on engagement or marriage because they could not support a family. Female nurses left on engagement or marriage because it was uncommon for a woman to work after marriage. Married (trained) nurses were therefore not usually female.

40 No. 250, Stamboek personeel, HAV.

4I No. 98I, Stamboek personeel (I886-I92I), HAV.

42 No. I97, Stamboek personeel (I886-I92I), HAV; JvVCV, I9I5, 63.

43 JvVCV, I9I5, 68-69. Not only male nurses moved into artisan work. A few female nurses also worked in the apothecary and the kitchen, and the house-mistress was a nurse. For both groups such work may have meant an improvement of living and working conditions or just a change from strenuous work. On the other hand, nursing provided an upward career for servants. Two of the linen girls went into training in the Boschhoek.

44 Viveen, “Het proces van gezinsverpleging met name op Veldwijk, I884-I920”, 4I.

45 Ibid., 43.

46 According to the legend, Dymphna, an Irish princess, came to Gheel in the sixth century (500). When she was born, her father, the king of Ireland, would have preferred a son. Disappointed, he left her and his beautiful wife in the care of priest Gereberne, who had converted his wife to Christianity. After his wife died, the king was overcome with grief 
and searched for another woman just like her. His advisors decided that no other woman but his own daughter would be of the same status as the Queen. Denying their relationship, her pagan father wanted to marry her. Filled with fear, Dymphna fled with her priest and eventually came to Gheel. The Irish king eventually found his daughter and her priest, and had them both beheaded. According to the legend, witnessing this scene frightened several lunatics to such an extent that they suddenly became cured. This made Dymphna, who had resisted the spirit of evil, the patron of lunatics. The site later became a place of miraculous healing. This version of the legend is taken from Parry-Jones, "The Model of the Gheel Lunatic Colony", 20I. Different versions with slight variations exist. See also Van der Meij-de Leur, Van Olie en Wijn, 89-90. According to Van der Meij-de Leur's version, the St. Dymphna Guesthouse and Chapel were built at this place.

47 During the nineteenth century, and also in the Veldwijk model, families were paid for boarding a patient.

48 Parry-Jones, "The Model of the Gheel Lunatic Colony", 202-3.

49 Meinema, Over Gezinsverpleging van Geesteszieken.

50 In Britain the system never fully developed. See Parry-Jones, "The Model of the Gheel Lunatic Colony", 207-II. In Holland too it was a small-scale endeavor, but remained in existence; even in the I920s various asylums expanded the number of patients in family care and a new colony was founded in I922. Van der Esch, Geschiedenis.

5I Sectie "gezinsverpleging", "Verslag betreffende het Christelijk gesticht 'Veldwijk", I90I, HDNP, VCV, no. 50I, doos I3.

52 Van Deventer, Van Dale, and Vos, Over gezinsverpleging van krankzinnigen.

53 Sectie "gezinsverpleging", "Verslag betreffende het Christelijk gesticht 'Veldwijk'”, I894, I896, I897, HDNP, VCV, no. 50I, doos I3; Viveen, "Het proces van gezinsverpleging met name op Veldwijk, I884-I920", 39-58.

54 See JvVCV, annual statistics on asylum population changes at Veldwijk (sectie "verloop der bevolking", Veldwijk).

55 Van Deventer, Van Dale, and Vos, Over gezinsverpleging van krankzinnigen, I4; Viveen, "Het proces van gezinsverpleging met name op Veldwijk, I884-I920", 33.

56 Van Deventer, Van Dale, and Vos, Over gezinsverpleging van krankzinnigen, 38-39.

57 JvMB, I900, 4; I901, 42, 48; I902, I58; I906, I07; Verslag van het Staatstoezicht, I903-8, 394.

58 JvMB, I904, 34-35. Artikel 2, I2, Reglement voor de Opleiding van Verpleegpersoneel in de drie gestichten der Vereninging, JvVCV, I895/96, Bijlage I.

59 Van Deventer, Van Dale, and Vos, Over gezinsverpleging van krankzinnigen, I8.

6oSectie "gezinsverpleging", "Verslag betreffende het Christelijk gesticht 'Veldwijk", I897, HDNP, VCV, no. 50I, doos I3. In I899 twenty-three families boarded patients, seventeen of them being personnel (idem, sectie "gezinsverpleging", I899); in I9०0 seventeen out of twenty-six families that boarded patients were personnel (idem, sectie "gezinsverpleging", I900).

6г Bouman, "Is het stelsel van gehuwde verplegers wel aan te bevelen?.”

62 Notulen van het Centraal Bestuur, 4-I-I909, HDNP, VCV, no. 50I, doos I4-I8, boek 3.

63 Van der Wal, "Gezinsverpleging bij gehuwde broeders."

$6_{4}$ See Wieringa, “Lotgevallen van de Valeriuskliniek." Wieringa argues that rather than accepting patriarchal domination based on obligation, workers began to defend their entitlement to a contractual relationship based on rights. Wieringa puts forward this 
argument in his discussion of the tension that existed within the VCV between their ideology of care as Christian philanthropy and care as a paid occupation. The VCV's ideology and resistance against the commercialization of work relationships legitimized its patriarchal attitude towards personnel, but on the other hand created much tension among personnel, who felt increasingly entitled to a better legal status and attempted to defend their rights (32-33).

65 Van der Kooij, Mans, 44-54; Van Gemert and Spijker, Verdichtsel en werkelijkheid, 58 $7 \mathrm{I}$.

66JvF, I898, sectie "personeel."

$67 \mathrm{JvMB}, 1900,36$.

68 Letter from P. N. Bras to J. Mullemeister, Bestuurslid, 2I maart I903, RANH, ATC, no. 338 , inv. no. I9.

69MvZ i6, no. 4 (1906): 177; $M N V V$ I, no. I (1907): I-2.

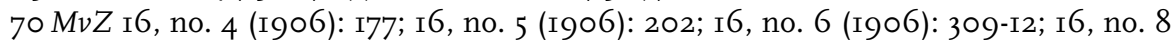
(I906):374-8I; I6, no. 9 (I906): 425-39; I6, no. II (I906): 55I-54; I6, no. I2 (I906): 59499.

7I Van der Kooij, Mans, 53 and Bijlage I, blad 3, tabel 4 and 5.

$72 M v Z$ i6, no. 4 (I906): I77; MNVVi (I907): 133-34.

73 MNVVI (I907/I908): I-II, I7-24, 47, 57-59, I60-62, 205-8, 24I-55, 263-70. See also Van Gemert and Spijker, Verdichtsel en werkelijkheid, 58-7I.

$74 M N V V$ I (1907): 83.

75 MNVVI (I907/1908): 285; 4 (I910): 7I-75.

$76 M N V V$ I (I907): 46, I24, I29.

77 See the listing of new members in every issue of $M N V V$.

78 MNVVi, no. I (1907): 7 .

79 JvMB, I904, 35-36; I905, 23, 32; I906, I4. In some asylums the male nurses home eventually acquired the task of preparing male nurses for their work on the wards, particularly introducing them to domestic skills and punctuality in domestic work, very similar to the function of the nurses home or preschool for female nurses. See Zondag, Naar Franekergaan, 20.

80 $M N V V$ i, no. I (1907): 9 .

8I $M N V V 8$ (I9I4): 236-37.

82 See for example $M N V V 6$ (I9I2):368-75; 8 (I9I4): I70-78, I82-83.

83 MNVV 8 (I9I4): I8I-83, 236-37. For Bras' involvement with the ANAB, see De Ambtenaar I, no. 2 (I9I0): 6; no. 4 (I9I0): 6. De Ambtenaar was the journal of the ANAB. It had several articles on nursing throughout the I9IOs in which it ridiculed the independent stance of the NVV and called on its readers to join the ANAB instead. For the initial activities of the Bloemendaal branch of the ANAB (Meerenberg), see "Huishoudelijk reglement van de afdeling 'Bloemendaal \& O.' van de ANAB (I9IO)”, in map "pamfletten, agenda's, jaarverslagen, enquete, schrijven”, portefeuille map 4, Internationaal Instituut voor Sociale Geschiedenis, Archief van de Algemene Nederlandse Ambtenarenbond afd. 's-Gravenhage, I9ı-I9ı8; and “jaarverslag I9I4 Bloemendaal \& O.” in map "correspondentie I9IO-I9I5", portefeuillemap 4, IISG, same archive.

84 Van Lanschot-Hubrecht, Waarom is een wettelijke regeling, 2.

85 Een eeuw krankzinnigenverpleging 1849-1949, Bijlage II, 266-67.

86 JvMB, I9I4, 24-25.

87 JvMB, I9I4, 29; I916, 30-31. 
88 Hospital directors successfully exploited the argument that the supply of nurses was insufficient for a further shortening of working hours, particularly during the economic depression of the early i920s. The legal regulation on the working hours of nursing personnel that eventually passed parliament in I929, on the eve of yet another economic recession, consolidated the fifty-five-hour working week, allowing nurses to spread a ten-hour working day over a period of at most fifteen hours. See Van der Kooij, Mans, 70. The regulations reflected the unsettled status and professional identity of nursing.

89 MNVV 8 (I9I4): 136, 236-37. For the shift of the NVV branch at Meerenberg to the ANAB, see "Jaarverslag I9I4 Bloemendaal \& O.", in map "correspondentie I9IoI9I5”, portefeuillemap 4, IISG, Archief van de Algemene Nederlandse Ambtenarenbond afd. 's-Gravenhage, I9I0-I8.

90 MNVVI2 (І9г8): 208-9.

9I Van der Kooij, Mans, 54 .

92 Reijnders, "De verplegerskwestie", 76-77.

93 The difference in the legitimization of their work may account for the quite nasty and bitter articles that NVV members wrote against their colleagues in the deacon association for epileptic patients in Haarlem and some members of the Christian Association of Nursing. See Bras, "Aan Br. H. Kooistra over zijn lezing"; Drosterij, "Philantropie en Vakverpleging."

94 Nolan, "Psychiatric Nursing Past and Present", I2 I-22, I77, I85-86.

95 Bouwmeester, "Paedagogiek en Verpleging", citation 247. [hoe meer verpleging is gebaseerd op pedagogische beginselen, hoe meer verpleging tot haar recht komt, 247]. It is possible that Bouwmeester was familiar with literature or textbooks for teachers at normal school, which he may have found applicable to nursing. This use of social scientific knowledge to articulate their role eventually became common among nurses, especially as a measure to distance themselves from medicine. I made this argument for the North American nursing context in Boschma, "Evenwicht en Groei" and in an unpublished paper, "Claiming Professionalism: Conflict and Collaboration between Nursing, Medicine and Social Science, I900-60”, presented at the AAMH Conference, New York, April 28-May I, I994.

96 Bouwmeester, "Paedagogiek en Verpleging”, 250.

97 Ibid., 248-53.

98 Ibid., 250.

99 Van der Bor, "Iets over de verpleging van krankzinnigen."

I00 Ibid., I54. Van der Bor referred to well-known nursing textbooks on mental care by physicians Scheffer (I9I4) and Van Delden (I897) and to the lecture series of physician Schnitzler, which had appeared in I9I5 in the Journal of Sick Nursing.

IOI Ibid., I57.

I02 Ibid., I57-58.

I03 For a discussion of the modern, secular notion of compassion that emerged in nursing, see Hamilton, "Constructing the Mind of Nursing."

IO4 The training model of the VCV is probably best interpreted as a transitional compromise between two opposing philosophies: that is, a religiously based model of instilling faith and a medical training model.

I05 Bouwmeester, "Paedagogiek en Verpleging”, 250. 


\section{Notes to Chapter VII:}

\section{Controversy and Conflict over the Social Position of Nurses}

I JvF I920, met bijbehorend blauwboek I9I3-I920, GAF, APZF, inv. no. 5133 .

2 Rekening Franeker over het dienstjaar I90 (loonsverhoging bedienend personeel I90I), GAF, APZF.

3 "Stukken betreffende een proces van verpleegster inzake verbranding van een patiente in het bad alsmede maatregelen te nemen met betrekking tot badinrichting I894I9O2" (hereafter cited as "Stukken proces van verpleegster"), RANH, ATC, archief no. I8I, inv. no. 457 .

4 Stuk no. I2, "Stukken proces van verpleegster", RANH, ATC, archief no. I8I, inv. no. 457.

5 The file included nineteen newspaper articles about the case. Stuk 53-7I, "Stukken proces van verpleegster", RANH, ATC, archief no. I8I, inv. no. 457.

6 Two other patients had died, one in 1893 and the other in I897. Stuk 20, "Stukken proces van verpleegster", RANH, ATC, archief no. I8I, inv. no. 457.

7 Stuk Io, "Stukken proces van verpleegster", RANH, ATC, archief no. I8I, inv. no. 457.

8 Stuk 9, Stuk I6, newspaper article by J. A. Levy, "Meerenberg", in De Amsterdammer, no. 25-07-1897, and newspaper article "Rechtdoende", also in De Amsterdammer. "Stukken proces van verpleegster", RANH, ATC, archief no. I8I, inv. no. 457.

9 Stuk IO, II, I6, “Stukken proces van verpleegster”, RANH, ATC, archief no. I8I, inv. no. 457.

Io Stuk I6, newspaper article by J. A. Levy, "Stukken proces van verpleegster", RANH, ATC, archief no. I8I, inv. no. 457.

II De Bosch Kemper, "De Meerenbergsche Zaak."

I2 Windmuller, De Galan, and Van Zweeden, Arbeidsverhoudingen in Nederland, 38; Poldervaart, Vrouwenstudies, 29-32.

I3 Van Holthoon, Mensen in Europa, 2I4-I5.

I4 Ibid., I73; Harmsen, "De Arbeiders en hun Vakorganisaties", 274.

I5 Nosokómos II (I9II): 883 .

I6 MvZ 4, no. 5 (I894): 6I-66; Bakker-van der Kooij, "De maatschappelijke positie”, 466 67.

I7 Nosokómos' minutes of the board: Notulen van de hoofdbestuursvergaderingen, october en november I904, juni I905, inv. no. 7, Archief Nosokómos, Nederlandse Vereniging tot bevordering der belangen van verpleegsters en verplegers 1900-1934, GA, archief no. 134. See Dock's reports, for example, American Journal of Nursing 8, no. 4 (I908): 274-79; American Journal of Nursing I7, no. 9 (I9I7): 8I2-I4. See Nutting and Dock, History of Nursing, 4:55-74 for a report on the history of nursing in Holland by Van Lanschot-Hubrecht.

I8 Notulen van de hoofdbestuursvergaderingen, november I9o8, inv. no. 8., Archief Nosokómos, GA, I34.

I9 Notulen Algemene Vergaderingen I893-I903, Map I, ANBZ, IISG, Amsterdam. For a discussion of the medical domination within the NBZ, see also Bakker-van der Kooij, "Mara", I99-203.

20 Map 48, notulen van de afdeling Friesland, vergadering I4 mei I902, ANBZ, IISG.

2I Map 49, notulen van de afdeling Haarlem, vergadering I5-2-I925, 25-II-I925, I6-IOI924, IO-I2-I937, ANBZ, IISG.

$22 \mathrm{MvZ}$ I3 (I903): I52-54; $M v Z_{\text {I3 }}$, no. Iо (I903): I74-87. 
23 Van der Kooij, Mans, 27-3I.

24 Ibid., I7-24.

25 The indecisive nature of the organization and its dependence on the authority of the medical director eventually began to be criticized by the influential nurse leader Frederike Meyboom. Notulen 6-6-I92I, I8-7-I92I, Notulenboek I920-I936, Map 4, Archief van de Bond van Directrices en Deputy directrices van Ziekeninrichtingen en Verenigingen van Ziekenverpleging (hereafter cited as Directrice-Bond), IISG. See also Van der Kooij, Mans, 28, n. 6, and Wiegman, “'Gij completeert zijn arbeid”, especially 305-6.

26 Map 3, Jaarverslagen, Directrice-Bond, IISG. See also Wiegman, “'Gij completeert zijn arbeid'."

27 Van der Kooij, Mans, 33. The exam that Nosokómos established for its members was more comprehensive than the standards set by the NBZ. See Van Lanschot-Hubrecht, Het vakonderwijs in de ziekenverpleging. In 1906 Nosokómos developed a two-year preparatory training course, schooling based on the domestic science model, which only a few nurses attended. Trainees had to pay a fee for the course. For a description of the program and the responses of the medical establishment, who considered the standards far too high, see Opleiding en examens van verplegenden, I8-i9.

28 For Nosokómos' petition to the municipal council of Haarlem about the poor conditions for nurses in the municipal hospital Elisabeth Gasthuis in I9I6, see Van der Vies and Van Rijn, "Adres aan den Raad der Gemeente Haarlem", Nosokómos, I6 (I9I6): 512I3 and for their propaganda article on the strenuous conditions of nursing work in the Endegeest asylum, also in I9I6, "Gestichts-leven", Nosokómos, I6 (I9I6): 545-47.

29 JvMB, I900, 44, sectie "mutaties"; "Verslag betreffende het Christelijk gesticht voor krankzinnigen 'Veldwijk' te Ermelo”, I900-I909, sectie “mutatie personeel”, HDNP, VCV, no. 50I, doos I3 (handwritten Annual Reports of Veldwijk by medical director J. van Dale).

30 "Afgewerkt met 45 à 50 jaar", Nosokómos I5 (I9I5): 8I9-20.

3I "Adres aan burgemeester en wethouders van 's-Gravenhage", IISG, Archief van de ANAB, afd. 's-Gravenhage, portefeuille map 9, map "Afschrift I5 dec. I9I6, adres rechspositie gemeente-ziekenhuispersoneel."

32 "Eisen der Vakvereenigingen voor het verplegend personeel van de Rijksinrichtingen voor Hooger Onderwijs opgemaakt door de hoofdbesturen van Nosokómos en van de Alg. Ned. Ambtenaarsbond", 3, IISG, Archief van de ANAB, afd. 's-Gravenhage, portefeuillemap 5, map "correspondentie I9I7."

33 Bouman, "Een Christelijk Bond voor Ziekenverpleging"; Bouman, "Openingswoord uitgesproken"; Vonk, "Verslag van de ze Algemene Vergadering."

34 The CBZ did not approve of petitioning the state to seek improvement of working conditions. See "Stellingen." Moreover, a strong rivalry existed between the nurses of the NVV and the CBZ. See Bras, "Aan Br. H. Kooistra over zijn lezing”; Kappers, "Nederl. Verplegers-Vakvereniging”

35 "Verslag van de 8e Algemene Vergadering van de Chr. Bond voor Ziekenverpleging, 4 oct. I9I0", Orgaan van de Chr. Bond voor Ziekenverpleging 7, no. Io (I910): I45-53.

36 Lindeboom and Van Lieburg, Gedenkboek, I33.

37 Lindeboom, "De betekenis."; Notulen van het Centraal Bestuur, I-4-I9I3; 30-5-1913, HDNP, VCV, no. 501, doos I4-18, boek 4.

$38 \mathrm{JvVCV}$, I9I8, 34. This female nurse took quite a risk by expressing her thoughts in the 
midst of this gathering of physicians, ministers, and other prominent VCV members, who were all male.

39 JvVCV, ı918, 48-49; Wieringa, “Lotgevallen van de Valeriuskliniek”, 48-49.

40 Rapport der commissie uit het algemeen bestuur der vereniging benoemd tot het instellen van en onderzoek naar de toestanden onder het verpleegpersoneel (juli I907), Stukken van de Vereniging no. 207, HDNP, VCV, no. 50I, doos 5I; JvVCV, I9I4, 20-2I; Een eeuw krankzinnigenverpleging 1849-1949, 266-67. The salaries at Meerenberg were exceptional at that time.

4I JvVCV, I9I9, 22-23; Van der Kooij, Mans, 69.

42 Boschma, “Agnes Karll”, especially I5I. For a discussion of the early parliamentary debates on nursing in Germany, see Kruse, Die Krankenpflegeausbildung seit der Mitte des 19. Jahrhunderts.

43 Abel-Smith, A History of the Nursing Profession, 82-83.

44 Ibid., 82-83; Rafferty, “The Politics of Nursing Education I860-I948”, I93-208.

45 Van Lanschot-Hubrecht, "The Present Conditions of Instruction for Nurses in Holland."

46 Van Lanschot-Hubrecht, Waarom is een wettelijke regeling.

47 Ibid., I-2.

48 Van Lanschot-Hubrecht, Het vakonderwijs in de ziekenverpleging; idem, Waarom is een wettelijke regeling; Opleiding en examens van verplegenden, 212-27, 23I-34.

49 Opleiding en examens van verplegenden, $\mathrm{I}-5$.

50 Ibid., 23I. The account of Jeanne van Lanschot-Hubrecht on the battle for registration in the Netherlands can be found in Nutting and Dock, History of Nursing, 4: 68-74.

5I Opleiding en examens van verplegenden, 6-9.

52 Ibid., 9 .

53 Ibid., II.

54 Ibid., 22.

55 Ibid., I7-22, 83-86, 204-12.

56 Goudswaard, Inleiding tot de geschiedenis van de verpleegkunst, I35-39.

57 Ibid.

58 See Van Lanschot-Hubrecht, Het vakonderwijs in de ziekenverpleging; idem., "Report."

59 In I92I the NBZ members numbered 4,233, Nosokómos 806, the NVV 4I3, and the ANAB 906. Bakker-van der Kooij, "Nurses and Social Consciousness", 27-28. See also Van der Kooij, Mans, bijlage I, blad 2 (the latter statistics do not include the ANAB).

6oWet van 2-5-I92I tot wettelijke bescherming van het diploma voor ziekenverpleging, overdruk uit het staatsblad no. 702; Besluit van 6-I2-I923, strekkende tot het bepalen van den dag waarop de Wet van 2-5-2I [..] in werking zal treden, overdruk uit het staatsblad no. 54I, AS, inv. no. 252I, WVS.

6r Van der Kooij, Mans, 8I-82.

62 Brief van de Minister van Binnenlandse Zaken en Landbouw aan de Inspecteurs van het Krankzinnigenwezen, I3-3-I924, brief no. 2I5 met drie bijlagen, AS, inv. no. 252I, WVS.

63 Ibid. The Netherlands had two state asylums by that time for indigent patients who came under the legal responsibility of the state government, such as military men or people without a permanent residence. The state asylums issued their own diploma of mental nursing.

64 Van Gemert and Spijker, Verdichtsel en werkelijkheid, 45; Goudswaard, Inleiding tot de 
geschiedenis van de verpleegkunst, I39-43; Van der Kooij, Mans, 8I.

65 Eventually in 1933, during a severe economic crisis and high unemployment among nurses, the Medical State Inspectors and Department of Health established a Council of Nursing that brought together employers' and employees' organizations (hospital, medical, and nurse leadership) to further negotiate training and practice standards of nursing. See Notulen van de Raad voor Ziekenverpleging I933-36, speciaal de "Oprichtingsvergadering van een Raad voor Ziekenverpleging 20-4-I933”, AS, inv. no. 2587, WVS.

66Cox, "De verpleegsters-kwestie."

67 For recognizing the influential role of W. H. Cox in Dutch psychiatry I am indebted to historian of psychiatry Leonie de Goei. See De Goei, “I900-I924." For Cox's biography, see Stärcke, "In Memoriam Willem Hendrik Cox."

68Cox, "De verpleegsters-kwestie"; idem, "De algemene ontwikkeling der candidaten." For the discussions and thoughts about the exam regulation of the newly appointed NVP exam committee in I9or, see Cox et al., "Kort overzicht."

69Cox, "De verpleegsters-kwestie", 235, 239.

70 Ibid., 237.

7 I Ibid., 235 .

72 Ibid., 235-38.

73 Ibid.

74 Cox, “De verpleegsters-kwestie”, 236.

75 Cox, "Idealen in de Krankzinnigenverzorging”, 65.

76 Bakker-van der Kooij, “Mara”, 2II-I3; Van der Kooij, Mans, 74-79, bijlage 6.

77 A case in point is the career of Meta Kehrer, a Buitengast Hospital nurse training graduate of I9I2, who after a few years of medical social work (I920) became chief inspector with the police department vice squad in Amsterdam in i923. See Den Broeder and Schaap, "Het maatschappelijk moederschap."

78 Sollicitanten registers [Applicant registers], RANH, ATC, archief no. I8I, inv. no. 36679. The applicant registers include several parts: a register of servant personnel from I 887 until I 890 and from I895 until I9II; as of I 895 the register consisted of three separate applicant register books, one for servant applicants, one for female nurse applicants (I890-I908), and two for male nurses applicants (I895-I9I0). From each of these three groups applicant entries of the first six months a year at five-year intervals from I890/1895 until I908/I910 were selected for analysis. Socio-demographic information and work history were recorded for all applicants, so the information gives a good picture of the applicant's social background. The registers give no consistent information about whether applicants were rejected, accepted, or had removed themselves from the list because they had found a job elsewhere. Therefore no percentage of accepted or rejected applicants can be given, although for some applicants an appraisal was given, or the statement "Rejected." Servant applicants: inv. no. 366, 367, 369; male nurse applicants: inv. no. 370, 376, 379; female nurse applicants: inv. no. 372, 374, 378.

79 Selected servant applicants, Sollicitanten registers, RANH, ATC, archief no. I8I, inv. no. $366,367,369$.

8o Duyvendak and Kooij, Sociale Geschiedenis, 69-75.

8I The records refer to "normaal school" or "kweekschool" (normal schools for teachers), and "industrieschool", which I translate as industrial school. It was probably a school for vocational training, which may have included home economics. 
82 Cox, "De verpleegsters-kwestie", 238.

83 JvMB, I900, 44-45. Many of them left after a short period of work because of marriage or family obligations. Engagement was another frequent reason for departure. Many nurses also left because they became sick, nervous, or overworked, and were found to be unfit for the job.

84 Kerkhoven and Vijselaar, "De zorg voor zenuwlijders rond I9०o"; Ackerknecht, Short History of Psychiatry, 82-100.

85 Van Deventer, “Ter nagedachtenis van Mej. G. Kuyk", MvZ 6, no.6 (February I896) 8I83; Ulfers, "In Memoriam Mej. G. Kuyk", $M v Z$ 6, no.6 (February I896):82-83; "Het Tehuis voor Zenuwlijderessen te Scheveningen." Kuijk regularly advertised for her home in the Maandblad voor Ziekenverpleging. The advertisements described the home as a home for female nervous patients and feeble-minded children. For an advertise-

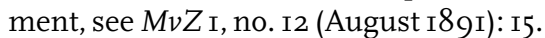

86 Van Deventer, "In Memoriam Dr. A. O. H. Tellegen.”

87 Kerkhoven and Vijselaar, "De zorg voor zenuwlijders rond I9०0."

88 Verslag van het Staatstoezicht, I89I-93, I58-67; I900-I902, 97-108, 263-64.

89 A I9II survey of the Dutch Nurses' Association found that a little over four thousand hospital nurses worked in about two hundred general hospitals. A little over two thousand mental nurses worked in the twenty-nine asylums in that same year. Opleiding en examens van verplegenden, I33, I88-89; $M v Z 22$, no.I (January I9I2): 2 I-22.

90 PNB 7 (I903): 290. Almost all asylums sent candidates at some point during this time, varying from only one candidate once to a few every year, but only six asylums sent candidates almost every year (Meerenberg, Medemblik, St. Joris, Utrecht, The Hague, and Endegeest asylums). Of those Meerenberg sent a relatively large number of candidates every year, a total of 245 during the whole decade (of whom I45 passed and Ioo failed or withdrew). The other five considerably smaller asylums sent 40, 38, 35, I5, and 22, respectively. Ibid., 246.

9I PB I2 (I894): II-I7; I3 (I895): 65-69; PNB 2 (I898): 234-42.

92 Cox, "De verpleegsters-kwestie", 239-42.

93 Schermers, "Ons verpleeg-personeel."

94 Ibid.

95 Verslag van het Staatstoezicht, I900-I902, 108-25.

96 Cox et al., "Rapport der Examen-Commissie I9OI-I902"; idem, "Rapport der ExamenCommissie I902-I903"; idem, "Kort overzicht”, 290-9I.

97 Cox et al., "Kort overzicht”, 297-300.

98 For the Veldwijk training regulations, see JvVCV, I895-96, bijlage I, LXXXII; Verslag van het Staatstoezicht, I900-I902, I08-25; PNB 5 (I901): 95-I88, 379-85; 7 (I903): 28589 .

99 PNB I5 (I9II): 297-305, especially 302 . In the period I904-9 a total of 422 nurses graduated from the A exam, whereas only 26 graduated from the B exam. The diploma was not required for private duty. Many general hospital nurses took mental cases in private duty as well. Neither psychiatrists nor general hospitals were able to control that field.

Iо० PNB I7 (1913): I47-56, I66-67.

го Cox et al., "Kort overzicht", 3 І6.

IO2 PNB 8 (I904): 439-53, 562-67.

I03 Despite increased medical authority, asylum physicians remained dissatisfied with 
their social position during the first decades of the twentieth century. Articles appeared regularly in their journals about the social position of psychiatrists. In Meerenberg, which employed six psychiatrists in addition to the medical director, three of the six physicians lived in the asylum. Eventually in I906 the Meerenberg board accepted a new rule that allowed all physicians to acquire a house outside the asylum grounds. See JvMB, I906, 2I. The asylum physicians' additional tasks in providing medical care to personnel, teaching nurses, or filling in in the pharmacy during evenings and weekends was another continuous source of dissatisfaction. See Van Deventer et al., "Rapport van de commissie", 2-6, and I4.

I04 PNB I4 (I9I0): 79-82, 455-60.

I05 Rafferty, The Politics of Nursing Knowledge, 30-4I.

Io6 See previous section on criteria for the rejection of Meerenberg applicants.

I07 Ibid., 54 .

Io8 Statistics drawn from Annual Reports (JvMB, JvF, JvVCV, sectie "verloop der bevolking").

IO9 Rafferty, The Politics of Nursing Knowledge, 33, 4I; Cox, "De verpleegsters-kwestie"; Cox, "Algemene ontwikkeling."

IIO Rosenberg, "Crisis in Psychiatric Legitimacy", 247-48.

III Blok and Vijselaar, Terug naar Endegeest, 40.

II2 Svedberg, "Narratives on Prolonged Baths."

II3 Ibid., 29.

II4 Ibid., 33 .

II5 Ibid., 30.

\section{Notes to Conclusion: The Politics of Mental Health Nursing}

I Klijn, Tussen caritas en psychiatrie,3I-62. Rather than actively seeking alternatives, as did their Protestant counterparts, the Roman Catholic leadership of the asylum expressed its objection to materialist notions more passively, never demonstrating much support for the inspectors' or physicians' point of view.

2 See Chapter VII, section "Controversy over the Somatic Approach and Biomedical Footing of Psychiatric Care."

3 Rosenberg, "The Crisis in Psychiatric Legitimacy."

4 The number of patients cured, improved, not cured, or deceased was reported annually in the annual report of Meerenberg. JvMB, table "verloop der bevolking", sectie geneeskundige dienst. For the percentages of chronic patients, see JvMB, I899, 76-79; I900, 92.

5 F. J. Stuurman, cited in Blok and Vijselaar, Terug naar Endegeest, 40. Translation: En daar wij, gestichtsgeneesheren, overigens therapeutisch zo goed als niets kunnen doen, moeten wij alles beproeven, hetgeen nog enig nut schijnt te doen.

6 Dwyer, Homes for the Mad, the chapter on the role of attendants.

7 Rafferty, The Politics of Nursing Knowledge, 30.

8 Nolan, "The Founding of Psychiatric Nurse Training"; Dingwall, Rafferty, and Webster, An Introduction to the Social History of Nursing, I23-44.

$9 \mathrm{JvMB}, \mathrm{1} 893,38, \mathrm{I4} 6$; 1912, 79.

Iо JvMB, I892, 20-27, 35; I900, 35-4I, 56; I9I0, I-I9, 75; I9I6, 24, 85.

II See also Nolan, "Psychiatric Nursing Past and Present”, I2 I-22, I77, I85-86.

I2 Wright, "Asylum Nursing”, , 65-6. 
I3 When in the early I920s rising costs of psychiatric care prompted psychiatrists of the Dutch Association of Psychiatry to look at possible budget cuts, they recommended that the salaries of student nurses be reduced considerably, leaving the salaries of graduate nurses at the same level, so that the wage structure would function as a stimulus to graduate. See Van der Scheer and Van der Hoeven, "Rapport betreffende bezuinigingen", 307-8. This measure was soon implemented in Meerenberg. See Een eeuw krankzinnigenverpleging 1849-1949, 266-67. See also Van Gemert and Spijker, Verdichtsel en werkelijkheid, 54 .

I4 JvMB, I908, 56-57; I9I7, 52.

I5 Van der Grinten, De vorming van de ambulante geestelike gezondheidszorg, 39-4I; Van der Scheer and Van der Hoeven, "Rapport betreffende bezuinigingen."

I6 Een eeuw krankzinnigenverpleging 1849-1949, 78-89; Kerkhoven, Beeld van de psychiatrie 1800-1970, I77-78.

I7 See Van der Grinten, Devorming van de ambulante geestelijke gezondheidszorg, 42-56.

I8 Vijselaar, Gesticht in de duinen, 279 



\section{List of Illustrations}

I. Provincial Asylum for the Insane Meerenberg near Amsterdam by G. J. Bos (drawing), Van Emrik \& Binger (lithograph) and J. J. Weeveringh (publisher). Lithograph, I86I (RANH inv. no. G[492.629.098.2]4).

2. Patients on bed rest in the observation ward with two nurses. Female department at the Franeker Asylum, ca. I900. Historical Photograph Collection, Psychiatric Hospital Franeker

3. Patient in a hydrotherapeutic wet pack, Meerenberg Asylum, ca. I900. (Historical photographs, Museum Meerenberg, Psychiatric Hospital Mentrum, Amsterdam. Courtesy of the Museum Geestelijke Gezondheidszorg (GGZ) Foundation, Utrecht.)

4. Patients and nurses in the department for prolonged bath treatment, Endegeest Asylum near Leiden, I907, by H. Jonker, photographer. (Historical photograph collection, Psychiatric Hospital Endegeest, Oegstgeest. Courtesy of the Museum GGZ Foundation, Utrecht.)

5. Jacob van Deventer lecturing mental nurses about three patients, Meerenberg Asylum, I897. Drawing by H. M. Krabbé, in an article “In Meerenberg” by C. K. Elout in Woord \& Beeld, June I897. (Historical collection, Museum Meerenberg, Psychiatric Hospital Mentrum, Amsterdam. Courtesy of the Museum GGZ Foundation, Utrecht.)

6. Three nurses attending a female patient suffering from an attack of hysteria, Pavilion III, Wilhelmina Gasthuis, Amsterdam, I907, by F.S. Meyers, psychiatrist. (Altrecht, Utrecht. Courtesy of the Museum GGZ Foundation, Utrecht.)

7. Father and Mother Vos, the steward and matron of the Franeker Asylum, their daughter and the head nurses of the male and female departments, most likely Baukje van Zuylen and Cornelia Wesselman, ca. I900. (Historical photograph collection, Psychiatric Hospital Franeker.) 
8. Early graduating class of the mental nurse training course at the Meerenberg Asylum, ca. I893. Antonia Wilhelmina van Deventer-Stelling, Jacob van Deventer's wife, is seated in the center in dark clothing. (Historical photographs, Museum Meerenberg, Psychiatric Hospital Mentrum, Amsterdam. Courtesy of the Museum GGZ Foundation, Utrecht.)

9. The Meerenberg nurses home for female mental nurses, Meerenberg Asylum, I904. (Historical photographs, Museum Meerenberg, Psychiatric Hospital Mentrum, Amsterdam. Courtesy of the Museum GGZ Foundation, Utrecht.)

Io.Pavilion father, mother and five male nurses, Veldwijk Asylum, ca. I89o (In G. A. Lindeboom and M. J. van Lieburg [Eds.]. Gedenkboek van de Vereniging tot Christelijke Verzorging van Geestes- en Zenuwzieken, 1884-1984, p. I31. Kampen: Kok, I984. Reprinted with permission.)

II. Female mental nurses at the Veldwijk Asylum, I9IO. (In G. A. Lindeboom and M. J. van Lieburg [Eds.]. Gedenkboek van de Vereniging tot Christelijke Verzorging van Geestes- en Zenuwzieken, 1884-1984, p. I28. Kampen: Kok, I984. Reprinted with permission.)

I2. Female nurse attending patients receiving prolonged bath treatment, Voorburg Asylum, I928. (Included in the Annual Report of the Voorburg Asylum, I928, Archives of the State Inspectors of the Insane and Insane Asylums I84I-I96I, inv. I57I, WVS, Rijswijk. Courtesy of the Museum GGZ Foundation, Utrecht.)

I3. Male nurse attending patients receiving prolonged bath treatment, Meerenberg Asylum, ca. I9I0. (Historical photographs, Museum Meerenberg, Psychiatric Hospital Mentrum, Amsterdam. Courtesy of the Museum GGZ Foundation, Utrecht.) 


\section{List of Abbreviations}

ACC Association for Christian Care (See VCV)

AG Archief van de Godshuizen (Archives of the Godshouses)

AHVZ Archief Haarlemse Vereniging voor Ziekenverpleging (Archives of the Association of Nursing at Haarlem)

AN Archief Nosokómos (Archive Nosokómos)

ANAB Algemene Nederlandse Ambtenaren Bond (Dutch League of Civil Servants)

ANBZ Archief Nederlandse Bond voor Ziekenverpleging (Archive of the Dutch Nurses' Association)

APZF Archief van het Psychiatrisch Ziekenhuis Franeker (Archives of the Psychiatric Hospital Franeker)

AS Archieven van de Inspecteurs van het Staatstoezicht op Krankzinningen and Krankzinningengestichten (Archives of the State Inspectors of the Insane and Lunatic Asylums)

ATC Archief van de Toezichthoudende Colleges over de Provinciale Ziekenhuizen in Noord-Holland (Archives of the Supervisory Colleges of the Provincial Hospitals in North Holland)

CBZ Christelijke Bond voor Ziekenverpleging (Christian Nurses' Association)

GA Gemeentearchief Amsterdam (Amsterdam Municipal Archives)

GAF Gemeentearchief Franeker (Franeker Municipal Archives)

GAH Gemeentearchief Haarlem (Haarlem Municipal Archives)

HAV Historisch Archief Veldwijk (Veldwijk Historical Archives)

HDNP Historisch Documentatiecentrum voor het Nederlands Protestantisme (Historical Documentation Center for Dutch Protestantism)

HVZ Haarlemse Vereniging voor Ziekenverpleging (Association of Nursing at Haarlem)

ICN International Council of Nurses

IISG Internationaal Instituut voor Sociale Geschiedenis (International Institute of Social History)

JvF Beredeneerd (Jaar)Verslag omtrent het Geneeskundig Gesticht voor Krankzinnigen te Franeker (Annual Report, Franeker)

JvMB (Jaar)Verslag betreffende het Gesticht "Meerenberg” (Annual Reports, Meerenberg)

JvVB Jaarverslag Voorburg (Annual Reports, Voorburg) 
JvVCV Jaarverslag der Vereniging tot Christelijke Verzorging van Krankzinnigen en Zenuwlijders in Nederland (Annual Reports of the Association for Christian Care of Insane and Nervous Patients in the Netherlands)

JvWV Jaarverslag van de WilhelminaVereniging (Annual Reports of the Wilhelmina Association)

MvZ Maandblad voor Ziekenverpleging (Journal of Nursing)

NBZ Nederlandse Bond voor Ziekenverpleging (Dutch Nurses' Association)

NCGV Nederlands Centrum Geestelijke Volksgezondheid (now called the Trimbos Instituut)

NCvT Notulen der vergadering van de Commissie van Toezicht over het gesticht Meerenberg (Minutes of the Supervisory Committee of the Meerenberg Asylum)

NVP Nederlandse Vereniging voor Psychiatrie (Dutch Association of Psychiatry)

NVPN Nederlandse Vereniging voor Psychiatrie en Neurologie (Dutch Association of Psychiatry and Neurology)

NVV Nederlandse Verplegers Vakvereniging (Dutch Male Nurses' Association)

MNVV Maandbladvan de Nederlandse Verplegers Vakvereniging (Journal of the Dutch Male Nurses' Association)

PB Psychiatrische Bladen (Journal of Psychiatry)

PNB Psychiatrische en Neurologische Bladen (Journal of Psychiatry and Neurology)

SH Stadsarchief 's-Hertogenbosch (City Archives of 's-Hertogenbosch [Den Bosch])

SV Stukken van de Vereniging tot Christelijke Verzorging (Documents of the Association for Christian Care)

RANH Rijksarchief Noord-Holland (State Archives in North Holland)

VCV Vereniging tot Christelijke Verzorging van Krankzinnigen en Zenuwlijders, later de Vereniging tot Christelijke Verzorging van Geestes- en Zenuwziekten, in Nederland (Dutch Association for the Christian Care of Insane and Nervous Patients, later called the Dutch Association for the Christian Care of Mental and Nervous patients)

WV Wilhelmina Vereniging (Wilhelmina Association)

WVS Ministerie van Welzijn, Volksgezondheid en Sport (Ministry of Welfare, Health and Sport) 


\section{List of Archives}

Gemeentearchief Amsterdam (Amsterdam Municipal Archives)

Archief Nosokómos, archief no. 134 (Archive Nosokómos)

Archief Vereniging voor Ziekenverpleging, archief no. 920 (Archives of the Association of Nursing)

Gemeentearchief Franeker (Franeker Municipal Archives)

Archief Psychiatrisch Ziekenhuis Franeker, I850-1920 (Archives of the Psychiatric Hospital Franeker)

Historisch Documentatiecentrum voor het Nederlands Protestantisme (I80o-heden), Vrije Universiteit, Amsterdam (Historical Documentation Center of Dutch Protestantism at the Free University of Amsterdam)

Archief van de Vereniging tot Christelijke Verzorging van Geestes- en Zenuwzieken (I884-I987), archief no. 50I (Archives of the Association for Christian Care)

Internationaal Informatiecentrum en Archief voor de Vrouwenbeweging, Amsterdam (International Information Center and Archive of the Women's Movement in Amsterdam)

Bibliotheekcollectie (Library collection)

Internationaal Instituut voor Sociale Geschiedenis, Amsterdam (International Institute of Social History)

Archief van de Bond van Directrices en Adjunct-directrices van Ziekeninrichtingen en Verenigingen van Ziekenverpleging, (I899-I966). (Archives of the Association of Women Directors and Deputy Women Directors of Hospitals and Nursing Associations )

Archief van de Nederlandse Bond voor Ziekenverpleging (1893-I963) (Archives of the Dutch Nurses Association)

Archief van de Algemene Nederlandse Ambtenaren Bond, afd. 's-Gravenhage (I9IoI9I8) (Archives of the Dutch League of Civil Servants, The Hague Branch) 
Ministerie van Welzijn, Volksgezondheid en Sport, Rijswijk (Ministry of Welfare, Health and Sport)

Archieven van de Inspecteurs van het Staatstoezicht op Krankzinnigen en Krankzinnigengestichten, I84I-I96I. (Archives of the State Inspectors of the Insane and Lunatic Asylums)

Psychiatrisch Ziekenhuis Mentrum, Amsterdam, locatie Santpoort (Psychiatric Hospital Amsterdam at Santpoort)

Museum Meerenberg

Psychiatrisch Ziekenhuis Franeker, locatie GrootLankum (Psychiatric Hospital Franeker, GrootLankum location)

Archief Psychiatrisch Ziekenhuis Franeker (Archives of the Psychiatric Hospital Franeker)

Psychiatrisch Ziekenhuis Reinier van Arkel, locatie Vught (Psychiatric Hospital Reinier van Arkel, Voorburg location)

Archief Voorburg (Archive Voorburg)

Psychiatrisch Ziekenhuis Veldwijk, Ermelo (Psychiatric Hospital Veldwijk in Ermelo)

Historisch Archief Veldwijk (Historical Archives of Veldwijk)

Rijksarchief Noord-Holland, Haarlem (State Archive of North Holland in Haarlem)

Archieven van de toezichthoudende colleges over de provinciale ziekenhuizen in Noord-Holland, I840/48-I944(I953), toegangsnummer I8I (Archives of the Supervisory Colleges of the Provincial Hospitals in North Holland)

Aanvulling op de archieven van de toezichthoudende colleges over de provinciale ziekenhuizen in Noord-Holland betreffende het Provinciaal krankzinnigengesticht Meerenberg, vanaf I9I8 Provinciaal Ziekenhuis nabij Santpoort, I847-I964, toegangsnummer 338 (Addition to the Archives of the Supervisory Colleges)

Archief van het Provinciaal Ziekenhuis nabij Santpoort I849-I99I, toegangsnummer 366 (Archives of the Provincial Hospital at Santpoort) 
Stadsarchief's-Hertogenbosch ('s-Hertogenbosch [Den Bosch] Municipal Archives) Archief van de Godshuizen, I8I5-I989. (Archive of the Godshouses)

Stichting Museum en Documentatiecentrum Geestelijke Gezondheidszorg (Museum GGZ), Historische Collectie, Nederlands Centrum Geestelijke Volksgezondheid (Trimbos Instituut), Utrecht (Historical Collection of the Museum of Mental Health at the Trimbos Institute)

Ramaer collectie

Meerenberg collectie

Medemblik collectie

Rijpperda Wierdsma collectie

Willem Arntsz Huis en Hoeve collectie

Universiteit van Amsterdam, bibliotheek (Library of the University of Amsterdam)

Jaarverslagen van de WilhelminaVereniging (I898-I9I5) (Annual Reports of the Wilhelmina Association)

Contemporary Journals

De Ambtenaar (I910-18)

Bethesda (1896-1920)

Maandblad voor Ziekenverpleging, later Tijdschrift voor Ziekenverpleging (I890-1921)

Maandblad van de Nederlandse Verplegers Vakvereniging (I907-I918)

Maandblad voor het Krankzinnigenwezen (continued as De Wilhelmina Gids) (I9I6-I9I8)

Nederlands Tijdschrift voor Geneeskunde (selected volumes, I890-I920)

Nosokómos (1900-I922)

Orgaan van de Christelijke Bond voor Ziekenverpleging (I904, I907-I9II)

Psychiatrische Bladen (1883-1896)

Psychiatrische en Neurologische Bladen (I897-I925)

Refájah (I9OI-I92I) 



\section{Bibliography}

Abel-Smith, B. A History of the Nursing Profession. London: Heinemann, I960. Ackerknecht, Erwin H. A Short History of Psychiatry. New York: Hafner, I968. Algra, H. Franeker stad met historie. Franeker: Wever, I983.

Baer, Ellen D. “Nursing's Divided House: A Historical View.” Nursing Research 34, no. I (1985): 32-38.

Bakker, Hilde, Leonie de Goei, and Joost Vijselaar. Thuis Opgenomen: Uit de geschiedenis van de Sociale Psychiatrie in Nederland. Utrecht: NCGV, I994.

Bakker-van der Kooij, Cora. "De maatschappelijke positie van verpleegsters in de periode I880-I940.” Tijdschrift voor Geschiedenis 90 (I983): 454-75.

Bakker-van der Kooij, Cora. "Nurses and Social Consciousness." Paper presented the Third Anglo-Dutch Conference on Occupations and Social Consciousness, Maastricht, I982.

Bakker-van der Kooij, Cora. "Mara. Pleegzuster zijn. Ontwikkelingen in de ziekenverpleging en de organisatiepogingen van verpleegsters in Nederland, 1870-1920." In Tweede jaarboek voor vrouwengeschiedenis, I93-221. Nijmegen: SUN, I981.

Baly, Monica E. Florence Nightingale and the Nursing Legacy. London: Croom Helm, I986.

Belzen, J. A. van. Psychopathologie en religie: Ideeën, behandeling en verzorging in de gereformeerde psychiatrie, 1880-1940. Kampen: Kok, I989.

Belzen, J. A. van, and Joost Vijselaar. “Dutch Psychiatry and Mental Health Care.” History of Psychiatry 2, no. 3 (I99I): 28I-88.

Benders, A. M. “De behandeling van krankzinnigen in het permanente bad.” Nosokómos (I9I5): 2I8-22, 233-37.

Bergh, Willem van der. “De oorzaken van krankzinnigheid.” JvVCV I (I884/85): 5I-64.

Berting, J. "In het brede maatschappelijke midden: de veranderende positie van de middengroepen in de Nederlandse samenleving tussen I850-I980.” In F. L. van Holthoon (Ed.), De Nederlandse samenleving sinds 1815: Wording en samenhang, II9-37. Assen: Van Gorcum, ig85.

Bie, Tineke de, and Wantje Fritschy. “De 'wereld' van Reveilvrouwen, hun liefdadige activiteiten en het ontstaan van het feminisme in Nederland.” In Jeske Reijs, Tineke van Loosbroek, Ulla Jansz, Maria Henneman, Annemarie de Wildt, and Mirjam Elias (Eds.), De eerste feministische golf: Zesde jaarboek voor vrouwengeschiedenis, 30-58. Nijmegen: SUN, I985.

Binneveld, J. M. W. Filantropie, repressie en medische zorg: Geschiedenis van de inrichtingspsychiatrie. Deventer: Van Loghum Slaterus, I985.

Binneveld, J. M. W., and M. J. van Lieburg. Psychiatric Reform in the Netherlands. Information bulletin no. 7. Center for the History of Society. Rotterdam: Erasmus Univ., I979.

Binneveld, J. M. W., and Rob Wolf. Een huis met vele woningen: Honderd jaar katholieke psychiatrie, 1885-1985. Den Bosch: Biblio, I985. 
Binneveld, J. M. W., C. Brinkgreve, A. J. Lameijn, H. F. M. Peeters, P. Vandermeersch, C. P. de Vos, and Joost Vijselaar. Een psychiatrisch verleden. Baarn: Ambo, I982.

Blok, Gemma. "Heropvoeden tot sociaal aangepast gedrag I9I8-I940." Utrecht: NCGV, I996. Photocopy.

Blok, Gemma. "Hersenverweking in Nederland: Het psychiatrisch vertoog over dementia paralytica, I844-I930." Master's Thesis in History, Univ. of Amsterdam, I995.

Blok, Gemma, and Joost Vijselaar. Terug naar Endegeest: Patiënten en hun behandeling in het psychiatrisch ziekenhuis Endegeest, 1897-1997. Nijmegen: SUN, I998.

Boekholt, P. Th. F. M. “De Nederlander Gaat Naar school.” In De Nederlandse samenleving sinds 1815: wording en samenhang, edited by F. L. van Holthoon, 203-23. Assen: Van Gorcum, I985.

Boer, Fré de. "Architectuur en krankzinnigen: De typologie van krankzinnigengestichten in de negentiende eeuw in Nederland." Akt 7, no. I (I983): 48-6o.

Boer, Fré de. "Van arbeiders onder krankzinnigen: Gereformeerden en krankzinnigen rond I900." Master's Thesis in History, Univ. of Groningen, I984.

Boerrigter, Broeder Edesius. Honderdvijftig jaar lang Broeders van Goede Werken: Een geschiedenis van de broeders van Onze Lieve Vrouwe van Lourdes, 1830-1980. Ronse: Congregatie van Broeders van O. L.V. van Lourdes, I980.

Boer, Herman W.J. de, and Gerard Pley. Grachtenzusters: Episoden uit honderdvijftigjaar Verenigingvoor Ziekenverpleging. Amsterdam: Prinsengrachtziekenhuis Amsterdam, I993.

Bor, H.van der. "Iets over de verpleging van krankzinnigen." NVV Io (I9I6): I53-58, I93-95.

Borkus, Marja, Thea Den Hartog, Henriette Lakmaker, Anja van Oostrom, and Dineke Stam. Vrouwenstemmen: 100 jaar vrouwenbelangen, 75 jaar vrouwenkiesrecht. Zutphen: Walburg Pers, I994.

Bosch Kemper, J. de. “De Meerenbergsche Zaak.” MvZ7, no. 6 (I897): I43-44.

Boschma, Geertje. "Evenwicht en Groei: De constructie van een verplegingswetenschappelijk domein in het werk van D. E. Johnson en H. E. Peplau.” Master's Thesis in Philosophy, Univ. of Groningen, I989.

Boschma, Geertje. "Agnes Karll and the Creation of an Independent German Nursing Association I900-I927." Nursing History Review 4 (I996): I5I-68.

Bouman, Leendert. "Een Christelijk Bond voor Ziekenverpleging?” Refájah I (I90I): I3235 .

Bouman, Leendert. "Is het stelsel van gehuwde verplegers wel aan te bevelen?” Bethesda 7 (July i90i): 169-76.

Bouman, Leendert. "Openingswoord uitgesproken in de oprichtingsvergadering van den Christelijke Bond voor Ziekenverpleging, 2 october I902.” Refájah 2 (I902/03): IIO-I6.

Bouwmeester, G. H. “Paedagogiek en Verpleging.” NVV6, no. 9 (September I9I2): 247-55.

Bras, P. N. “Aan Br. H. Kooistra over zijn lezing 'Verpleging van mannen door mannen.'” MNVV6, no. Io (October I9I2): 279-84.

Brinkgreve, C. "De zorg voor zenuwlijders in Nederland rond de eeuwwisseling en de opkomst van de psychoanalyse.” In J. W. M. Binneveld et al. (Eds.), Een psychiatrisch verleden, I8I-205. Baarn: Ambo, I982.

Broeder, Lea den, and Renée Schaap. "Het maatschappelijk moederschap van Meta Kehrer, de eerste hoofdinspectrice bij de Amsterdamse zedenpolitie.” Lover I5, no. 2 (I988): 83-88.

Brosius, Dr. A. “S. Weir Mitchell's Systeem bij de behandeling van Neurosen.” PB 4 (I886): 2I5-22; 5 (I887): 97-I06. 
Callenbach, J. R. Friedrich Von Bodelswingh. Nijkerk: Callenbach, I930.

Cappelle, H. van. "Het toenemen der bevolking van de Krankzinnigen-gestichten in Nederland.” PB I (I883): 5-I3.

Carpenter, Mick. "Asylum Nursing before I9I4: A Chapter in the History of Labour." In Rewriting Nursing History, edited by Celia Davies, I23-46. London: Croom Helm, I980.

Castel, R. L'ordre psychiatrique: L'age d'or de l'alienisme. Paris: Minuit, I976.

Church, Olga M. "Emergence of Training Programs for Asylum Nursing at the Turn of the Century." Advances in Nursing Science 7, no. 2 (I985):35-46.

Church, Olga M. "From Custody to Community in Psychiatric Nursing." Nursing Research 36, no. I (I987): 48-55.

Church, Olga M. "That Noble Reform: The Emergence of Psychiatric Nursing, I880I963." Ph.D. diss., Univ. of Illinois, I982.

Cowan, F. M. “Over de verplegingsquaestie.” PB 9 (I89I): 29I-95.

Cox, W. H. "De algemene ontwikkeling der candidaten voor het diploma der Nederl.Ver. voor Psychiatrie en Neurologie, met eenige opmerkingen over het lager onderwijs." PNB 7 (1903): 273-84.

Cox, W. H. “De Verpleegsters-kwestie.” PNB 2 (I898): 234-42.

Cox, W. H. "Idealen in de Krankzinnigenverzorging, mede in verband met het Instituut Schuurmans Stekhoven." PNB 2I (I9I7): 53-70.

Cox, W. H., S. Reeling Brouwer, L. S. Meijer, J. C. I. Van der Hagen, and Th. E. Frijlinck. "Kort overzicht der gebeurtenissen in zake de reorganisatie van het examen, in verband met de voorstellen der Examen-Commissie op de Zomer-Vergadering van I903." PNB 7 (I903): 290-316.

Cox, W. H., S. Reeling Brouwer, L. S. Meijer, J. C. I. Van der Hagen, and Th. E. Frijlinck. "Rapport der Examen-Commissie van de NVP over het jaar I9OI-I902." PNB 6 (I902): $379-85$.

Cox, W. H., S. Reeling Brouwer, L. S. Meijer, J. C. I. Van der Hagen, and Th. E. Frijlinck. "Rapport der Examen-Commissie van de NVP over het jaar I902-I903." PNB 7 (I903): 285-89.

Curwen, John. Handleiding voor Oppassers in Gasthuizen voor Krankzinnigen. Translated and revised by F. A. Hartsen. Utrecht: Kemink \& Zn, I862. Museum GGZ, Medemblik Collectie, G2o.

D’Antonio O'Brien, Patricia. "Negotiated Care: A Case Study of the Friends Asylum, I800-I850." Ph.D. diss., Univ. of Pennsylvania, Philadelphia, I992.

Dale, J. H. A. van. “De Personeelquaestie.” Refájah 5, no. 7 (January i906): 145-52.

Dale, J. H. A. van. “De toestand van ons verpleegpersoneel.” Bethesda 6 (I901):52-58.

Davies, Celia (Ed.). Rewriting Nursing History. London: Croom Helm, I980.

Delden, B. van. Onze krankzinnigen en hunne verpleging. Utrecht: Honig, I897.

Deutsch, A. The Mentally Ill in America. New York: Doubleday, I937.

Deventer, J. van. “Bijdrage tot de leer der waanzin op neurastenischen bodem." In Feestbundel der Nederlandsche Vereeniging voor Psychiatrie ter eere van haar 25-jarig bestaan, I73-86. Den Bosch: Teulings, I896.

Deventer, J. van. "Cursus in Krankzinnigen-verpleging." Manuscript in two parts, I892. Museum GGZ, Medemblik Collection, G22, G23.

Deventer, J. van. "De eischen eener goede Krankzinnigen-Verpleging." Parts I and 2. $M v Z$ I, no. I (September I89o): 2-8; no. 2 (October I890): I-8. 
Deventer, J. van. “De organisatie der krankzinnigengestichten.” PNB 9 (I905): 4I2-20.

Deventer, J. van. “De voorbereidende opleiding der verplegenden.” $M v Z$ I3, no. 9 (I903): I52-55.

Deventer, J. van. “Eenige opmerkingen over de psychische behandeling van krankzinnigen.” PB 7 (I888): 20-3I.

Deventer, J. van. "Eenige beschouwingen over krankzinnigenverpleging." PB Iо (I892): 232-5I.

Deventer, J. van. “Examen in de krankzinnigenverpleging.” PB Iо (I892): 2 I8.

Deventer, J. van. Handboek der krankzinnigenverpleging. Amsterdam: Van Heteren, I897.

Deventer, J. van. "Het Wilhelmina-fonds.” PNB I (I897): 2 II-I3.

Deventer, J. van. “In Memoriam Dr. A. O. H. Tellegen.” PB 8 (I904): 776-77.

Deventer, J. van. "Isoleren of niet isoleren." PB XIV (I896): I9-23.

Deventer, J. van. Krankzinnigenverpleging in de eerste helft der vorige eeuw. Amsterdam: Van Heteren, I90I.

Deventer, J. van. “Reactie op S. A. van der Chijs.” $M v Z$ I, no. II (July I89I): 4.

Deventer, J. van. “Te groote gestichten.” PB I0 (I89I): I99-204.

Deventer, J. van. “Vrije Verpleging.” PNB 5 (I901): 48-51.

Deventer, J. van, J. C. van der Hagen, A. Couvée, J. H. A. van Dale, and J. C. Th. Scheffer. "Rapport omtrent den actueelen toestand van het verplegend personeel in de Nederlandse krankzinnigengestichten." Originally in PNB 5 (I9OI): I03-88. Reprinted: I9OI. Museum GGZ, Ramaer Collection, RAM I696, I-96. Trimbos Institute, Utrecht.

Deventer, J. van, J. F. Plet, C. J. Marcus, A. M. Benders, and N. J. A. Francken. "Rapport van de commissie belast met het onderzoek naar de positie van geneesheren in krankzinnigengestichten in Nederland." Originally in PNB 5, I9०9. Reprinted: I909. Museum GGZ, Ramaer Collection, RAM I657, I-I7. Trimbos Institute, Utrecht.

Deventer, J. van, J. H. A. Van Dale, A. O. H. Tellegen, Trijlinck, and Le Rütte. "Rapport omtrent het isoleervraagstuk." I902. Museum GGZ, Ramaer collection, RAM-I680.

Deventer, J. van, J. H. A. van Dale, and W. Vos. Over gezinsverpleging van krankzinnigen. Amsterdam: F. van Rossen, I902.

Deventer, J. van, W. P. Ruysch, and A. O. H. Tellegen. "De verbetering van het verplegend personeel in de Nederlandse krankzinnigengestichten.” PB 8, no. I (I890): 222-36.

Digby, Anne. Madness, Morality, and Medicine: A Study of the York Retreat, 1796-1914. Cambridge: Cambridge Univ. Press, I985.

Digby, Anne. "Quantitative and Qualitative Perspectives on the Asylum." In Problems and Methods in the History of Medicine, edited by Roy Porter and Andrew Wear, 153-74. London: Croom Helm, I987.

Dingwall, Robert, Anne Marie Rafferty, and Charles Webster. An Introduction to the Social History of Nursing. London: Routledge, I988.

Dingwall, Robert, Anne Marie Rafferty, and Charles Webster. "Mental Disorder and Mental Handicap." In by Robert Dingwall, Anne Marie Rafferty, and Charles Webster (Eds.), An Introduction to the Social History of Nursing, I23-44. London: Routledge, 1988.

"Discussie over de stellingen van de heer Van Deventer, tijdens de NVP vergadering van I4-6-i888." PB 6 (I888).

Dommisse, Fré. Krankzinnigen. Rotterdam: Brusse, I929.

Donkersloot, N.B. Raadgevingen aan Oppassers en Bedienden in Krankzinnigen-gestichten. Dordrecht: Geneeskundig gesticht voor krankzinnigen, 1865 .

Doorn, J. A. A. van. “De strijd tegen armoede en werkloosheid in historisch perspectief." 
In Van particuliere naar openbare zorg en terug?, edited by W. P. Blockmans and L. A. van der Valk, I-30. Amsterdam: Neha, I992.

Dörner, K. Bürger und Irre. Munich: Europäische Verlaganstalt, I969.

Drenth, Annemieke van, and Francisca de Haan. The Rise of Caring Power: Elizabeth Fry and Josephine Butler in Britain and the Netherlands, Amsterdam: Amsterdam Univ. Press, I999. .

Drinka, G. F. The Birth of Neurosis. New York: Simon \& Schuster, I984.

Drosterij, C. "Philantropie en Vakverpleging." MNVV ıо (І9І6): I20-2I.

Duyvendak, Maarten, and Pim Kooij. Sociale Geschiedenis: Theorie en Thema's. Assen: Van Gorcum, i992.

Duyvesteyn, C. Historisch overzicht provinciaal geneeskundig gesticht voor krankzinnigen Meerenberg. Haarlem: Tjeenk Willink, I897.

Dwyer, Ellen. Homes for the Mad: Life Inside Two Nineteenth-Century Asylums. New Brunswick, USA: Rutgers Univ. Press, I987.

Dwyer, Ellen. “Stories of Epilepsy I880-I930.” In Charles E. Rosenberg and Janet Golden (Eds.), Framing Disease: Studies in Cultural History, 248-72. New Brunswick, USA: Rutgers Univ. Press, I992.

Ederveen, Francis. "Niet voor rede vatbaar: Beeld en behandeling van de geestesgestoorden in de stad Groningen, I605-I702.” Master's Thesis in History, Univ. of Groningen, I987.

Een eeuw krankzinnigenverpleging 1849-1949: Gedenkboek ter gelegenheid van het honderdjarig bestaan van het Provinciaal Ziekenhuis nabij Santpoort. Santpoort: Provinciaal Ziekenhuis, I949.

Eijk-Osterholt, Corrie van, and Kurt Bökenkamp. Wartaal van een Gek: Het schokkende verhaalvan Johanna Stuten-te Gempt. The Hague: Kruseman's Uitgeverij, I983.

Eijt, José. Religieuze vrouwen: Bruid, moeder, zuster: Geschiedenis van twee Nederlandse zustercongregaties, 1820-1940. Hilversum: Verloren, I995.

Eijt, José. “Zindelijkheid en Zuinigheid: De voorbeeldfunctie van vrouwelijke religieuzen in de ziekenverpleging gedurende de negentiende eeuw." Gewina I6, no. 2 (I993): 80-91.

Ellemers, J. E. “Pillarization as a Process of Modernization.” Acta Politica I9, no. I (I984): I29-44.

Esch, P. van der. Geschiedenis van het Staatstoezicht op Krankzinnigen. 3 vols. Leidschendam: Ministerie van Vomil, I975-80.

Esch, P. van der. “Jacob van Deventer." Tijdschrift Voor Ziekenverpleging 4, no. I2 (I95I): 313I4.

Essen, Mineke van. Onderwijzeressen in niemandsland: Vrouwen in opvoeding en onderwijs. Nijkerk: Intro, I985.

Essen, Mineke van. Opvoeden met een dubbel doel: Twee eeuwen meisjes onderwijs in Nederland. Amsterdam: SUA, I990.

Feestbundel van de Nederlandse Vereniging voor Psychiatrie ter ere van haar 25-jarig bestaan. Den Bosch: Teulings, I896.

Foucault, Michel. Madness and Civilization: A History of Insanity in the Age of Reason. New York: Pantheon, I965. 
Garmanikow, Eva. “Nurse or Woman: Gender and Professionalism in Reformed Nursing, I860-I923." In Anthropology and Nursing, edited by Pat Holden and Jenny Littlewood, II0-29. London: Routledge, I99I.

Gemert, Victor van, and Truus Spijker. Verdichtsel en werkelijkheid: Een verkennende studie van de ambivalentie ten opzichte van zorgen en verzorgen in de verpleging. Lochem: De Tijdstroom, I982.

Gempt, Johanna te. Mijne Ervaringen in het Krankzinnigengesticht te 's-Gravenhage. The Hague: Hoekstra, 1892.

Geneeskundige gids: Adresboek voor Nederland. Brussels: A. Gosse \& Cie, 1903/1904.

Ginzberg, Lori D. Women and the Work of Benevolence: Morality, Politics, and Class in the Nineteenth-Century United States. New Haven: Yale Univ. Press, I990.

Goei, Leonie de. "I900-I924, de oprichting van de Nederlandse Vereniging tot bevordering der geestelijke volksgezondheid." Utrecht: NCGV, I996. Photocopy.

Goei, Leonie de. Notitie betreffende een reglement voor behoud van historische patientendossiers. Utrecht: NCGV, I989.

Goffmann, E. Asylums: Essays on the Social Situation of Mental Patients and Other Inmates. New York: Doubleday, I96I.

Goudswaard, N. B. Inleiding tot de geschiedenis van de verpleegkunst. Rotterdam: Erasmus, I994.

Grinten, Tom van der. De vorming van de ambulante geestelijke gezondheidszorg: Een historisch beleidsonderzoek. Baarn: Ambo, i987.

Grob, Gerald. Mental Illness and American Society 1875-1940. Princeton: Princeton Univ. Press, 1983.

Grob, Gerald. Mental Institutions in America: Social Policy to 1875. New York: Free Press, I973.

Groot, A. de. Veldwijk in verleden tijd: De eerste 50 jaar van Psychiatrische Ziekenhuis Veldwijk te Ermelo. Harderwijk: Wedding, I976.

Hamilton, Diane. "Constructing the Mind of Nursing." Nursing History Review 2 (I994): $3-28$.

Harmsen, Ger. “De Arbeiders en hun Vakorganisaties.” In F. J. Holthoon (Ed.), De Nederlandse samenleving sinds 1815, 26I-82. Assen: Van Gorcum, 1985.

Haw, Camilla M. “John Conolly's Attendants at the Hanwell Asylum I839-I852." History of Nursing Society Journal 3, no. I (1990): 26-58.

Hecker, E. Gids voor de huisgenooten van krankzinnigen voor tijdens en na de verpleging dezer lijders in een gesticht. Translated from German by Dr. C. P. ter Kuile, with a preface by Dr. A. H. van Andel. Enschede: Van der Loef, ı877. Museum GGZ, Medemblik Collectie, $\mathrm{G}_{3} 8$.

Heemstra, M. J. barones van. Honderdjarig bestaan van de psychiatrische inrichting te Franeker 1851-1951. Leeuwarden: Jongbloed, I95I.

Hermanides, S. R. “Het wezen der krankzinnigheid.” JvVCV 2 (I885/86): 58-9I.

"Het gesticht te Zutphen: Uit het verslag van de toestand van het geneeskundig gesticht voor krankzinnigen te Zutphen over het jaar I 890 door den eersten geneesheer dr. Van der Chijs." PB 9 (I89I).

Heyrman, Eug. Gedenkboek bij de eeuwfeestviering van de congregatie der Zusters van Barmhartigheid van Ronse 1845-1945. Gent: Claeys-Vergheughe, I946.

Holthoon, F. L. van. “De armenzorg in Nederland.” In F. L. van Holthoon (Ed.), De Neder- 
landse samenleving sinds 1815: Wording en samenhang, I75-86. Assen: Van Gorcum, I985. Holthoon, F. L. van. Mensen in Europa: Ontwerp voor een sociale geschiedenis van Europa na 1750. Alphen a/d Rijn: Samson, I977.

Hoogt, M. J. van der. Handleiding voor de geestelijke verzorging van krankzinnigen. Kampen: Kok, 1908.

Hoogt, M. J. van der. “Ons Zusterhuis ‘De Boschhoek.” Bethesda 5 (1900): 147-49.

Hoogt, M. J. van der. “Onze huisvaders en -moeders.” Bethesda 3 (I898/99): 35-37.

Hoogt, M. J. van der. "Reglement voor de Opleiding van Verpleegpersoneel in de drie Stichtingen der Vereniging." Bethesda 6 (I901): 6-9.

Houwaart, E. S. De hygiënisten: Artsen, staat en volksgezondheid in Nederland, 1840-189o. Groningen: Historische Uitgeverij, I99I.

Hughes, John S. "Country Boys Make the Best Nurses: Nursing the Insane in Alabama I86I-I910.” Journal of the History of Medicine 49 (I994): 79-106.

Hunter, R., and I. McAlpine. Three Hundred Years of Psychiatry. Oxford: Oxford Univ. Press, I963.

Hutschemaekers, G. J. M. Neurosen in Nederland: Vijfentachtig jaar psychisch en maatschappelijk onbehagen. Nijmegen: Sun, I990.

Instructiën en verordeningen betreffende het beheer van het gesticht voor behoeftige krankzinnigen te Franeker 1850-1886. Franeker: Koksma, I886. Museum GGZ Medemblik Collectie, G3o.

Jaarverslag der Vereniging tot Christelijke Verzorging van Krankzinnigen en Zenuwlijders in Nederland 1884-1920. 37 vols. Den Bosch: Schneijder \& Broekhuis, I885-I92I.

Jaarverslag van de Wilhelmina Vereeniging. I8 vols. The Hague: Wilhelmina Vereniging, I898-igi4.

Jak, Theo. Armen van Geest: Hoofdstukken uit de geschiedenis van de Nederlandse Zwakzinnigenzorg. Amsterdam: Jacob van Campen, I988.

Jak, Theo. Huizen van Barmhartigheid: Zorg voor zwakzinnigen in Nederland in de tweede helft van de negentiende eeuw met bijzondere aandacht voor 's Heeren Loo. Ermelo: Vereniging 's Heeren Loo, I993.

Janssens, G. "De behandeling en verpleging van onrustige en opgewekte krankzinnigen." $M v Z$, I7, no. I (I907): 52I-34.

Jansz, Ulla. Denken over sekse in de eerste feministische golf. Amsterdam: Van Gennep, I990. Jelgersma, G. “Het ontbreken van het corpus callosum in de hersenen.” PB 8 (I890): 32.

Jelgersma, G. Leerboek der psychiatrie. Amsterdam: Scheltema \& Holkema, I9II.

Jelgersma, G. "Nieuwe proeven over localisatie van functiën de groote hersenen." Nederlands Tijdschrift voor Geneeskunde (1887): 4I.

Jelgersma, G. “Zenuw-inrichtingen.” PNB I (I897): I85-9I.

Jones, C. The Charitable Imperative: Hospitals and Nursing in Ancien Regime and Revolutionary France. London: Routledge, I989.

Jonge, J. A. de. De Industrialisatie in Nederland tussen 1850 en 1914. Nijmegen: SUN, I976.

Jonge, J. A. de. Geschiedenis van het moderne Nederland: Politieke, economische en sociale ontwikkelingen. Houten: De Haan, I988.

Jongmans, J. W. M. De Zusters van Coudewater: Geschiedenis van het klooster van de Zusters van Barmhartigheid te Rosmalen 1870-1985. Rosmalen: Coudewater, I985.

“Jubileum Mw. Kassies.” Refájah I4 (I9I4/I5): 88-96. 
Kappelhof, A. C. M. Reiniervan Arkel 1442-1992. Den Bosch: PZ Reinier van Arkel, I992.

Kappelhof, Ton, and Rob Wolf. "Patientendossiers: een verwaarloosde categorie van archiefstukken.” Nederlands Archievenblad 89 (I985): I69-80.

Kappers, J. H. “In memoriam Henriëtte Koffijberg.” Refájah 18, (1918/19): 75-79.

Kappers, J. H. “Nederl. Verplegers-Vakvereniging.” Orgaan van de Chr. Bond voor Ziekenverpleging 4, no. I (January I907): 23.

Kemper, J. de Bosch. “De Meerenbergsche Zaak.” MvZ7, no. 6 (I897): I43-44.

Kerkhoven, Annemarie. Beeld van de psychiatrie 1800-1970. Zwolle: Waanders, I996.

Kerkhoven, Annemarie, and Joost Vijselaar. "De zorg voor zenuwlijders rond I9०o." In Giel Hutschemaekers and Christoph Hrachovec (Eds.), Heer en heelmeester: negentig jaar zorg voor zenuwlijders 1903-1993, 27-58. Nijmegen: SUN, I993.

Klijn, Annemieke. Tussen caritas en psychiatrie: Lotgevallen van zwakzinnigen in Limburg 1879-1952. Hilversum: Verloren, I995.

Knight, Denise D. (Ed.). “The Yellow Wall-Paper” and Other Selected Stories of Charlotte Perkins Gilman. Newark: Univ. of Delaware Press, I994.

Koffijberg, Henriëtte. "Lessen in de Beginselen der Krankzinnigenverpleging voor de Leerlingen van de Vooropleidingschool voor Verpleegsters van 'Veldwijk': 'Berkenhof' door Zr. H. Koffijberg.” I909. Manuscript, HAV, PZ Veldwijk, Ermelo.

Kolk, J. van der. "Over bedbehandeling in de krankzinnigengestichten.” PNB 20 (I9I6): $477-87$.

Kooij, Cora H. van der. “I890-I990, De vermaatschappelijking van de zorg.” In Honderd jaar verplegen: Een bijsluiter over gisteren met een opening naar morgen, edited by A. H. M. van den Bergh-Braam, Cora H. van der Kooij, and A. E. W. M. van de Pasch, I3-64. Lochem: De Tijdstroom, I99०.

Kooij, Cora H. van der. Mans die moeten hier ter sijden: De organisaties van verplegend personeel in Nederland in de periode 1880-1930. Master's Thesis in History, Univ. of Utrecht, I979. Revised, unpublished manuscript, I990.

Kossman, E. H. De Lage Landen 1780-1980: Twee eeuwen Nederland en Belgie. Deel I (Vol. I) I780-I9I4. Amsterdam: Agon, I986.

Kramer, F. Geschiedenis van de zorg voor geesteszieken. Lochem: De Tijdstroom, I990.

Kraus, Gerard. Krankzinnigheid in Nederland. Groningen: Wolters, I933.

Kruif, J. de. "De prijs van de armenzorg." Tijdschrift voor Sociale Geschiedenis 20, no. I (I994): 24-5I.

Kruse, A. P. Die Krankenpflegeausbildung seit der Mitte des 19. Jahrhunderts. Stuttgart: Kohlhammer, I987.

Kuyk, Gerritje. “Correspondentie.” MvZ I, no. I2 (August I89I): I4.

Laarse-de Bruin, Ada van der. "Veranderingen in de Krankzinnigenverpleging van I88oI970.” Master's Thesis in Historical Psychology, Catholic Higher Professional School, Tilburg, I98I.

Laat, F. C. M. de. "Van psychiatrisch verpleegkundige tot ...?": Een historisch overzicht van de ontwikkelingen rond psychiatrische verpleegkunde.” Master's Thesis in Social Psychology, Univ. of Amsterdam, I984.

Lagemann, Ellen C. (Ed.). Nursing History: New Perspectives, New Possibilities. New York: Teacher's College Press, i983.

Lanschot-Hubrecht, J. C. van. Het vakonderwijs in de ziekenverpleging. Amsterdam: Van Looij, I909. 
Lanschot-Hubrecht, J. C. van. “Report.” American Journal of Nursing I7, no. 9 (I9I7): 8I2I4.

Lanschot-Hubrecht, J. C. van. “The Present Conditions of Instruction for Nurses in Holland." American Journal of Nursing 8, no. 4 (1908): 274-79.

Lanschot-Hubrecht, J. C. van. Waarom is een wettelijke regeling van opleiding en examens voor verplegenden van staatswege dringend nodig? Amsterdam: Vereniging tot verkrijging van een wettelijke regeling van opleiding en examens voor ziekenverpleegsters en verplegers, I909.

Legemaate, Johannes. De rechtspositie van vrijwillig opgenomen psychiatrische patienten. Arnhem: Quint, I99I.

Lieburg, M. J. van. Bronovo 1865-1990: Van 's-Gravenhaagsche Diakonessen-Inrichting tot Ziekenhuis Bronovo. Kampen: Kok, I990.

Lieburg, M. J. van, and Hilary Marland. "Midwife Regulation, Education, and Practice in the Netherlands during the Nineteenth Century." Medical History 33 (I989): 296-3I7.

Lijphart, Arend. Democracy in Plural Societies: A Comparative Exploration. New Haven: Yale Univ. Press, I977.

Lijphart, Arend. The Politics of Accommodation: Pluralism and Democracy in the Netherlands. 2nd ed. Berkeley: Univ. of California Press, I975.

Lindeboom, G. A., and M. J. van Lieburg. Gedenkboek van de vereniging tot christelijke verzorging van geestes- en zenuwzieken, 1884-1984. Kampen: Kok, I984.

Lindeboom, Lucas. "De arbeiders onder krankzinnigen en zenuwlijders: hoedanige personen er noodig zijn en hoe het benoodigde aantal voortdurend te verkrijgen?" JvVCV 6 (I889/90): 48-57.

Lindeboom, Lucas. "De betekenis van het christelijk geloof voor de geneeskundige wetenschap, in het bijzonder voor de psychiatrie." JvVCV 3 (I886/87): 47-84.

Loo, L. Frank van. “Den arme gegeven...”: Een beschrijving van armoede, armenzorg en sociale zekerheid in Nederland 1784-1965. Meppel: Boom, I987.

Lynaugh, Joan E. "From Respectable Domesticity to Medical Efficiency: The Changing Kansas City Hospital, I875-I920.” In Diana E. Long and Janet Golden (Eds.), The American General Hospital: Communities and Social Contexts, 2I-39. Ithaca: Cornell Univ. Press, I989.

Lynaugh, Joan E., and S. Reverby. "Thoughts on the Nature of History." Nursing Research 36, no. I (1987): 4, 69.

MacDonald, Michael. "The Medicalization of Suicide in England: Laymen, Physicians, and Cultural Change, I500-I870.” In Charles E. Rosenberg and Janet Golden (Eds.), Framing Disease: Studies in Cultural History, 85-103. New Brunswick, USA: Rutgers Univ. Press, I992.

Maggs, Christopher J. The Origins of General Nursing. London: Croom Helm, I985.

Marland, Hilary (Ed.). The Art of Midwifery: Early Modern Midwives in Europe. London: Routledge, I993.

McPherson, Kathryn. Bedside Matters: The Transformation of Canadian Nursing, 1900-1990. Toronto: Oxford Univ. Press, I996.

McPherson, Kathryn, Cecilia Morgan, and Nancy M. Forestell. "Introduction: Conceptualizing Canada's Gendered Pasts.” In Kathryn McPherson, Cecilia Morgan, and Nancy M. Forestell (Eds.), Gendered Pasts: Historical Essays in Femininity and Masculinity in Canada, I-II. Don Mills: Oxford Univ. Press, I999. 
Meij-de Leur, A. P. M. van der. Van Olieen Wijn: Geschiedenis van verpleegkunde, geneeskunde en sociale zorg. Amsterdam: Elsevier, I98I.

Meinema, Th. Over Gezinsverpleging van Geesteszieken. Antonia Wilhelmina Fonds, I922.

Melosh, Barbara. “The Physician's Hand”: Work Culture and Conflict in American Nursing. Philadelphia: Temple Univ. Press, I982.

Melster, E. J. A. Mishandelingen ondervonden in het "Oude en Nieuwe Gasthuis": Geneeskundig Gesticht voor Krankzinnigen te Zutfen. Enschede: Van der Loef, I899.

Mooij, Annet. Geslachtsziekten en besmettingsangst: Een historisch-sociologische studie 1850-1990. Meppel: Boom, I993.

Moore, J. A Zeal of Responsibility: The Struggle for Professional Nursing in Professional England, 1868-1883. London: Univ. of Georgia Press, I988.

Naber, Johanna W. A. Het leven en werken van Jeltje de Bosch Kemper. Haarlem: Tjeenk Willink, I9ı8.

Neisser, C. Ueber die Bettbehandlung der akuten Psychosen. Munich: Sitz \& Schauer, I900.

Nelson, Sioban. "Entering the Professional Domain: The Making of the Modern Nurse in I7th Century France." Nursing History Review 7 (I999): I7I-87.

Nolan, Peter. A History of Mental Health Nursing. London: Chapman \& Hall, I993.

Nolan, Peter. "Psychiatric Nursing Past and Present: The Nurses' Point of View." Ph.D. diss., Univ. of Bath, England, I989.

Nolan, Peter. "The Founding of Psychiatric Nurse Training and Its Aftermath." British Journal of Psychiatry I59 (I99I): 46-52.

Noordman, J. M. A. Om de kwaliteit van het nageslacht: Eugenetica in Nederland 1900-1950. Nijmegen: SUN, I989.

Notten, J. W. A. De geesteskranke en zijne behandeling. Nijkerk: Callenbach, I894.

Nutting, M. Adelaide, and Lavinia L. Dock. History of Nursing. 4 vols. New York: Putnam, I907-I2.

O'Brien, Patricia. "All a Woman's Life Can Bring: The Domestic Roots of Nursing in Philadelphia, I830-I885." Nursing Research 36, no. I (1987): I2-I7.

Onrust, Marjan. "Waanzin gevangen: Over de gebouwde vorm van de opsluiting van waanzin." Master's Thesis in Sociology, Univ. of Amsterdam, I993.

Oosterhof, Hanneke. Het Apeldoornse Bosch: Joodse psychiatrische inrichting 1909-1943. Heerlen: De Voorstad, 1989.

Oosterwijk Bruijn, W. van. "Het huisgezin en de krankzinnigheid.” JvVCV 4 (I887/88): 44-6r.

Opleiding en examens van verplegenden: Rapport uitgebracht door den centralen gezondheidsraad. The Hague: Gebr. Belinfante, I9II.

Os, M. van, and W. J. Wierenga (Eds.). Wetenschap en rekenschap, 1880-1980: Een eeuw wetenschapsbeoefening aan de Vrije Universiteit. Kampen: Kok, I980.

Over Instellingen tot Verpleging van Zieken met een Verslag van de Oprigting der Vereeniging tot Ziekenverpleging te Amsterdam uitgegeven vanwege het Bestuur. Amsterdam: Van Heteren, 1845 .

Parry-Jones, William L. “The Model of the Gheel Lunatic Colony and Its Influence on the Nineteenth-Century Asylum System in Britain." In Madhouses, Mad-doctors, and Mad- 
men: The Social History of Psychiatry in the Victorian Era, edited by Andrew Scull, 20 I-I7. London: Athlone Press, I98I.

Peeters, H. F. M., and C. F. de Vos. "Historische fasen in aard en behandeling van geesteszieken.” In Een psychiatrisch verleden, by J. M. W. Binneveld et al., II-25. Baarn: Ambo, I982.

Peeters, H. F. M., M. Kuilman, E. J. Bijnen, and L. de Vos. "Historische veranderingen in aard en behandeling van geestesziekten: Een exploratief kwantitatief onderzoek in het psychiatrisch ziekenhuis Voorburg te Vught, I885-I977.” Utrecht: Trimbos Insitute, I980. Mimeographed.

Peplau, Hildegard. "Future Directions in Psychiatric Nursing from the Perspective of History." Journal of Psychosocial Nursing 27, no. 2 (1989): 18-28.

Persijn, C. J. van. “Ter Herinnering aan Dr. B. H. Everts, Oud-Directeur van Meerenberg.” PB I (I883): I37-45.

Peters, U. H. “The German Classical Concept of Schizophrenia.” In John G. Howells (Ed.), The Concept of Schizophrenia: Historical Perspectives, 63-7I. Washington: American Psychiatric Press, I99I.

Pleij, Gerard. "Uit beschaafde nood geboren: De Algemene Nederlandsche VrouwenVereniging Tesselschade.” In Tweede Jaarboek voor vrouwengeschiedenis, 46-79. Nijmegen: SUN, i98I.

Poldervaart, Saskia. Vrouwenstudies: Een inleiding. Nijmegen: SUN, I985.

Poplin, Irene Schuessler. “A Study of the Kaiserswerth Deaconess Institutes' Nurse Training School in I850-1851: Purposes and Curriculum.” Ph.D. diss., Univ. of Texas at Austin, I988.

Porter, Roy. A Social History of Madness. London: Weidenfeld \& Nicolson, I987.

Porter, Roy. "Shaping Psychiatric Knowledge: The Role of the Asylum." In Roy Porter (Ed.), Medicine in the Enlightenment, 255-73. Amsterdam: Rodopi, I995.

"Preadvies in zake aansluiting aan den Nederlandse Bond voor Ziekenverpleging door de Examen-Commissie." PB I3 (1895): 70-78.

Querido, A. Het Wilhelmina Gasthuis. Lochem: De Tijdstroom, I966.

Querido, A. Krankzinnigenrecht. Haarlem: Bohn, I939.

Qvarsell, Roger. "Locked Up or Put to Bed: Psychiatry and the Treatment of the Mentally Ill in Sweden, I800-I920.” In The Anatomy of Madness: Essays in the History of Psychiatry, edited by W. F. Bynum, Roy Porter, and Michael Shepherd, vol. II, 86-97. London: Travistock, 1985 .

Rafferty, Anne Marie. “The Politics of Nursing Education I860-I948.” Ph.D. diss., Univ. of Oxford, England, I991.

Rafferty, Anne Marie. The Politics of Nursing Knowledge. London: Routledge, I996.

"Reglement voor de Opleiding van Verpleeg-personeel in de drie gestichten der Vereniging." JvVCVI895/96: Bijlage I.

Regt, Ali de. Arbeidersgezinnen en beschavingsarbeid: Ontwikkelingen in Nederland 1870-1940: Een historisch-sociologische studie. Meppel: Boom, I986.

Reijnders, J. “De verplegerskwestie.” $M v Z$, I3, no. 5 (I903): 75-77.

Reverby, Susan M. Ordered to Care: The Dilemma of American Nursing, 1850-1945. Cambridge: Cambridge Univ. Press, I987.

Reynvaan, Anna. "Hoe de Nederlandse vrouw haar taak als ziekenverpleegster opvat." 
MvZ I, no. 9 (I89I): 8-го.

Ridder, Denise de. "Het ontstaan van de aangewezen afdeling, I890-I920." In Honderd Jaar Krankzinnigheid: Geschiedenis van de Krankzinnigenwetgeving in Nederland, edited by Joost Vijselaar, III-25. Utrecht: NCGV, I984.

Righart, Hans. De Katholieke Zuil in Europa: Een vergelijkend onderzoek naar het ontstaan van verzuiling onder katholieken in Oostenrijk, Zwitserland, België en Nederland. Meppel: Boom, I986.

Righart, Hans. "Moraliserinsoffensief in Nederland in de periode 1850-1880." In Harry Peeters, Lène Dresen-Coenders, and Ton Brandenburg (Eds.), Vijf eeuwen gezinsleven: Liefde, huwelijk en opvoeding in Nederland, I94-207. Nijmegen: SUN, I988.

Rijpstra-Verbeek, Mimi. Dienend in het wit. Lochem: De Tijdstroom, I968.

Risse, Guenter B., and John Harley Warner. "Reconstructing Clinical Activities: Patient Records in Medical History." Social History of Medicine 5, no. 2 (I992): I83-206.

Roelink, J. Een blinkend spoor: Beeld van een eeuw geschiedenis der Vereniging voor Wetenschappelijk Onderwijs op Gereformeerde Grondslag. Kampen: Kok, I979.

Roode, J. "Verpleging in de afgelopen 25 jaar." Ons Niews, Orgaan van het PZ Franeker, special issue “I25 jaar Franeker” (March/April I976): 9-ІІ.

Rosen, George. Madness in Society: Chapters in the Historical Sociology of Mental Illness. New York: Harper Torchbooks, I968.

Rosenberg, Charles E. "Clio and Caring: Agenda for American Historians and Nurses." Nursing Research 36, no. I (1987): 67-68.

Rosenberg, Charles E. "Florence Nightingale on Contagion: The Hospital as a Moral Universe.” In Charles E. Rosenberg (Ed.), Healing and History, in6-36. New York: Science History Publications, I979.

Rosenberg, Charles E. “Review Article: Recent Developments in the History of Nursing." Sociology of Health and Illness 4, no. I (March I982): 86-94.

Rosenberg, Charles E. The Care of Strangers: The Rise of America's Hospital System. New York: Basic Books, I987.

Rosenberg, Charles E. "The Crisis in Psychiatric Legitimacy: Reflections on Psychiatry, Medicine and Public Policy." In Explaining Epidemics and Other Studies in the History of Medicine, edited by Charles E. Rosenberg, 247-48. Cambridge: Cambridge Univ. Press, I992.

Rothman, David. The Discovery of the Asylum. Boston: Little, Brown, I97I.

Russell, Richard. "The Lunacy Profession and Its Staff in the Second Half of the Nineteenth Century, with special reference to the West Riding Lunatic Asylums." In The Anatomy of Madness: Essays in the History of Psychiatry, edited by W. F. Bynum, Roy Porter, and Michael Shepherd, vol. III, 297-315. London: Routledge, I988.

Ruysch, W. P. De huisvesting onzer krankzinnigen. Haarlem: Tjeenk Willing, I89o. GGZ Museum, Medemblik Collectie, G62.

Sap, H. “De opleiding van 't verplegend personeel." Orgaan van de Christelijke Bond van Ziekenverpleging 4 (1907): 39-47.

Scheer, W. M. van der, and H. van der Hoeven. "Rapport betreffende bezuinigingen in de krankzinnigenverpleging." PNB 28 (I924):306-I6.

Schermers, D. Handleiding bij het verplegen van krankzinnigen en zenuwlijders. Leiden: Donner, I898. Second printing,I90I.

Schermers, D. “Ons verpleeg-personeel.” PNB 2 (I898): 514-28. 
Schermers, D. “Opleidingskwesties.” Refájah I8 (I918/I9): I29-32, I69-7I, I77-8I.

Schoondermark, Anna. Wenken voor adspirant-krankzinnigenverpleegsters. Amsterdam: De Bussy, I9I9.

Scott, Joan W. Gender and the Politics of History. New York: Columbia Univ. Press, I988. Revised edition, I999.

Scull, Andrew. Museums of Madness: The Social Organization of Insanity in Nineteenth-Century England. London: Allen Lane, I979.

Scull, Andrew. "Psychiatry and Its Historians." History of Psychiatry 2, no. 3 (I99I): 239-50.

Scull, Andrew. Social Order/Mental Disorder: Anglo-American Psychiatry in Historical Perspective. Berkeley: Univ. of California Press, I989.

Scull, Andrew. The Most Solitary of Afflictions: Madness and Society in Britain 1700-1900. New Haven: Yale Univ. Press, I993.

Sedler, Mark J. “Concepts of Schizophrenia I600-180o.” In John G. Howells (Ed.), The Concept of Schizophrenia: Historical Perspectives, 47-57. Washington: American Psychiatric Press, I99I.

Sharpe, Jim. "History from Below.” In Peter Burke (Ed.), New Perspectives on Historical Writing, 24-4I. Cambridge: Polity Press, I99I.

Shortt, S. E. D. Victorian Lunacy. Cambridge: Cambridge Univ. Press, I986.

Smith, L. D. "Behind Closed Doors: Lunatic Asylum Keepers, I800-I860.” Social History of Medicine (I988): 30I-27.

Spijker, Truus. Mooi en beschaafd verplegen: Een historische analyse van een vrouwenberoep. Lochem: De Tijdstroom, I98I.

Stärcke, A. "In Memoriam Willem Hendrik Cox (I86I-I933).” PNB 38 (I934): I2-24.

Stearns, Peter N. "Introduction: Social History and Its Evolution." In Peter N. Stearns (Ed.), Expanding the Past: A Reader in Social History: Essays from the Journal of Social History, 3-16. New York: New York Univ. Press, ig88.

Stelling, A. (Frau van Deventer). "Erfahrungen beim patronat für convalescente Epileptiker.” Sonderabdruck aus dem IV. Internationalen Kongreß für Irrenpflege, Berlin Iوı。. Museum Meerenberg, Psychiatric Hospital Amsterdam, Santpoort, "Depot diverse brochures".

"Stellingen: Ligt het op den weg van den [Chr.] Bond een onderzoek in te stellen naar de arbeids- en dienstvoorwaarden zijner leden?” Orgaan van de Chr.Bond voor Ziekenverpleging 4 (1907): 159-60.

Stellingwerff, J. Dr. Abraham Kuyper en de Vrije Universiteit. Kampen: Kok, I987.

Stephan, B. H. De behandeling van sommige vormen van zenuwlijden met mestkuren. Amsterdam: Verslyus, I896.

Stockman, R. Geen rede mee te rijmen: Geschiedenis van de psychiatrie. Gent: Aurelia Books, I989.

Strumpf, Neville E., and Nancy Tomes. "Restraining the Troublesome Patient: A Historical Perspective on the Contemporary Debate." Nursing History Review I (I993):3-24.

Stuurman, S. Verzuiling, Kapitalisme en Patriarchaat: Aspecten van de ontwikkeling van de moderne staat in Nederland. Nijmegen: Sun, I983.

Suzuki, Akihito. "The Politics and Ideology of Non-Restraint: The Case of the Hanwell Asylum.” Medical History 39 (I995): I-I7.

Svedberg, Gunnel. "Narratives on Prolonged Baths from Psychiatric Care in Sweden During the First Half of the Twentieth Century." International History of Nursing Journal 5, no. 2 (Spring 2000): 28-35. 
Swaan, Abram de. De mens is de mens een zorg. Amsterdam: Meulenhoff, I983.

Swaan, Abram de. Zorg en de staat: Welzijn, onderwijs en gezondheidszorg in Europa en de Verenigde Staten in de nieuwe tijd. Amsterdam: Meulenhoff, I989.

Szasz, T. The Myth of Mental Illness. Rev. ed. New York: Harper \& Row, I974.

Tellegen, A. O. H. "Bezwaren van de NVP tegen de eisen gesteld aan examen-kandidaten gesteld door de Nederlandse Bond der Ziekenverpleging (I893).” PB I2 (I894): 6I-63.

Tellegen, A. O. H. "Het verleden, het heden en de toekomst der Krankzinnigenverpleging in Nederland.” PB 8 (1890): I89-96.

Tellegen, A. O. H., W. P. Ruysch, and J. van Deventer. "Preadvies in zake aansluiting aan den Nederlandse Bond voor Ziekenverpleging door de Examen-Commissie.” PB I3 (I895): 70-78.

Tellegen, A. O. H., W. P. Ruysch, and J. van Deventer "Rapport der Examen-Commissie van de Nederlandse Vereeniging voor Psychiatrie over het jaar I894." PB I3 (I895): 6569 .

Temkin, O. The Double Face of Janus and Other Essays in the History of Medicine. Baltimore: Johns Hopkins Univ. Press, I977.

Tervoert, J. B. Nuttige wenken voor de goede opvoeding der R.K. kinderen als voorbehoedmiddel voor krankzinnigheid. Den Bosch: Stokvis \& Zn, I905.

Tervoert, J. B. Opmerkingen over de verpleging van krankzinnigen. Oostakker: Drukkerij de Broeders van O. L. V. van Lourdes, I892.

Thompson, Margaret S. "The Wages of Sin: The Problem of Alcoholism and General Paralysis in Nineteenth-Century Edinburgh.” In W.F. Bynum, Roy Porter, and Michael Shepherd (Eds.), The Anatomy of Madness, vol. III, 3I6-40. London: Routledge, I988.

Thurner, Manuela. "Subject to Change: Theories and Paradigms of U.S. Feminist History." Journal of Women's History 9, no. 2 (Summer I997): I22-I46.

Tijn, Th. van. "Het Sociale Leven in Nederland, I875-I895, I895-I9I4.” In D. P. Blok (Ed.), Algemene Geschiedenis der Nederlanden, vol. I3, 77-100, 295-326. Haarlem: Fibula-Van Dishoeck, I978.

Tomes, Nancy. The Art of Asylum-Keeping: Thomas Story Kirkbride and the Origins of American Psychiatry. Philadelphia: Univ. of Pennsylvania Press, I994.

Tomes, Nancy. "The Private Side of Public Health: Sanitary Science, Domestic Hygiene, and the Germ Theory, I870-1900." Bulletin of the History of Medicine 64, no. 4 (I990): 509-39.

Valk, Louise A. van der. "Van Pauperzorg tot Bestaanszekerheid I9I2-I965.” Ph.D. diss., Erasmus Univ., I986.

Velden, Henk van der. “The Dutch Health Services before Compulsory Health Insurance, I900-I94I." Social History of Medicine 9, no. I (April I996): 49-68.

"Veldwijk. Na 50 jaar, I886-I936." Refájah 35 (January/February I935/36): 267-358.

Verdoorn, J. A. Het gezondheidswezen te Amsterdam in de 19de eeuw. Nijmegen: SUN, I98I.

Verheij, Rob, and Theo Klein Overmeen. Omzien in Zorg: Bij het Afscheid van de Broeders van Reinier van Arkel. Vught: PZ Reinier van Arkel, I992.

Verslag betreffende het Gesticht Meerenberg over het jaar 1887-1920. 34 vols. Haarlem: Enschede en Zonen, I888-I92I.

Verslag over den Staat der Gestichten voor Krankzinnigen in de jaren 1869-1884. 4 vols. The Hague: Van Weelden en Mingelen, I878-9I. 
Verslag van het Staatstoezicht op Krankzinnigen en Krankzinnigengestichten en over de Staat dier Gestichten in de jaren 1885-1929. I2 vols. The Hague: Van Weelden en Mingelen, I892-I932.

Vicinus, Martha. Independent Women: Work and Community for Single Women, 1850-1920. London: Virago, I985.

Vies, H. G. van der, and D. E. van Rijn. "Adres aan den Raad der Gemeente Haarlem." Nosokómos I6 (I9I6): 512-13.

Vijselaar, Joost. "De zedekundige behandeling en de afschaffing van de lijfsdwang in het gesticht Meerenberg, I840-1875." In Een psychiatrisch verleden, by J. M. W. Binneveld et al., I20-53. Baarn: Ambo, I982.

Vijselaar, Joost. “Een Eerste Inspectie: Over de Inspectie in de Negentiende Eeuw.” Maandblad Geestelijke Volksgezondheid 38, no. 6/7 (1983): 650-65.

Vijselaar, Joost. "Egodocumenten van psychiatrische patienten uit de negentiende eeuw." Sociologisch Tijdschrift I4, no. 4 (February I988): 645-6I.

Vijselaar, Joost. Gesticht in de duinen: De geschiedenis van de provinciale psychiatrische ziekenhuizen van Noord-Holland van 1849 tot 1994. Utrecht: Trimbos Insitute, I997.

Vijselaar, Joost. Krankzinnigen gesticht: Psychiatrische inrichtingen in Nederland, 1880-1910. Utrecht: NCGV, I992.

Vijselaar, Joost. "Neerlands eersten psychiater": Dr. J. N. Ramaer, 1817-1887. Utrecht: Nederlandse Vereniging voor Psychiatrie, I995.

Vijselaar, Joost. "Schroeder van der Kolk en de Krankzinnigenwet van i84I." Maandblad Geestelijke Volksgezondheid 40, no. 3 (I985): 27I-85.

Viveen, Helene. "Het proces van gezinsverpleging met name op Veldwijk, I884-I920." Master's Thesis in History, Free Univ. of Amsterdam, I980.

Vonk, J. "Verslag van de 2e Algemene Vergadering van de Chr. Bond voor Ziekenverpleging, I8 November I903." Bethesda 9 (I904): I4-I7.

Vught, J. P. A. van, and C. P. Voorvelt OFM. Kloosters op schrift: Een bibliografie over de orden en congregaties in Nederland in de negentiende en twintigste eeuw. Nijmegen: Dienstencentrum Kloosterarchieven in Nederland, Katholiek Documentatie Centrum, I992.

Waaldijk, Berteke. Het Amerika der vrouw: Sekse en geschiedenis van maatschappelijk werk in Nederland en de Verenigde Staten. Groningen: Wolters-Noordhoff, I996.

Wal, O. van der. "Gezinsverpleging bij gehuwde broeders.” MNVV 4 (I9I0): 87-88.

Walsum, G. C. van. "Bijdrage tot de microscopisch-anatomische techniek van het zenuwstelsel." Nederlands Tijdschrift voor Geneeskunde II (I895): 40I.

Walsum, G. C. van. "Demonstratie van een nieuwe schedelzaag, een methode voor het afdrukken van schedeldoorsneden (6o antropologische doorsneden), mikrophotogrammen van het zenuwstelsel.” PNB 4 (1900), 378-86.

Weiner, Dora. "The French Revolution, Napoleon, and the Nursing Profession." Bulletin of the History of Medicine 46, no. 3 (May-June I972): 274-305.

Weisglas, M. "De overgang van oppassers en oppasseressen naar verpleegsters en verplegers in de krankzinnigen gestichten.” Master's Thesis in History, Univ. of Amsterdam, ig8I.

Wiegman, Nanny. “'Gij completeert zijn arbeid’: Over de professionalisering van het verpleegkundig beroep (I880-I925)." Gewina I9, no. 4 (I996): 296-3I2.

Wiegman, Nanny. "The Origins of Modern Nursing in the Netherlands." Nursing History Review 4 (1996): 83-98. 
Wiegman, Nanny. “Zusters in smetteloos wit: Een blanco bladzijde in de Nederlandse geschiedschrijving?” Gewina 16 , no. 3 (I993): 68-79.

Wieringa, W. J. "Lotgevallen van de Valeriuskliniek." In Een halve eeuw arbeid op psychiatrisch-neurologisch terrein 1910-1960: Gedenkboek bij het 50-jarig bestaan der Valeriuskliniek, II-88. Wageningen: Zomer \& Keuning, I960.

Windmuller, J. P. C. de Galan, and A. F. van Zweeden. Arbeidsverhoudingen in Nederland. Utrecht: Het Spectrum, i983.

Winkler, Cornelis. Herinneringen (1855-1941). Arnhem: Van Loghum Slaterus, I947.

Wright, David. "Asylum Nursing and Institutional Service: A Case Study of the South of England, I86I-I88I.” Nursing History Review 7 (I999): I53-I69.

Zondag, A. Naar Franeker gaan: Herinneringen en reflecties van een oud hoofdverpleegkundige. Franeker: Van Wijnen, I995 


\section{Index}

aangewezen afdeling (designated wards)

I39, 268

Abel-Smith, B. I46, 269

abuse II9, I20, I22, I23, I36

Ackerknecht, E.H. 252

active therapy 233

acute mania I3I

admission II9, I24, I27, 239

certified - 249

length of - 239

Afscheidingsbeweging 54,55

aggression 132, 136

Algemeen Nederlandsch Vakverbond

(General Dutch Federation of Trade

Unions) I92

Algemene Nederlandse Ambtenaren Bond

(General Dutch League of Civil

Servants [ANAB]) I90, 203

Algemene Nederlandse Christelijke

Ambtenarenbond

(Dutch League of Christian

Civil Servants) 204

Algra, H. 247

American Journal of Nursing $20 \mathrm{I}$

American National Committee for Mental

Hygiene 233

Amsterdamse Huishoudschool

(Amsterdam School of Home

Economics) 93

Applicant registers 284

apprenticeship 87, 99, I45

architecture 43,67

Association

- for After-Care of Discharged Epileptic Patients 97

- of Nursing 87, 108

- of Sick Nursing (White Cross) 86, 9I, 93, 94, I04, I43, I77

- of Women
- of Women Directors and Deputy

Women Directors of Hospitals

and Associations of Nursing

(Vereniging van Directrices en

Adjunct-Directrices van ziekenhuizen

en verenigingen voor zieken-

verpleging) 202

- for Women Suffrage (Verening Voor Vrouwenkiesrecht [VVV]) 89

- to Achieve the Legal Regulation of

Training and Exams of Nurses

(Vereniging tot verkrijging van een

wettelijke regeling van opleiding en

examens voor ziekenverpleegsters en

verplegers) 206, 207

asylum

dementia - I26

growth -50

personnel - I06

reform - 3I, 33, 34, 38, 58

Veldwijk - I27

Willem Arntsz - 46

attendants I5, I9, 2I, 38, 39, 4I, 43, 45, 58

Baer, E. D. 269

Bakker, H. 26I

Baly, M. E. 243

bath therapy $6_{3}$

bath treatment (see hydrotherapy) 70, 72,

I7O, 222

- and prolonged baths in Swedish

psychiatry 222

- and risk of eczema 73

Beard, George Miller 253

bed rest I9, 63, 65, 66, 67, 68, 69, II4,

I28, I3I, I32, I34, I37, I43, I60, 228, 254

- and risk 70

bed treatment $66, \mathrm{I} 28,22 \mathrm{I}$

Bedlam 46 
Beets, Maria E. II3, 26I

behavioural code 246

Beimer, Hendrik I38, I82

Belzen, J.A. Van 242, 250, 25I, 252

Benders, A.M. 254

Bergh, W. Van der 252

Berns, A.W.C. 9I

Berting, J. 277

Bethel Institute (Deacon and Deaconess) in Bielefeld I53

Billroth, Theodor 77

Binneveld, Hans 23, 5I, 242, 244-252, 255 , 274,275

biomedical footing of psychiatric care 219

Blinde, A. J. de 65

Blok, G. 242, 252, 286

Bodelswingh, Pastor Friedrich Von 153

Boer, F. de 245

Boer, Miss J. W. E. de 152

Boerrigter, Broeder E. 274, 275

Bonebakker, A. (Physician) 97

Boone, Teunis 183

Bootsma (Pastor) 164

Bor, H. van der I95, 280

Bosch Kemper, Jeltje de 90, 93, 95

Boschhoek II3, $\mathrm{I}_{3}$

- and preparatory training $\mathrm{I} 66$

- nurses home $\mathrm{I}_{3}$

Bouman, Leendert I85, 204, 278

Bouwmeester, G.H. I94, 280

brain

- disease I9, 60, 62

- research 65

- trauma 138

Bras, P.N. I44, I77

career of - I86, I92

Breuning, S. Doedes 5I

Brinkgreve 265

British Medico-Psychological Association 77

Broeders van Onze Lieve Vrouwe van Lourdes (Brothers of Our Lady of Lourdes, The) 48, IOI, I67, I78

Brosius, A. 253

Brothers I47, I53, I67

Dorotheus - see Tervoert

- of Our Lady of Lourdes (Broeders van
Onze Lieve Vrouwe van Lourdes) 48, IOI, I67, I78

Buitengast Hospital 53, 75, 95, I43, 255

Buller, Miss G. I52

Burgerziekenhuis (Civic Hospital) 77, 9I

Butler, Josephine 83

Carpenter, M. 25, 243

CBZ ( Christian Nurses Association (Christelijke Bond voor Ziekenverpleging) see Christelijke Bond voor Ziekenverpleging

Central Health Council 207

Chijs, Van der 98

Christelijke Bond voor Ziekenverpleging (Christian Nurses Association [CBZ]) I65, I99, 204

Christian

- Association for Epileptics I77

- Nurses Association (Christelijke Bond voor Ziekenverpleging [CBZ]) see Christelijke Bond voor Ziekenverpleging

- mission 167

- psychiatry 55, 56, 63, I53, 225

- Reformed Church 54, 55, 56

- revival 82

chronic mania 136

Church, Olga 24, 243

class

- conciousness I86

- differentiation $2 \mathrm{I} 3$

classification I24, 264

Clinical School of Medicine 25I

College of Regents IOI

Conference on Nursing of the Sick 96

Congregation

- of Lazarists 8I

- of Mercy (Congregation van Goede Werken) 48

Conolly, John 60

continuous observation 77

control

- mechanism II9

- watch II9

cottage system 57

Counter Reformation 8I 
Cowan, F.M. 77, 255

Cowles, Edward 24

Cox, Willem Hendrik (Medical Director) 2IO, 2I5, 2I7, 2I $8,284,285$

D'Antonio, Patricia 2I, 22, 242, 244, 245, 25I, 262, 266

Dale, J.H.A. van (Medical Director) 65, I49, I58, I62, I63, I65, I83, 272, 273

Davies, C. 23, 243

Deaconess

- Institute 85

- movement I6, 55, 82

Deacons I77, 255

decubitus II4, II7

degeneration 62

delusions I3I, I35, I36

dementia 2I2

senility $\mathrm{I} 27$

- paralytica I32

- praecox 136

dependency I25

Designated Wards (Aangewezen Afdeling) I39, 268

deterioration 132

Deutch, Albert 2I, 242

Deventer, Jacob van (Physician) 63, 67, 68, 75, 76, Іо0, І02, I06, II4, I23, I42, I5O, I77, I79, 209, 2I7, 254, 255, 257, 259, 26I, 262, 265, 267, 276

diagnoses 43, I23, I24, I3I, 238 acute mania I3I brain disease I9, 60, 62 chronic mania 136 delusions I3I, I35, I36 degeneration 62 dementia $2 \mathrm{I} 2$ senility I27 paralytica $\mathrm{I} 32$ praecox 136

epilepsy I29, 212 hallucinations 136 hysteria neurasthenia 139

idiocy I26, I29, 2 I2

imbecily 129

incontinence I29, I33

insania neurasthenica I39

neurotica 139

lunatics 3I

manic depression I3I

melancholia I33, I34

nervous afflictions 138

paralysis I32, I33

paranoia 136

pneumonia 137

psychosis I29

secondary Dementia I29

seizures I29, I30, I39

syphilis $\mathrm{I} 32$

tuberculosis 70, 129, I64, 214, 22I

Digby, Anne 2I, 242, 248, 25I, 263

Dingwall, Robert 25, 229, 243

dismissal II9, I34, I35, I47

Dochters van Maria en Joseph (Daughters of Mary and Joseph) 84

Dock, Lavinia 20I, 257

Doleantiebeweging 54

domestic ideology 87, I4I, I68, 203, 228

Donkersloot, N.B. 40, 247

Doorn, J.A.A. van 245, 248

Drenth, Annemieke van I6, 82

Drenth, Van (Pastor) 83, I63, 24I, 255, 256

Drinka, G.F. 253

Drosterij, C. I9I, I92

Dutch

- Association of Psychiatry

(Nederlandse Vereniging voor Psychiatry

[NVP]) 65, I00, IOI, I03, I04, I07, I53, I57, I88, I93, I99, 207, 259, 264

- Christian Literary League II3

- League of Christian Civil Servants (Algemene Nederlandse Christelijke Ambtenarenbond) 204

- Nurses Association (Nederlandse Bond voor Ziekenverpleging ([NBZ]) 97, I07, I98, 200, 20I, 206, 207

- and Medical Domination 20I

- and Nurse Leaders 202

- NBZ 105

- Psychiatric Historiography 243

- School of Social Work 88

Duyvendak, M. 248 
Dwyer, Ellen 2I, 23, II5, I2 I, I22, 228, 242, 247, 26I, 262, 266, 286

education elementary - I59, I6I, 218, 247

- for girls 88, I45, 257

- standards 203, 207

Eeden, Frederik van 2OI

Eijt, José 82, 84, 24I, 242, 248, 255, 256, 274,275

Enlightenment I8, 3I

epilepsy $\mathrm{I} 29,2 \mathrm{I} 2$

Institute for -97

Episcopal Hierarchy 46,85

escape I35, I36, I38

Esch, Pieter van der 2I, 242, 245, 249, 257

Evangelical movement 54

Evangelicalism I6, 82

Everts, Bernardus 37, 39, 4I

exploitation 203, 204

family I25

$$
\begin{aligned}
& \text { - care } \\
& \text { - and boarding patients I } 83 \\
& \text { - and Gheel Asylum I84 } \\
& \text { - and Meerenberg I84 } \\
& \text { - and NVP I84 } \\
& \text { - and the Belgian town of Gheel } \\
& \text { I } 84 \\
& \text { - and Veldwijk I84 } \\
& \text { - ideology (and VCV) I53 }
\end{aligned}
$$

Feith, C. J. 34

female

- authority ${ }_{15} 6$

- charitable orders 82

- compassion 8I, 87, 92, I06, I4I, I66, 209, 2I9, 22I, 227, 228

- congregation I68

- hierarchy I45

- independence 203

- mental nurses I6I

- nurses I44, I52, I6I, I63, 209, 211 - civilized attitude II4, II5, I4I

Genis, Sophia 2I6

Kuyk, Gerritje 2I5

Lanschot-Hubrecht, Jeanne van 200
- leaders I92

- question 210

Steen, Johanna Van (Student Nurse)

I97

pavilion 156

religious orders $\mathrm{I} 68$

volunteer society 36

Fliedner, Theodor 85

Foekema van Sytzema, Lady 201

food refusal 136

forced feeding 134,136

Foucault, Michel 2I, 33, 245

Franeker 158

- asylum 27, 38, 39, 42, 52, 68, I43,

I44

- and management I7I

Free Association of Women (Vrije Vrouwen Vereniging) 89

Free University 56, 162

Frijlinck, Th. E. 2I 8

Fry, Elizabeth 83

Garmanikow, Eva Ioo

Gemert, Victor Van 26, 244, 256, 258, 279

General

- Dutch Federation of Trade Unions

(Algemeen Nederlandsch Vakverbond) I92

- Dutch League of Civil Servants (Algemende Nederlandse Ambtenaren Bond [ANAB]) I90, 203

Genis, Sophia 2I6

Gevaerts, Lady 20I

Gheel Lunatic Colony 278

Gierveld, Mother Hendrika ${ }_{15} 6$

Glorieux, E. H. Stefanus ${ }^{16} 7$

Godshouses 27, I68, 248, 242, 262

Goei, L. de 26I

Goffman, Erving 2I, I2I

Goudswaard, N. B. 283

Griesinger, Wilhelm 60

Grinten, T. van der 265, 287

Grob, Gerald 22, 52, 242, 247, 249, 250, 25I, 265, 266

Groot, A. de 245, 275

Gruyters, Elisabeth 85 
Gunning, W. M. (Medical Professor) 96, IO2

Haan, Francisca de I6, 82, 83, 241, 255, 256

Hagen, C.I. Van der I72, 218

Haitsma Mulier-Baroness van Sytzama, W. 106,152

hallucinations 136

Hamilton, D. 280

Haw, C. .M. 243, 246

health and social progress 202

Heemstra, M. J. Baroness van 247

Heeren, Jacobus 85

Hees, Anna C van 84

Heije, Jan Pieter 86

heredity 62

Heyrman, E. 274

Hilarius (Father) I70

historiography 20

Holthoon, F. L. van 277

homes for nervous patients

- and career opportunities for nurses

$2 \mathrm{I} 5$

- and Villa Christiana 2I6

Hoogt, M.J. van der (Asylum Minister) I5 6, 272, 273

hospital

Buitengast - 53, 75, 95, I43, 255

Burgerziekenhuis (Civic Hospital) 77 , 9I

medicine - I9

- nurse training 96

- reform 92

house

fathers - 157

mothers - 82, 86, 90, I49, I55, I63, 258

Toynbee - 88

Houwaart 25I, 258

Hughes, John 25, 243, 246

Hulst, Aafke Gesina van $20 \mathrm{I}$

Hunter, Richard 2I

Hutschemaeker, Giel 52, 243, 249, 25I, $263,264,268$

hydrotherapeutic wrappings 132

hydrotherapy $63,70,7 \mathrm{I}$ prolonged bath treatment 72,187

hysteria neurasthenia 139

idiocy I26, I29, 2 I2

imbecily 129

incontinence $\mathrm{I} 29, \mathrm{I} 33$

indigent $33,44,45,58, \mathrm{I} 2 \mathrm{O}, \mathrm{I} 26,2 \mathrm{1} 2,226$

- patients 247, 248

Inner Mission 54, 55, 85

insania

neurasthenica 139

neurotica 139

instruction 40, 4I, I47, I93

International

- Congress on Insanity Care 97

- Council of Nurses (ICN) 200

investigation I23, I34, I97

isolation I3I, I32, I34, I37

Jacobs, Aletta 257

Jak, T. 243

Jansen, J.Th. I52, I77

Janssens, G. 254

Jansz, Ulla 242, 246, 256, 257

Jelgersma, G. (Psychiatrist) 268

Jones, C. 255,256

Jongmans, J.W.M. 245, 249

Journal of Sick Nursing (Maanblad voor

Ziekenverpleging) 95, 96, I02

Kappelhof, Ton 47, 5I, 242, 243, 248, 249, 275

- and Wolf 263

Kassies de Buisonje, Miss I55

Kehrer, Meta 284

King William

-I 34,46

- II 46

Klijn, Annemieke I68, 24I, 249, 265, 286

Knight, D.D. 255

Koffijberg, Henriette II3, II4, II7, I66, I92, 254, 26I

Kooij-Bakker, C. van der 244, 255, 257, 258, 259

Kooij, Cora van der 25, 99, 212, 260, 280, 283,284

Kraepelin, Emil 6I, 72 
Kramer, F. 254

Kraus, G. 249

Kuyk, Gerritje 98, 2I5, 2I6, 259 career of - 2I5

Kuyper, Abraham 250

Labor Act 200, 205

labor

- market I75, 234

- movement 200

laboratory $6_{5}$

Lagemann, Ellen C. 23, 243

Lammers van Bueren, R. 39, 6I

Lanschot-Hubrecht, Jeanne van 200, $206,207,279,283$

leisure clubs I49

Levy, J.A. (Lawyer) 197

Lieburg, M. J. van 242, 250

Lijphart, Arend I7, 24I

Lindeboom, Lucas 55, I53, I62, 205, 242, 250

Loo, L.F. van 24I, 248

lunatics 3I

Luyten, Johannes M. I90

Lynaugh, J.E. 243

Maanblad voor Ziekenverpleging (Journal of Sick Nursing [MvZ]) 95, 96, I02

Maandblad van de Nederlandse Verplegers Vakvereniging (Monthly Journal of the NVV) I90

MacDonald, M. 267

madhouse 3I, 244

Maggs, C. J. 243, 270

male

- nurses 2I, I44, I45, I75-I96, 2II, 2I9,

223, 228

- activism I86-I92

- and a diploma 178

- and artisans I80

- and boarding patients I85

- and career opportunities I77

- and living in I75, I76

- and male nurses home I90

- and marginalization I77

- and marriage $\mathrm{I} 75, \mathrm{I} 78, \mathrm{I} 83$

- and military service $\mathrm{I} 82$
- and role conflict $\mathrm{I} 82$

Beimer, Hendrik I38, I82

Boone, Teunis 183

Bor, H. van der I95

Bouwmeester, G.H. I94

Bras, P.N. I77

Bras, P.N., Career of 186-192

Drosterij, C. I9I

Gatsonides I23

Jansen, J.Th. I77

Meuleman, E. I77

Muis, B I9o

Oene, Lambertus van 183

- question 176

Reijnders 176

- trained I79

Vries, de I85

Wieringa, Reint 183

Zondag, A. II8

- pavilion 156

- religious order I7O

- student nurses 158

mania I3I, 2I2

manic

- behaviour I32

- depression I3I

Marland, H. 257

marriage 277

married nurses $\mathrm{I} 83$

matron 44, I43

McAlpine, Ida 2I

McPherson, K. 242, 259

medical training 25I

Meerenberg asylum 27, 35, 36, 37, 60,

I03, 42, 53, I42, I48, I52, I57

- and female nurse applicants 2 I2

- and chronic mental illness 226

- and corridor system 37, 245

- and floor plan 245

- and male nurse applicants $2 \mathrm{I} 2$

- and number of personnel 232

- and register of applicants $2 \mathrm{I} 2$

- association 106

- floor plan 237

- nurse-to-patient ratios 230

Meijer, L.S. 218

Meinema, Th. 278 
melancholia I33, I34

Melosh, B. 243

mental

- health

- movement 233

- nursing 15,28

- illness I5, 6I, I24

- and disease entity $6 \mathrm{I}$

- and etiology 221, 226

- and idiocy I25

- and organic cause 67

- and psychological approaches 2II, 220

- nurse I5, I9, 20, 28, I03, I36, I4I,

24I

- and career opportunities 23I

- and civilized attitude 220

- and class background 2I2, 2I4

- and inexperienced workforce 223 , 230

- and marriage 2I3

- and preschool 106

- and psychological influence 2II

- and refinement 2IO, 2II

- and running a business 216

- and state registration 28

- in private duty 105

- nurse training I5, I6, 75, 8I, I00, I4I,

I45, 215, 227

- and educational structure I57

- and gender 20

- and hierarchy 146

- and male Nurses 193

- and nursing orders and Voorburg asylum $\mathrm{I} 67$

- and staffing asylums 234

- and theoretical course and physicians I58-I59

- and VCV I53, I60

- and Veldwijk

Mercier, Helene 88

Meuleman, E. I77

missionary zeal $\mathrm{I} 67,227$

Monthly Journal of the NVV (Maandblad van de Nederlandse Verplegers) I90

Mooij, A. 252 moral treatment 3I, 32, 57, 63, 220, 246

Morel, Benedict A. 62

mortality rates I29, 239

Mother Catherine 168

Muis, B I90

Naber, J. W. A. 258

Napoleon 33

Nationaal Bureau voor Vrouwenarbeid

(National Bureau for Women's Work) 90

National

- Bureau for Women's Work (Nationaal Bureau voor Vrouwenarbeid) 90

- Exhibition of Women's Labor (Nationale Tentoonstelling Vrouwenarbeid) 89

- Women's Council (Nationale Vrouwenraad) 90

Nationale

- Tentoonstelling Vrouwenarbeid

(National Exhibition of Women's Labor) 89

- Vrouwenraad (National Women's Council) 90

NBZ see Nederlandse Bond voor

Ziekenverpleging (Dutch Nurses

Association [NBZ])

Nederlandse Bond voor Ziekenverpleging

(Dutch Nurses Association [NBZ]) 97,

I05, I07, I98, 200, 201, 206, 207

- and Medical Domination $20 \mathrm{I}$

- and Nurse Leaders 202

Nederlands Christelijke Bond van

Verpleegpersoneel (Dutch Christian

League of Nursing Personnel) 205

Nederlands Christelijk Vakverbond (Dutch

Christian Union) 205

Nederlandse Vereniging tot bevordering der

Geestelijke Volksgezondheid (Dutch

Association for the Promotion of

People's Mental Health) 233

Nederlandse Vereniging voor Psychiatrie en

Neurologie (Dutch Association of

Psychiatry and Neurology [NVPN]) I72

Nederlandse Vereniging voor Psychiatry

(Dutch Association of Psychiatry 
[NVP]) see NVP

Nederlandse Verplegers Vakvereniging

(Dutch Male Nurse Professional

Association [NVV]) see NVV

Neisser, Clemens 66, 75, 250, 253,

255

nervous afflictions 138

neurasthenia 253

night shifts I49, I50

Nightingale, Florence 24,77

Nolan, Peter 25, 193, 229, 24I, 243, 259, 280,286

Nosokómos (Professional Nurse

Organization) I9I, I99, 200, 206, 207, 208

- and female nurse organization 203

- and Lanschot-Hubrecht, Jeanne van (Secretary) 200

nosology 6I

Notten, J. W. A (Minister) I60, I62, 272

nurse(s)

- artisan 44, I43, I79, I83

- training $\mathrm{I} 8 \mathrm{O}, \mathrm{I} 8 \mathrm{I}$

- and work 228

- career opportunities 2I5

- dress code 147

- home I48, I50, I63

Boschhoek $\mathrm{I}_{3}$

- organization 229

- practice act 203

- training (see also mental nurse training) $76,96,98, \mathrm{I0}, \mathrm{I} 26, \mathrm{I} 4 \mathrm{I}$, I43-I44, 2 OI

- and male nurses I80

- and state education 208

- programs 92

- schools IO2

- system 99

- probation I57, I65

- work

- and exploitation I97

- and physical exhaustion 197

- and working conditions I97, I98, 203, 207

- and working hours I48, I97

- written culture I94 nursing

- and pedagogy I94

- activism I99

- bureau Io8, 189

- private duty 202

- education 202

- educational standards 202

- hierarchy I43

- journals 194

- of the sick 20I

- orders 248

- orders (Roman Catholic) I67

- organizations I99

- practice act 208

- registration 206

- registration laws 206

skilled - 75

- textbook II4, I25, I28, I30, I34, I59, I60, I6I, I93, I95, 222, 26I, 280

- workforce and morality 209

Nutting, A. 257

NVP - Nederlandse Vereniging voor

Psychiatry (Dutch Association of

Psychiatry) 65, IOO, IOI, I03, I04, I07,

I53, I57, I88, I93, I99, 207, 259, 264

- exam I05, I44, I57, I72, 210, 2I5, 219

- and number of graduates $2 \mathrm{I} 6$

- and two-level exam system 2I7-I8

- and Voorburg asylum I69

- committee I04, 210, 2I6, 2I7, 218

NVPN see Nederlandse Vereniging voor

Psychiatrie en Neurologie (Dutch

Association of Psychiatry and

Neurology [NVPN])

NVV ( Nederlandse Verplegers Vakvereniging

(Dutch Male Nurse Professional

Association [NVV]) 208

- and Centraal Adresbureau (Central Address Bureau) I89

- and unions I90

- journal I94

O'Brien, P. 269

occupational therapy 233

Oene, Lambertus van I83

Onrust, M. 248

Oort, A. H. I43 
Oosterwijk Bruijn (VCV Board) I54

open air treatment and tuberculosis 70

opium I34

paralysis I32, I33

paranoia 136

Parry-Jones, W. L. 278

patients

communication with - I95

demented - I27, I28

dying - I28

- fees 232

melancholic - I34

nervous - 2II

- records I23, I24, 263

- work 74

Paul, Vincent de 8I

Peplau, H. 243

persecution 136

Persijn, Cornelis Johannes van 40, 45, 5I, 53

Peters, U. H. 25I

petitions 203

physical exhaustion I37

pillarization (verzuiling) I6-I8, 27, 56

Pinel, Philippe 3I

Pleij, G. 257

pneumonia I37

poor

- law 35

- relief I8, 3I, 33, 244

Poplin, I.S. 256

preparatory training school I07, II3, I $\sigma_{3}$,

I65

preventive pre- and after-care services 233

Prinsengracht Hospital 87

private duty $2 \mathrm{I} 7$

- market (for nurses) I89, 202

- and nervous patients 2I5

- and physicians 2I5

- home for nervous patients 98

professional

- (educational) standards 203

- organization I5I, I62

- regulation 202

Provincial Committee of Medical

Inspection of North Holland 86 psychiatric

- clinic and university 6I

- medicine 105, I42, 210 - and therapeutic impasse 222, 234

psychiatrists 225

psychosis 129

psychotherapeutic conversation 220

Queen Wilhelmina's 90

Qvarsell, Roger 63, 66, 244, 245, 250, 25I, 252, 253, 245, 255, 258, 259, 270

Rafferty, Anne Marie 25, II4, I4I, 229, 242-243, 256, 258, 26I, 268, 274, 286

Ramaer, Johannes, Nicolaas 6I

record keeping I23

recovery rates 226

Reeling Brouwer, S. 218

Reformation 3I, 34, 45, 54

register of graduate mental nurses 208 -

209

registered

- mental nurse 209

- nurse 209

registration of nurses 206

- and physicians 207

Regt, A. de 247, 257, 270, 275, 277

regulations, licensing 203

Reijnders, J. I92, 275, 280

Reinier van Arkel asylum 46, 47, I68, I72

religious orders 99, I03, 248

religious revival 45,54

rest home 107, I90

restraint 35, I3I

mechanical - 32, 38, 45, I3I

Reveil-beweging (Reveil-Movement) I6, 54,85

Reverby, S. 243

Reynvaan, Anna 98, I04, I45, I92, 259

Richards, Linda 24

Ridder, D. de 249, 268

Righart 248, 250

Risse, G. B. 263

Roman Caltholic

- nursing order 172

- congregation 85

- orders $8 \mathrm{I}$ 
- organizations

Rosen, G. 252

Rosenberg, Charles 40, 75, 243, 247, 250, 25I, 253, 255, 286

Rothman, David 2I

Roucan, Miss J. C. 143

Russell, R. 243

Ruysch, W. P. (State Inspector) I02, I06, I66, 2I7

Saint Dymphna Guesthouse I84

salaries I50, I63, I66, I82, I9I, I97, 205, $217,230,231,240$

sanatorium 190

Santpoort (Provincial Hospital near Santpoort) 60

Sap, H. I64, I65, 204, 273

Scheer, Willem M. van der (Medical

Director) I2O, I22, 233

Scheffer, J. C. Th. 26I

Schermers, David (Medical Director) 56 , II4, I59, I6I, 207, 2I7, 249, 26I, 265 , 266, 267, 272, 285

Schoondermark, A. 273

Schreve (Medical Director) IO4

Schroeder, van der Kolk, J. L. C. 34, 39, $60,245,244,246,252,253,254$

Schuurmans Stekhoven (Physician) Io9

scientific psychiatry I5, 59, I5I

- and biomedical footing 220, 225

Scott, Joan W. 242, 256

Schorer, Lady S. 106, I52

schools

Clinical School of Medicine 25I

College of Regents IOI

Dutch School of Social Work 88

Free University 56, 162

preparatory training - I07, $\mathrm{II}_{3}, \mathrm{I}_{6} 3$,

I65

University Medical 25I

University of Leiden I43

Scull, Andrew 22, 33, 5I, I2 I, 242, 244 ,

$245,248,252,262,264$

secondary dementia I29

sedative medications $63,68, \mathrm{I} 28, \mathrm{I} 3 \mathrm{I}, \mathrm{I} 32$

Sedler, M. J. 25I

seizures I29, I30, I39 self

mutilation 136

organization of nurses $20 \mathrm{I}$

separation of space 120

servants $40,43,44$

civil - 203

female -44

male - 44

male and female - 37

Sharpe, J. 244

single womanhood 155

sisters I47, I53, I55, I67

Sister Hidding $\mathrm{I}_{3}$

Sisters

- of Good Works ${ }^{6} 67$

- of Mercy (or Daughters of Charity) 48-49, 8I

social

- consciousness 199

- legislation 200

- position of nurses I97, 234

- position of psychiatrists 272

- progress 203

somatic

- care I5

- treatment 63, 77, II9,I3I, 2I9, 228

- and conflicting demands 22I

- and costs 232

- and restraints 222

Spijker, Truus 26, 256, 258, 279

State Inspectorate of the Insane 52, I23, $2 \mathrm{I} 6$

- reports I3I

state

- protection (for nurses) 206

- registration of nurses 206, 208

- regulation 207

statistics on suicide I35

Stearns, P. N. 244

Steen, Johanna Van I97, I98

Stelling, Antonia Wilhelmina 96, 97, Io6, I45, I52, I92, 259

Stephan, B. H. 77

steward 44, I43

Stumpff, J. E. 26I

Stuurman, S. 250 
suicide 35, 65, 73, I30, I33, I34, I35, I38,

254

survey on nursing personnel I80

Suzuki, A. 244, 26I

Svedberg, Gunnel 222, 286

Swaan, A.de 264

syphilis I32

Szasz, Thomas 2I

taxonomy 6I

Tellegen, A. O. H. (Inspector) IOI, I०6, 2I6, 217

Temkin, O. 25I

Tervoert, J. B. (Brother Dorotheus) I7I, I72, 275

Tesselschade 93

textbook (on care of the insane) I7I

Thyssen (Physician) 94

Tilanus, C. B. 87

Tomes, Nancy 2I, 23, 32, 242, 244, 245, $25 \mathrm{I}$

Toynbee house 88

trade unions I99

Travaglino, P. H. M. 26I

Trenité, A. N. Nolst 26I

trying behaviour I28

tuberculosis 70, 129, I64, 214, 22I

Tuke, William 3I

turnover I63, I97, 209, 23I

- of nursing staff I 62

Uhlenbroek-van den Brink, MS 86

uniform I47, I54, I62, 2IO-2II

university

- and psychiatric clinic 6I

Medical Schools 25I

University of Leiden I43

Unqualified Personnel 203, 209

Valk, L.A. van der 245

VCV 57, 63, 64, II4, I28, I57, I59, I82, I85, I93, 204, 225

- and Dennenoord asylum I60

- and nurse training 2I8

- sylums I64, 218

Bloemendaal asylum I6o

- clinic (Valeriuskliniek) 205
Drenth, Van (Pastor) I63

- nurses' activism 204

Oosterwijk Bruijn (Board) I54

Schermers, D. (Medical Director) 207, $2 \mathrm{I} 7$

Vecordia 136

Velden, H. van der 25I

Veldwijk asylum 27, 54, 57, 65, II3, I49, I54

Vereniging tot verkrijging van een wettelijke regeling van opleiding en examens voor ziekenverpleegsters en verplegers (Association to Achieve the Legal Regulation of Training and Exams of Nurses) 206, 207

Vereniging van Directrices en AdjunctDirectrices van ziekenhuizen en verenigingen voor ziekenverpleging (Association of Women Directors and Deputy Women Directors of Hospitals and Associations of Nursing) 202

Vereniging, Wilhelmina I98

Verening Voor Vrouwenkiesrecht

(Association of Women's Suffrage [VVV]) 89

Vermeulen, Cornelis (Medical Director) $65,156,160$

verzuiling (pillarization) I6-I8, 27, 56

Vicinus, M. I4I, 256, 258

Vijselaar, Joost 23, 45, 50, I36, 242, $243,244,245,246,25 \mathrm{I}, 254,255$, 265,287

violence 45, 50, I36-I37

Viveen, H. 278

Veldwijk asylum I27

voluntary treatment and nervous patients I39

Voorburg asylum I6, I7, 27, 49, IOI, I20, I27, I67, I68, I70, I7I, I78

- and brothers I7I

Voorhelm Schneevoogt, G. E. 86

voting rights 200

Vries, J. de (Medical Director) I43, I85

Vrije Vrouwen Vereniging (Free

Association of Women) 89

Vught, J. P. A. van 248 
Waaldijk, B. 88, 242, 256, 257

Wal, Van der 278

Walsum, G.C. van (Medical Director) 72, 73, I48, I52, I59

Warner, J. H. 263

Webster, Charles 25, 229, 243

Weiner, D. 248

Weir Mitchell, Silas 77, 253, 255

Wesselman, Cornelia I44, I52

wet packs 7I, II7, II8, 266

wet sheets II5

White Cross I04, I43, I77

- Association of Sick Nursing 93, 94

- exam Io4

- graduates 146

- training course 95

Wiegman, Nanny 26, 243, 244, 256, 257, 258

Wieringa, Reint (VCV Board) I6o, I83, 252, 278

Wilhelmina

- Association (Vereniging [WV]) Io6, I07, I09, IIO, I66, 210, 2II
- Home (Wilhelminahuis) o6, ı०9, I63, I66

Bienfait, Bodel Miss (Director) IIO

Willem Arntsz asylum 46

Winkler, Cornelis (Professor of Psychiatry) 207

women's

- activism 83, 227

- associations Arbeid Adelt and Tesselschade 89

- movement 83,88

Wright, D. 286

York Retreat 245, 248

Zondag, A. 26I

Zusters

- Onder de Bogen (Sisters under the Arches) 85

- van de Choorstraat (Sisters of the Choor Street) 84

- van Goede Werken 48

Zuylen, Baukje van I44, I52 